Universidade de São Paulo

Instituto de Astronomia, Geofísica e Ciências Atmosféricas

\author{
Douglas Galante
}

\title{
Efeitos Astrofísicos e Astrobiológicos de Gamma-Ray Bursts
}

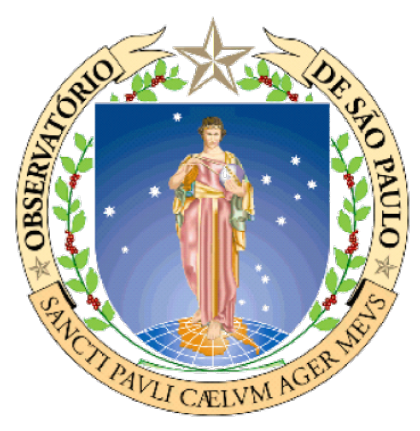

São Paulo

2009 
Douglas Galante

\section{Efeitos Astrofísicos e Astrobiológicos de Gamma-Ray Bursts}

Tese apresentada ao Instituto de Astronomia, Geofísica e Ciências Atmosféricas da Universidade de São Paulo como requisito parcial para a obtenção do título de Doutor em Ciências.

Área de concentração: Astronomia

Orientador: Prof. Dr. Jorge Ernesto Horvath

São Paulo

2009 
À minha querida família 
Ao iniciar um trabalho de doutorado, temos pouca idéia de como ele se tornará parte de nossas vidas. Muitos, como eu, iniciaram a carreira científica ainda jovens, inexperientes e autoconfiantes, assumindo esse compromisso sem ter a real dimensão do peso que carregariam. Um projeto de doutorado, no entanto, é um compromisso entre orientador e orientado, de responsabilidade e dedicação de ambas as partes. Tive a oportunidade de ter um orientador que, mais que Astronomia, ensinou-me a buscar minha independência intelectual e a não ter medo de grandes desafios. Obrigado Jorge, por seu incentivo, infinita paciência, bom humor e pelo autêntico chá turco.

Agradeço a minha família, que sempre me incentivou a buscar meus sonhos e seguir meus próprios caminhos. Sem o apoio de meus pais e irmã nunca teria conseguido.

Agradeço a todos meus amigos e colegas do IAG, do curso de Ciências Moleculares e da Física, com quem passei boa parte dos últimos anos.

Agradeço também a todos os professores e funcionários da USP, que tanto me ensinaram.

Agradeço, por fim, à Fapesp, que financiou meu doutorado. 
"Quam multa non posse, priusquam sint facta, judicantut?" (Quantas coisas são consideradas impossiveis até que sejam realizadas)

Plínio, o Velho 
O presente trabalho tem 0 objetivo principal de compreender os possíveis efeitos da radiação energética de um evento de Gamma-Ray Burst (GRB) sobre o meio interestelar no entorno de seu local de geração e em planetas possivelmente iluminados.

Gamma-Ray Bursts foram detectados pela primeira vez nos anos 60 e rapidamente atraíram a atenção da comunidade astrofísica, uma vez que as energias emitidas apenas em $\gamma$ poderiam alcançar $10^{54} \mathrm{erg}$, o equivalente a massa de repouso do Sol. Não se conhecia nenhum mecanismo tão eficiente para extrair energia gravitacional para produzir tal evento. Mais tarde, a possibilidade da emissão ser colimada abaixou a energia em $\gamma$ para $5 \times 10^{50} \mathrm{erg}$, mas o mecanismo central de geração ainda não foi completamente desvendado, havendo muito espaço para alternativas exóticas.

Estudamos os efeitos de um GRB sobre o meio interestelar, em uma tentativa de distinguir os remanescentes do GRB do gerado por múltiplas supernovas. Usamos argumentos energéticos e sobre a possibilidade de alterações químicas e isotópicas devido a reações fotonucleares.

Também trabalhamos com as implicações biológicas da iluminação de planetas por um GRB, concluindo que os efeitos de tais eventos podem afetar seriamente a biosfera de um planeta mesmo a distâncias de $10 \mathrm{kpc}$. 


\section{Abstract}

The present work has the main goal of understanding the possible effects of the hard gamma radiation produced during a Gamma-Ray Burst (GRB) event both on the interstellar medium surrounding the source of the burst and on planets possibly illuminated.

Gamma-Ray Bursts were first detected on the 60's and quickly have attracted the attention of the astrophysical community, since the energies emitted just in $\gamma$ could reach $10^{54} \mathrm{erg}$, the rest mass of the Sun. No mechanism was known to be so efficient in extracting gravitational energy to produce such emission. Later on, the possibility of the emission being collimated has lowered the energy of the $\gamma$ to $5 \times 10^{51} \mathrm{erg}$, but the central engine has not yet been completely understood, and there is still ample room for exotic alternatives.

We have studied the effects of GRB on the ISM, in an attempt to distinguish the candidates of GRB remnants from those generated by multiple supernovae. We have used both energetic arguments and the possibility of chemical alterations due to photonuclear reactions.

We have also worked on the biological implications of the illumination of planets by a GRB, concluding that the effects of such event could seriously harm the biosphere of a planet even at distances of $\sim 10 \mathrm{kpc}$. 


\section{Sumário}

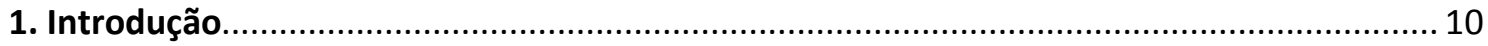

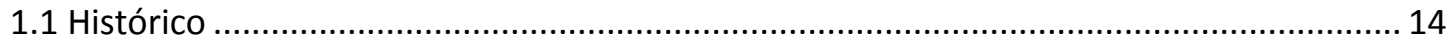

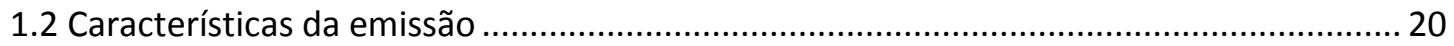

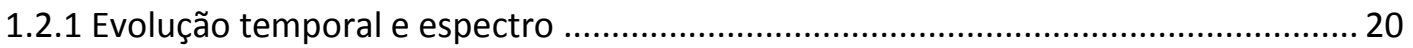

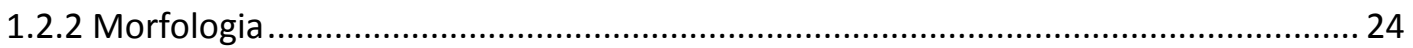

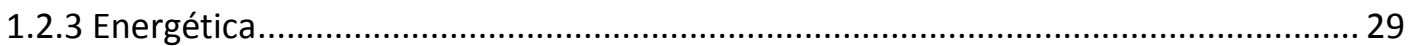

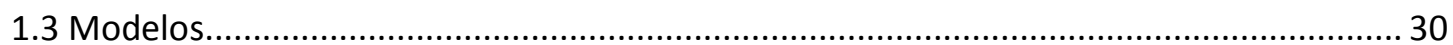

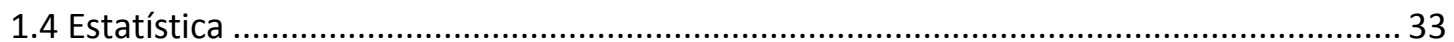

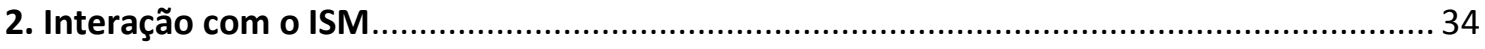

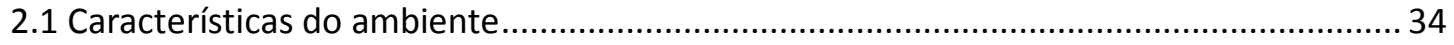

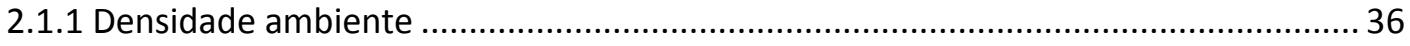

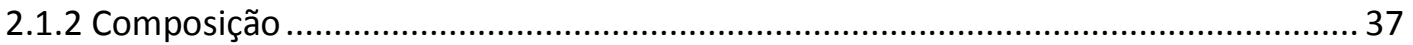

2.2 Remanescentes - formação e detecção ......................................................................... 38

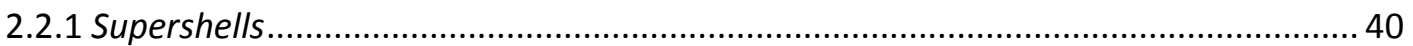

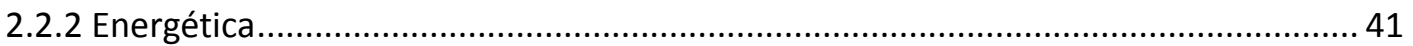

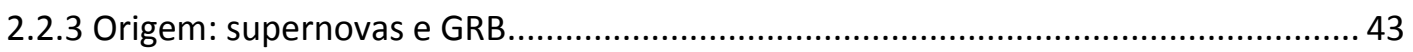

2.3 Efeitos "químicos" do GRB no ISM: Reações fotonucleares .............................................. 45

2.3.1 Seções de choque: A importância da ressonância gigante ........................................... 46

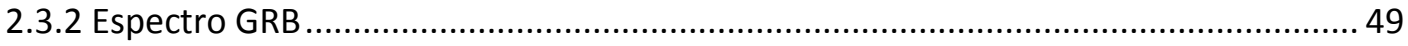

2.3.3 Alterações na distribuição química ............................................................................... 49

3. Efeitos de um GRB sobre um planeta tipo-terrestre............................................................ 55

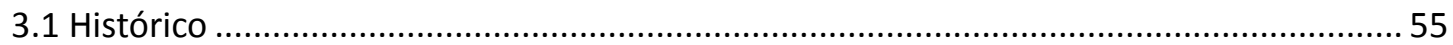

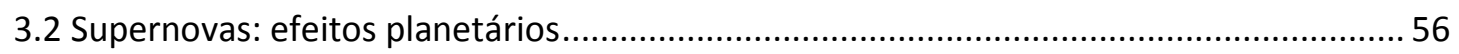

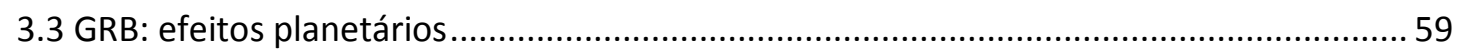

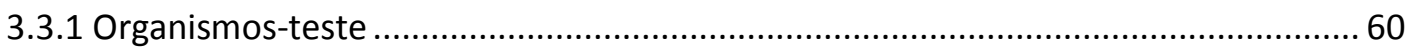

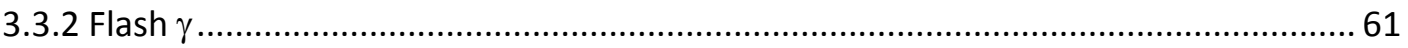

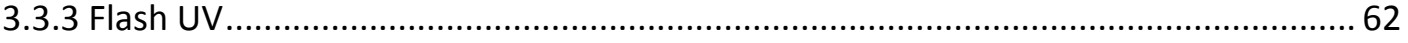

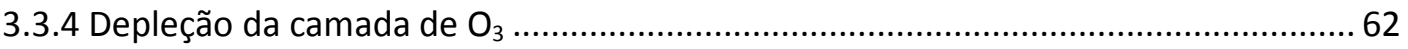

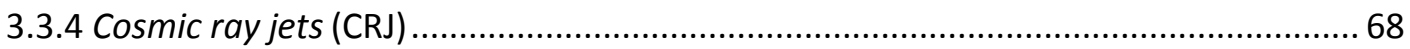

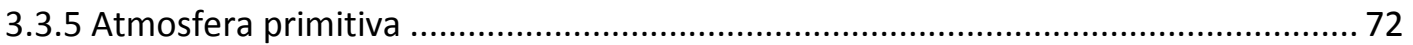

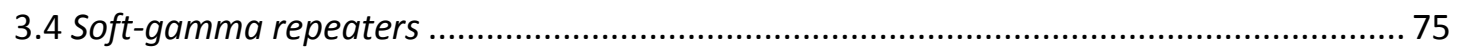


3.4.1 Efeitos sobre um planeta

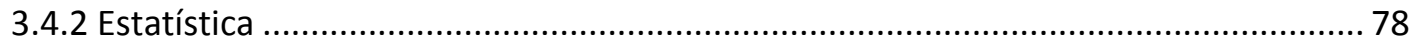

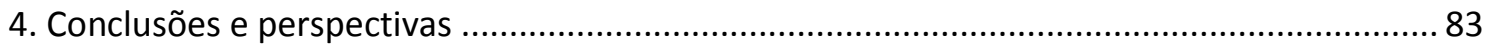

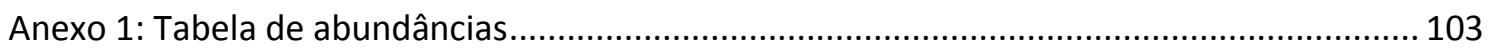

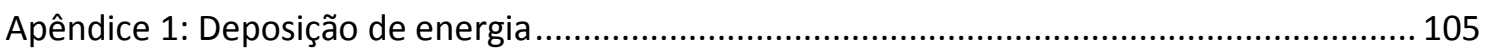

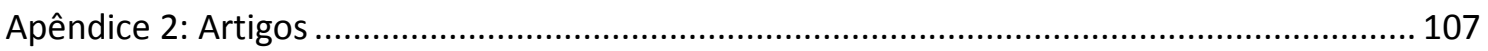




\section{Introdução}

O presente trabalho de doutorado tem o objetivo de fazer a conexão entre uma classe de eventos astrofísicos conhecidos como Gamma-Ray Bursts (GRB), ou Surtos de Raios Gama, com seus efeitos sobre o meio interestelar (ISM) circundante e sobre um planeta porventura iluminado pela radiação de alta energia. A tese se desenvolverá de forma interdisciplinar, pois serão abordados temas típicos das áreas de astronomia, física nuclear, biologia e ecologia teórica. Quando necessário, serão fornecidos esclarecimentos em notas de rodapé ou apêndices sobre temas específicos que não sejam de conhecimento comum, ou de fácil referência. Serão fornecidas as conversões de unidades para o Sistema Internacional em notas de rodapé, quando forem empregadas unidades específicas das diferentes áreas.

Essa tese não tem a pretensão de desenvolver a teoria de geração dos surtos em si, a qual vem sendo construída por outros grupos e será apresentada brevemente nesta introdução, mas sim de analisar os possíveis cenários astrofísicos, planetários e biológicos gerados por esse tipo de evento raro no Universo, onde uma grande quantidade de energia (ao redor de $10^{52} \mathrm{erg}^{1}$ ) é gerada e emitida majoritariamente na região espectral entre centenas de $\mathrm{keV}$ e dezenas de $\mathrm{MeV}^{2}$. Esse é um caso de especial interesse na astrofísica, pois fótons nessa faixa de energia são usualmente pouco emitidos pelas fontes mais abundantes no Universo, as estrelas, salvo em algumas condições extremas.

As estrelas têm, em primeira aproximação, um espectro de emissão tipicamente de corpo negro, ou seja, obedecendo à lei de Planck (Eq. 1). Comparando-se os espectros estelares reais com a função teórica pode-se associar uma temperatura a cada estrela, chamada de temperatura de corpo negro da estrela.

$$
B(\lambda, T)=\frac{2 h c^{2}}{\lambda^{5}} \frac{1}{e^{\frac{h c}{\lambda k T}}-1}
$$

Eq. 1: função de distribuição de Planck em função do comprimento de onda e da temperatura do corpo negro.

A Fig. 1 representa um diagrama de Hertzsprung-Russel (HR) de um conjunto de estrelas. Pode-se notar que existe uma grande diversidade de tipos de objetos nesse

\footnotetext{
$1 \mathrm{erg}=1 \times 10^{-7} \mathrm{~J}$

${ }^{2} 1 \mathrm{eV}=1.6 \times 10^{-12} \mathrm{erg}$
} 
diagrama, no entanto, a temperatura típica estelar está compreendida na faixa de 3000 a $30000 \mathrm{~K}$.

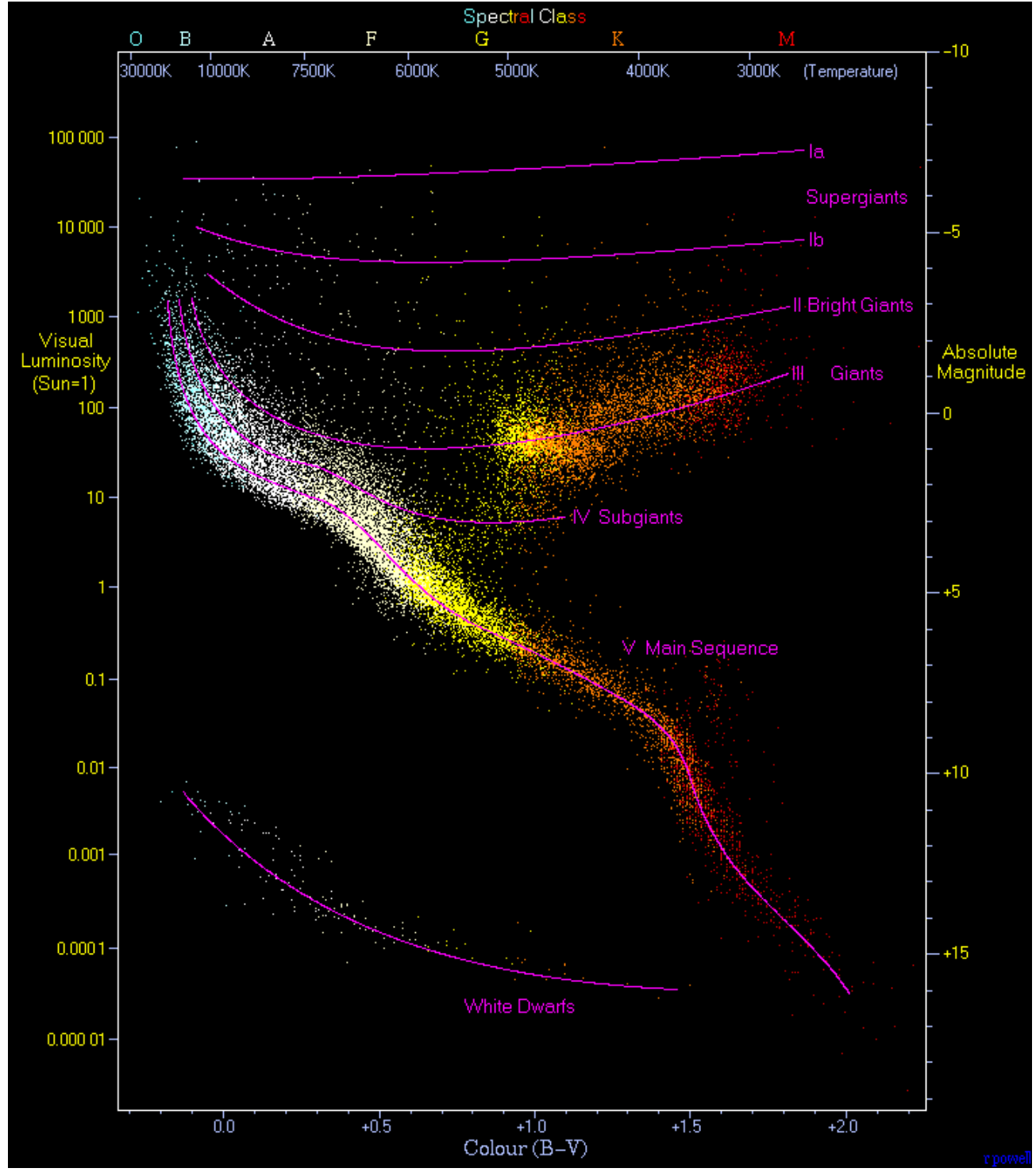

Fig. 1: Diagrama de Hertzsprung-Russell (Powell 2009) com 22.000 estrelas do catálogo Hipparcos e 1.000 do catálogo Gliese para estrelas próximas. Notamos que apenas algumas regiões do diagrama são ocupadas, sendo a linha diagonal a mais predominante, conhecida como Seqüência Principal. Na parte inferior esquerda estão as anãs brancas. Acima da Seqüência Principal estão as subgigantes, gigantes e supergigantes. O Sol está na seqüência principal com luminosidade 1 (magnitude absoluta 4.8) e índice de cor B-V 0.66 (temperatura de $5780 \mathrm{~K}$, tipo espectral G2).

Os espectros de emissão das estrelas não são puramente de corpo negro, tendo sobrepostas linhas de absorção de elementos da atmosfera estelar, bem como eventos de emissão não térmicos, de mais alta energia, como os causados por flares. Essas características são, no entanto, menos importantes que a emissão térmica. Na Fig. 2 são apresentadas algumas curvas da distribuição de Planck para temperaturas tipicamente estelares. 


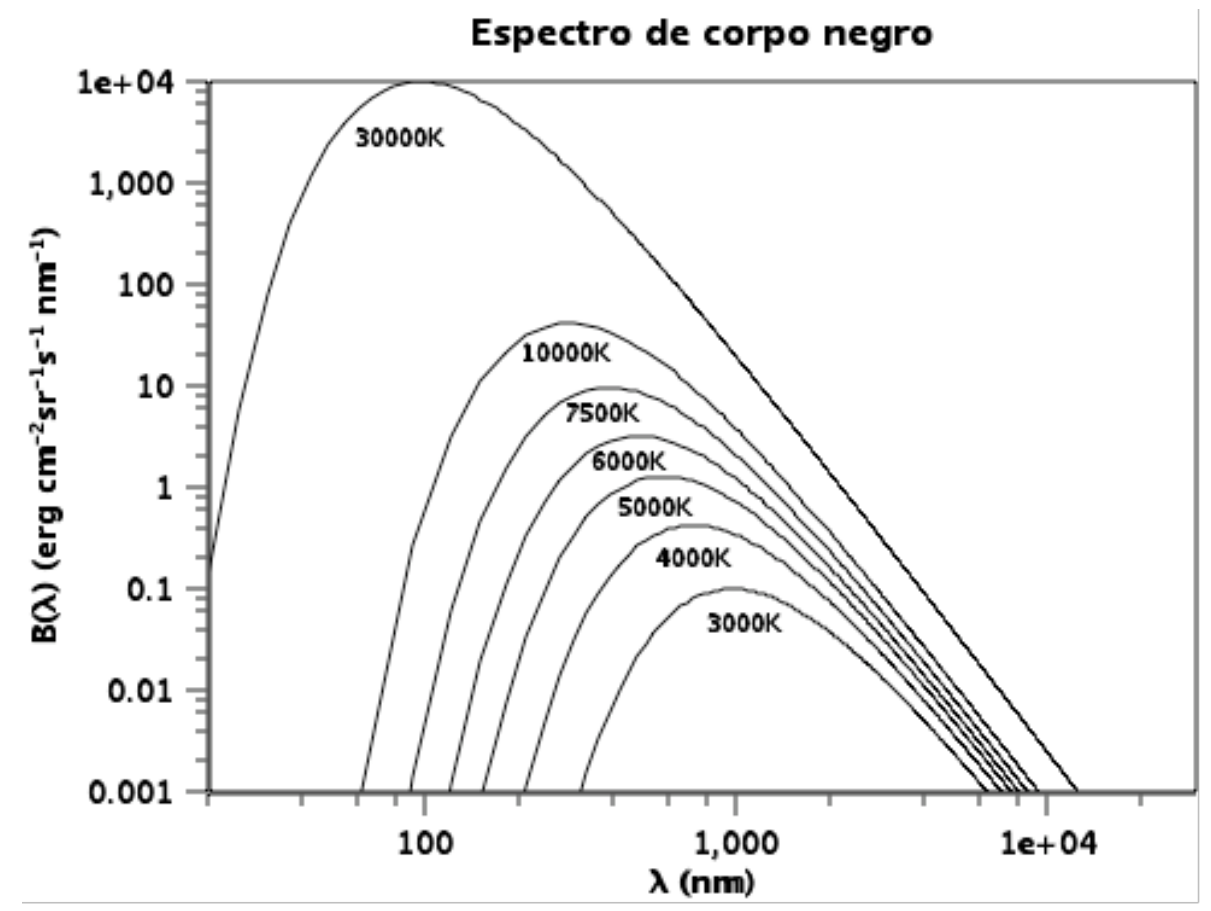

Fig 2: Espectro de corpo negro para temperaturas típicas estelares, em função do comprimento de onda.

Podemos relacionar as temperaturas de corpo negro com as energias típicas dos fótons emitidos pelas estrelas usando a relação $\mathrm{E}=\mathrm{kT}$, onde $\mathrm{k}$ é a constante de Boltzmann. Para temperaturas variando entre 3000 e 30000K teríamos energias típicas dos fótons entre 0.26 e $2.6 \mathrm{eV}$. Como comparação, o potencial de ionização do átomo de $\mathrm{H}$ é $13.6 \mathrm{eV}$. Para que o pico de emissão de um corpo negro ocorresse na faixa de $\mathrm{MeV}$, como é observado para os gamma-ray bursts, a temperatura deveria ser da ordem de $10^{11} \mathrm{~K}$. Claramente, a emissão de radiação gama nos surtos não ocorre por processos térmicos, como será discutido adiante.

Pela grande diferença de energia, a física da interação dos fótons estelares deve ser diferente da física dos fótons de alta energia produzidos pelos surtos, e é essa idéia que iremos desenvolver.

A tese está organizada em duas grandes partes, uma sobre o os efeitos dos fótons de alta energia sobre o meio interestelar e outra sobre os efeitos sobre um planeta tipoterrestre (com atmosfera). Com essa separação, a tese terá um encadeamento espacial: a partir do progenitor do surto serão estudados os efeitos imediatos em sua vizinhança, 
como a possibilidade de escavação de uma supershell (Heiles 1979) e alteração na distribuição química e isotópica do meio. Em seguida estudaremos os efeitos sobre um planeta distante (a partir de alguns pc até $\mathrm{kpc}^{3}$ ), em especial sobre sua atmosfera e Biologia. Na primeira etapa trabalharemos com problemas tipicamente astronômicos e de física nuclear, enquanto na segunda trataremos da interface da Astronomia com a Biologia, conhecida atualmente como Astrobiologia.

A Astrobiologia é uma ciência recente, surgida da necessidade da integração de conceitos de diferentes áreas do conhecimento para a compreensão da origem e evolução da vida na Terra e, possivelmente, em outros lugares do Universo. O avanço da tecnologia aeroespacial permitiu o aumento de estudos nessa área, tanto por sondas enviadas a planetas e satélites do Sistema Solar quanto por detecções astronômicas indiretas (Mix, Armstrong et al. 2006).

Dentre as questões gerais abordadas pela Astrobiologia, podemos destacar: formação e detecção de moléculas pré-bióticas em planetas, envelopes circunstelares, meio interestelar, cometas e poeira cósmica; influência de eventos astrofísicos no surgimento e manutenção da vida na Terra; análise das condições de habitabilidade (viabilidade da vida) em outros planetas ou satélites, em especial vida microbiana, detecção de exoplanetas, em especial rochosos e, mais recentemente, a busca de indícios de vida fora da Terra por meios indiretos (espectroscópicos) e diretos (sondas).

Nos últimos anos, tem havido um crescente interesse na inserção da biosfera terrestre em seu contexto astronômico (Nealson and Conrad 1999). Deixando de ser considerada auto-contida, hoje pode ser vista como um sistema aberto em que, durante sua formação, teve parte de sua matéria-prima trazida do espaço por cometas e meteoros (Chyba, Thomas et al. 1990). Existe mesmo a possibilidade de a vida ter se originado fora do planeta e, posteriormente, chegado à Terra, colonizando-a, em um processo chamado panspermia (Arrhenius 1980; Weber and Greenberg 1985; Melosh 1988; Horneck, Rettberg et al. 2001). A biosfera terrestre permanece sujeita ao ambiente espacial, essencialmente pela interação com a radiação solar e com raios cósmicos (Cockell, Rettberg et al. 2003), sendo a vida no planeta influenciada continuamente pela evolução solar ou por eventos astrofísicos vizinhos de alta energia, como supernovas, surtos de raios gama e giant flares de soft-gamma repeaters (Thorsett 1995; Scalo and

\footnotetext{
${ }^{3} 1 \mathrm{pc}=3.26$ anos-luz $=3.1 \times 10^{16} \mathrm{~m}$
} 
Wheeler 2002; Galante and Horvath 2007; Galante and Horvath 2009; Martin, Cardenas et al. 2009).

\subsection{Histórico}

Gamma-Ray Bursts, ou Surtos de Raios Gama, foram identificados pela primeira vez em 1967 pelos Satélites americanos Vela, desenvolvidos pela equipe de Los Alamos. A rede de satélites Vela era constituída por 4 satélites em órbita geocêntrica com raio de aproximadamente $1.2 \times 10^{5} \mathrm{~km}$, cada um portando 6 detectores de cintilação de CsI de $10 \mathrm{~cm}^{3}$, arranjados de maneira a garantir uma sensibilidade espacial praticamente isotrópica na faixa de $0.2-1.5 \mathrm{MeV}$. Os satélites tinham como principal objetivo monitorar testes nucleares em terra conduzidos pela URSS e, portanto, os dados colhidos ficaram restritos por muitos anos, até serem publicados pela primeira vez em 1973 (Klebesadel, Strong et al. 1973), identificando os primeiros surtos gama. Os resultados foram rapidamente confirmados por outros instrumentos (Wheaton, Ulmer et al. 1973), ficando claro que os surtos não eram provenientes nem do Sol, nem da Terra.

A equipe de cientistas que analisou os dados estava interessada em procurar, no background das contagens, eventos de alta energia que poderiam ser associados a supernovas. Foram reportados 16 eventos com grande variabilidade em suas curvas de luz, com durações entre 0.1 e 30 s, porém, nenhum deles pode ser associado posteriormente a supernovas observadas na região do ótico. Essa associação não pôde, no entanto, ser descartada naquele momento, pois a resolução angular dos satélites era de cerca de $5^{\circ}$. O espectro de energia mostrou-se claramente duro (predominância de fótons de alta energia), com um comportamento em lei de potência (Cline, Desai et al. 1973), e o fluxo, na região entre 0.2 e $1.5 \mathrm{MeV}$, estava entre $10^{-5}$ e $2 \times 10^{-4} \mathrm{erg} \mathrm{cm}^{-2}$.

A descoberta de um novo fenômeno astrofísico motivou a comunidade científica, a qual rapidamente apresentou propostas de modelos para explicar a emissão. Em 1974 ocorreu a "Texas Conference on Relativistic Astrophysics", onde Ruderman (Ruderman 1975) expõe os modelos teóricos existentes na literatura que poderiam ser usados para explicar essa classe de evento, porém, não houve um consenso. Levaria ainda muitos anos para que o mecanismo de emissão fosse mais bem conhecido, e, mesmo hoje, ainda há questões em aberto.

$\mathrm{Na}$ época, parte da discussão girava em torno da localização das fontes. Três cenários eram apresentados: no disco Galáctico (centenas de pc), no halo Galáctico 
(alguns kpc) e a distâncias cosmológicas (vários Gpc). O cenário local, no disco, era o preferido na época, em especial porque admitir distâncias cosmológicas implicaria em energias totais muito altas, podendo chegar a $10^{54} \mathrm{erg}$, para o caso de emissão resultar isotrópica. Além disso, acreditava-se firmemente que os surtos estavam associados com eventos magnetosféricos em estrelas de nêutrons Galácticas.

Estava claro que havia duas maneiras de discriminar entre os cenários, uma delas sendo graficar número de eventos contra intensidade, o que mostraria se eles estavam distribuídos homogeneamente no espaço Euclidiano; a outra, testando a anisotropia da distribuição, o que requeria um grande número de eventos detectados. As contagens de GRBs já indicavam uma tendência à distribuição ser mais plana que a distribuição Euclidiana clássica, indicando uma distribuição não local. Isso explicaria o fato de experimentos em balão, com detectores de maior volume, não serem capazes de coletar surtos mais fracos. A questão foi melhor respondida com a confirmação da isotropia da distribuição espacial, a qual foi resultado do acúmulo de alguns milhares de eventos pelo "Burst and Transient Source Experiment" (BATSE), parte do satélite Compton (Compton Gamma Ray Observatory), um experimento de grande sensibilidade na faixa de $30 \mathrm{keV}-1.9 \mathrm{MeV}$, com cobertura de todo o céu.

Se as fontes tivessem origem no disco Galáctico, seria de se esperar que houvesse uma maior densidade de eventos em torno do plano Galáctico, o que não se mostrou verdade, como se pode observar pela Fig. 3, onde os eventos estão distribuídos isotropicamente. 


\section{BATSE Gamma-Ray Bursts}

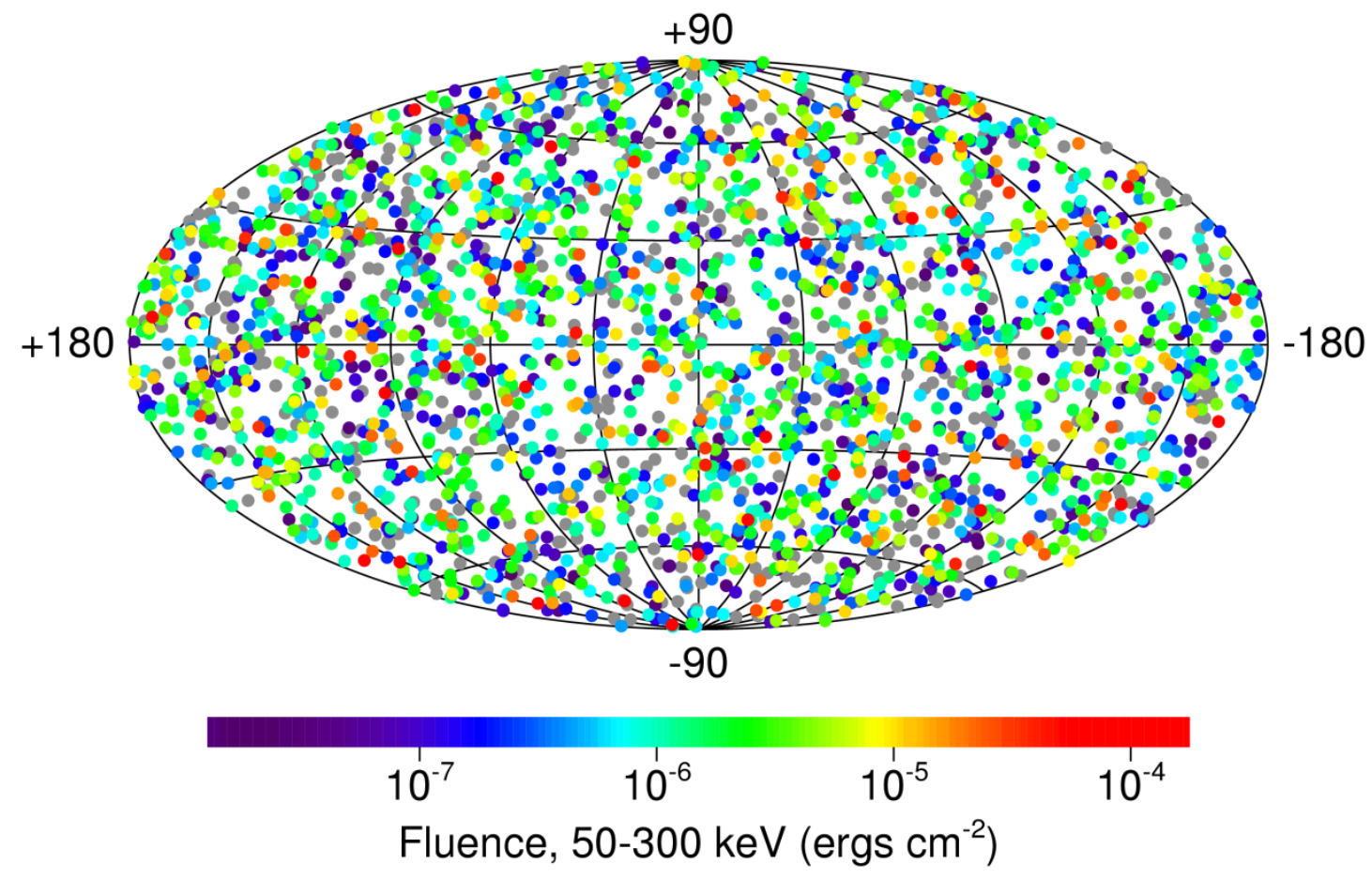

Fig. 3: Mapa de GRBs todo o céu feito pelo BATSE (Briggs 2009), apresentado em coordenadas Galácticas. Não foram encontrados evidências estatísticas de desvios da isotropia, como dipolos ou quadrupolos e correlações de dois pontos (Briggs, Paciesas et al. 1996).

O BATSE, além de demonstrar a isotropia dos surtos, também foi responsável por confirmar que esses eram eventos distintos espectralmente de outros fenômenos, como X-ray Bursters e Soft-Gamma Repeaters, os quais tinham espectros substancialmente deslocados para energias menores e estavam associados a estrelas de nêutrons jovens altamente magnetizadas em nossa Galáxia. Também foram mostradas algumas correlações entre as propriedades dos GRBs, por exemplo, surtos curtos tendem a ser mais intensos e com espectro deslocado para energias mais altas.

No entanto, os dados obtidos pelo BATSE não foram suficientes para eliminar a possibilidade dos eventos estarem no halo da Galáxia, longe o suficiente do Sol para que uma assimetria de dipolo não se manifestasse. Para resolver a questão era necessário associar os surtos com algum outro objeto astronômico, que pudesse ser observado em outros comprimentos de onda. O problema é que o BATSE tinha incertezas na posição de 1 a $2^{\circ}$ para os surtos mais intensos, e de até $5^{\circ}$ para os mais fracos, o que dificultava qualquer associação. 
Um avanço fundamental para resolver a questão da escala veio com o satélite italiano BeppoSax, o qual foi capaz de fornecer a localização do surto com incertezas de alguns minutos de arco após algumas horas do início do evento. Dessa forma foram descobertos os primeiros afterglows em comprimentos de onda maiores, como no ótico e em rádio (Costa, Frontera et al. 1997; Frail, Kulkarni et al. 1997; vanParadijs, Groot et al. 1997). O afterglow é uma emissão tardia do surto, que pode durar muito além da fase inicial, chegando a dias, permitindo assim o acompanhamento por telescópios no ótico e em rádio, em terra e no espaço, com melhor resolução que os telescópios gama e de raios-X. Dessa maneira, foram medidas absorções intensas no afterglow do surto GRB970528 com redshift $\mathrm{z}=0.835$ (Metzger, Djorgovski et al. 1997) e, em seguida, z=3.4 para o evento GRB971214 (Kulkarni, Djorgovski et al. 1998), o qual pode ser associado a sua galáxia hospedeira. Se sua emissão fosse isotrópica, o GRB971214 teria emitido $3 \times 10^{53} \mathrm{erg}$ apenas em raios gama. Para o GRB990123 a energia seria ainda maior, cerca de $2 \times 10^{54} \mathrm{erg}$ (Bloom, Odewahn et al. 1999), sendo a galáxia hospedeira identificada no ótico e o redshift ${ }^{4}$ medido pelo Hubble Space Telescope. Ficou claro que as fontes não estavam na Galáxia, mas sim a distâncias cosmológicas, e, portanto, a energia das fontes deveria ser muito alto, mais alta do que qualquer outro fenômeno astrofísico conhecido até o momento. Além disso, a emissão dos surtos mostrou-se não mais restrita apenas aos fótons gama, tendo uma fenomenologia mais rica que forneceria evidências do mecanismo de geração do evento, bem como de sua dinâmica e evolução.

A geração seguinte de satélites incluiu o Swift, uma missão americana com participação internacional lançada em 2004. O aumento de sensibilidade com o Swift permitiu o registro de um número maior de eventos, permitindo separá-los em duas grandes famílias, ou seja, tendo uma distribuição bimodal: curtos (duração ao redor de 0.3s) e longos (duração ao redor de 30s) (Gehrels, Chincarini et al. 2004). Esse

${ }^{4} \mathrm{O}$ deslocamento para o vermelho em freqüências da radiação eletromagnética, ou redshift, pode ter várias causas. Estamos considerando apenas o redshift cosmológico, ou seja, causado pela expansão do Universo. Pode ser calculado por $1+z=\frac{a\left(t_{0}\right)}{a\left(t_{e}\right)}$, onde $\mathrm{a}(\mathrm{t})$ é o fator de escala do Universo, o qual depende do modelo cosmológico empregado. Para redshifts baixos $(z<<1)$, pode-se usar a aproximação $z \approx \frac{v}{c}=\frac{d}{d_{H}}$, onde $\mathrm{d}_{\mathrm{H}}$ é a distância de Hubble (13.8 bilhões de anoz-luz) Hogg, D. W. (1999). "Distance measures in cosmology." arXiv:astro-ph/9905116v4.. 
resultado já estava sugerido pelos dados do BATSE, mas está claramente ilustrado pelo Swift na Fig. 4.

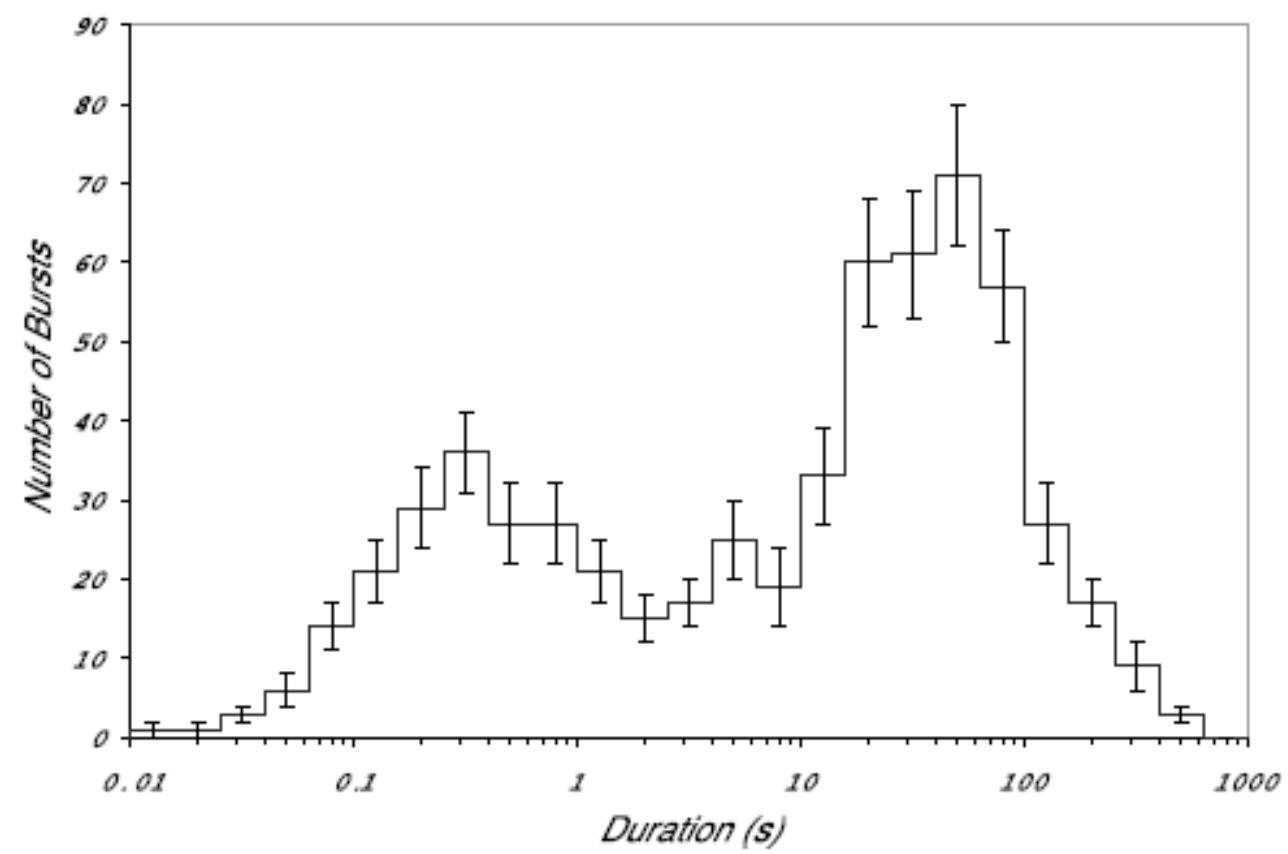

Fig 4: Distribuição de eventos registrados pelo Swift em função da duração, mostrando claramente a existência de um grupo de surtos curtos (0.3s) e um grupo de surtos longos (30s) (Gehrels, Chincarini et al. 2004).

A existência de dois grupos na distribuição de durações dos surtos é acompanhada, como já foi dito anteriormente, de uma diferença também no espectro. Surtos curtos têm espectro mais duro (deslocado para energias maiores) que os longos (Kouveliotou, Meegan et al. 1993). Atualmente atribuímos essa diferença às fontes dos eventos, que seriam distintas. Surtos curtos estariam associados a eventos de coalescência (mergers) de estrelas de nêutrons, enquanto longos estariam associados a eventos de colapso gravitacional, como em collapsars ou hipernovas (Rosswog 2003). Porém, no caso do surto GRB 070201 localizado na galáxia de Andrômeda não foi registrada nenhum sinal nos detectores de ondas gravitacionais em operação, contrariando em mais de 20 sigma a predição teórica (Abbott, Abbott et al. 2008). Assim, parece razoável questionar a origem da binária compacta em coalescência desde uma perspectiva puramente observacional.

Vários outros satélites foram importantes no desenvolvimento da física dos GRBs. O HETE-2, lançado em 2000, foi o primeiro satélite a registrar um surto curto desde sua emissão inicial (prompt emission) até o afterglow (Grindlay, Zwart et al. 2006), ajudando a restringir os possíveis modelos para seu mecanismo de geração. O 
Integral, lançado em 2002 pela ESA (European Space Agency) conta com uma plataforma com instrumentos capazes de observar em gama, raios-x e ótico, permitindo o monitoramento do surto em várias faixas de energia (Winkler, Courvoisier et al. 2003). Em 2008 foi lançado o mais sensível satélite para altas energias até o momento, o GLAST (Gamma-Ray Large Area Space Telescope), que depois seria rebatizado de Fermi. Além de uma área coletora muito maior que seu antecessores, os detectores do Fermi são capazes de trabalhar de $30 \mathrm{keV}$ até $300 \mathrm{GeV}$, abrindo possibilidades para nova fenomenologia em energias maiores. A Fig. 5 representa o céu visto pelo Fermi, com algumas fontes de raios-x e gama identificadas.

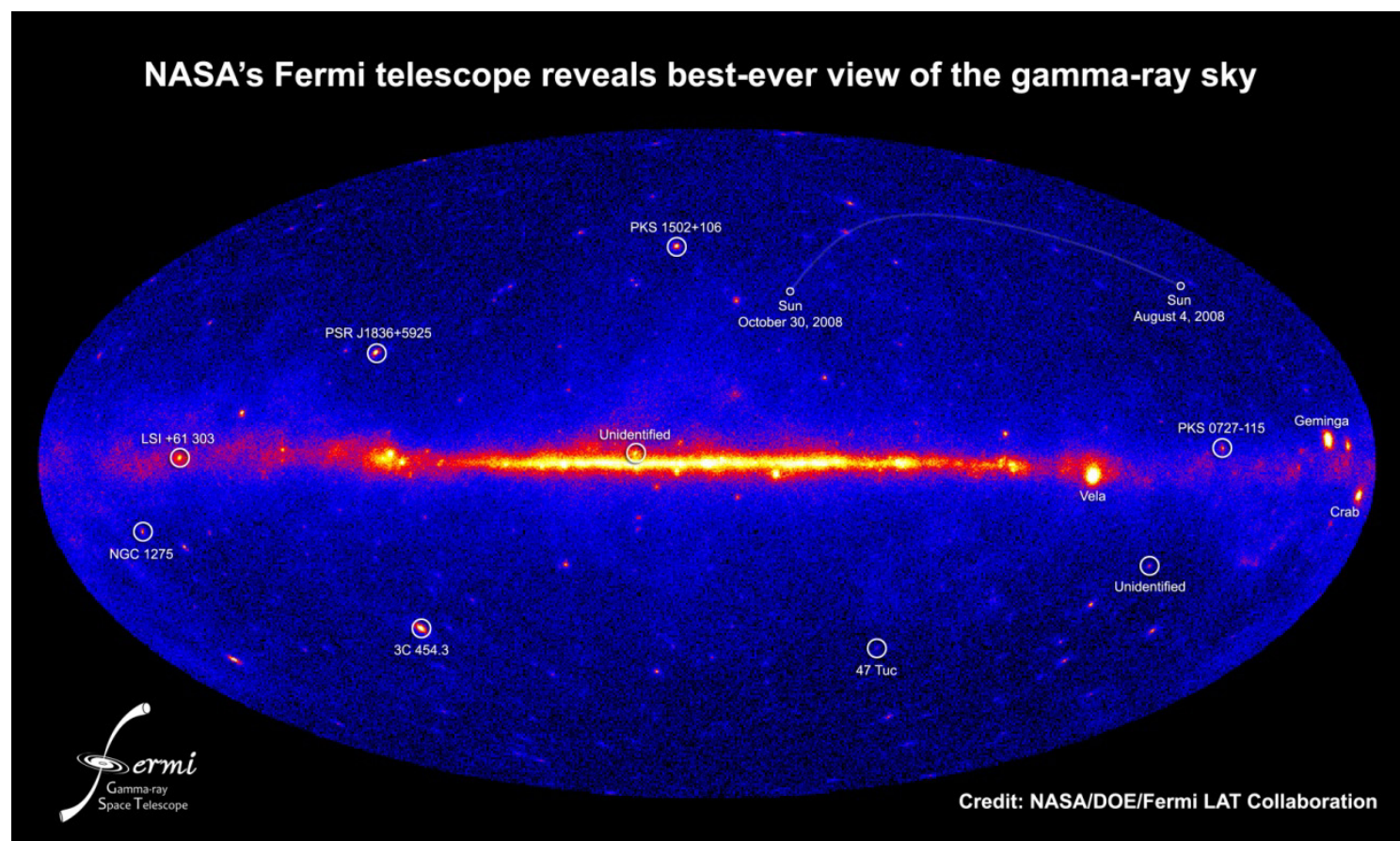

Fig. 5: Mapa de todo o céu pelo satélite Fermi, com algumas fontes ainda não identificadas, detectadas pela grande sensibilidade e resolução angular.

Algumas observações em terra também foram importantes para 0 desenvolvimento da física de GRB. A radiação gama é altamente absorvida pela atmosfera, não chegando ao solo, mas, se a energia dos fótons for muito alta, eles são capazes de iniciar um chuveiro de partículas no topo da atmosfera, o qual pode ser observado pela radiação Cerenkov de partículas ultra-relativísticas, por telescópios de fluorescência, por exemplo. São eventos parecidos aos produzidos por raios cósmicos de ultra-alta energia $\left(>10^{15} \mathrm{eV}\right)$, os quais podem ser detectados por essa técnica com os grandes detectores como o observatório Pierre Auger Sul, na Argentina (Abraham, Aglietta et al. 2004). Utilizando um observatório semelhante, o Milagrito, em Los 
Alamos, Novo México, foram observados fótons de ultra-alta energia associados a um surto gama (Atkins, Benbow et al. 2000). Nesse detector, os fótons acima de $100 \mathrm{GeV}$ produzem pares partícula-antípartícula no interior de tanques de água, na qual elas se movem com velocidades ultra-relativísticas, emitindo a característica radiação Cerenkov. A área coletora do detector cobria $1800 \mathrm{~m}^{2}$, tendo sensibilidade e resolução angular suficientes para permitir a associação com grande confiabilidade estatística dos fótons detectado a um surto (GRB 970417a). Os mecanismos de produção de fótons tão energéticos por GRBs ainda estão para ser completamente elucidados (Razzaque, Meszaros et al. 2004).

\subsection{Características da emissão}

A emissão inicial dos GRBs é usualmente explicada por radiação síncrotron ou Compton inversa de partículas carregadas relativísticas em região de choques em material ejetado, na presença de campos magnéticos fortes $\left(\sim 10^{15} \mathrm{G}\right)$.

A emissão inicial é seguida de um afterglow, o qual ocorre em energias mais baixas, do ótico ao rádio. Essa emissão é proveniente da interação e desaceleração da matéria ejetada no evento com o meio interestelar no entorno do progenitor. Graças à presença do afterglow, que pode durar alguns dias, dependendo das condições do meio (essencialmente a densidade), foi possível associar GRB a suas galáxias hospedeiras e medir seus redshifts.

\subsubsection{Evolução temporal e espectro}

A emissão inicial dos GRBs apresenta grande variação entre um evento e outro. Inicialmente, temos de separar em surtos curtos e longos, conforme discutido anteriormente. Mesmo com essa separação, o espectro de um surto de mesmo tipo não é idêntico ao de outro, apresentando variações, como no número de picos na curva de luz (número de fótons detectados em função do tempo, para determinada energia, ou faixa de energia, fixos) e presença de estruturas de alta freqüência, conforme podemos notar na Fig. 6. 

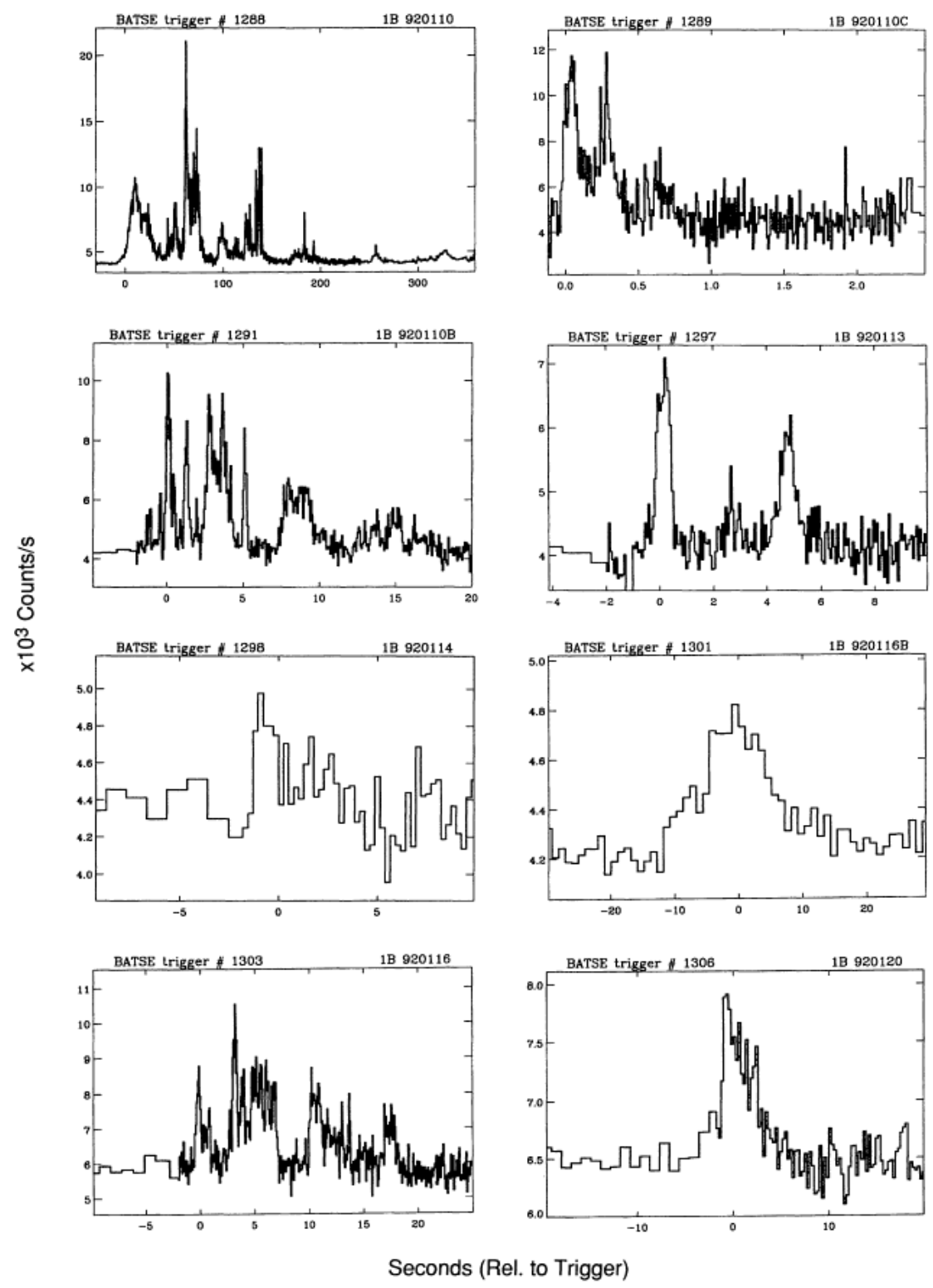

Fig. 6: Diversidade das curvas de luz (número de fótons $x$ tempo), segundo observações do BATSE (Fishman, Meegan et al. 1994).

A variabilidade nas curvas de luz reflete as propriedades do local de emissão. Tomando-se as menores estruturas nessas curvas, a qual está na escala de $\delta t / \Delta t \approx 10^{-3} s$, podemos inferir que o tamanho mínimo da fonte onde são produzidas é de $c \frac{\delta t}{\Delta t} \approx 3 \cdot 10^{10} \cdot 10^{-3}=3 \cdot 10^{7} \mathrm{~cm}$, para garantir causalidade relativística.

O espectro de emissão é, no entanto, mais simples, podendo ser descrito empiricamente por uma lei de potência quebrada, ou seja, duas leis de potência conectadas de forma suave. No caso dos GRBs, o ajuste clássico é conhecido como 
função de Band (Band, Matteson et al. 1993), conforme mostrado na Eq. 2 e ilustrado na Fig. 7.

$$
N(E)=\left\{\begin{array}{l}
A\left(\frac{E}{100 k e V}\right)^{\alpha} \exp \left(-\frac{E}{E_{0}}\right),(\alpha-\beta) E_{0} \geq E \\
A\left[\frac{(\alpha-\beta) E_{0}}{100 k e V}\right]^{\alpha-\beta} \exp (\beta-\alpha)\left(\frac{E}{100 k e V}\right)^{\beta},(\alpha-\beta) E_{0} \leq E
\end{array}\right.
$$

Eq. 2: Função de Band

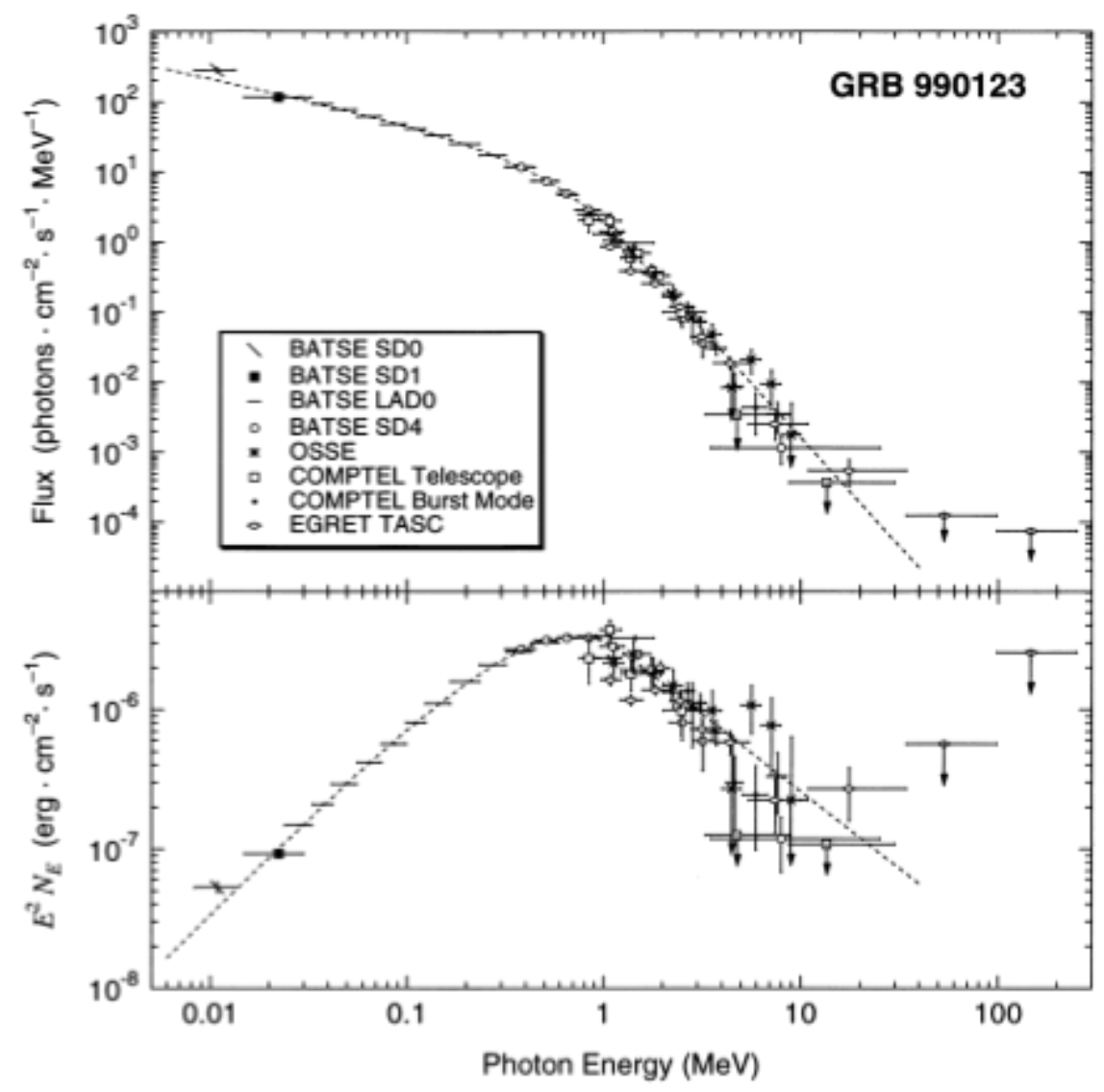

Fig. 7: Ajuste da função de Band para a emissão inicial do GRB 990123, cujo pico de emissão está em cerca de 720 keV (Briggs, Band et al. 1999).

Para energias mais altas o espectro não está totalmente claro em seguir a função de Band. Como exemplo, podemos mostrar os limites superiores para fluxos conforme medidos pelo EGRET e Milagrito, na Fig. 8. 


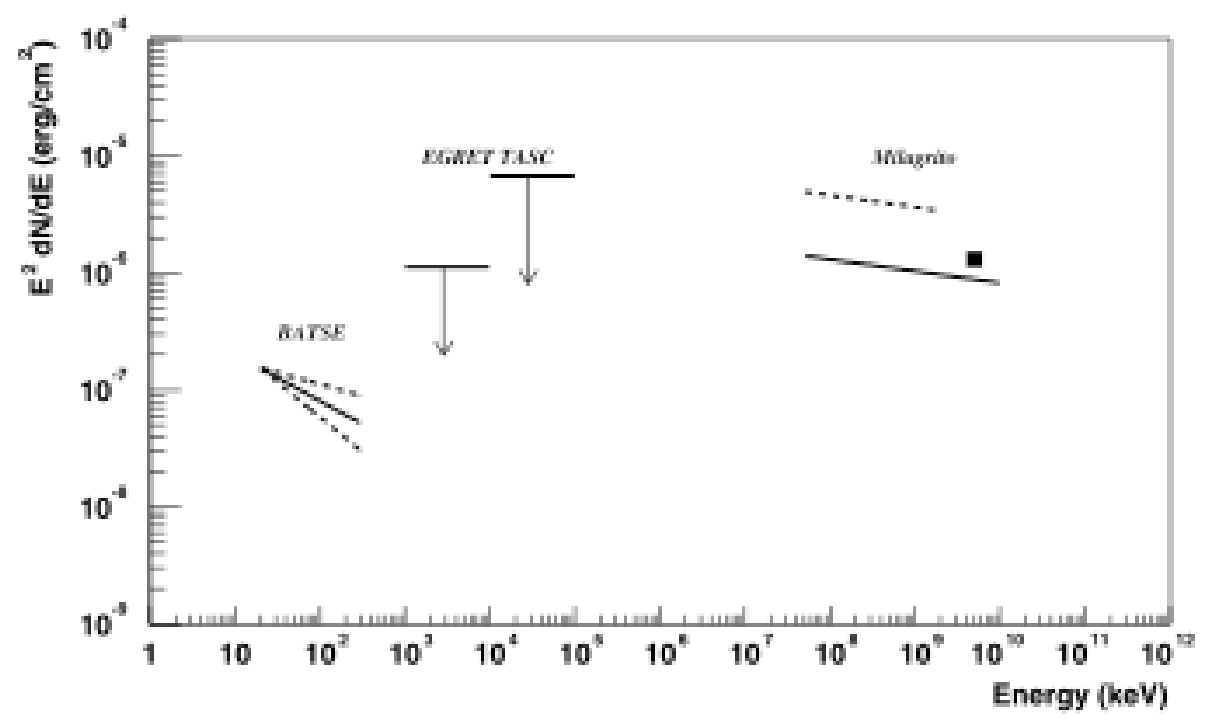

Fig. 8: Distribuição espectral em energia do GRB 970417a mostrando um ajuste em lei de potência única para os dados do BATSE, dois limites superiores para 1 e $10 \mathrm{MeV}$ conforme medidos pelo instrumento TASC do EGRET e três formas espectrais possíveis consistentes com observações do Milagrito (Atkins, Benbow et al. 2003).

A emissão dos afterglows ocorre em várias freqüências simultaneamente, como mostrado na Fig. 9, sendo seu espectro em rádio, Fig. 10, bem explicado pelo modelo de emissão síncrotron.

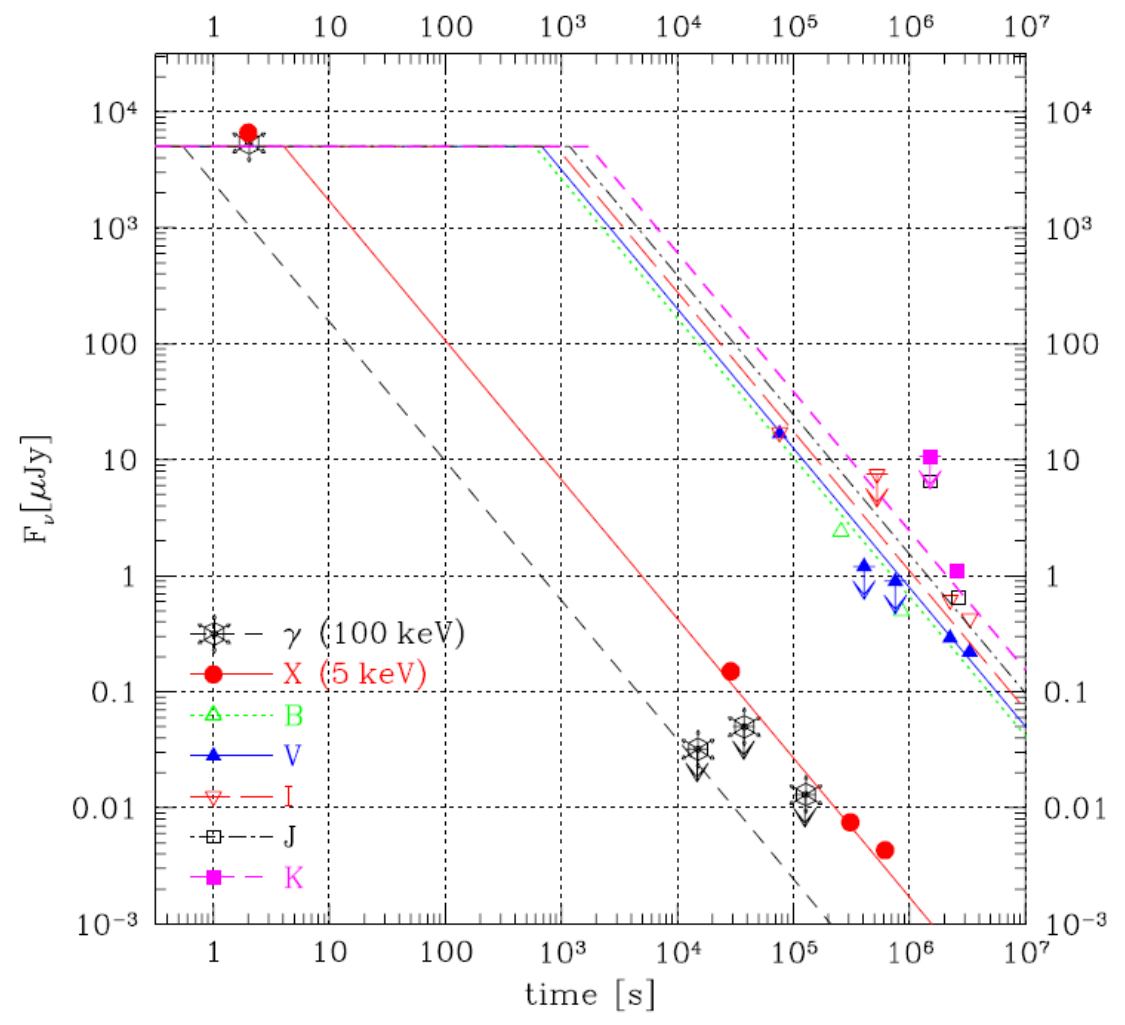

Fig. 9: curvas de luz para o GRB 970228 de gama até infravermelho próximo. As linhas representam as predições de um modelo de onda de choque relativística (Wijers, Rees et al. 1997). 


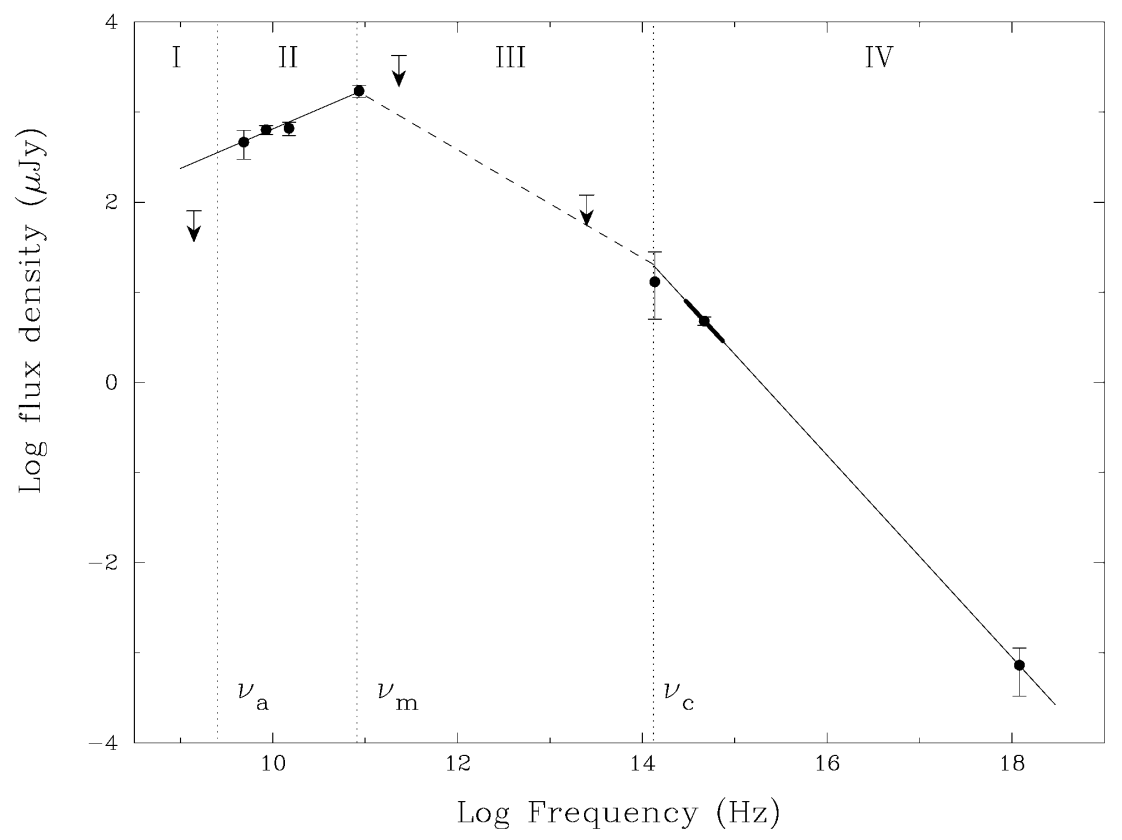

Fig. 10: Espectro do afterglow do GRB $970508 \mathrm{em} \mathrm{t}=12$ dias após o surto inicial, comparado a um modelo de emissão síncrotron em choques (Galama, Wijers et al. 1998).

Além da produção de fótons de alta energia, seria esperado que GRB fossem locais de possível aceleração de raios cósmicos até energias ultra-altas $\left(>10^{18} \mathrm{eV}\right)$ (Biermann, Medina Tanco et al. 2004). Ainda não há, entretanto, sinais claros de correlação entre eventos de raios cósmicos dessa energia com GRB, em grande parte devido à baixa estatística e baixa resolução angular dos detectores atuais.

\subsubsection{Morfologia}

Como a emissão inicial é fruto de choques de material ejetado de uma fonte central em velocidades relativísticas com o meio e consigo mesmo (provocando choques externos e internos), com fatores de Lorentz $\Gamma \approx 100-1000$, a emissão produzida sofrerá um beaming relativístico (Rybicki and Lightman 1979), sendo a emissão direcionada em um cone na direção de propagação, com angulo de abertura $\theta \approx 1 / \Gamma$. Além disso, as observações indicam que a emissão em si é geometricamente colimada, ou seja, a matéria não é ejetada de forma esfericamente simétrica pelo progenitor do surto, mas sim preferencialmente em jatos. Alguns fatores podem proporcionar uma ejeção colimada:

Rotação: concentra a matéria em torno do progenitor ao longo de seu equador, por ação de força centrífuga, formando um toro de maior densidade que a existente 
sobre o pólo. Dessa maneira, a região polar do progenitor terá densidade ótica menor, permitindo que matéria e radiação escapem com maior facilidade;

Campos magnéticos: a rotação sozinha provavelmente não seria suficiente para colimar a ejeção em jatos na abertura que acreditamos observar. Para tanto, é necessária a presença de um campo magnético intenso, com as linhas de campo enrolando-se ao longo do pólo, sendo os efeitos magneto hidro-dinâmicos (MHD) que criarão um canal para o transporte da matéria das regiões internas do progenitor, formando o jato (Fig. 11).
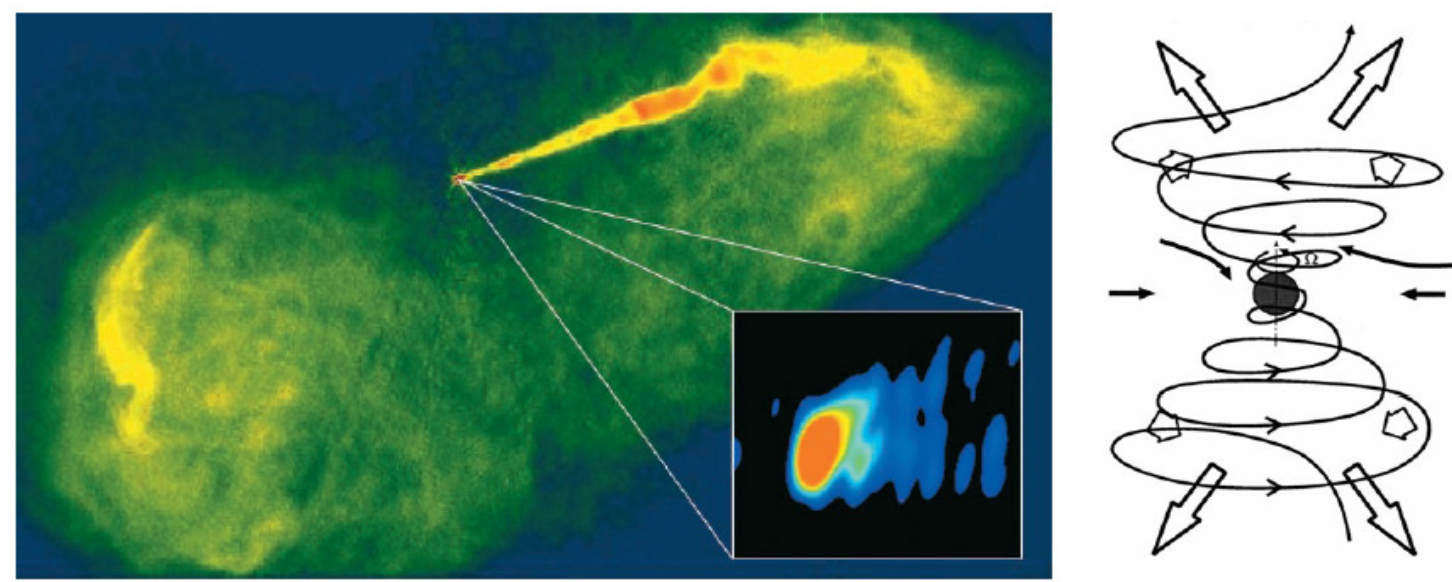

A

B

Fig. 11: (A) Exemplo de jato relativístico na galáxia M87, mostrando um dos jatos colimados (o contra-jato está direcionado afastando-se da Terra, por isso não é observado) e os lobos emitindo, que emitem de forma isotrópica. (B) Esquema ilustrando o funcionamento da aceleração e colimação em processos MHD, onde um objeto central magnetizado rotacionando torciona as linhas de campo em uma hélice espiral.

Combustão assimétrica: Alguns autores propõem que a emissão colimada nos eventos de GRB pode ser gerada na combustão assimétrica de cores de estrelas de nêutrons, durante a formação de uma estrela estranha (composta por matéria predominantemente SQM - strange quark matter) (Lugones, Ghezzi et al. 2002; B. Paczynski 2005).

Os jatos são desejáveis por permitir diminuir a energia dos surtos. Se assumirmos uma emissão isotrópica, a energia, apenas em gamas, teria que ser em torno de $10^{54}$ erg para muitos eventos, o que é equivalente à energia de repouso do Sol ( $\left.E_{S o l}=M_{S o l} c^{2}\right)$. A Eq. 3 apresenta a maneira de calcular a energia isotrópica equivalente de um surto para o qual tenha sido medido um fluxo $F_{\gamma}$ e uma distância $D$ (pelo redshift, por exemplo).

$$
E_{i s o}=F_{\gamma} \cdot 4 \pi D^{2}
$$


Para atingirmos tamanha energia, seria necessária uma eficiência muito grande na conversão de energia magnética e cinética em eletromagnética nas fontes dos surtos, ou então, quantidade de matéria ejetada muito maior que o razoável para esse tipo de evento. Assumindo uma emissão colimada, a energia pode ser calculada como na Eq. 4, onde $\Omega$ representa o ângulo sólido de emissão do jato.

$$
E_{\text {colimada }}=F_{\gamma} \cdot \Omega D^{2} \quad \text { Eq. } 4
$$

Claramente basta diminuir o ângulo de emissão e teremos uma diminuição proporcional na energia.

Há evidências observacionais que a emissão gama nos surtos realmente é colimada geometricamente, além de relativisticamente: inicialmente, quando $\Gamma$ ainda é muito alto, toda a emissão estará confinada relativisticamente dentro do ângulo sólido $\Omega$ da colimação geométrica (digamos, pelos campos magnéticos). Dessa maneira, um observador dentro do cone recebe apenas a radiação produzida dentro do jato, estando causalmente desconectado do exterior. Com o tempo a velocidade diminui, portanto diminui $\Gamma$ e aumenta o ângulo do beaming relativístico. Quando $1 / \Gamma \geq \Omega$, passaremos a enxergar as bordas do cone de colimação geométrico e perceberemos um déficit de energia por unidade de ângulo sólido. Essa é a causa mais aceita para a quebra acromática na curva de luz dos GRB (Rhoads 1997; Rhoads 1999), mostrada na Fig. 12. É importante notar que esse é um fenômeno puramente relativístico e geométrico, portanto, deveria ser independente da freqüência da radiação. 


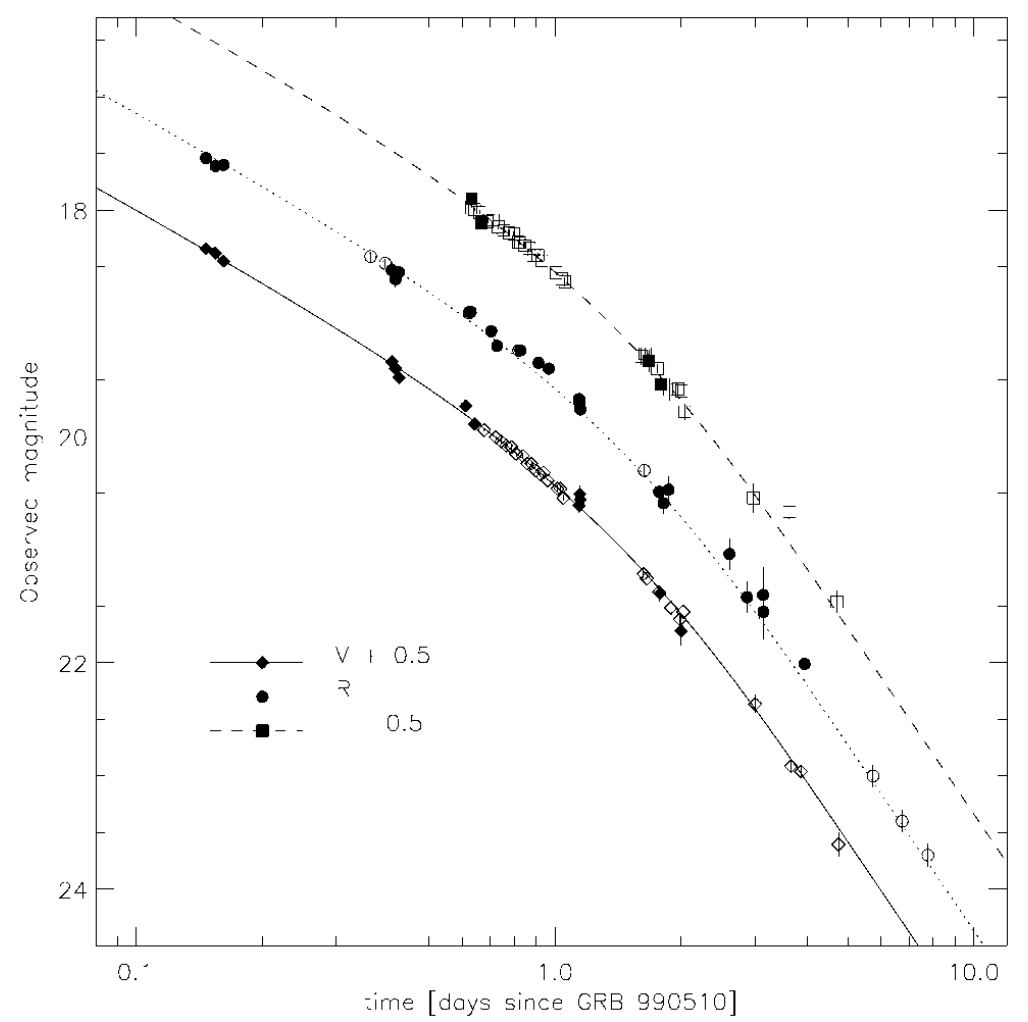

Fig. 12: Mudança de inclinação na curva de luz do afterglow do GRB 990510, indicando a presença de "quebra" no espectro gerada pela presença de colimação geométrica da emissão (Harrison, Bloom et al. 1999).

Pelas observações das quebras na curva de luz, pode-se inferir o ângulo de abertura do jato, conforme mostrado na Fig. 13, o qual tem distribuição centrada em aberturas de $4^{\mathrm{o}}$ (Frail, Kulkarni et al. 2001), o equivalente a cerca de $0.01 \mathrm{sr}^{5}$.

${ }^{5}$ Podemos relacionar o ângulo de abertura de um cone com seu ângulo sólido por $\Omega=2 \pi(1-\cos \theta)$, sendo a unidade de ângulo sólido o ster-radiano (sr). 

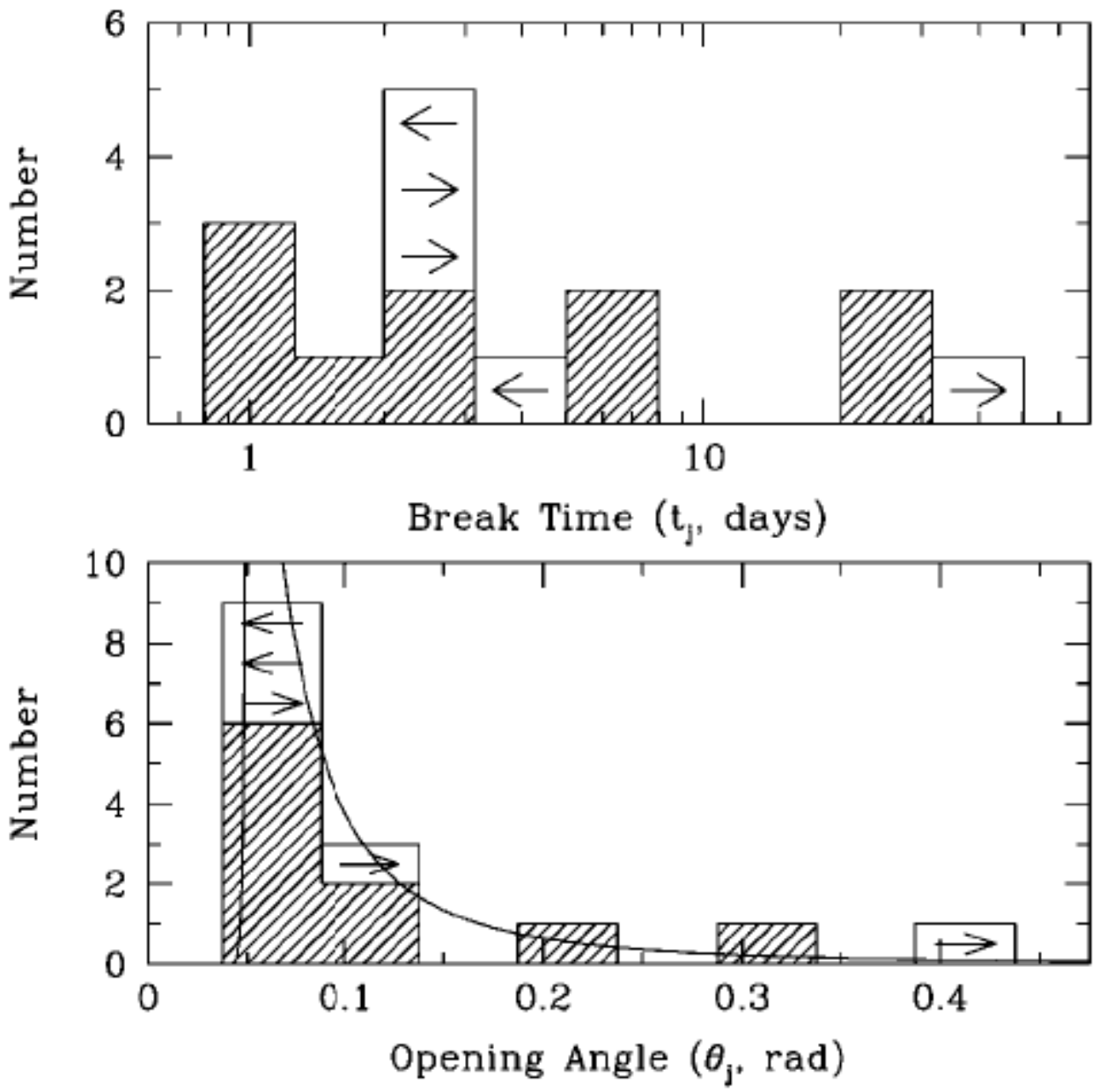

Fig. 13: Medidas da quebra de curva de luz e o ângulo de abertura do jato inferido (Frail, Kulkarni et al. 2001).

No entanto, dados do Swift mostraram a ocorrência de uma quebra cromática (Panaitescu, Meszaros et al. 2006): a quebra no espectro observada em raios-x não foi observada no ótico. Se ambas as emissões fossem geradas pelo mesmo mecanismo, elas deveriam apresentar uma quebra simultânea. O mecanismo de geração dessa quebra cromática não está totalmente claro até o momento.

Modelos de jato também são usados para associar GRB com outros eventos de energia menor, os X-Ray Flashes. Com propriedades muito semelhantes, mas com espectros significativamente mais moles (deslocados para menor energia), esses eventos seriam criados por GRB observados não diretamente alinhados com o jato de emissão, mas ligeiramente fora dele (Zhang, Dai et al. 2004). 


\subsubsection{Energética}

Levando-se em conta os fluxos observados, os quais variam entre $10^{-6}$ e $10^{-4} \mathrm{erg}$ $\mathrm{cm}^{-2}$ e as distâncias cosmológicas, a energia emitida em gamas, no caso de emissão isotrópica poderia chegar a $10^{54} \mathrm{erg}$, equivalente a massa de repouso do Sol.

No entanto, conforme discutido na seção 1.2.2, há evidências que a emissão seja colimada, portanto, a energia emitida seria concentrada em pequenos ângulos, cerca de diminuindo a energia total em gamas de $10^{54}$ para cerca de $3 \times 10^{51}$ erg (Frail, Kulkarni et al. 2001), conforme mostrado na Fig. 14. Corrigindo as estimativas de energia segundo a colimação, para os surtos observados, chega-se a conclusão que GRB apresentam um reservatório padrão de energia em gamas.

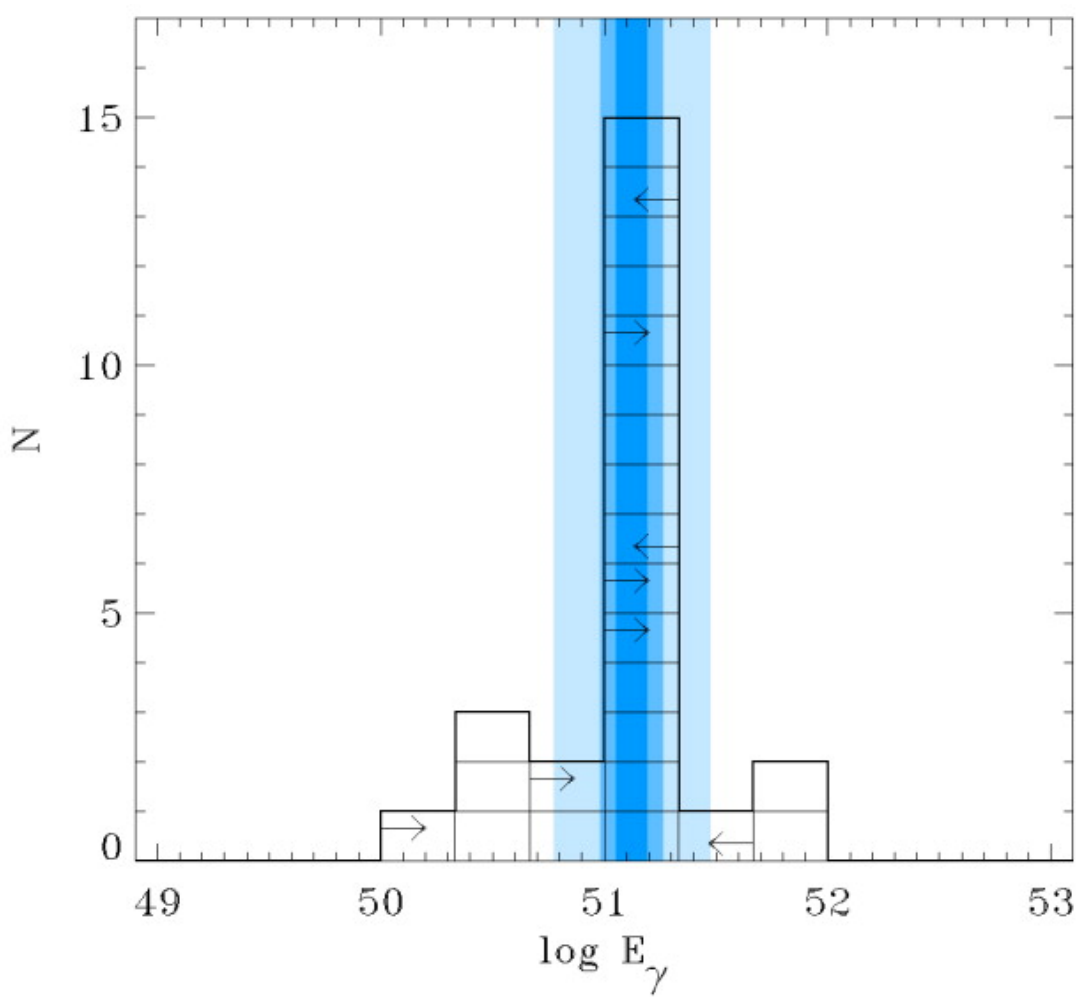

Fig. 14: Histograma da energia em gamas para GRB após a correção para a colimação geométrica, apresentando concentração de dados em torno de $3 \times 10^{51} \mathrm{erg}$ (Bloom, Frail et al. 2003).

Para serem usados como velas-padrão, assim como são usadas supernovas e cefeidas, é necessário usar algumas relações entre parâmetros dos GRB, as quais têm se mostrado constantes (Ghirlanda, Ghisellini et al. 2006), e não sua energia isotrópica diretamente. Dessa maneira, é possível usar GRBs para restringir parâmetros cosmológicos em redshifts altos, em especial por eles terem quebrado a barreira do $\mathrm{z}=6$, além da qual poucos objetos são observados. É possível que os primeiros GRBs tenham se formado logo após a formação das primeiras estrelas, e, possivelmente, os primeiros 
GRBs observáveis em $z=60$ (Naoz and Bromberg 2007), porém uma discussão dessa aplicação está fora do escopo desta tese.

\subsection{Modelos}

Os modelos de GRB baseiam-se, em grande parte, em uma premissa fundamental: o processo inicia-se com uma grande quantidade de energia gravitacional liberada em uma região pequena do espaço. A forma de extração de energia gravitacional do objeto central mais eficiente parece ser por mecanismos magnéticos, como Blandfor-Znajek para buracos negros em rotação (Blandford and Znajek 1977). Grande parte dessa energia é convertida em pares $v \bar{v}$ (neutrino/anti-neutrino) e em ondas gravitacionais (na faixa de $10^{2}-10^{3} \mathrm{~Hz}$ ), os quais escapam quase que livremente da região de emissão, porém, até o momento não foram detectados (por dificuldades técnicas, no caso das ondas gravitacionais, e por não ter ocorrido um surto na Galáxia recentemente, para os neutrinos). Uma pequena parcela da energia gravitacional liberada é convertida em uma fireball, composta de pares $e^{+} e^{-}$, raios-gama e uma pequena parcela de bárions.

Essa região esférica irá se expandir adiabaticamente, no início, de forma relativística. Carregando matéria e linhas de campo magnético do progenitor, a expansão criará ondas de choque internas e externas, onde partículas carregadas poderão emitir radiação síncrotron ou Compton inverso. Essa expansão pode ocorrer de maneira esfericamente simétrica ou colimada em jatos, como ilustrado na Fig. 15.

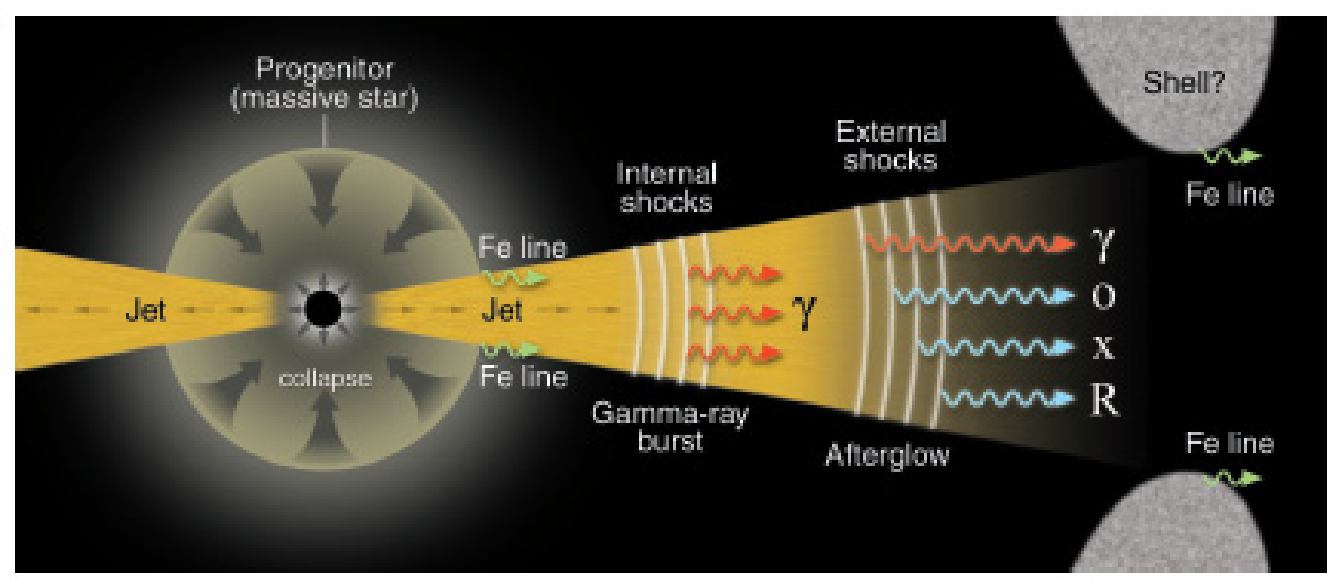

Fig. 15: Esquema de geração da emissão inicial gama nos choques internos da expansão e do afterglow em múltiplas freqüências, nos choques externos (Meszaros 2001). 
Existem dois modelos principais para a geração da radiação nesse cenário, o Fireball (Zhang and Meszaros 2004) e o Cannonball (Dar and De Rujula 2004). As principais diferenças entre esses modelos é que o Cannonball pressupõe que a matéria não é ejetada em uma concha esférica como mostrado na Fig. 15 para um modelo Fireball, mas sim em "bolas de canhão", ou seja, em pedaços finitos e repetidos, os quais se chocam com os fótons da região proporcionando um blueshift ${ }^{6}$ por espalhamento Compton inverso, conforme ilustrado na Fig. 16. A variabilidade na emissão inicial dos surtos estaria relacionada exatamente ao processo de geração dos gamas, quando as conchas esféricas ou os projéteis se chocam. Como a ejeção de matéria não é uniforme, a curva de luz será variável e refletirá as propriedades do local de emissão.

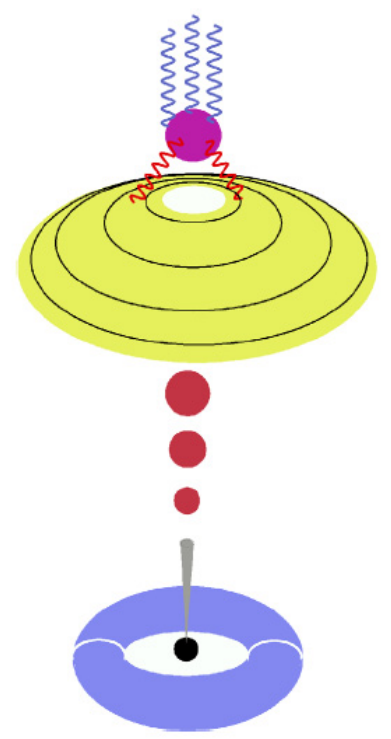

Fig. 16: Modelo Cannonball, onde a matéria é ejetada de forma descontínua pelo objeto central massivo, formando projéteis que irão causar blueshift nos fótons do ambiente, até energia de fótons gama (Dar and De Rujula 2004).

Os modelos de surtos longos consideram que o progenitor, no geral, está relacionado com uma estrela massiva em colapso, com um toro ao longo de seu equador acretando algumas frações de massa solar por segundo sobre o objeto central. Os candidatos a progenitores são hipernovas (Paczynski 1998) e colapsares (Fryer, Woosley et al. 1999). Hipernovas são eventos onde estrelas muito massivas $\left(\sim 100 \mathrm{M}_{\text {Sol }}\right)$ em rotação cujo core colapsa, formando um buraco-negro e deixando um toro de matéria que continua acretando, além de expulsar as camadas externas da estrela.

\footnotetext{
${ }^{6}$ blueshift: desvio para o azul, ou seja, para radiação de freqüência mais alta.
} 
Colapsares são estrelas massivas que sofrem colapso pela coalescência (merger) com uma estrela companheira, também resultando em um buraco-negro.

Como são associados a colapsos gravitacionais, surtos longos deveriam, em grande parte dos casos, estar também associados a eventos de supernova. As primeiras evidências observacionais fortes surgiram em 1998 (Galama, Vreeswijk et al. 1998), quando uma supernova (SN 1998bw) foi observada dentro das caixas de erro de localização de um GRB. Em 2003, foi observada a evolução espectral de um GRB, partindo de sua típica emissão inicial para a de uma supernova (SN 2003dh), o que mostrou que os dois eventos deveriam estar relacionados espacialmente e temporalmente (Hjorth, Sollerman et al. 2003; Kawabata, Deng et al. 2003; Matheson, Garnavich et al. 2003; Kosugi, Mizumoto et al. 2004).

Surtos curtos são usualmente relacionados a processos de coalescência entre duas estrelas de nêutron ou estrela de nêutrons e um buraco negro (Goodman 1986; Paczynski 1986; Eichler, Livio et al. 1989; Meszaros and Rees 1997). O remanescente da coalescência emite grande quantidade de neutrinos e anti-neutrinos, cuja aniquilação geraria a emissão gama, como mostra a Fig. 17. O disco de rotação cria naturalmente o cenário para a geração da emissão polarizada em dois jatos.
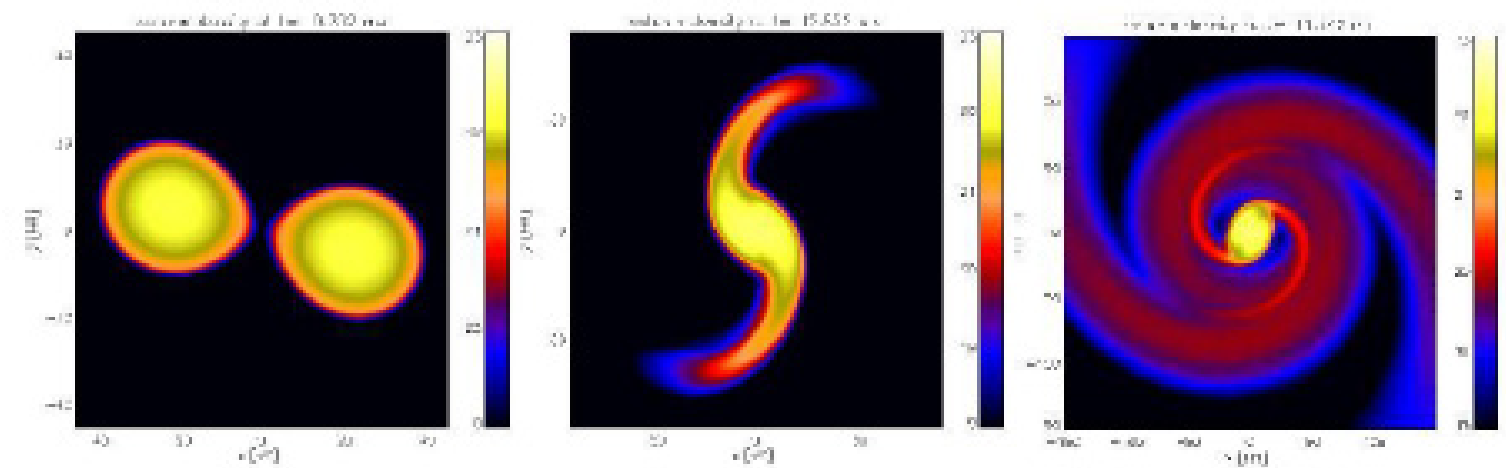

Fig. 17: Simulação de duas estrelas de nêutrons em coalescência (Rosswog 2003).

Há alguns modelos alternativos ao de colapso gravitacional, como o de conversão de matéria bariônica em matéria estranha (SQM), conforme apresentado na seção 1.2.2, o qual pode explicar, por exemplo, a falta de ondas gravitacionais para o GRB 070201 (Abbott, Abbott et al. 2008). Ainda há espaço para alternativas aos mecanismos de geração dos surtos. 


\subsection{Estatística}

A estimativa da taxa de ocorrência de GRB cosmológicos é de $10^{-6} y r^{-1}$ por galáxia, ou seja, um evento a cada milhão de anos (Cohen and Piran 1995). Essa taxa é, na verdade, a taxa de eventos observados, uma vez que a emissão é provavelmente bastante colimada. Grande parte dos eventos acontece com o jato em direcionado para longe da Terra, e esses eventos não observamos. Usando o cenário admitindo um ângulo sólido de colimação de $10^{-2} \mathrm{sr}$, a taxa real de eventos cresceria algumas centenas de vezes.

Além disso, como os surtos provavelmente dependem da existência de progenitores massivos $\left(\sim 100 \mathrm{M}_{\mathrm{Sol}}\right)$, a taxa de ocorrência de GRB deve seguir fortemente a taxa de formação estelar, como mostrado na Fig. 18. Espera-se, portanto, que no passado a taxa de ocorrência possa ter sido até 3 ordens de grandeza maior que a atual, importante para os casos dos capítulos 2 e 3, quando procuraremos os efeitos dos GRBs sobre o ISM e sobre planetas.

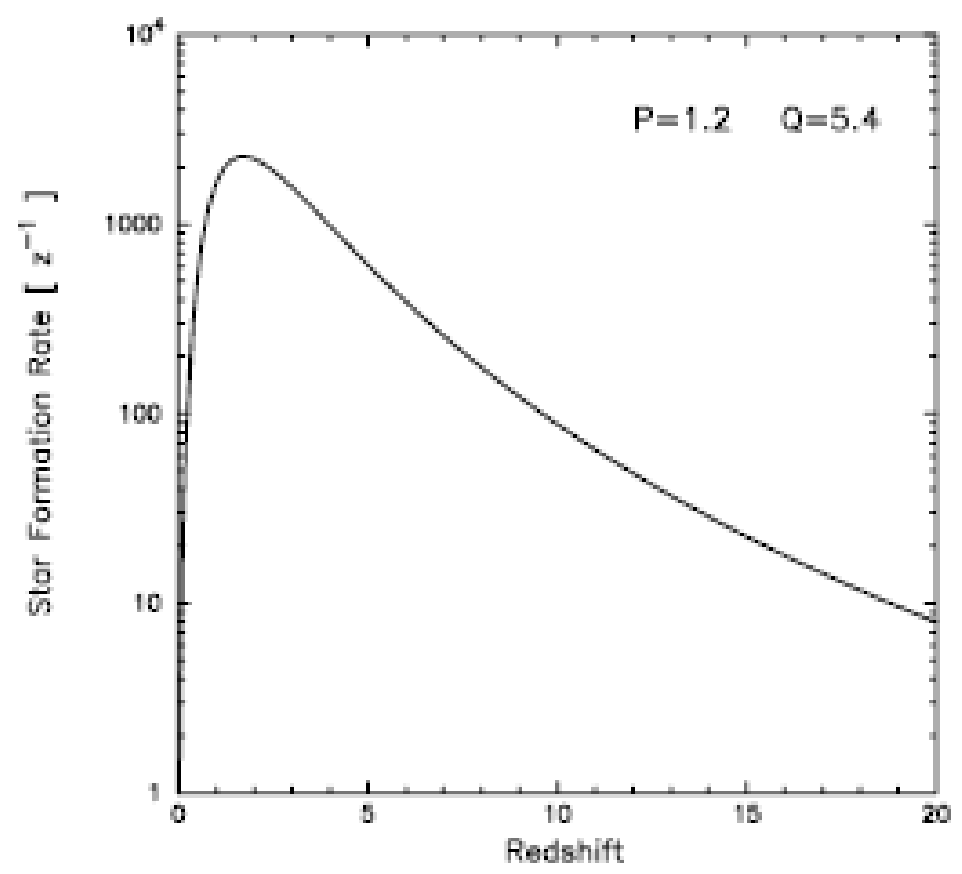

Fig. 18: Taxa de GRB como função do redshift (Lamb, Donaghy et al. 2005). A curva considera uma taxa de formação estelar de (Rowan-Robinson 2001). 


\section{Interação com o ISM}

Nesse capítulo serão tratados os efeitos de um GRB sobre o seu meio circundante. Nosso objetivo é o de fornecer evidências para a distinção entre remanescentes de GRB e de outros cenários, como o de múltiplas supernovas, ajudando, dessa maneira, a identificar esses remanescentes em nossa Galáxia e em outras.

Serão abordadas duas conseqüências sobre o meio: a capacidade mecânica de GRBs criarem grande cavidades $(\mathrm{d} \sim 1 \mathrm{kpc})$ de baixa densidade no meio, as chamadas supershells (Tenorio-Tagle and Bodenheimer 1988), sendo comparadas com o modelo tradicional de múltiplas supernovas; e a possibilidade de os fótons de alta energia dos GRB produzirem reações fotonucleares sobre os núcleos dos átomos presentes em seu entorno, transmutando parte desses elementos e modificando assim a abundância química do ambiente, possivelmente de forma detectável.

\subsection{Características do ambiente}

Apesar de não estar claro exatamente quais são os progenitores de GRBs, é praticamente um consenso que eles são resultado da etapa final de um processo de evolução estelar (Rees 2000; Meszaros 2001; Rosswog 2003; Cusumano, Mangano et al. 2006; Meszaros 2006). Surtos longos são classicamente relacionados a progenitores massivos (Paczynski 1998; Fryer, Woosley et al. 1999), podendo, em alguns modelos, necessitar de estrelas com massas de até $\sim 100 \mathrm{M}_{\text {Sol }}$ para ocorrerem, enquanto surtos curtos seriam gerados por mergers $^{7}$ de estrelas de nêutrons (ou estrela de nêutrons e buraco negro).

Como os surtos curtos são gerados por objetos $\operatorname{compactos}^{8}$, e estes são resultado da evolução estelar possivelmente após um evento de supernova (Heger, Fryer et al. 2003), durante a qual eles podem ser acelerados a grandes velocidades (Arzoumanian, Chernoff et al. 2002), acredita-se devido ao impulso (kick) recebido durante a explosão, é razoável supor que eles se encontrem longe da região de formação estelar no momento

\footnotetext{
${ }^{7}$ Merger $=$ fusão ou coalescência

$8 \mathrm{Em}$ astronomia, denominam-se objetos compactos às anãs brancas, estrelas de nêutrons, estrelas exóticas e buracos negros, ou seja, objetos com grandes massas e pequenos raios. Sua estrutura é suportada, usualmente, pela pressão de degenerescência e não por forças eletrostáticas, tendo densidades próximas às nucleares e raios entre 1 e $100 \mathrm{~km}$.
} 
da geração do surto. Surtos longos, no entanto, ocorrem com estrelas massivas e, portanto devem estar próximos da região onde seus progenitores foram formados, já que, quanto mais massiva a estrela, mais rápida sua evolução (Weaver, Zimmerman et al. 1978; Bond, Arnett et al. 1984).

Dessa forma, durante todo o capítulo faremos referência aos surtos longos, por estarem inseridos, provavelmente, em um meio mais denso que os surtos curtos.

As estrelas de alta massa são raras, como se pode notar pela Função de Massa Inicial (Initial Mass Function - IMF) apresentada na Fig. 19, em que o número de estrelas com massa $100 \mathrm{M}_{\text {Sol }}$ formado seria $\sim 2 \times 10^{-5}$ do número de estrelas formadas com $1 \mathrm{M}_{\text {Sol. }}$ A função apresentada é a proveniente do modelo de Salpeter (Salpeter 1955).

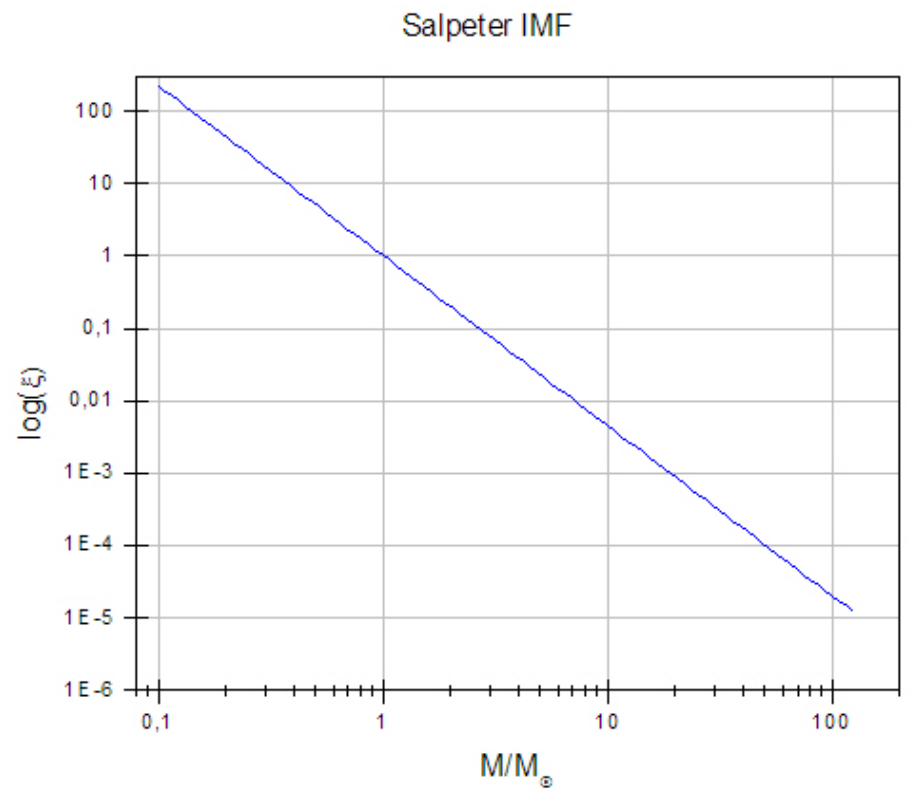

Fig. 19: Função de Massa inicial tipo Salpeter (Salpeter 1955), $\xi=\left(\frac{M}{M_{\odot}}\right)^{-2.35}$.

A Função de Massa Inicial fornece a fração de estrelas formadas em determinado intervalo de massa normalizado pelo número de estrelas formadas com uma massa solar. Essa função é bastante universal, pois depende, principalmente, de parâmetros dinâmicos da região de formação estelar (Padoan, Nordlund et al. 1997). Mesmo com cálculos mais detalhados (Miller and Scalo 1979), a forma e as escalas da função de Salpeter ainda se mantêm e são consistentes com as observações para diferentes sistemas (Kroupa 2002). Não é óbvio que essa função seja universal, pois ela 
poderia depender de parâmetros variáveis, como a metalicidade ${ }^{9}$ da região de formação estelar.

De fato, existe a possibilidade de a IMF ter sido distinta na primeira geração de estrelas (chamada de População III), devido a sua baixíssima metalicidade (seu gás era de origem primordial, sendo seu elemento mais pesado o ${ }^{7} \mathrm{Li}$ ), com uma formação estelar preferencial em altas massas, talvez entre 10 e $100 \mathrm{M}_{\text {Sol }}$ (Nakamura and Umemura 1999; Bromm, Coppi et al. 2002; Nakamura and Umemura 2002). Talvez essa primeira população estelar tenha gerado um grande número de fontes possíveis para GRBs (Bromm and Loeb 2006), que eventualmente serão observados para redshifts muito altos $(>10)$ com os futuros telescópios, pois a maior parte das estrelas dessa geração já deve ter passado por sua fase explosiva, com exceção de eventuais "relíquias" de baixa massa (Christlieb, Bessell et al. 2002). Além das estrelas mais antigas, galáxias recentes, porém, com baixa metalicidade, também apresentam maior tendência a formação de estrelas massivas e, provavelmente, GRBs (Sollerman, Östlin et al. 2005; Stanek, Gnedin et al. 2006).

\subsubsection{Densidade ambiente}

As regiões de formação estelar são, em grande parte, nuvens moleculares densas $\left(10^{2}-10^{6} \mathrm{~cm}^{-3}\right)$ e frias $(10-20 \mathrm{~K})$ (Shu, Adams et al. 1987; Ferrière 2001), como mostrado na Fig. 20. Essas condições são necessárias para permitir que a nuvem inicie o processo de colapso gravitacional, quando se fragmentará formando os núcleos das futuras estrelas.

\footnotetext{
${ }^{9} \mathrm{~A}$ metalicidade é definida como a razão logarítmica entre a densidade de átomos de um "metal" e a densidade de átomos de hidrogênio, em comparação com a mesma razão solar: $[\mathrm{Fe} / \mathrm{H}]=\log \left(\frac{N_{F e}}{N_{H}}\right)_{\text {Estrela }}-\log \left(\frac{N_{F e}}{N_{H}}\right)_{S o l}$. É importante notar que "metal", em astronomia, refere-se a qualquer elemento distinto do hidrogênio e hélio.
} 


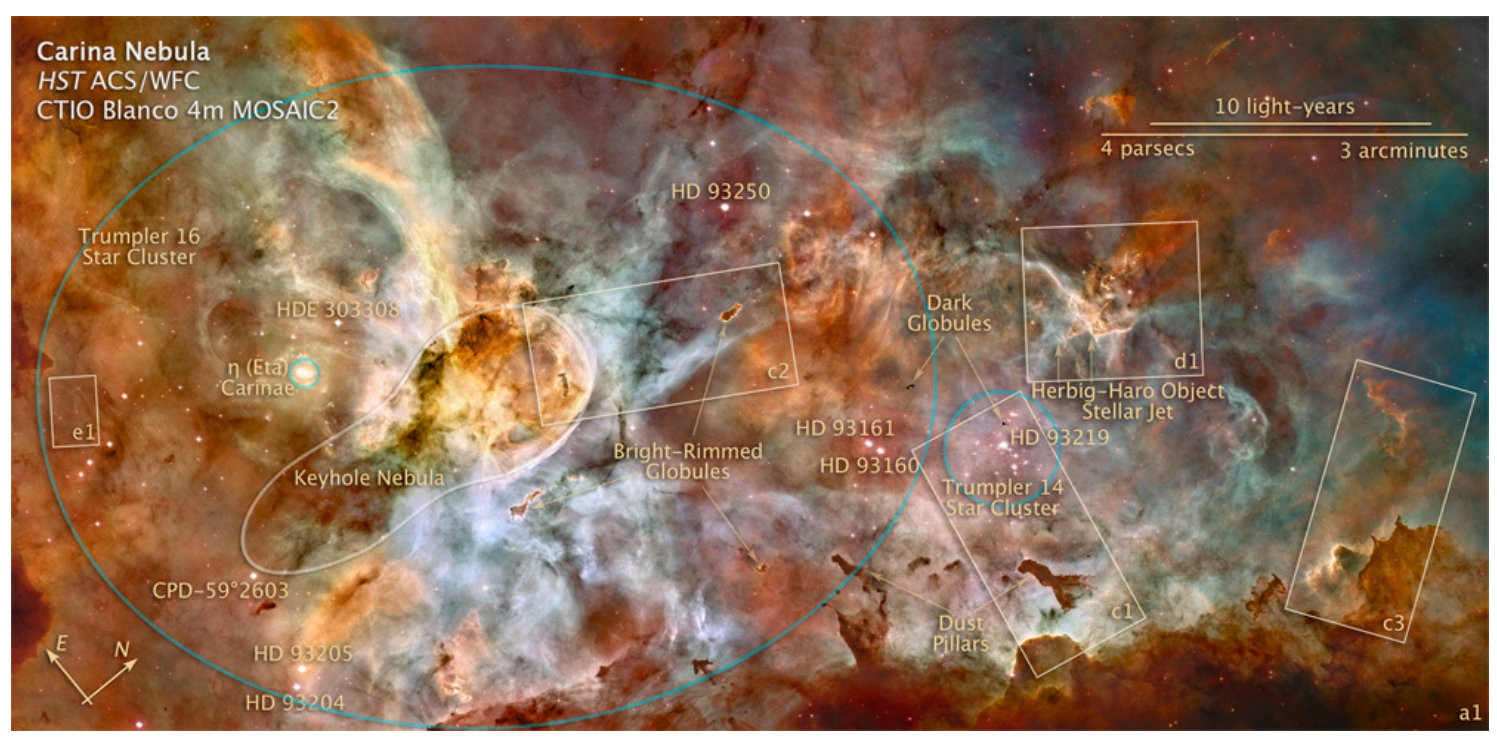

Fig. 20: Nebulosa de Carina (NGC 3372) em cores falsas (The Hubble HeritageProject 2007).

Nuvens moleculares gigantes podem ter tamanhos de dezenas de parsecs e massas entre $10^{5}$ e $3 \times 10^{6} \mathrm{M}_{\text {Sol }}$. Essas nuvens normalmente são complexos de nuvens menores, com tamanhos entre 2 e 5 parsecs e massa entre $10^{3}$ e $10^{4} \mathrm{M}_{\text {Sol }}$. A estrutura das nuvens é bastante complexa, formada por subunidades chamadas clumps, cuja densidade é tipicamente da ordem de $10^{3} \mathrm{~cm}^{-3}$ para hidrogênio, enquanto nas outras áreas fica em torno de $10^{2} \mathrm{~cm}^{-3}$ (Shu, Adams et al. 1987). No entanto, algumas regiões passando por episódios de formação estelar massiva foram observadas com densidades ainda mais altas, até $10^{6} \mathrm{~cm}^{-3}$ (Plume, Jaffe et al. 1997).

A condensação do gás nas nuvens pode ocorrer espontaneamente, pela existência prévia de regiões de maior densidade, as quais funcionarão como sementes gravitacionais, ou pode ocorrer de forma induzida, por ondas de choque de uma supernova vizinha que inicie uma onda de compressão (Vanhala and Cameron 1998).

A densidade das regiões onde ocorrem os GRBs deve estar nessa ordem, entre $10^{2}-10^{6} \mathrm{~cm}^{-3}$, sendo muito mais densas que o meio interestelar convencional $\left(1 \mathrm{~cm}^{-3}\right)$, porém, muito menos densas que uma região na CNTP (Condições Normais de Temperatura e Pressão: $\mathrm{P}=1 \mathrm{~atm}, \mathrm{~T}=273 \mathrm{~K}$ ), onde $n \approx 10^{20} \mathrm{~cm}^{-3}$.

\subsubsection{Composição}

Nuvens moleculares formam-se pela concentração gravitacional do gás préexistente, herdando assim sua composição. Como temos apontado, as primeiras nuvens moleculares possuíam composição pós-Big Bang, ou seja, havia ocorrido apenas a 
nucleossíntese primordial, havendo apenas $\mathrm{H}$, He e traços de Li como matéria bariônica, formando grandes estruturas gravitacionalmente em colapso. Quanto menor a metalicidade, maior o tamanho da nuvem, como podemos constatar na Grande Nuvem de Magalhães ${ }^{10}$ (Large Magellanic Cloud - LMC) (Pak, Jaffe et al. 1998).

O colapso dessas nuvens moleculares primordiais formou a primeira geração de estrelas, a População III, com a qual se iniciou o enriquecimento químico do Universo, que as Populações II e I herdaram e contribuíram com sua própria nucleossíntese.

Dessa maneira, podemos encontrar nuvens moleculares com diferentes metalicidades no Universo. Em nosso trabalho, iremos utilizar as composições solares, por estarem mais bem estudadas e calibradas (Anders and Grevesse 1989; Lodders 2003) por observações da fotosfera solar e de medidas com meteoritos. A Fig. 21 apresenta as abundâncias dos elementos para o Sistema Solar. Tabelas detalhando essas informações estão reproduzidas no Anexo 1.

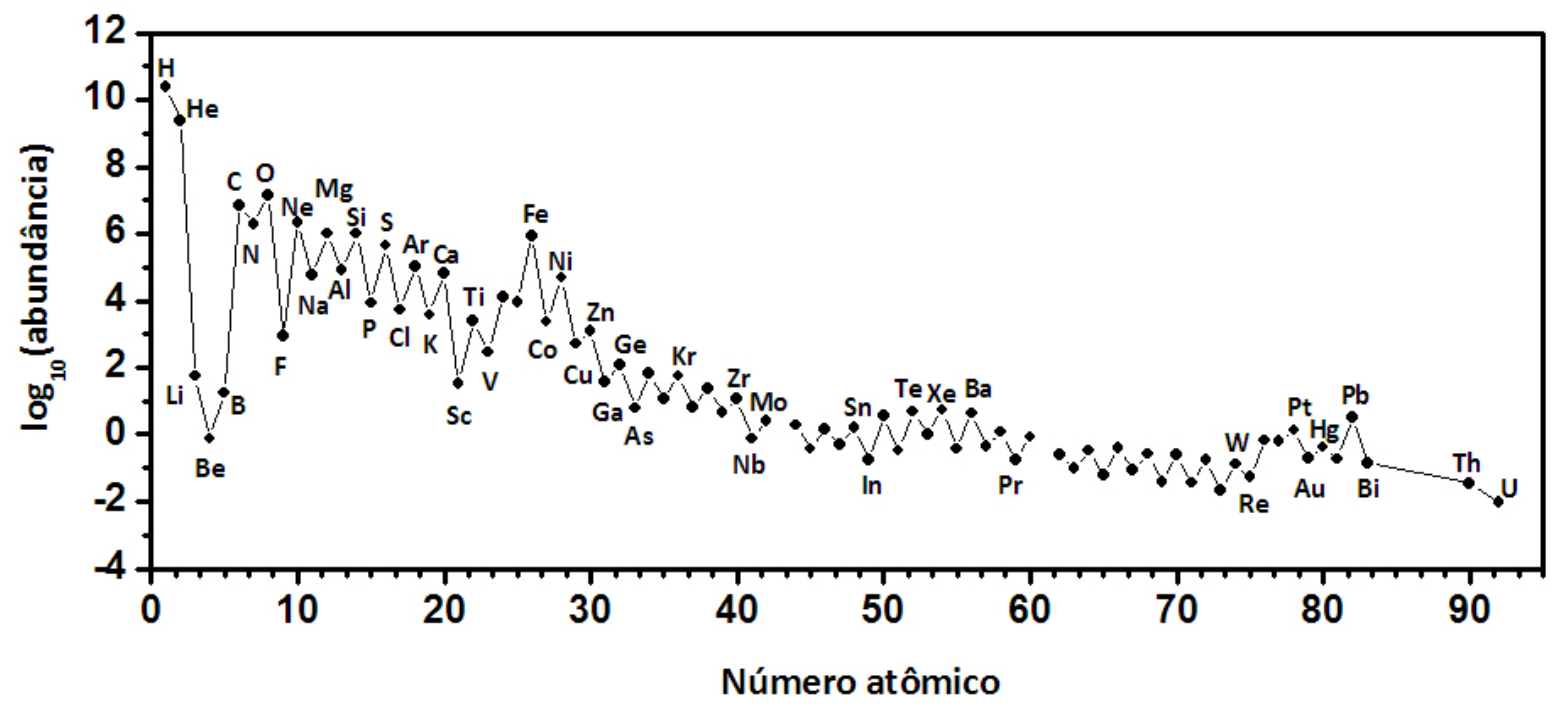

Fig. 21: Abundância dos elementos no Sistema Solar, calculadas a partir de observações solares e de meteoritos, normalizadas pelo Si definido como sendo $10^{6}$ (Lodders 2003).

\subsection{Remanescentes - formação e detecção}

Iremos considerar que a energia cinética dos surtos seja, no mínimo, equivalente à liberada em gamas, supondo a ocorrência de uma eqüipartição (Vietri, De Marco et al. 2003). Dessa maneira, supondo uma emissão isotrópica, ou fracamente colimada,

${ }^{10}$ Galáxia vizinha $(50 \mathrm{kpc}$ ) a Via Láctea, visível a olho nu no hemisfério Sul: Bok, B. J. (1966). "Magellanic Clouds." Annual Review of Astronomy and Astrophysics 4(1): 95144. 
teríamos $10^{54}$ erg de energia liberados em uma região de alta densidade, no interior de uma nuvem molecular. No caso colimado, essa energia em gamas seria da ordem de $10^{51} \mathrm{erg}$, semelhante a uma supernova (Woosley and Weaver 1986), porém o GRB ainda conta com energia adicional associada ao afterglow. No entanto, para o cenário usual de geração da radiação gama em um GRB por meio de choques internos é natural supor que a energia cinética seja ao menos duas ordens de grandeza maior que a energia em gamas, ou seja, $E_{K}>10^{53} \mathrm{erg}$.

A liberação de tal quantidade de energia irá escavar uma cavidade no ISM, de maneira simular a que ocorre com as supernovas, deixando uma concha de material chocado cercando uma região de baixa densidade e alta temperatura $\left(\sim 10^{6} \mathrm{~K}\right)$. A estrutura do remanescente por ser bastante complexa, como mostrado na Fig. 22, causada pela interação com o ISM, que pode gerar instabilidades do tipo RayleighTaylor.

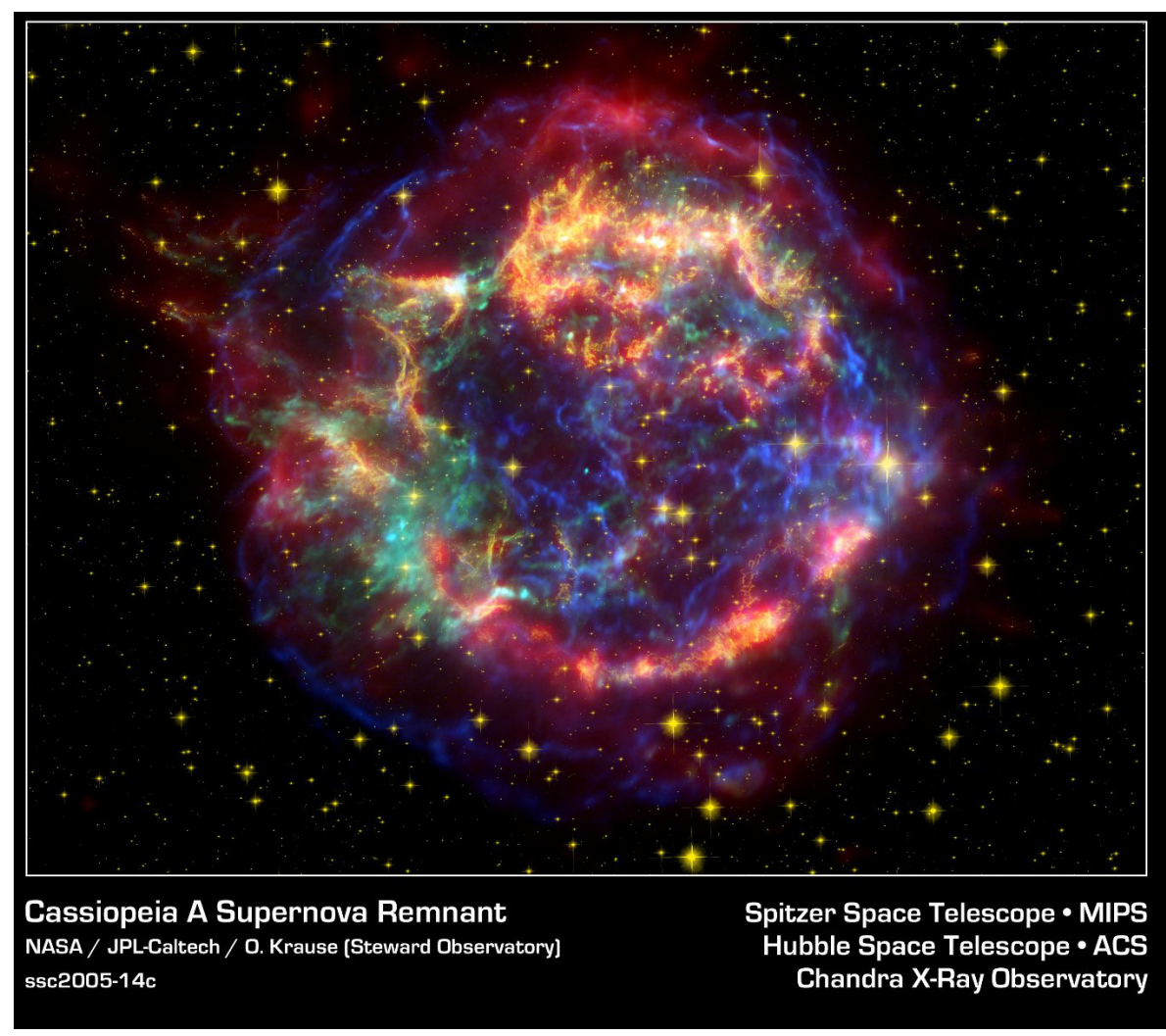

Fig. 22: Nebulosa do Cassiopéia A, remanescente de supernova tipo II com idade de $\sim 300$ anos.

A dinâmica de expansão do remanescente de uma supernova é bem conhecida (Chevalier 1974; Chevalier and Gardner 1974). No início, devido à grande injeção de energia (tipicamente $10^{51}$ erg para uma supernova), ocorre uma expansão livre, ou seja, 
praticamente independente do meio. Nessa fase, $R \propto t$, tendo duração de algumas centenas de anos ( $\left.\mathrm{t}_{\text {sweep }}\right)$ e chegando até cerca de $4 \mathrm{pc}$. A segunda fase inicia-se quando o remanescente acumulou mais matéria do meio que sua própria massa, quando então ocorre com uma expansão adiabática, chamada de fase Sedov-Taylor na qual $R \propto t^{2 / 5}$, podendo durar milhares de anos $\left(t_{\text {shell }}\right)$ e chegando a cerca de $20 \mathrm{pc}$. Na última fase, chamada de snowplow, o material arrastado colapsa em uma fina $(<1 \mathrm{pc})$, densa $\left(10^{6}-\right.$ $\left.10^{8} \mathrm{~cm}-3\right)$ e fria concha, devido ao resfriamento radiativo, a qual continua se expandindo com $R \propto t^{2 / 7}$ por alguns milhões de anos ( $\mathrm{t}_{\mathrm{SNR}}$, até que sua velocidade seja comparável à velocidade de turbulência do gás do ISM $(\sim 10 \mathrm{~km} / \mathrm{s})$, quando podemos considerar que o remanescente se dissipou. A Fig. 23 apresenta um esquema da expansão.

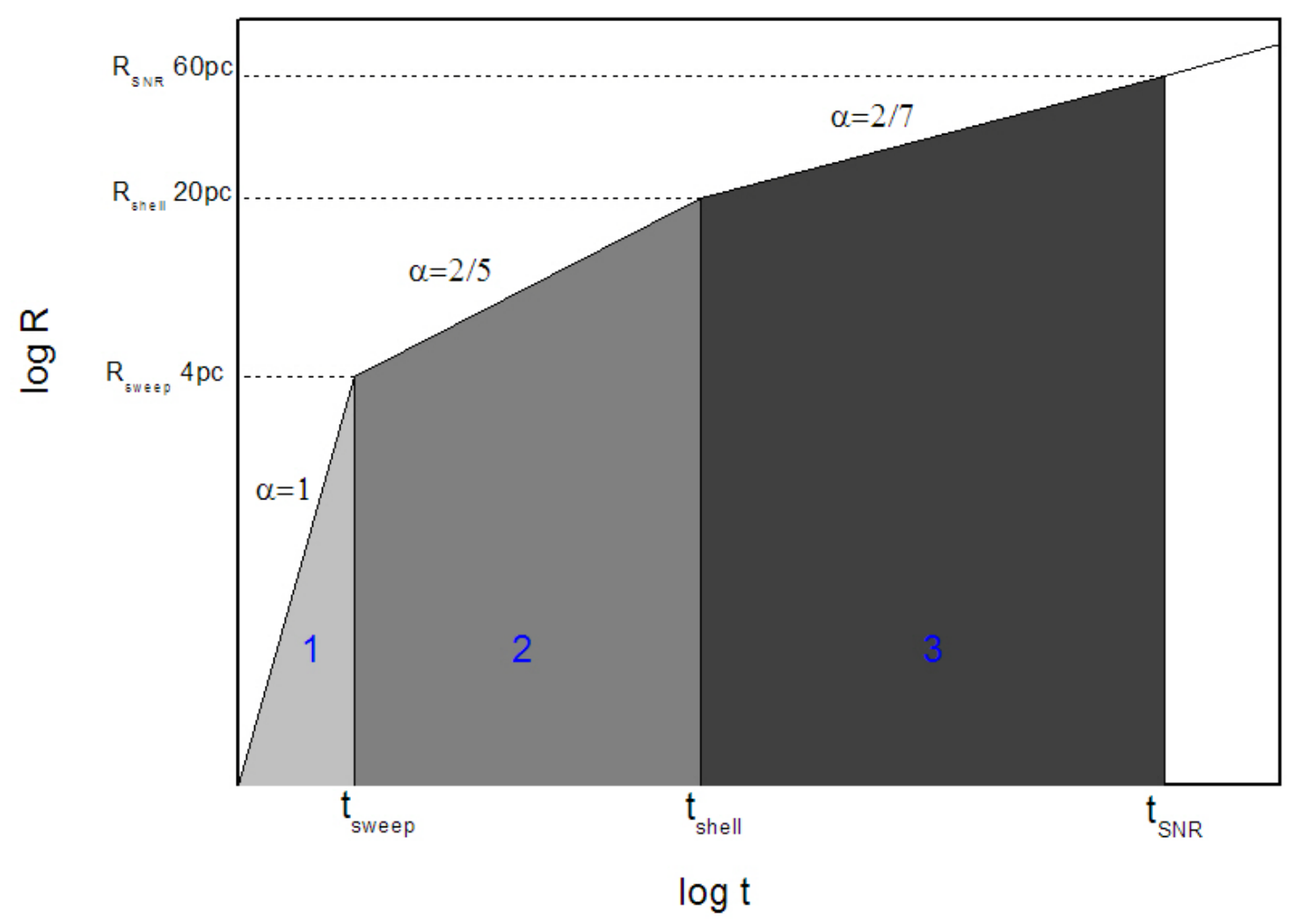

Fig. 23: Dinâmica da expansão do remanescente de uma supernova, com o raio, R, em parsecs. 1: fase de expansão livre, $R \propto t, t_{\text {sweep }} \approx 100$ anos ; 2: fase de Sedov-Taylor, $R \propto t^{2 / 5}, t_{\text {shell }} \approx 1000$ anos; 3 : fase de snowplow, $R \propto t^{2 / 7}, t_{S N R} \approx 10^{6}$ anos.

\subsubsection{Supershells}

Supershells são regiões do ISM similares aos remanescentes de supernova: baixas densidades em seu interior, altas temperaturas, porém com raios uma ou duas ordens de grandeza maiores que os de remanescentes de supernova, podendo chegar a 
ter alguns kpc de raio (Tenorio-Tagle and Bodenheimer 1988). São identificadas em observações de rádio de $\mathrm{HI}^{11}$ como grandes estruturas expandindo-se com velocidades coerentes de até centenas de $\mathrm{km} / \mathrm{s}$. Podem ser vistas também no ótico e raios-X, devido à presença de gás ionizado e altamente aquecido.

Algumas dessas regiões chegam a ser maiores que o disco de uma galáxia espiral como a Via Láctea, com escala de altura ${ }^{12}, \mathrm{Z}_{0}$, de cerca de $200 \mathrm{pc}$. Um evento de supershell poderia "vazar" para fora do disco, gerando uma estrutura conhecida como fonte galáctica. Esse fenômeno pode explicar a existência de nuvens frias em alta velocidade acima do plano galáctico (Bregman 1980; Igumentshchev, Shustov et al. 1990; Melioli, Brighenti et al. 2008), porém parece não influenciar a distribuição química radial (Melioli, Brighenti et al. 2008). No entanto, as supershells, em seu término de expansão, poderiam dar origem a novas regiões de gás compacto que poderiam iniciar o processo de formação estelar (Silich, Elias et al. 2008).

Há dezenas de supershells identificadas na Galáxia e nas Nuvens de Magalhães (Grande e Pequena), bem como em outras galáxias (Heiles 1979; Tenorio-Tagle and Bodenheimer 1988; Bruhweiler, Fitzurka et al. 1991; Hunter 1994), sendo sua origem ainda não completamente solucionada.

Algumas tentativas de identificar remanescentes de GRBs na Galáxia advêm da possível conexão com a aceleração de raios cósmicos de ultra-alta energia, os quais teriam rigidez magnética suficiente para não serem isotropizados pela interação com o campo magnético da Galáxia, mantendo assim a informação de sua origem (Vietri, De Marco et al. 2003; Biermann, Medina Tanco et al. 2004); ou ainda, pela identificação de fótons de fótons de altíssimo energia $\left(10^{12} \mathrm{eV}\right)$, cujo mecanismo de geração ainda não é claro, e são tentativamente associados aos surtos (Atoyan, Buckley et al. 2006).

\subsubsection{Energética}

A energia cinética necessária para escavar uma cavidade de $1 \mathrm{kpc}$ no ISM é bastante grande. Utilizando a teoria de expansão de remanescentes de supernovas (Chevalier 1974; Chevalier and Gardner 1974), tal como feito por Heiles (1987),

\footnotetext{
${ }^{11}$ Denomina-se $\mathrm{HI}$ o hidrogênio neutro, observado usualmente em astronomia pela sua transição hiperfina em $1420 \mathrm{MHz}$, ou $21 \mathrm{~cm}$.

12 Observa-se uma distribuição exponencialmente decrescente de estrelas com o aumento da altura em relação ao centro do disco Galáctico. Escala de altura refere-se à altura em que essa densidade cai para $1 / e$ do valor inicial.
} 
podemos calcular brevemente qual seria essa energia, desde que exista uma estimativa razoável da densidade local e boas medidas de distância e velocidade.

A velocidade de expansão de uma concha esférica $\left(\mathrm{V}_{\text {shell }}\right)$ em sua fase final (snowplow), onde se espera observar a maioria dos remanescentes, pela própria natureza da identificação, é descrita pela Eq. 5, onde $E_{54}$ é a energia cinética em unidades de $10^{54} \mathrm{erg}, \mathrm{n}_{1}$ é a densidade numérica do meio e $\mathrm{R}_{\mathrm{kpc}}$ é o raio da concha em kpc.

$$
V_{\text {shell }}=4.5 \mathrm{~km} \mathrm{~s}^{-1} E_{54}^{0.71} n_{1}^{-0.80} R_{k p c}^{-2.2} \quad \text { Eq. } 5
$$

Ela irá se expandir até que sua velocidade aproxime-se à velocidade de turbulência do ISM, ou seja, $V_{\text {shell }}=10 \mathrm{~km} \mathrm{~s}^{-1}$, o que pode levar até cerca de $10^{7}$ anos. Para esse valor, teríamos que o raio da concha seria dado pela Eq. 6 .

$$
R_{k p c}=0.7 E_{54}^{0.32} n_{1}^{-0.36} \quad \text { Eq. } 6
$$

E a energia cinética necessária seria dada pela Eq. 7.

$$
E_{54}=3.05 n_{1}^{1.12} R_{k p c}^{3.12} \quad \text { Eq. } 7
$$

Sendo esse raio alcançado após um tempo de expansão ( $\left.t_{\text {shell }}\right)$ dado pela Eq. 8 .

$t=21 E_{54}^{0.32} n_{1}^{-0.36} 10^{6}$ anos $\quad$ Eq. 8

Dessa maneira, é possível associar uma energia cinética e um tempo de expansão para uma dada supershell bastando saber seu tamanho e a densidade do meio considerada constante neste modelo. Apresentamos alguns dados calculados para a amostra de Tenorio-Tagle e Bodenheimer (1988) na Tabela 1.

Tabela 1: propriedades de supershells (Tenorio-Tagle and Bodenheimer 1988).

\begin{tabular}{|c|c|c|c|c|c|}
\hline Remanescente & $\begin{array}{c}\boldsymbol{D} \\
(\boldsymbol{k p c})\end{array}$ & $\begin{array}{c}\boldsymbol{R} \\
(\boldsymbol{p c})\end{array}$ & $\log \boldsymbol{M} / \mathbf{M}_{\mathbf{0}}$ & $\begin{array}{c}\log \boldsymbol{E}_{\boldsymbol{K}} \\
(\mathbf{e r g})\end{array}$ & $\begin{array}{c}\boldsymbol{V} \\
\left(\mathbf{k m} \boldsymbol{~}^{-1}\right)\end{array}$ \\
\hline GS 095+04-113 & 12.9 & 800 & 7.3 & 53.5 & 10 \\
\hline GS 064-01-97 & 16.9 & 1260 & 7.1 & 53.8 & 22 \\
\hline GS 057+01-33 & 13.8 & 630 & 7.0 & 53.6 & 18 \\
\hline GS 029+00+133 & 8.7 & 400 & 6.3 & 52.6 & 20 \\
\hline GS 022+01+139 & 9.5 & 300 & 6.4 & 53.0 & 18 \\
\hline GS 033+06-49 & 22.0 & 700 & 6.8 & 52.9 & - \\
\hline GS 067-02-37 & 11.1 & 800 & 5.9 & 51.7 & - \\
\hline GS 081-05-37 & 7.5 & 800 & 6.9 & 52.9 & - \\
\hline GS 091-04-69 & 9.0 & 800 & 6.8 & 52.8 & - \\
\hline GS 174+02-64 & 2.5 & 500 & - & 53.0 & $>90$ \\
\hline
\end{tabular}




\begin{tabular}{|c|c|c|c|c|c|}
\hline BB 69 & - & 592 & 6.8 & 53.1 & - \\
\hline BB 16 & - & 300 & 6.0 & 52.2 & - \\
\hline BB 114 & - & 347 & 6.1 & 52.3 & 8 \\
\hline BB 130 & - & 335 & 6.3 & 53.1 & 21 \\
\hline LMC 2 & 52.5 & 475 & 7.0 & 53.0 & 30 \\
\hline LMC 4 & 52.5 & 900 & 7.1 & 53.0 & 36 \\
\hline
\end{tabular}

Mesmo depois de descartadas "falsas" supershells, é notável observar que algumas delas precisariam de centenas de supernovas explodindo quase simultaneamente, ou, alternativamente, uma injeção única de energia maior que 1053erg. Na ausência de uma resposta clara, consideraremos essas como candidatas a remanescentes de GRBs, possibilidade discutida a seguir.

\subsubsection{Origem: supernovas e GRB}

O cenário clássico para o fornecimento da energia necessária para a geração de supershells tem sido o de múltiplas supernovas.

Com efeito, uma única supernova não teria energia suficiente para criar tal cavidade, porém, uma associação $\mathrm{OB}^{13}$ poderia conter número suficiente de progenitores de supernova que explodiriam em um curto intervalo de tempo ( $10^{7}$ anos), criando um vento capaz de comprimir o material ao seu redor e impulsioná-lo, formando a cavidade (Bruhweiler, Gull et al. 1980; Heiles 1987; McCray and Kafatos 1987; Maclow and McCray 1988; Maciejewski, Murphy et al. 1996), de forma similar à expansão de bolhas estelares (Weaver, McCray et al. 1977). Esses modelos numéricos e observações indicam que cerca de 10-100 supernovas seriam suficientes para gerar grande parte das supershell de até cerca de $300 \mathrm{pc}$. No entanto, um número muito maior seria necessário para as cavidades de $1 \mathrm{kpc}$, e não há associações OB grandes o suficiente observadas em galáxias próximas para explicar esse cenário (Kennicutt, Edgar et al. 1989).

Para supershells desse tamanho há controvérsias se modelos de supernova seriam capazes de explicar sua formação, devido à aparente falta de associações OB grandes o suficiente e a falta de supershells que indiquem essa origem, como, por

${ }^{13}$ Associação OB: grupo fracamente ligado gravitacionalmente de estrelas $\mathrm{O}$ e $\mathrm{B}$, as mais massivas, brilhantes e de vida curta existentes. 
exemplo, um grande número de pulsares no interior da supershell (Perna and Gaensler 2004). O cenário alternativo é o das supershells, ao menos às de dimensões de cerca de $1 \mathrm{kpc}$, terem sido impulsionadas por GRB (Loeb and Perna 1998; Efremov 1999; Perna and Raymond 2000).

Em contraste, a energética dos GRB (Frail, Kulkarni et al. 2001) poderia facilmente dar conta da energia cinética necessária para impulsionar a expansão das supershells, uma vez que, no caso não colimado a energia emitida em gamas seria de $10^{54} \mathrm{erg}$ e no caso colimado $10^{51} \mathrm{erg}$, sendo essa apenas uma fração da energia cinética do evento.

Mesmo no caso de surtos colimados, o remanescente de um GRB deveria ser esfericamente simétrico, pelo próprio efeito de sua dinâmica, conforme esquematizado nas Fig. 24 e 25. Isso torna os remanescentes de múltiplas supernovas e de GRB difíceis de serem distinguidos, uma vez que as fases tardias da expansão ( $t>10^{5}$ anos) carregam pouca informação dos seus momentos iniciais.

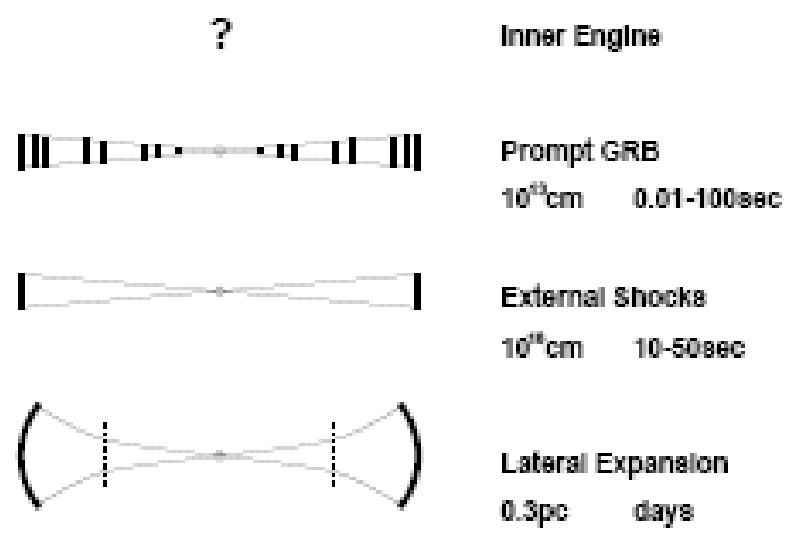

Fig. 24: Evolução esquemática de um GRB em sua fase relativística. De cima para baixo: a) Algum tipo de mecanismo gera jatos relativísticos; b) Choques internos geram a emissão gama; c) Choques externos produzem o afterglow; d) $\mathrm{O}$ jato se expande lateralmente na desaceleração (Piran and Ayal 2001). 


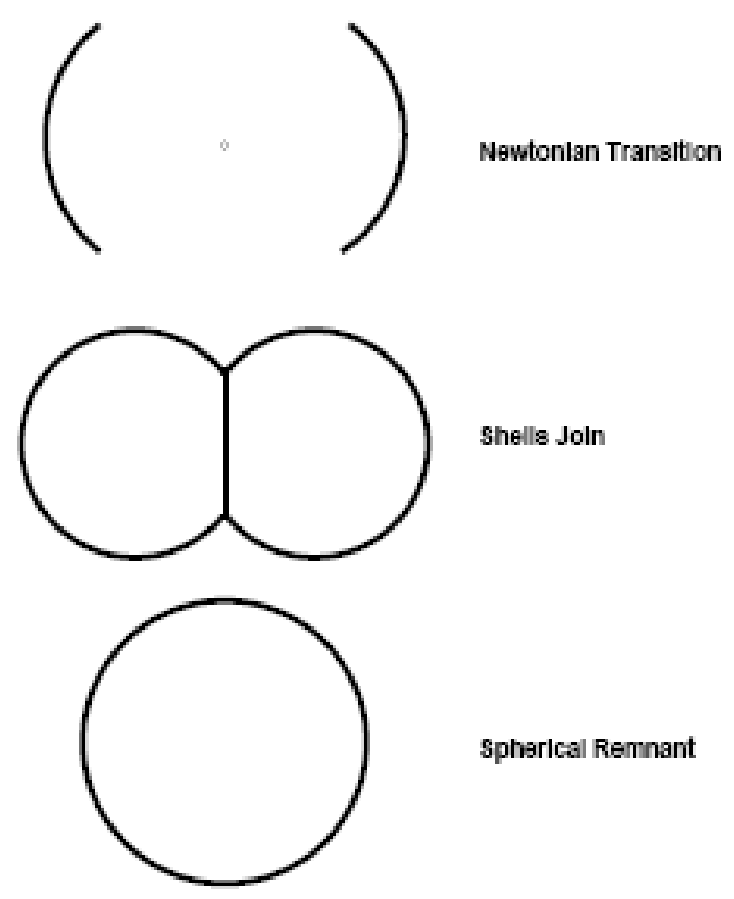

Fig. 25: Evolução do remanescente de um GRB. De cima para baixo: condições iniciais no momento da transição Newtoniana, distribuição assimétrica; b) Conchas colidem ao longo do plano equatorial; c) Em estágios finais forma-se uma concha esférica (Piran and Ayal 2001).

Em remanescentes novos, é simples distinguir os dois cenários, uma vez que no caso de múltiplas supernovas, a supershell ainda deveria apresentar atividade em seu interior. GRB poderiam também ser identificados pela assinatura da radiação emitida pelo gás em resfriamento, o qual foi aquecido e ionizado pelo afterglow (Perna and Raymond 2000; Perna, Raymond et al. 2000; Bhargavi, Rhoads et al. 2003).

Grande parte da dificuldade reside em distinguir os progenitores das supershells em suas fases tardias. Algumas possibilidades incluem a identificação de um enriquecimento químico não usual, esperado para o caso de múltiplas supernovas, mas não para o de GRB (Perna and Raymond 2000). Em especial, são esperados enriquecimentos de $\mathrm{O}, \mathrm{Si}, \mathrm{Ne}$ e $\mathrm{Mg}$.

\subsection{Efeitos "químicos" do GRB no ISM: Reações fotonucleares}

Como a escala natural da energia de pico nos GRB é da ordem da energia de ligação nuclear, a incidência de fótons $\gamma$ no material circunstelar pode ter efeitos importantes ainda não explorados na composição do mesmo. Propomos um novo mecanismo para distinguir o cenário de múltiplas supernovas e de GRB para a formação de supershells. O intenso fluxo de radiação gama emitido durante o surto poderia causar 
reações fotonucleares sobre os núcleos dos átomos em sua vizinhança, causando alterações químicas e isotópicas observáveis.

Tais reações são, em grande parte, desconsideradas em cenários astrofísicos devido à baixa quantidade de fótons de alta energia, à baixa densidade do ISM e à baixa seção de choque ${ }^{14}$ fotonuclear. $\mathrm{O}$ ambiente de um GRB pode ser um cenário viável para a ocorrência desse tipo de reação, e provavelmente um dos únicos eventos astrofísicos onde poderemos encontrar assinaturas observáveis desse processo.

\subsubsection{Seções de choque: A importância da ressonância gigante}

Os núcleos têm seções de choque para fótons inferior a de outros processos nucleares. Para a maioria das reações nucleares, a seção de choque está em torno de 1barn. Em um extremo, temos as seções de choque para a absorção de nêutrons de baixa energia em torno de $10^{3}$ barn e, no outro, a de absorção de fótons, ao redor de $10^{-3}$ barn.

Reações nucleares podem ser comparadas às reações eletrônicas. Podem ocorrer excitações e ionizações, ou, no caso de núcleos, emissão de nucleons ${ }^{15}$. O modelo de camadas para o núcleo é semelhante ao modelo de Rutherford-Bohr par a o cálculo de auto-estados eletrônicos, porém com os nucleons presos dentro de um poço de potencial gerado pela competição entre força nuclear forte, de atração, e a força eletrostática, de repulsão (Elliott 1958; Elliott 1958; Brown and Wildenthal 1988). Neste modelo, podem ser calculados os auto-estados de energia para diferentes configurações dos nucleons.

Em especial, nucleons podem apresentar modos de excitação coletivos, quando os mesmos estão em ressonância (Elliott 1958; Elliott 1958; Chomaz 1997). Esses modos são muito favorecidos. Em energias de $15-25 \mathrm{MeV}$, os núcleos apresentam a chamada ressonância gigante (Giant Dipole Resonance - GDR), quando prótons e nêutrons no interior do núcleo são excitados de maneira a criar um momento de dipolo elétrico oscilante, conforme esquematizado na Fig. 26.

\footnotetext{
${ }^{14}$ Seção de choque, $\sigma$, está relacionada com a probabilidade de interação entre uma partícula e outra, tendo unidade de área, em uma analogia com a probabilidade de um projétil atingir um alvo de determinada área. Em nosso caso o projétil é um fóton de alta energia e o alvo os núcleos do ISM.

A unidade usada para $\sigma$ é o barn, sendo que 1 barn $=10^{-24} \mathrm{~cm}^{2}$.

${ }^{15}$ Nucleons: partículas que compões os núcleos, como prótons e nêutrons.
} 


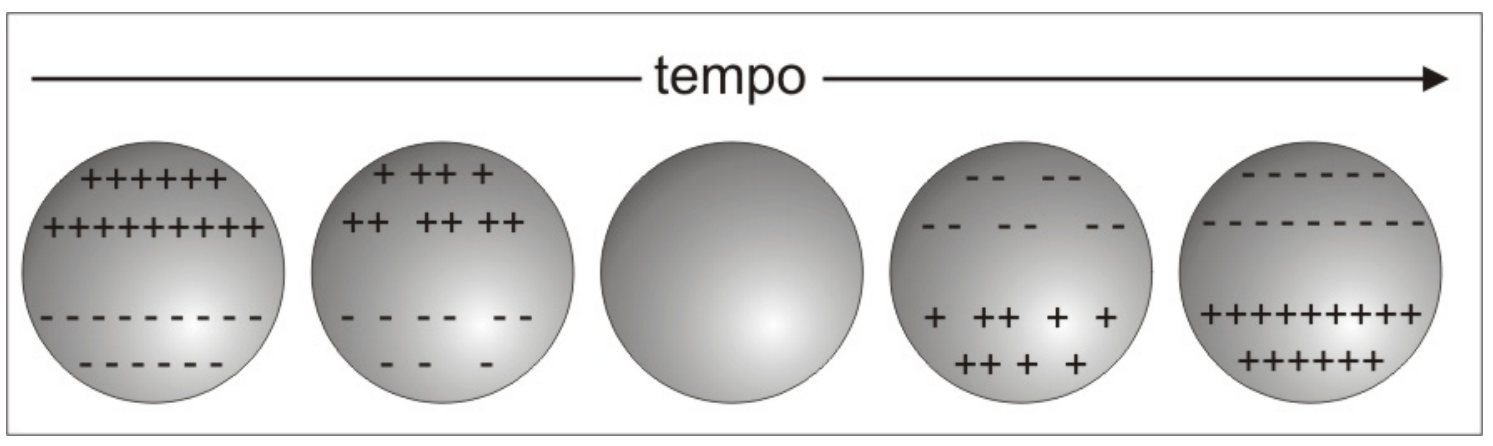

Fig. 26: Esquema de um núcleo na ressonância gigante - prótons e nêutrons são excitados coletivamente, e de forma anti-simétrica, gerando um dipolo elétrico oscilante no núcleo, segundo modelo de Steinwedel e Jensen (Steinwedel and Jensen 1950).

Nessa configuração favorecida, os núcleos absorvem fortemente, tendo um aumento na seção de choque, conforme ilustrado na Fig. 27.

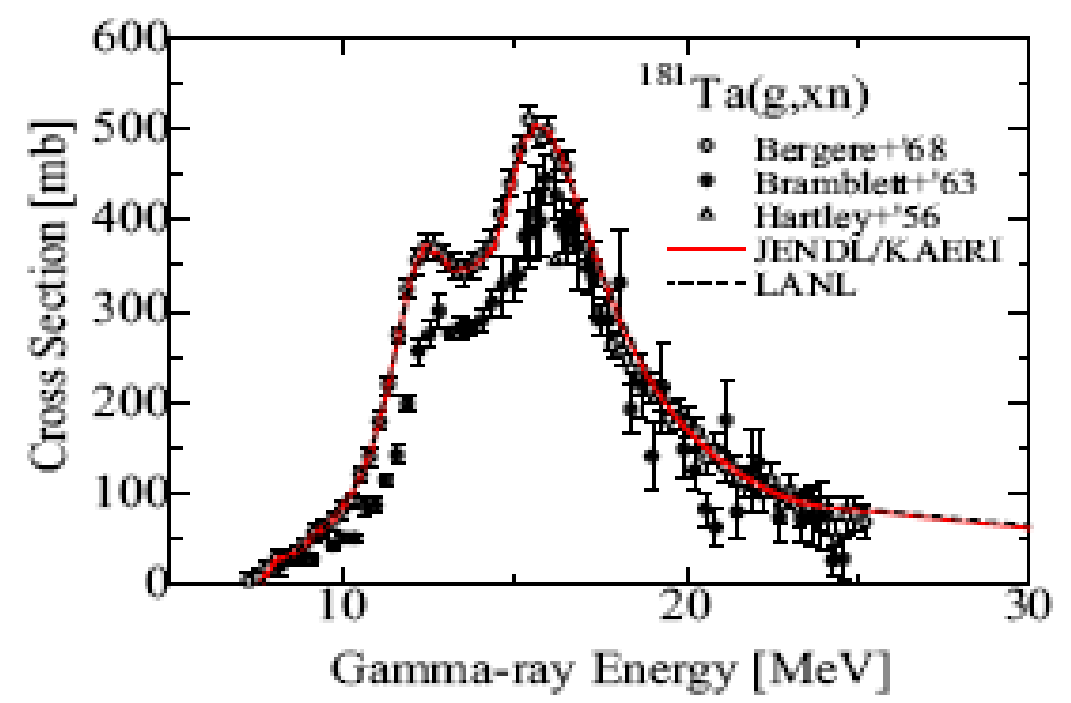

Fig. 27: Seção de choque para o ${ }^{181} \mathrm{Ta}$, comparando dados experimentais com modelo (linha vermelha cheia e preta tracejada) (IAEA 2000).

É bem conhecido que, para núcleos esféricos, a forma da seção de choque para a ressonância gigante pode ser bem aproximada por uma distribuição Lorentziana, mostrada na Eq. 9.

$$
\sigma_{a b s}\left(E_{\gamma}\right)=\frac{\sigma_{R} E_{\gamma}^{2} \Gamma_{G D R}^{2}}{\left(E_{\gamma}^{2}-E_{G D R}^{2}\right)^{2}+E_{\gamma}^{2} \Gamma_{G D R}^{2}} \quad \text { Eq. } 9
$$

$\mathrm{Na}$ equação acima, $\sigma_{R}$ é o valor máximo da distribuição, $E_{G D R}$ e $\Gamma_{\mathrm{GDR}}$ são energia e largura da ressonância gigante. A posição da ressonância pode ser ajustada experimentalmente por uma função do número de nucleons $A$ (número de prótons + número de nêutrons), como mostrado na Eq. 10 e na Fig. 28:

$$
E_{G D R}=31.2 A^{-1 / 3}+20.6 A^{-\frac{1}{6}}(\mathrm{MeV}) \quad \text { Eq. } 10
$$




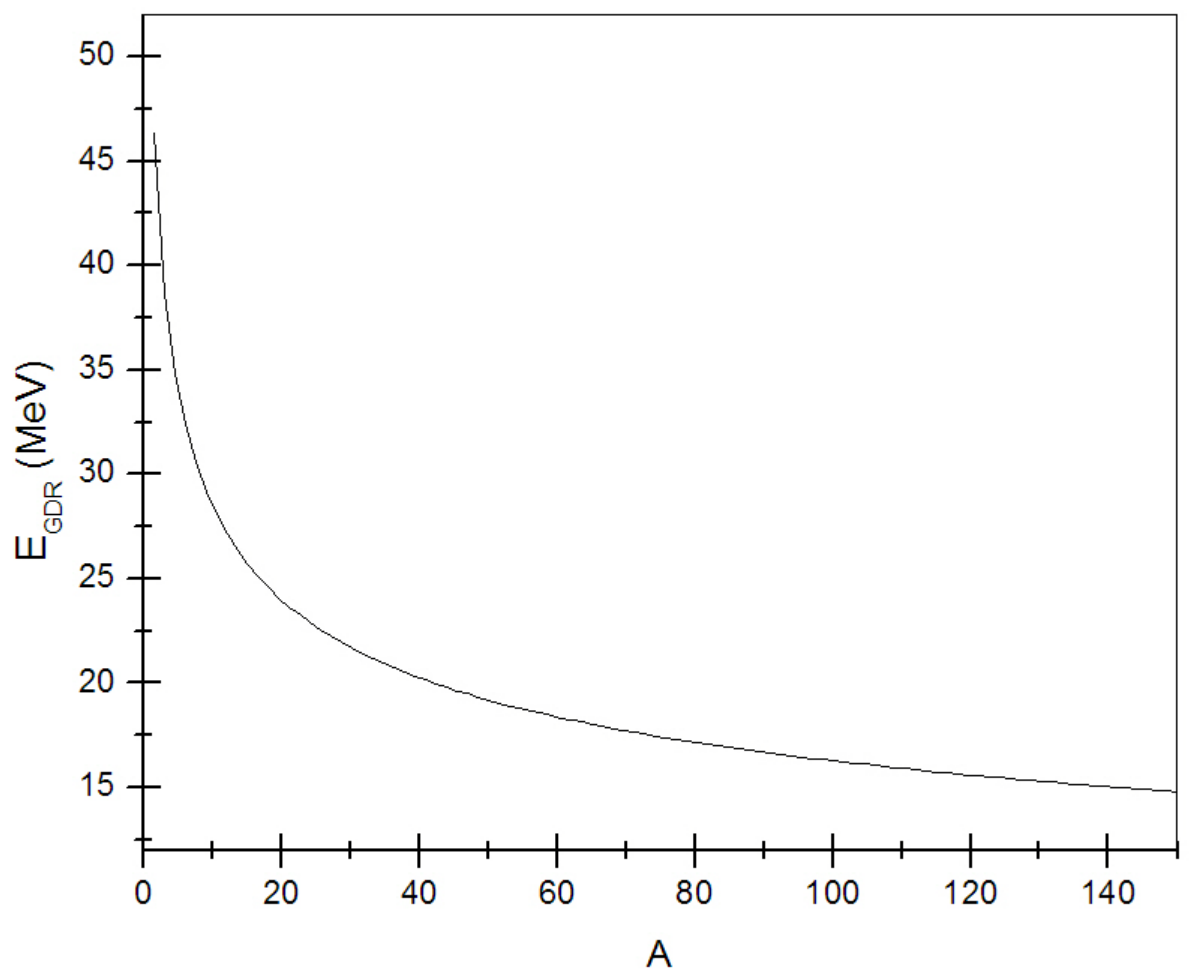

Fig. 28: Valor da posição da ressonância gigante como função do número de nucleons $A$ (Chomaz 1997).

$\mathrm{Na}$ região de dezenas de $\mathrm{MeV}$ teremos um aumento significativo da seção de choque para os núcleos (Ishkhanov, Yudin et al. 2000; Kamerdzhiev and Kovalev 2006), em especial, para os mais pesados. A seção de choque fica em torno de $10 \mathrm{mbarn}$ para núcleos leves e 100mbar para pesados. Os valores atualizados para as todos os núcleos medidos pode ser encontrado em (IAEA 2000).

O principal resultado de uma reação fotonuclear é a stripping de nêutrons, ou seja, estes são arrancados do núcleo. Grande parte das reações ocorre com o stripping de 2 nêutrons, e uma pequena parcela com o stripping de 1 nêutron (Tajima and Ejiri 2003), sendo o resultado dependente do núcleo em questão. Como regra geral, adotaremos a reação do tipo $\gamma, 2 n$, ou seja:

$$
{ }_{Z}^{A} X(\gamma, 2 n){ }_{Z}^{A-2} X
$$

Simbolizado na notação usual da Física Nuclear, onde, fora dos parênteses está o alvo e dentro os projéteis de entrada e saída. Uma vez conhecidas as seções de choque de cada elemento, podemos simular a passagem dos $\gamma$ e a geração dos núcleos-filho para posterior identificação. 


\subsubsection{Espectro GRB}

Diferentemente de grande parte de outros fenômenos astrofísicos, GRBs liberam grande parte de sua energia em gamas. Dessa maneira, teremos grande quantidade de fótons capazes de excitar os núcleos exatamente na região da ressonância gigante, possibilitando o stripping de nêutrons, conforme discutido anteriormente.

Tomaremos um espectro típico de GRB, usando um ajuste por função de Band (Band, Matteson et al. 1993), conforme mostrado na Fig. 29, e, por meio desse, calcularemos o número de fótons na região da ressonância gigante, entre $15-25 \mathrm{MeV}$. Apesar do fluxo nessa região ser 6 ordens de grandeza menor que na região da centena de $\mathrm{keV}$ ele ainda é superior ao encontrado na maioria dos ambientes astrofísicos.

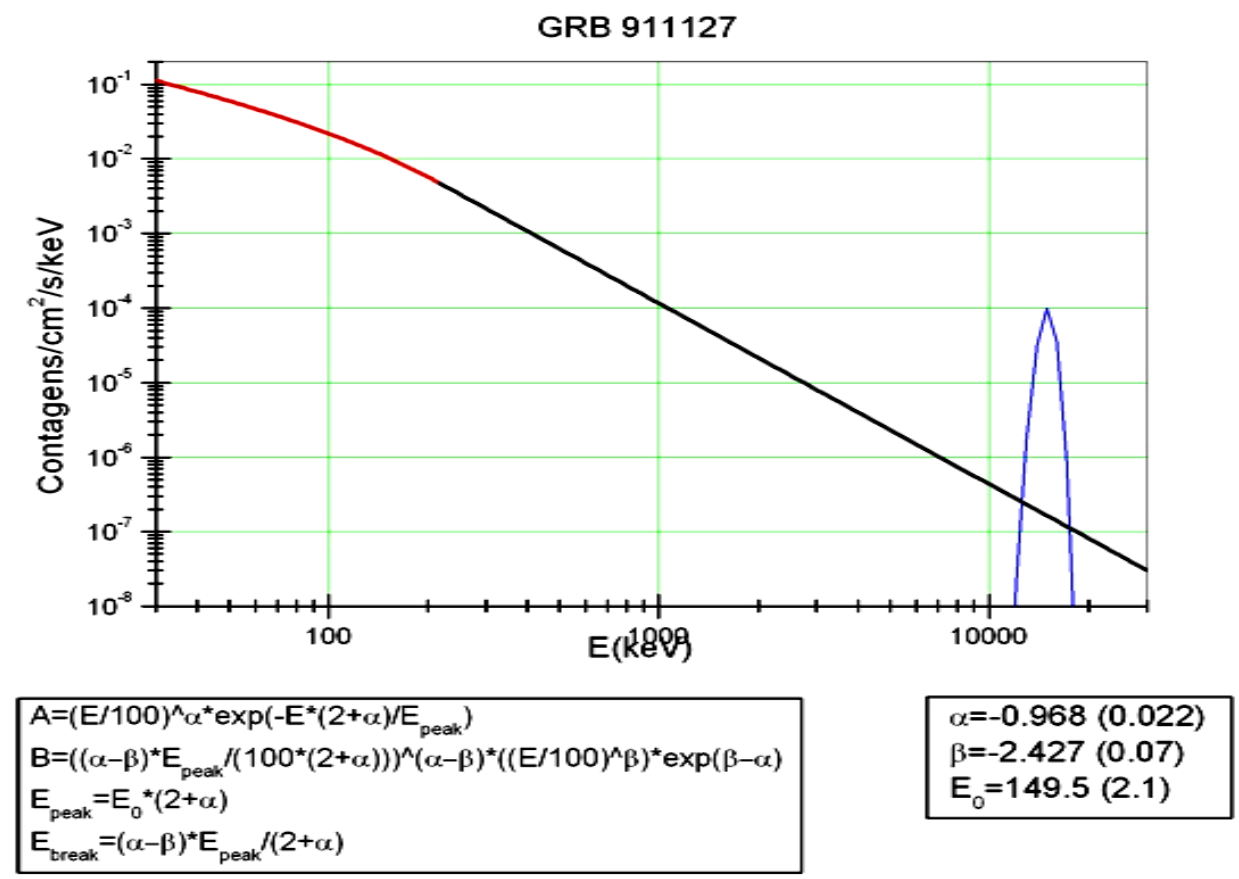

Fig. 29: Comparação do ajuste de uma função de Band para o GRB 911127 (em azul e preto) com a seção de choque fotonuclear, evidenciando a importância da ressonância gigante.

Considerando a luminosidade isotrópica do surto de $10^{54} \mathrm{erg}$, teríamos a produção de cerca de $10^{59}$ fótons nessa faixa de energia. Tais fótons se propagariam pelo meio ao seu redor, podendo reagir com os núcleos com uma probabilidade proporcional a sua seção de choque. Desconsideraremos os fótons de outras faixas de energia, por sua baixa seção de choque fora da região de ressonância.

\subsubsection{Alterações na distribuição química}

Considerando a distribuição de abundâncias inicial do meio circunstelar como igual à solar, como simplificação, conforme apresentada na seção 2.1.2, calcularemos 
agora as possíveis alterações nesse espectro. Devemos, no entanto, estar cientes que GRBs são mais prováveis de ocorrerem em regiões mais pobres em metais.

Após as reações de stripping de nêutrons é formada uma geração de núcleosfilhos, ricos em prótons. Esses núcleos são instáveis, no geral com meia-vida variando de $10^{-3}$ a $10^{2} \mathrm{~s}$. Para a escala de duração do supershell, consideraremos que os núcleosfilho decaem instantaneamente por $\beta^{+}$.

Exemplos de reações $\gamma, 2 n$ e $\gamma, n$ são apresentados nas Fig. 30 e 31, usando como exemplo o ${ }^{16} \mathrm{O}$. Na Fig. 30, o ${ }^{16} \mathrm{O}$ sofre uma reação de stripping de 2 neutrons, formando o núcleo ${ }^{14} \mathrm{O}$. A meia-vida desse núcleo é de $70.59 \mathrm{~s}$, decaindo por $\beta^{+}$em ${ }^{14} \mathrm{~N}$, o qual é estável. Na Fig. 31 é considerado o caso, menos provável, de stripping de 1 neutron, formando o ${ }^{15} \mathrm{O}$, que, em 2 min decai em ${ }^{15} \mathrm{~N}$, estável.

\begin{tabular}{|c|c|c|c|c|c|c|}
\hline & ${ }^{15} \mathrm{Ne}$ & ${ }^{16 \mathrm{Ne}}$ & ${ }^{17} \mathrm{Ne}$ & ${ }^{18} \mathrm{Ne}$ & $19 \mathrm{Ne}$ & 20ㅇ \\
\hline & ${ }^{14} \mathrm{~F}$ & $15 \mathrm{~F}$ & $16 \mathrm{~F}$ & ${ }^{17} \mathrm{~F}$ & $18 \mathrm{~F}$ & $19 \mathrm{~F}$ \\
\hline 120 & 130 & 14 & 150 & 160 & 170 & 180 \\
\hline${ }^{11} \mathrm{~N}$ & ${ }_{12} \mathrm{~N}$ & $13 \mathrm{~N}$ & $14 \mathrm{~N}$ & $15 \mathrm{~N}$ & $16 \mathrm{~N}$ & $17 \sqrt{2}$ \\
\hline${ }^{10} \mathrm{C}$ & ${ }^{11} \mathrm{C}$ & ${ }^{12} \mathrm{C}$ & ${ }^{13} \mathrm{C}$ & ${ }^{14} \mathrm{C}$ & ${ }^{15} \mathrm{C}$ & 16 \\
\hline${ }^{9} \mathrm{~B}$ & ${ }^{10} \mathrm{~B}$ & ${ }^{11} \mathrm{~B}$ & ${ }^{12} \mathrm{~B}$ & ${ }^{13} \mathrm{~B}$ & ${ }^{14} \mathrm{~B}$ & 15 \\
\hline${ }^{8} \mathrm{Be}$ & ${ }^{9} \mathrm{Be}$ & & ${ }^{1} \mathrm{Be}$ & ${ }^{12} \mathrm{Be}$ & ${ }^{13} \mathrm{Be}$ & \\
\hline
\end{tabular}

Fig. 30: Exemplo do resultado de uma reação $\gamma, 2 n$ sobre o ${ }^{16} \mathrm{O}$, seguida do decaimento por $\beta^{+}$do ${ }^{14} \mathrm{O}$ em ${ }^{14} \mathrm{~N}$.

\begin{tabular}{|c|c|c|c|c|c|c|}
\hline & ${ }^{15} \mathrm{Ne}$ & ${ }^{16} \mathrm{Ne}$ & $17 \mathrm{Ne}$ & ${ }^{18} \mathrm{Ne}$ & ${ }^{19} \mathrm{Ne}$ & $20 \mid$ \\
\hline & ${ }^{14} \mathrm{~F}$ & $15 \mathrm{~F}$ & $16 \mathrm{~F}$ & ${ }^{17} \mathrm{~F}$ & $18 \mathrm{~F}$ & \\
\hline & ${ }^{13} 0$ & 140 & 150 & 160 & 170 & 18 \\
\hline $11 \mathrm{~N}$ & ${ }_{12} \mathrm{~N}$ & $13 \mathrm{~N}$ & $14 \mathrm{NJ}$ & ${ }^{15} \mathrm{~N}$ & $16 \mathrm{~N}$ & \\
\hline${ }^{19} \mathrm{C}$ & ${ }^{11} \mathrm{C}$ & ${ }^{12} \mathrm{C}$ & ${ }^{13} \mathrm{C}$ & $1+C$ & ${ }^{15} \mathrm{C}$ & \\
\hline${ }^{9} \mathrm{~B}$ & ${ }^{10} \mathrm{~B}$ & ${ }^{11} \mathrm{~B}$ & ${ }^{12} \mathrm{~B}$ & ${ }^{13} \mathrm{~B}$ & ${ }^{14} \mathrm{~B}$ & \\
\hline & & & & & ${ }^{13} \mathrm{~B}$ & \\
\hline
\end{tabular}

Fig. 31: Exemplo do resultado de uma reação $\gamma, n$ sobre o ${ }^{16} \mathrm{O}$, seguida do decaimento por $\beta^{+}$do ${ }^{15} \mathrm{O}$ em ${ }^{15} \mathrm{~N}$. 
Se considerarmos agora um espectro de abundâncias plano como simplificação, calculamos todos os núcleos-filho formados e, sendo todos ricos em prótons e instáveis dentro de nossa escala de tempo, decaindo por $\beta^{+}$. Em alguns casos, esses produtos de decaimento também eram instáveis e tiveram de decair novamente, em um processo de relaxação. Para as reações de $\gamma, 2 n$ foram necessários 3 etapas de decaimento formando 4 gerações, e, para $\gamma, n, 2$ etapas de decaimento, formando 3 gerações. O produto dessas reações está mostrado nas Fig. 32 e 33.
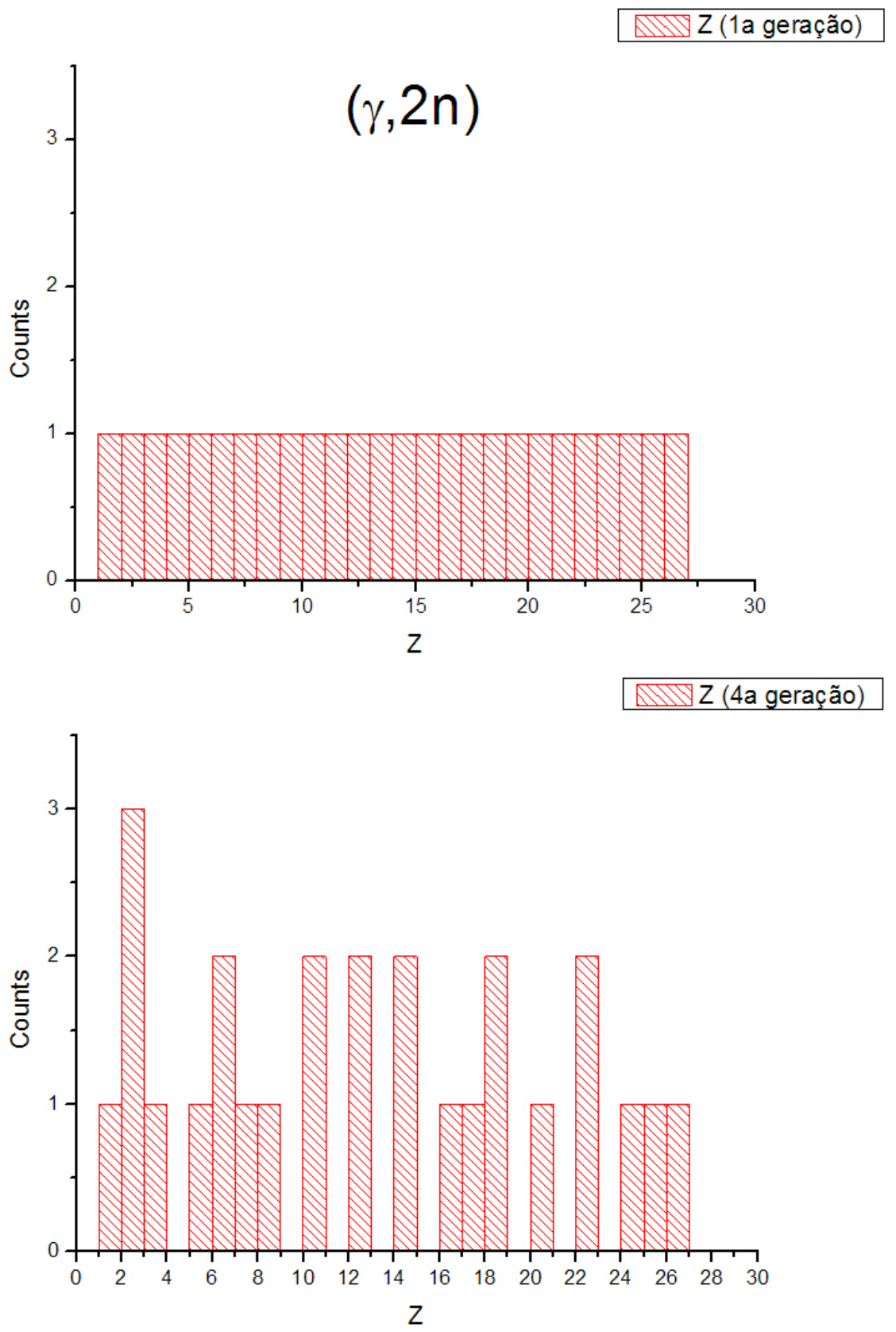

Fig. 32: Alteração em um espectro de distribuição de elementos de número atômico $Z$ plano após reações do tipo $\gamma, 2 n$. 

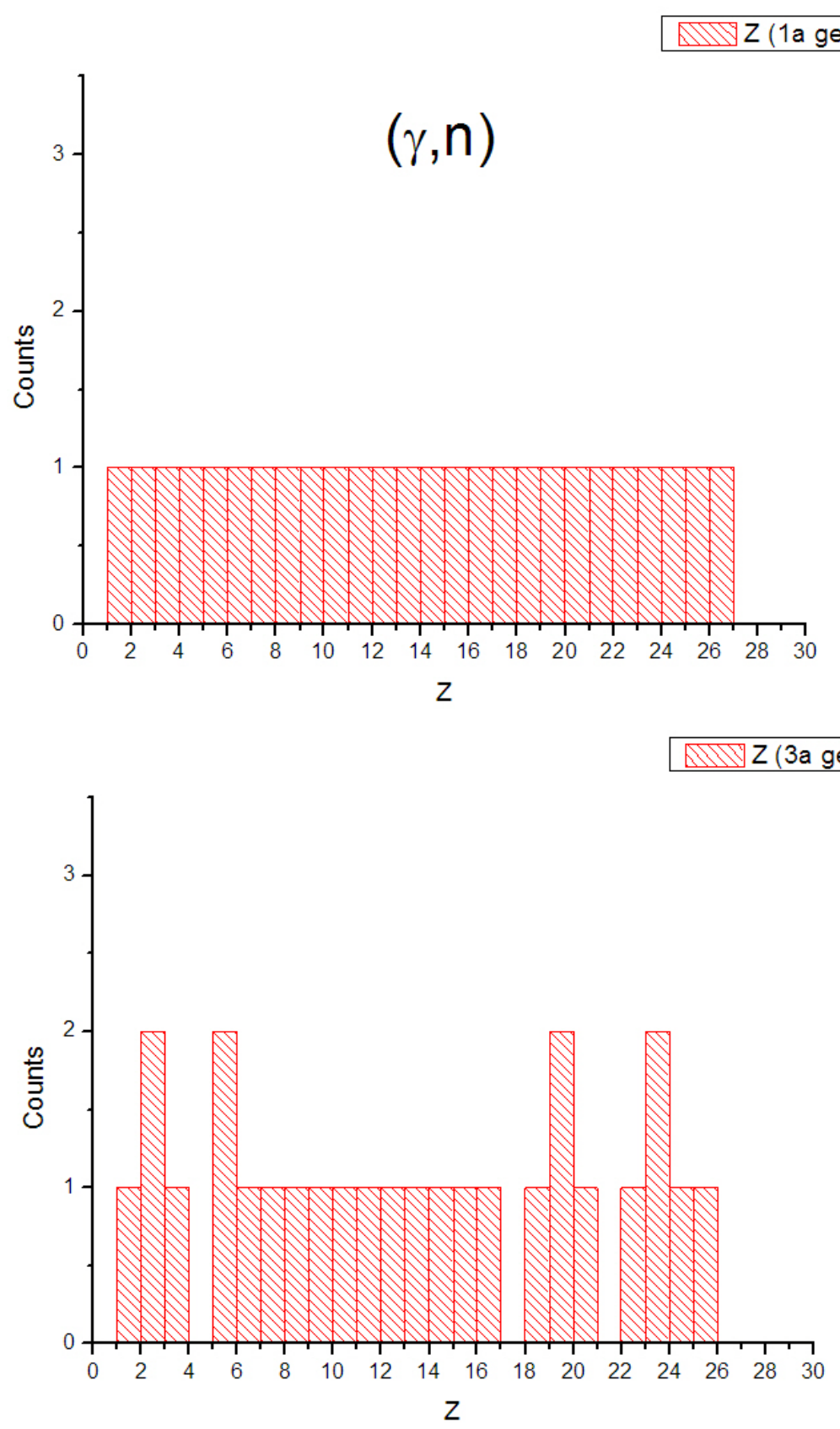

Fig. 33: alteração em um espectro de distribuição de elementos de número atômico $Z$ plano após reações do tipo $\gamma, n$.

Apliquemos agora para o caso real, de um GRB imerso em uma região de densidade numérica $1000 \mathrm{~cm}^{-3}$ e com um espectro de abundância solar formando uma supershell de diâmetro de $1 \mathrm{kpc}$ com espessura de $1 \mathrm{pc}$. Consideraremos que a iluminação pelos fótons gama ocorreram de forma isotrópica, apenas como simplificação, e trabalharemos até $Z=26(\mathrm{Fe})$.

Se somarmos todos os isótopos para cada Z, teremos o resultado apresentado na Fig. 34, onde estão mostradas as variações na abundância para cada elemento. Vemos 
que as variações máximas ocorreriam para o $\mathrm{B}$ e $\mathrm{F}$, pois eles receberiam incrementos provenientes dos abundantes $\mathrm{C}$ e Ne.

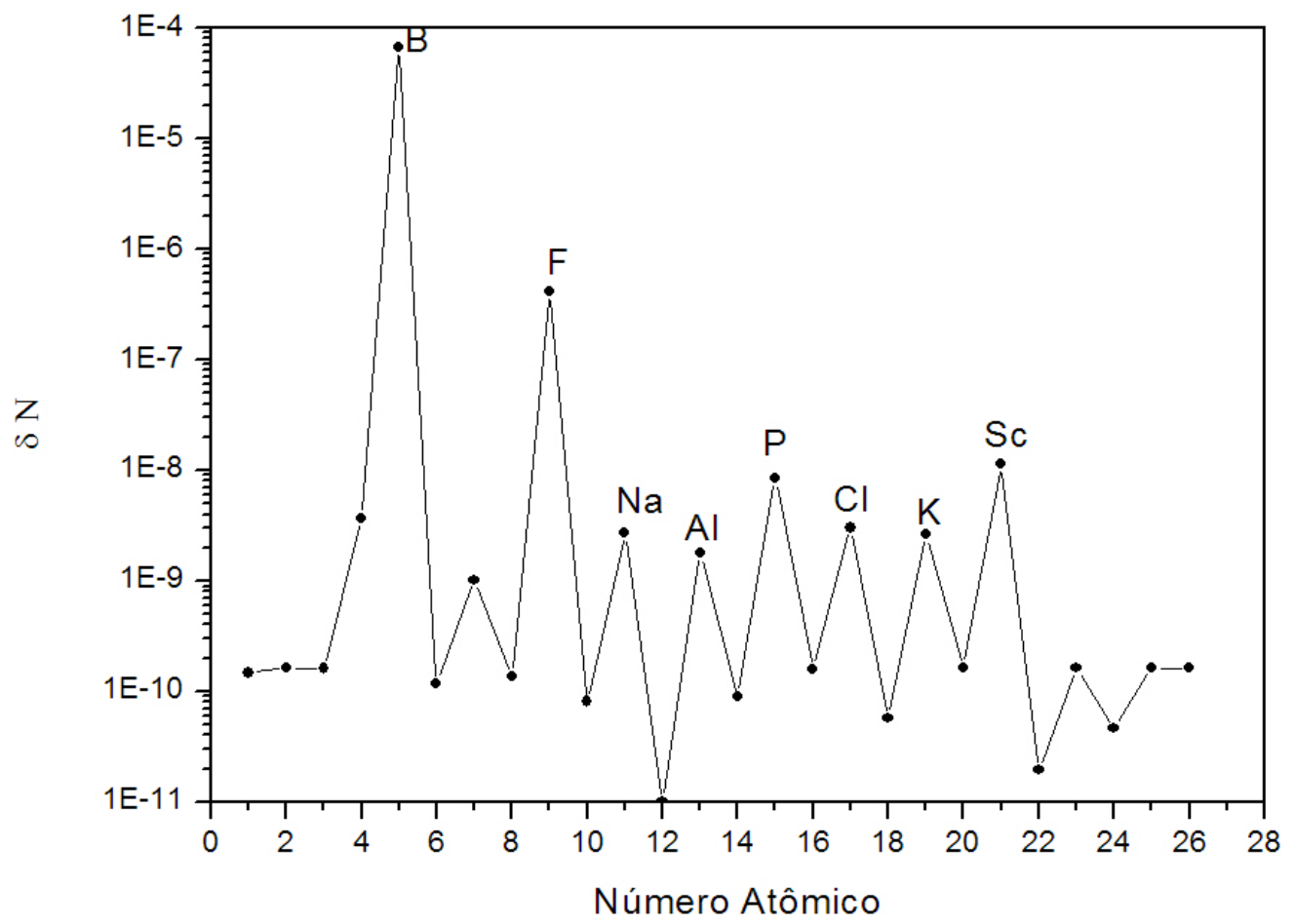

Fig. 34: Variação na abundância química considerando-se reações $\gamma, 2 n$ causadas por um GRB.

Nesse momento, calculamos a variação apenas para a reação $\gamma, 2 n$, pois sabemos que esse é o canal preferencial de decaimento, bem como pudemos notar que a variação na abundância pelas reações $\gamma, n$ é menos rica (vide Fig. 33).

Fizemos também o detalhamento das reações para os diversos isótopos formados, até o Fe. Além de modificar as abundâncias absolutas, as reações fotonucleares podem induzir a variações isotópicas significativas. A Tabela 2 apresenta os resultados obtidos: 
Tabela 2: Variação relativa na abundância de alguns isótopos estáveis até o Fe após um surto, considerando reações $\gamma, 2 n .{ }^{44} \mathrm{Ti}$ tem vida-média de 47.3 anos e ${ }^{53} \mathrm{Mn}$ de $3.7 \times 10^{6}$ anos, e estão apresentados em valores absolutos de número de átomos formados, não em valores relativos (em fundo cinza).

\begin{tabular}{|c|r|}
\hline Núcleo & $\boldsymbol{\delta} \boldsymbol{N}$ \\
\hline${ }^{17} \mathrm{O}$ & $-1,37000 \mathrm{E}-08$ \\
\hline${ }^{18} \mathrm{O}$ & $1,10000 \mathrm{E}-06$ \\
\hline${ }^{21} \mathrm{Ne}$ & $1,61138 \mathrm{E}-07$ \\
\hline${ }^{22} \mathrm{Ne}$ & $6,61000 \mathrm{E}-08$ \\
\hline${ }^{25} \mathrm{Mg}$ & $1,33983 \mathrm{E}-08$ \\
\hline${ }^{26} \mathrm{Mg}$ & $1,33456 \mathrm{E}-07$ \\
\hline${ }^{29} \mathrm{Si}$ & $3,46435 \mathrm{E}-08$ \\
\hline${ }^{30} \mathrm{Si}$ & $2,63496 \mathrm{E}-06$ \\
\hline${ }^{33} \mathrm{~S}$ & $1,02681 \mathrm{E}-06$ \\
\hline${ }^{36} \mathrm{Ar}$ & $1,73685 \mathrm{E}-07$ \\
\hline${ }^{37} \mathrm{Cl}$ & $4,40926 \mathrm{E}-08$ \\
\hline${ }^{38} \mathrm{Ar}$ & $4,09436 \mathrm{E}-05$ \\
\hline${ }^{43} \mathrm{Ca}$ & $6,54791 \mathrm{E}-09$ \\
\hline${ }^{44} \mathrm{Ti}$ & $3,56 \mathrm{E}+49$ \\
\hline${ }^{46} \mathrm{Ti}$ & $1,45894 \mathrm{E}-07$ \\
\hline${ }^{49} \mathrm{Ti}$ & $3,57432 \mathrm{E}-08$ \\
\hline${ }^{50} \mathrm{Cr}$ & $3,13009 \mathrm{E}-07$ \\
\hline${ }^{53} \mathrm{Mn}$ & $2,30 \mathrm{E}+51$ \\
\hline${ }^{54} \mathrm{Fe}$ & $2,56918 \mathrm{E}-07$ \\
\hline
\end{tabular}

Como referência, as densidades de colunas observadas em quasares (QSO) são de cerca de $10^{13}$ a $10^{15} \mathrm{~cm}^{-2}$. Teremos que, no caso de GRBs imersos em regiões densas, com até $1000 \mathrm{~cm}^{-3}$, produtos de reações com tais densidade de coluna em distâncias tão pequenas como a $1 \mathrm{pc}$ do centro do evento. Dessa maneira, é esperado que os produtos das reações fotonucleares no entorno de GRBs sejam espectroscopicamente observáveis, possivelmente funcionando como diagnóstico para a distinção do cenário de múltiplas supernovas.

No entanto, podem haver dificuldades para a observação dessas variações de abundância. Sendo a emissão $\gamma$ altamente colimada, os núcleos formados podem estar em região onde não são visíveis. Além disso, é necessário que haja uma fonte de radiação para excitar os átomos formados, para os quais se espera a variação isotópica ou química. Nem sempre será possível que as condições sejam favoráveis à observação. 


\section{Efeitos de um GRB sobre um planeta tipo-terrestre}

Consideraremos nesse capítulo os efeitos da incidência do fluxo radiativo proveniente de um GRB sobre um planeta que esteja dentro do cone de iluminação da emissão $\gamma$ inicial. Nosso objetivo é estimar os efeitos biológicos de uma irradiação curta, intensa e de alta energia, porém também mostraremos que essas irradiações podem ter efeitos de longa duração.

Além disso, trataremos de outra fonte astrofísica de intensa de radiação de alta energia, os chamados soft-gamma repeaters. Tais eventos, apesar de menos energéticos, têm uma maior probabilidade de ocorrerem próximo a Terra, ou terem ocorrido no passado, por isso eles se tornam interessantes.

\subsection{Histórico}

O estudo da interação da radiação com sistemas biológicos data da descoberta da radiatividade, no final de 1800, com os trabalhos de Antoine Henri Becquerel, Marie e Pierre Curie e Wilhelm Conrad Röntgen. Becquerel descobriu a radiatividade do elemento urânio (Becquerel 1901), o casal Curie isolou um novo elemento mais radiativo que o próprio urânio, o qual eles denominaram de rádio (Curie and Laborde 1903) e Röntgen produziu os primeiros raios-X artificialmente, por meio de um tubo de raios catódicos (Kotzur 1994). Imediatamente surgiram os primeiros estudos sobre os efeitos da radiação sobre sistemas químicos e biológicos (Becquerel 1901; Becquerel and Curie 1901). Marie Curie percebeu as possibilidades práticas dos elementos radiativos e da radiação para a medicina, estabelecendo um serviço pioneiro, juntamente com sua filha Irène, de radiografias durante a primeira guerra, salvando a vida de muitos franceses. Além disso, aplicando a capacidade da radiação de matar tecidos biológicos, fundou a radioterapia, utilizando o gás radônio para eliminar tecidos danificados de soldados, e, após a guerra, de civis. Foram necessários vários anos para que os efeitos deletérios da radiação fossem percebidos.

Com as teorias atômicas do início do século $\mathrm{XX}$ foram desvendados os princípios de geração da radiação, o que culminou com a era nuclear na metade de século, em especial, com o desenvolvimento da fissão nuclear controlada e da bomba atômica. Desenvolveu-se assim, a ciência da radioproteção. Era necessário compreender os mecanismos de interação da radiação com a matéria para criar sistemas de blindagem 
eficientes, e também com sistemas biológicos, para minimizar ou tratar os efeitos pósirradiação; ou maximizá-los, no caso do desenvolvimento de armas nucleares.

$\mathrm{Na}$ mesma época, com a corrida espacial, a radiação nesse ambiente começava a tornar-se uma preocupação, uma vez que era necessário manter seres humanos por períodos cada vez maiores em órbita e na longa viagem até a Lua, longe da proteção do campo magnético terrestre (Schaefer 1952; Knauf 1959; Tobias 1959; Newell and Naugle 1960). Os primeiros estudos sobre os efeitos da radiação solar sobre a biologia na superfície do planeta também se expandiam nessa época (Hollaender and Swanson 1946; Shklovski 1961).

Atualmente, existe um extenso estudo dos efeitos da radiação de origem astrofísica sobre um planeta, em especial, sobre a Terra. No entanto, grande parte desses estudos concentra-se na faixa espectral solar, devido à sua predominância, no caso terrestre, especialmente no solo. Dessa maneira, são privilegiados estudos na região visível e ultravioleta (UV) do espectro eletromagnético (Peak, Peak et al. 1984; Hader and Worrest 1991; Yang, Mei et al. 1994; Gascon, Oubina et al. 1995; Sinha, Kumar et al. 1995; Hader and Figueroa 1997; Cockell 1998; Madronich, McKenzie et al. 1998; Cockell 2000; Cockell 2000; Cockell and Horneck 2001; Sinha, Klisch et al. 2001; Day and Neale 2002; Rozema, Bjorn et al. 2002; De La Vega, Rettberg et al. 2005; Hader and Sinha 2005), deixando-se de lado, em grande parte, a radiação de mais alta energia.

\subsection{Supernovas: efeitos planetários}

Os primeiros trabalhos que procuraram compreender os efeitos de radiação astrofísica esporádica de alta energia sobre o planeta utilizaram como fonte as supernovas (Ruderman 1974; Whitten, Cuzzi et al. 1976; Ellis and Schramm 1995; Crutzen and Bruhl 1996). Iremos descrever alguns dos resultados obtidos por esses grupos.

Todos esses trabalhos procuraram calcular a alteração química da atmosfera, catalisada pela radiação das supernovas. O objetivo era estimar a redução da camada de ozônio $\left(\mathrm{O}_{3}\right)$ e, conseqüentemente, o aumento do fluxo UV solar na superfície do planeta, já que o $\mathrm{O}_{3}$ atua como absorvedor de UV (conforme mostrado na Fig. 35). 


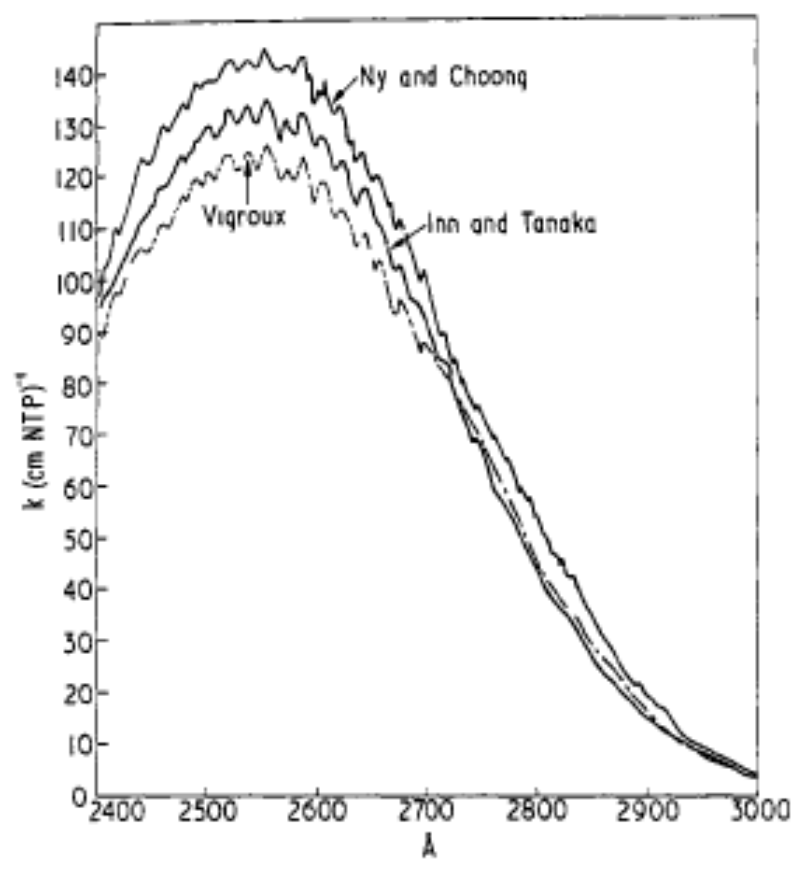

Fig. 35: Coeficientes de absorção do ozônio na região UV do espectro (Hearn 1961).

O trabalho clássico de Ruderman (Ruderman 1974) na década de 70 foi o primeiro a apontar quantitativamente os efeitos possíveis de uma supernova próxima $(\sim 15 \mathrm{pc})$ sobre a Terra. Nesse trabalho, mostra-se que a radiação poderia alterar a química atmosférica de forma a causar uma depleção na densidade de coluna do gás ozônio, o que aumentaria o fluxo de UV solar chegando ao solo. Ruderman utiliza o fluxo $\gamma$ produzido pelas explosões, bem como possíveis raios cósmicos nelas acelerados como fonte de energia para a alteração da química atmosférica. Os cálculos de Ruderman indicam valores de depleção de ozônio entre 3 e $60 \%$ que durariam por quase cem anos, o tempo aproximado de recuperação da química atmosférica após a absorção de radiação da supernova. Para esses cálculos, foi utilizada uma aproximação analítica para o sistema químico atmosférico, ignorando transporte e distribuição espacial.

Whitten et al (Whitten, Cuzzi et al. 1976) aperfeiçoaram o modelo, retirando a necessidade da aceleração de raios cósmicos na supernova, mecanismo que eles consideraram pouco eficiente. Nesse modelo, é considerada a interação da radiação $\gamma$ da supernova e de seu remanescente em expansão, o qual englobaria o planeta por $10^{3}-$ $10^{4}$ anos, tempo durante o qual o fluxo de raios cósmicos (principalmente prótons) seria aumentado, produzindo efeitos comparáveis aos de Ruderman, porém com durações maiores. 
Nos anos 80 fica demonstrado que eventos astronômicos podem influenciar radicalmente a evolução da vida na Terra, com a descoberta de grande concentração de irídio em camadas sedimentares da transição Cretáceo-Terciário (KT), formada há 60 milhões de anos, distribuídas globalmente (Alvarez, Alvarez et al. 1980; Alvarez, Kauffman et al. 1984). Esse elemento é extremamente raro na crosta terrestre, sendo associado a meteoritos. Apesar de a cratera ter sido identifica apenas em 1990, na costa do México, ficou claro que uma grande extinção havia sido causada por um asteróide.

Nos anos 90 a influência das supernovas no planeta é revisitada. Ellis e Schramm (Ellis and Schramm 1995) refizeram os cálculos de Ruderman, chegando a conclusões semelhantes, ou seja, uma depleção significativa de $95 \%$ da câmara de ozônio para distâncias de até 10pc. Os autores apontam para a grande sensibilidade dos organismos marinhos, em especial fitoplanctons, a um aumento repentino no fluxo UV. Esses organismos são fotossintetizantes e base da cadeia alimentar marinha, bem como responsáveis por boa parte da regulação química da atmosfera. Uma depleção desses organismos poderia prejudicar o ecossistema global de forma dramática.

Crutzen e Brühl (Crutzen and Bruhl 1996) refinaram os cálculos utilizando um modelo químico mais completo e levando em conta diferenças de latitude. Dessa maneira, prevêem que os cálculos anteriores estavam sendo superestimados, chegando ao máximo a uma depleção moderada de $15 \%$ na camada de ozônio. Essa depleção estaria concentrada principalmente em altas latitudes, onde poderia chegar a 70\%, mas a região equatorial seria, em grande parte, poupada. Dessa maneira, consideram improvável um efeito significativo na biosfera causado por uma supernova.

Em 2002, Benítez (Benitez, Maiz-Apellaniz et al. 2002) propõe que o excesso de ${ }^{60} \mathrm{Fe}$ encontrado em amostras do fundo dos oceanos é proveniente de uma supernova que explodiu a cerca de 2 milhões de anos, próxima à Terra. Essa supernova teria ocorrido na associação OB Escórpio-Centauro, hoje distante de 130pc do Sol, e poderia ter causado uma significativa depleção de ozônio, provocando ou contribuindo para a extinção marinha da transição Plioceno-Pleistoceno. Pela primeira vez houve uma evidência observacional de uma supernova ocorrendo concomitantemente a um evento de extinção. 


\subsection{GRB: efeitos planetários}

Nesta seção iremos desenvolver um cálculo para estimar os danos causados por um GRB sobre a biosfera de um planeta semelhante à Terra, ou seja, com a presença de uma atmosfera (Galante and Horvath 2007), calculando distâncias mínimas para que esses efeitos sejam significativos para a biosfera. Os trabalhos feitos anteriormente baseavam-se na ionização atmosférica causada por raios $\gamma$ e raios cósmicos provenientes de supernovas. Como GRBs produzem uma quantidade de radiação ionizante muito superior a de uma supernova, eles seriam muito mais eficientes na destruição da camada de ozônio. Thorsett (Thorsett 1995) foi um dos primeiros autores a levantar essa possibilidade.

Não é impossível que GRBs possam ter tido um grande impacto na Terra, podendo ter havido ao menos um evento no último bilhão de anos (Melott, Lieberman et al. 2004). Outros planetas possivelmente habitados, em galáxias com formação estelar mais acentuada que a Via Láctea, ou próximos a regiões com grande concentração de estrelas massivas, como associações OB, estariam ainda mais sujeitos a esses eventos, podendo a vida ser reiniciada por grandes extinções, ou mesmo eliminada completamente (Annis 1999).

Para essa seção, admitiremos um cenário de GRB longo, como esquematizado na Fig. 36, com duração de 10 s, energia emitida em gamas e cinética de $5 \times 10^{50}$ erg e jato com ângulo sólido $\Omega$ de $0.01 \mathrm{sr}$. Iremos desprezar a absorção desses fótons de alta energia pelo ISM, devido à baixa seção de choque fotonuclear (teríamos no máximo uma absorção de $1 \%$ dos fótons emitidos na região da formação do remanescente, vide capítulo 2).

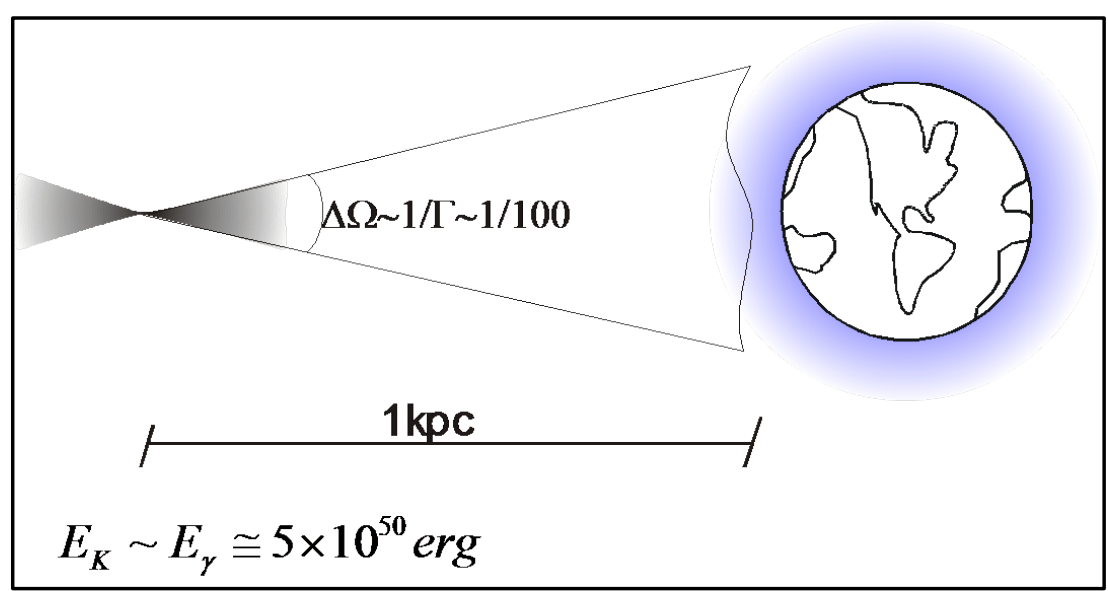

Fig. 36: Esquema da irradiação da Terra por um GRB. A emissão gama colimada atingiria a atmosfera sendo transmitida, reprocessada e alteraria a química da atmosfera. 
Usaremos um espectro de Band (capítulo 1, Eq. 2) para a emissão inicial, com energia típica dos fótons em centenas de $\mathrm{keV}$. O fluxo, a uma dada distância, deve ser simplesmente $F_{\gamma}=L / \Delta \Omega D^{2}$, onde L é a luminosidade $\gamma$ do surto (energia total emitida, $\left.5 \times 10^{51} \mathrm{erg}\right), \Delta \Omega$ é o ângulo sólido do jato e $D$ a distância. Para o planeta, consideraremos a atmosfera com composição atual, porém com duas densidades diferentes: atmosfera atual, com densidade de coluna $\rho=1024 \mathrm{gcm}^{-2}$ e uma atmosfera fina, com $\rho=$ $100 \mathrm{~g} \mathrm{~cm}^{-2}$, na tentativa de simular uma atmosfera primitiva terrestre (Kasting 1993; Cockell 2002).

Alguns outros trabalhos recentes fizeram estimativas detalhadas da depleção de $\mathrm{O}_{3}$ causada por um surto (Thomas, Jackman et al. 2005; Thomas, Melott et al. 2005), porém como desejamos comparar todos os possíveis efeitos do surto, incluímos também a propagação da radiação $\gamma$ e a de um jato de raios cósmicos (cosmic ray jets $-C R J)$. Dividimos, assim, em quatro os efeitos de um surto sobre o planeta: flash $\gamma$, flash UV, depleção de $\mathrm{O}_{3}$ e cosmic ray jets (CRJ), os quais serão tratados separadamente.

\subsubsection{Organismos-teste}

De maneira a quantificar os danos à biosfera, escolhemos dois microorganismos para serem usados como parâmetro biológico: as bactérias Escherichia coli (E.coli) e Deinococcus radiodurans (D.radiodurans). A bactéria E.coli é extremamente sensível à radiação, em especial UV, enquanto que D.radiodurans é classificada como um poliextremófilo, devido à sua resistência a muitos agentes deletérios, como radiação UV e ionizante, peróxidos orgânicos e dessecação (Battista 1997). Na tabela 3 estão resumidas as doses e fluxos para a morte de $90 \%$ de uma população dessas bactérias.

Tabela 3: Doses e fluxos para sobrevivência de 10\% para uma população de bactérias E.coli e D.radiodurans para radiação ionizante (Ghosal, Omelchenko et al. 2005) e UV (Gascón, Oubiña et al. 1995).

\begin{tabular}{|c|c|c|c|}
\hline Organismo & $D_{\mathbf{1 0}}^{\text {ion }}(\boldsymbol{k G y})$ & $\boldsymbol{F}_{\mathbf{1 0}}^{\mathbf{i o n}}\left(\mathrm{Jm}^{-\mathbf{2}}\right)$ & $\boldsymbol{F}_{\mathbf{1 0}}^{U V}\left(\mathrm{Jm}^{-\mathbf{2}}\right)$ \\
\hline E.coli & 0.7 & $3.5 \times 10^{5}$ & 22.6 \\
\hline D.radiodurans & 11 & $5.5 \times 10^{6}$ & $5.53 \times 10^{2}$ \\
\hline
\end{tabular}

Essa escolha pragmática nos fornece limites superior e inferior para a resistência à radiação, permitindo inferir uma "zona habitável" (Kasting, Whitmire et al. 1993) de distâncias dos surtos e de formação estelar intensa. Note que não estamos afirmando que 
esses organismos representam a fauna procarionte primitiva terrestre, a qual, provavelmente, era mais semelhante às bactérias cianofíceas atuais, como as que produzem os estromatólitos (Lowe 1980). Os limites obtidos devem ser entendidos como a faixa possível baseada em organismos bem medidos e estudados.

A partir das doses e fluxos para 90\% de depleção, podemos calcular a distância $\mathrm{D}_{10}$, ou seja, a distância máxima que o GRB pode estar para depositar sobre o planeta a dose de radiação que cause essa depleção. Conhecendo o fluxo necessário para depositar a dose, basta aplicar $F_{\gamma}=L / \Delta \Omega D^{2}$ para encontrar a distância, pressuponde-se conhecida a abertura angular do jato $(\Delta \Omega)$ e a luminosidade do surto $(L)$.

\subsubsection{Flash $\gamma$}

O efeito mais direto do surto é que parte da radiação $\gamma$ é transmitida diretamente pela atmosfera, chegando ao solo. Segundo Smith (Smith, Scalo et al. 2004), propagando os fótons através da atmosfera com um código Monte Carlo, incluindo espalhamento Compton e absorção, para uma atmosfera fina $\left(30<\rho<100 \mathrm{~g} / \mathrm{cm}^{2}\right), 1 \%$ da radiação incidente atingiria o solo, sendo que a energia média dos fótons seria deslocada de $200 \mathrm{keV}$ para $20 \mathrm{keV}$, ou seja, para a faixa de raios-X. No caso de atmosferas espessas, como a atual $\left(\rho=1024 \mathrm{~g} / \mathrm{cm}^{2}\right)$, o bloqueio seria quase que completo, sendo que apenas $6 \times 10^{-29}$ do fluxo incidente chegaria ao solo.

Dessa maneira, é importante considerar o caso de atmosfera fina para a Terra primitiva, a qual estaria sujeita a radiação $\gamma$ proveniente de um surto.

O principal efeito biológico de radiação dessa energia é a produção de radicais livres por fotoionização, os quais têm efeito tóxico para a célula, e quebra direta do DNA. Convertemos as doses necessárias para a depleção de $90 \%$ da população em fluxo de fótons utilizando a deposição de energia em água, conforme detalhado no Apêndice 1 , sendo que os valores desses fluxos já estão inclusos na Tabela 3.

Para obtermos tais fluxos $\gamma$ no solo, temos que considerar a transparência da atmosfera já discutida. Para o flash $\gamma$, apenas o caso de atmosfera fina é relevante, sendo que, dessa maneira, a distância máxima para 90\% de depleção da população de E.coli seria de 390pc, enquanto para D.radiodurans seria de no máximo a 100pc. Para a atmosfera espessa, a energia do surto seria praticamente toda depositada na atmosfera.

Essa irradiação, apesar de intensa para o caso da atmosfera fina, iluminaria apenas um dos hemisférios o planeta, por ter duração próxima a do surto, de 10s. 


\subsubsection{Flash UV}

O mesmo mecanismo de espalhamento Compton atenuando a irradiação direta provoca um reprocessamento dos fótons de alta energia para a faixa do $\mathrm{UV}$, causando o chamado flash UV. Smith et al (Smith, Scalo et al. 2004) calculam para o caso de atmosferas finas uma reemissão UV entre $1-10 \%$ do fluxo $\gamma$ inicial e, no caso de atmosferas espessas, entre $2 \times 10^{-3}-4 \times 10^{-2}$. Esses cálculos foram realizados desconsiderando aerossóis, que poderiam absorver o UV e mudar muito o resultado da irradiação, uma vez que ela tem tempo de duração de poucos segundos.

Os efeitos biológicos da radiação UV provêm da forte absorção que moléculas de DNA e RNA têm nessa faixa de energia, sofrendo dimerização de nucleotídeos, especialmente nas bases pirimidínicas (Hader and Sinha 2005). De fato, o fluxo necessário para a morte de $90 \%$ da população é cerca de $10^{4}$ vezes menor que o de radiação ionizante (Tabela 3) para a E.coli.

Considerando as eficiências de conversão de $\gamma$ em UV (Smith, Scalo et al. 2004) e traduzindo esses fluxos em distâncias, chegamos às distâncias máximas de 48 $152 \mathrm{kpc}$ para E.coli e 10 - 31kpc para D.radiodurans, no caso de atmosfera fina, e 21 96kpc para E.coli e 4 - 9kpc para D.radiodurans em atmosferas atuais.

D.radiodurans suporta fluxos maiores, por isso pode sobreviver mesmo após irradiações de surtos mais próximos.

\subsubsection{Depleção da camada de $\mathrm{O}_{3}$}

O efeito de mais longa duração de um GRB seria a destruição ou depleção da camada de ozônio. O tempo de reconstituição da camada é da ordem de anos ou mesmo décadas (Thomas, Melott et al. 2005) e, portanto, os efeitos do aumento do fluxo de UV solar seriam sentidos muito fortemente pelos organismos, de forma global, enquanto que os flashes $\gamma$ e UV discutidos acima teriam basicamente a mesma duração do surto, ou seja, algumas dezenas de segundos, estando restritos a apenas o hemisfério iluminado e a efeitos causados por incidência direta nos organismos.

Primeiro devemos calcular a depleção de ozônio gerada pela radiação $\gamma$, sendo que iniciaremos extrapolando os resultados de Ruderman para supernovas (Ruderman 1974), o qual pressupõe que o ozônio é destruído pela reação catalítica com NO:

$$
\begin{aligned}
& \mathrm{NO}+\mathrm{O}_{3} \rightarrow \mathrm{NO}_{2}+\mathrm{O}_{2} \\
& \mathrm{NO}_{2}+\mathrm{O} \rightarrow \mathrm{NO}+\mathrm{O}_{2}
\end{aligned}
$$


Ou seja, por essas reações, $\mathrm{O}_{3}$ seria sistematicamente convertido em $\mathrm{O}_{2}$ enquanto houvesse NO presente (antes dele ser degradado ou reagir com outras moléculas).

A cinemática da reação pode ser modelada de maneira simplificada pela Eq. 11:

$$
\frac{\left[O_{3}\right]}{\left[O_{3}\right]_{0}}=\frac{\sqrt{19+9 X^{2}}-3 X}{2}
$$

Onde $X=\frac{\left[N O_{X}\right]}{\left[N O_{X}\right]_{0}}$ e assume-se que:

- A oxidação de $\mathrm{NO}_{2}$ por O é o passo limitante do ciclo;

- A razão $[\mathrm{O}] /\left[\mathrm{O}_{3}\right]$ é constante;

- $\left[\mathrm{NO}_{\mathrm{X}}\right]_{0}$ reduz $\left[\mathrm{O}_{3}\right]$ para metade do valor caso não houvesse nenhum $\mathrm{NO}_{\mathrm{X}}$ presente.

Durante a irradiação $\gamma,\left[\mathrm{NO}_{\mathrm{X}}\right]$ aumenta devido à produção de átomos de $\mathrm{N}$ livres pelos fótons de alta energia:

$$
\mathrm{N}^{*}+\mathrm{O}_{2} \rightarrow \mathrm{NO}+\mathrm{O}
$$

Se considerarmos, numa aproximação, todo o $\mathrm{NO}_{\mathrm{X}}$ como sendo $\mathrm{NO}$, a taxa de produção é dada pela Eq. 12:

$$
\frac{10}{(10+y)}=\frac{\text { moléculas de NO }}{\text { parde ions }},
$$

onde y é a abundância de NO inicial em ppb, a qual tomaremos como sendo igual a $3 p p b$.

Usando os valores de Ruderman (Ruderman 1974), temos que $1 J \cong 2.8 \times 10^{17}$ pares de íons.

A taxa de produção de moléculas de $\mathrm{NO}$ em função do fluxo incidente de radiação ionizante, $\phi$, seria dada então pela Eq. 13:

$$
R_{N O}=\phi\left(J / m^{2} / s\right) \times 2.8 \times 10^{17}\left(\frac{\text { pares ion }}{J}\right) \times\left(\frac{10}{10+y}\right)\left(\frac{\text { molec NO }}{\text { pares ion }}\right) \times \frac{10^{9}(\mathrm{ppb})}{5 \times 10^{27}\left(\mathrm{molec} / \mathrm{m}^{2}\right)}
$$

Eq. 13: Taxa de produção de NO em função do fluxo de radiação incidente.

Simplificando e integrando ao longo da duração de um surto (10s), teríamos a Eq. 14:

$$
R_{N O}=0.43 \phi\left(\mathrm{J} / \mathrm{m}^{2}\right) p p b
$$

\section{Eq. 14}

Apliquemos nas definições anteriores (Eq. 15): 


$$
X=\frac{[N O]}{[N O]_{0}}=1+\frac{R_{N O}}{[N O]_{0}},
$$

onde $[\mathrm{NO}]_{0}=3 \mathrm{ppb}$, obtemos a Eq.16:

$$
X\left(\phi\left(J / m^{2}\right)\right)=1+0.67 \times 10^{-2} \phi\left(J / m^{2}\right)
$$

Basta substituirmos esse resultado na Eq. 11, obtendo assim a forma funcional para a depleção de $\mathrm{O}_{3}$ segundo Ruderman, em função da fluência $\gamma$ no topo da atmosfera.

Gehrels (Gehrels, Laird et al. 2003) faz um tratamento mais sofisticado do problema, usando um modelo computacional para a atmosfera, a qual é irradiada com um espectro tirado da supernova SN1987a, com energia total, em $\gamma$, de 9x10 16 erg.

Fazendo os cálculos para 10,20, 50 e 100pc Gehrles aponta uma tendência da depleção de ozônio variar com de forma inversamente proporcional com a distância à supernova, elevada a um parâmetro $\mathrm{n}: D_{S N}^{-n}$, onde $1.3<\mathrm{n}<1.9$. Usaremos o valor médio, $n=1.6$.

Para uma distância de $10 \mathrm{pc}$, Gehrels apresenta um gráfico (Fig. 37) da redução global de ozônio, como função da latitude em que ocorre a irradiação:

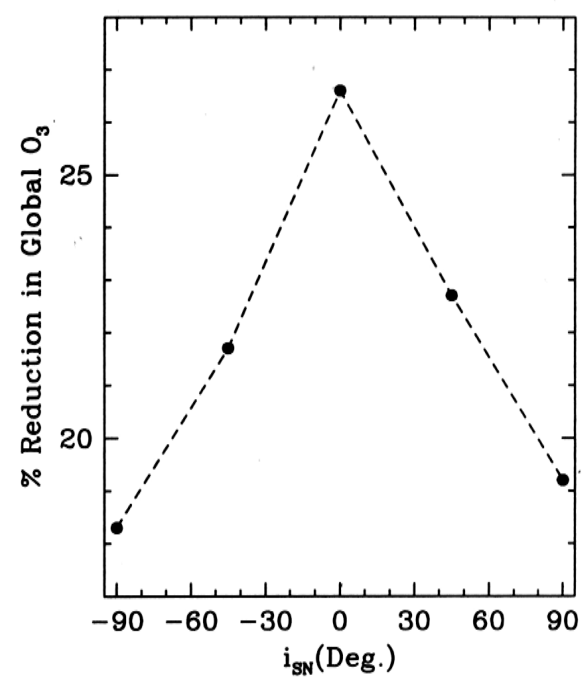
2003).

Fig. 37: Depleção de O3 em função da latitude, segundo Gehrels (Gehrels, Laird et al.

Ajustando os pontos da Fig. 37 com uma gaussiana e fazendo a média angular, obtemos uma depleção média de $22.58 \%$. 
Com esses dados, podemos calcular a depleção de ozônio como função da fluência $\gamma$ no topo da atmosfera para Gehrels, como mostrado na Eq. 17:

$$
\frac{\left[\mathrm{O}_{3}\right]}{\left[\mathrm{O}_{3}\right]_{0}}=1-7.2 \times 10^{-4.6} \phi^{0.8}\left(\mathrm{~J} / \mathrm{m}^{2}\right)
$$

\section{Eq. 17}

A Fig. 38 mostra graficamente a comparação dos resultados de Ruderman e Gehrels:

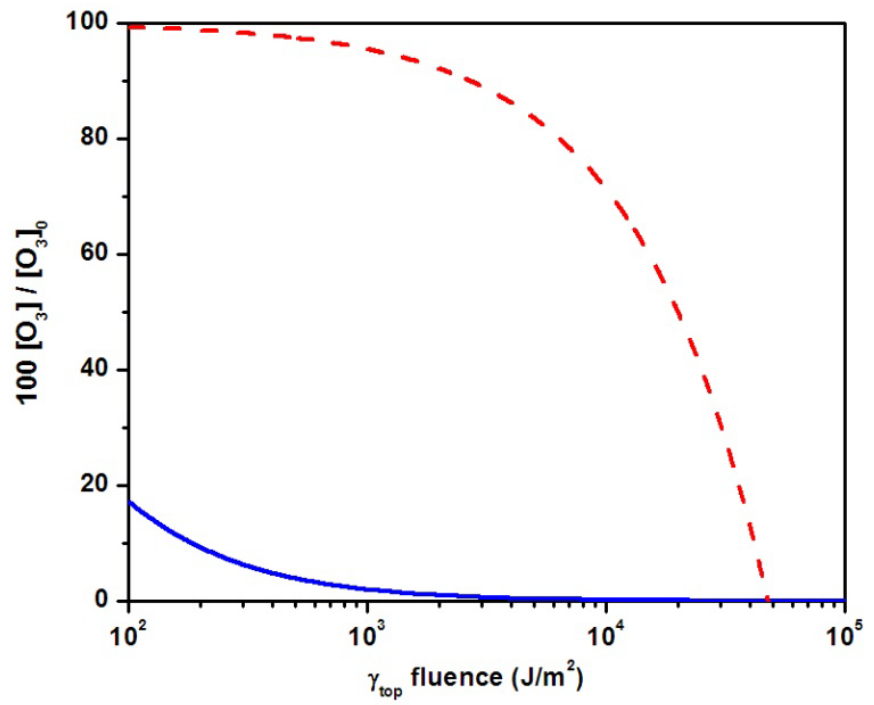

Fig. 38: Comparação dos cálculos de depleção de $\mathrm{O}_{3}$ segundo Ruderman, em linha azul, e Gehrels, em vermelha tracejada.

Vemos como a aproximação de Ruderman é muito drástica. Praticamente todo o ozônio seria destruído com fluências pouco maiores que $10^{3} \mathrm{~J} / \mathrm{m}^{2}$. Adotaremos a fórmula ajustada a partir dos dados de Gehrels para nossa análise, por ser construída por meio de um modelo mais completo e realista que a aproximação de Ruderman.

Para entendermos como essa diminuição no ozônio levaria ao aumento do fluxo de UV, em especial na região do UVB $(200$ - $300 \mathrm{~nm})$, a mais importante biologicamente, usamos a abordagem de Madronich (Madronich, McKenzie et al. 1998), segundo o qual a variação no fluxo de UV é proporcional à variação no ozônio elevada a uma potência negativa, o fator RAF (Radiation Amplification Factor):

$$
U V_{B I O} \sim\left(\mathrm{O}_{3}\right)^{-R A F}
$$

Para cada tipo de efeito biológico uma faixa do espectro será mais relevante, logo, esse fator de amplificação será diferente, pois a sensibilidade dos organismos ao fluxo UV é fortemente dependente da freqüência, devido aos diferentes mecanismos de reparo de danos envolvidos (Wood 1996). 
Para o caso de eritrema cutâneo (queimadura superficial do tecido), a faixa de máximo efeito se encontra em torno de 300nm, e o RAF=1.1 (Madronich, McKenzie et al. 1998). Essa banda também é eficiente para causar a morte de E.coli.

Na Fig. 39 é apresentado o gráfico do aumento do fluxo de UV nessa região do espectro, comparando novamente os resultados de Rudeman e Gehrels novamante.

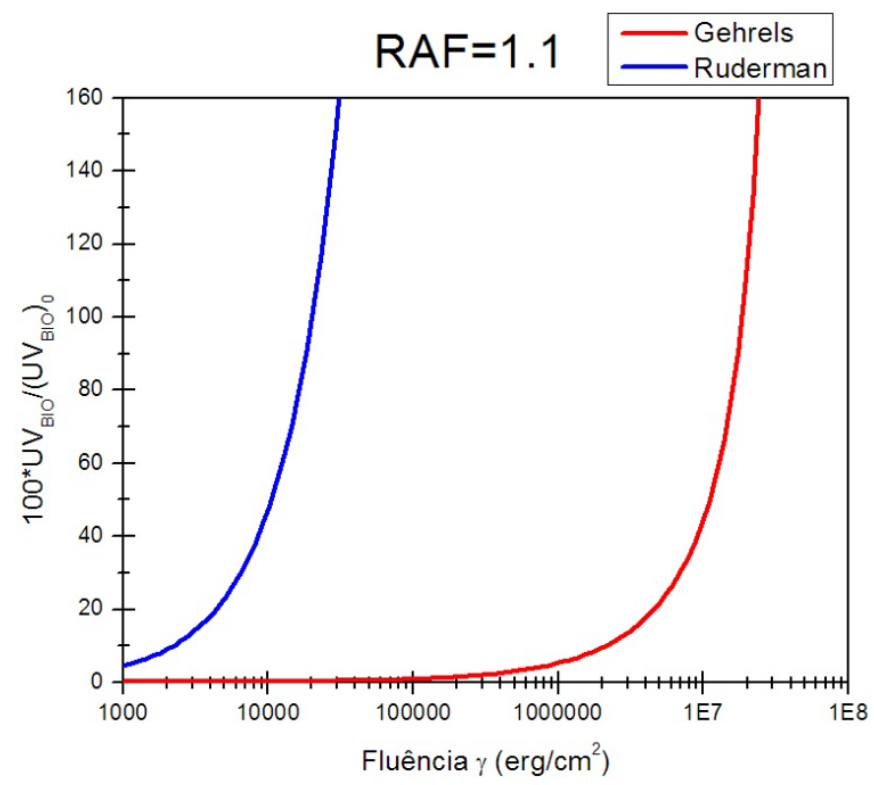

Fig. 39: Comparação do aumento do fluxo UV solar na região de 300nm para os modelos de Ruderma e Gehrels.

No caso de Gehrels, para que tenhamos um aumento de $100 \%$ em $\mathrm{UV}_{\mathrm{BIO}}$, precisamos de fluências da ordem de $2 \times 10^{7} \mathrm{erg} / \mathrm{cm}^{2}$. Gehrels (Gehrels, Laird et al. 2003) adota esse patamar como um aumento suficiente para que tenhamos efeitos biológicos significativos.

Para sabermos qual a fluência chegando ao solo, usaremos a teoria mais simples de transferência radiativa aplicando a lei de Beer-Lambert (Eq. 18) de absorção exponencial:

$$
\phi_{U V}=\left(\phi_{U V}\right)_{0} e^{-\sigma N}
$$

$\sigma=$ seção de choque do $\mathrm{O}_{3}$

$\mathrm{N}=$ densidade de coluna de $\mathrm{O}_{3}$

Nessa aproximação, estamos desprezando outros absorvedores de UV, como o vapor de água, e processos de espalhamento. Podemos, portanto, estar superestimando os efeitos da diminuição do mesmo. 
Usaremos $N=350 D U^{16}=9.4 \times 10^{22} \mathrm{molec} / \mathrm{cm}^{2}$, que é um valor médio para a densidade de coluna de ozônio atual para a Terra.

Para as seções de choque, adotaremos os valores de seção de choque de absorção do $\mathrm{O}_{3}$ abaixo:

$$
\begin{aligned}
& \sigma(\lambda=300-305 \mathrm{~nm})=3.4 \times 10^{-19} \mathrm{~cm}^{2} \\
& \sigma(\lambda=250 \mathrm{~nm})=1.0 \times 10^{-17} \mathrm{~cm}^{2}
\end{aligned}
$$

Usando agora a lei de Beer-Lambert, mas introduzindo um fator de depleção para a densidade de coluna de ozônio segundo Ruderman, e usando que o fluxo $U_{\mathrm{B}}$ no topo da atmosfera é da ordem de $\phi_{0} \sim 10^{4} \mathrm{~J} / \mathrm{m}^{2} / \mathrm{s}$, temos a Eq. 19, cujo gráfico é mostrado na Fig. 40.

$$
\phi_{\text {sup }}\left(\mathrm{J} / \mathrm{m}^{2} / \mathrm{s}\right)=\phi_{0}\left(\mathrm{~J} / \mathrm{m}^{2} / \mathrm{s}\right) e^{\left.-\left(\sigma_{\overline{[O}}^{\left[\mathrm{O}_{3}\right]}\right]_{0}\right)}
$$

\section{D (kpc)}

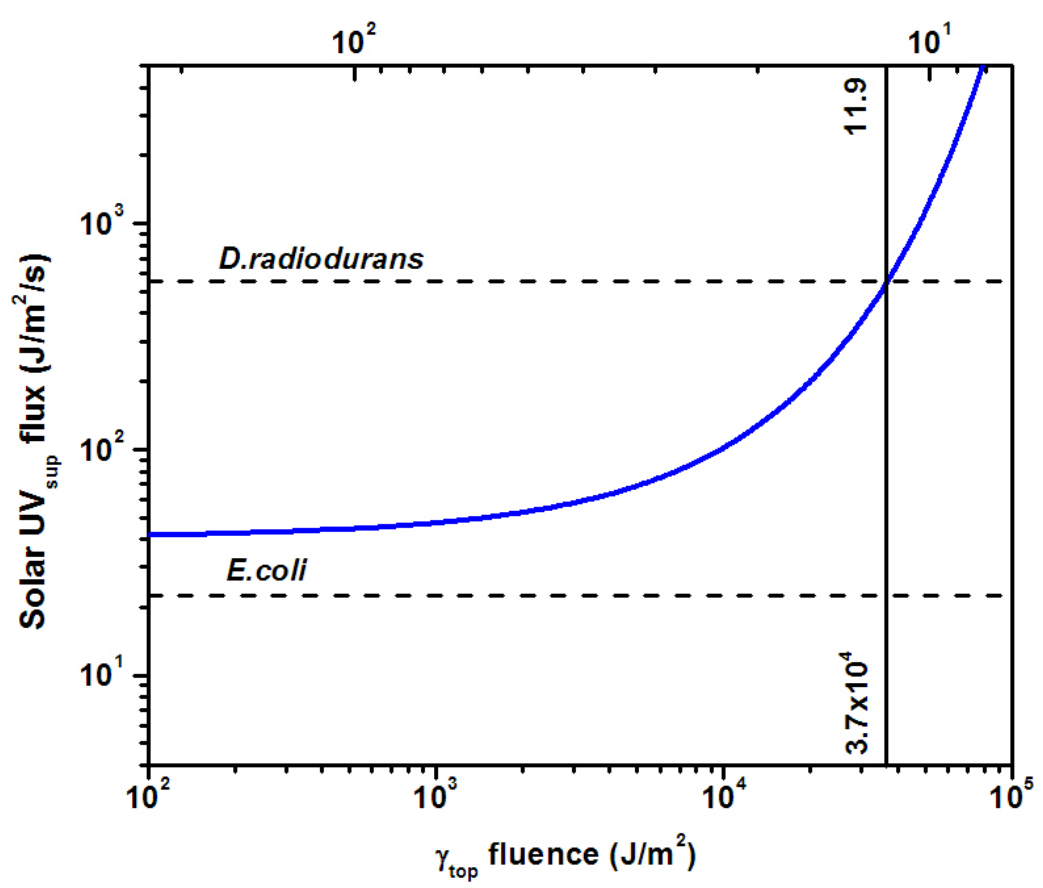

Fig. 40: Fluxo $U V_{B}$ solar ao nível do mar, em função da fluência $\gamma$ no topo da atmosfera (escala inferior) e da distância à fonte do surto (escala superior). Estão graficados os fluxos UV para $90 \%$ de mortalidade de E.coli e D.radiodurans, como limiares biológicos.

Pelo gráfico da Fig. 40, notamos que o fluxo mínimo para causar 90\% de depleção para D.radiodurans ocorre na distância máxima de $11.9 \mathrm{kpc}$. A dose de UV solar sem depleção de $\mathrm{O}_{3}$ já é letal para E.coli.

${ }^{16} \mathrm{DU}=$ Dobson unit: unidade de medida de $\mathrm{O}_{3}$ atmosférico. 


\subsubsection{Cosmic ray jets (CRJ)}

Como apontado no Capítulo 2, cabe adotar a suposição de que ocorre a eqüipartição de energia na fonte do GRB, ou seja, que a mesma energia irradiada em $\gamma$ é usada para aceleração de partículas. Assim, adotaremos uma luminosidade de $5 \times 10^{50} \mathrm{erg}$ a $10 \mathrm{kpc}$, tanto para as partículas aceleradas quanto para os $\gamma$, produzindo um fluxo de $10^{7} \mathrm{erg} / \mathrm{cm}^{2}$ para ambos, se levarmos em conta a colimação de $\Delta \Omega=1 / \Gamma$ igual para ambos os casos com $\Gamma=100$ (fato não óbvio, este é um tema ainda em aberto (Vietri, De Marco et al. 2003), no entanto, o importante, no momento, é considerarmos a possibilidade de presença de partículas (prótons) de alta energia decorrentes do mesmo processo que gerou a emissão $\gamma$ do GRB, e cujo efeito poderia ser devastador (Dar, Laor et al. 1998)).

Ao atingir a atmosfera, o CRJ produziria uma série de partículas secundárias e cascatas, as quais podem atingir o solo ou mesmo regiões subterrâneas e submarinas, como nos casos dos múons de alta energia. Isso expande o raio de atuação de um GRB, que estaria limitado às regiões próximas à superfície, devido a pouca penetrabilidade da radiação $\gamma$ e UV.

Precisamos ser capazes de resolver as equações de cascata para gerar o espectro de múons produzidos por um espectro inicial de raios cósmicos. Os primários ao colidirem com núcleos atmosféricos produziriam píons e kaons, os quais decairiam em múons e neutrinos, conforme Eq. 20:

$$
p+N \rightarrow \pi+K \rightarrow \mu+v
$$

No caso de um fluxo primário monocromático, podemos usar a aproximação usada por Dar (Dar, Laor et al. 1998), mostrada na Eq. 21:

$$
\left\langle N_{\mu}\right\rangle \cong \frac{\left(0.0145 E_{p}[\mathrm{TeV}]\right)}{\cos \theta}\left(E_{p} / E_{\mu}\right)^{0.757}\left(1-E_{\mu} / E_{p}\right)^{5.25}
$$

Eq. 21: Aproximação pra um fluxo primário monocromático.

Essa fórmula nos fornece o número médio de múons de alta energia $\left(>\mathrm{E}_{\mu}\right)$ produzidos por nucleons primários de energia $\mathrm{E}_{\mathrm{p}}$, os quais não decaem na atmosfera $\mathrm{e}$ atingem o nível do mar num ângulo zenital $\theta<\pi / 2$.

Para o caso de um espectro incidente de primários, podemos usar a equação fornecida por Lipari (Lipari 1993), Eq. 22, dedutível a partir de Gaisser (Gaisser 1992): 


$$
\phi_{\mu}(E, \theta)=\left[L_{\pi}(\alpha)\left(1+\frac{L_{\pi}(\alpha)}{H_{\pi}(\alpha)} \frac{E \cos \theta}{\varepsilon_{\pi}}\right)^{-1}+L_{K}(\alpha)\left(1+\frac{L_{K}(\alpha)}{H_{K}(\alpha)} \frac{E \cos \theta}{\varepsilon_{K}}\right)^{-1}\right] K E^{-\alpha}
$$

Eq. 22: Fluxo de múons gerado por um espectro primário em lei te potência.

$\mathrm{Na}$ Eq. 22 estão separadas as contribuições devido ao decaimento de píons e de kaons, e é valida apenas acima de $20 \mathrm{GeV}$, pois abaixo dessa energia deve-se levar em conta também o decaimento dos secundários. $\mathrm{O}$ espectro de primários é dado por $\mathrm{KE}^{-\alpha}$, onde $\alpha$ é o índice espectral (all nucleon).

Os vários parâmetros das interações foram tirados de Lipari (Lipari 1993) e Hillas (Hillas 1971) sem que haja demasiada incerteza sobre eles.

Para testar a fórmula, usemos os valores de $\alpha=2.7$ e $K=1.85$ de raios cósmicos Galácticos na Terra, e $\theta=0$, obtendo a forma funcional mostrada na Eq. 23, a qual está graficada na Fig. 41.

$$
\phi(E[G e V])=\frac{0.0424}{(1+0.0026 E) E^{2.7}}
$$

Eq. 23

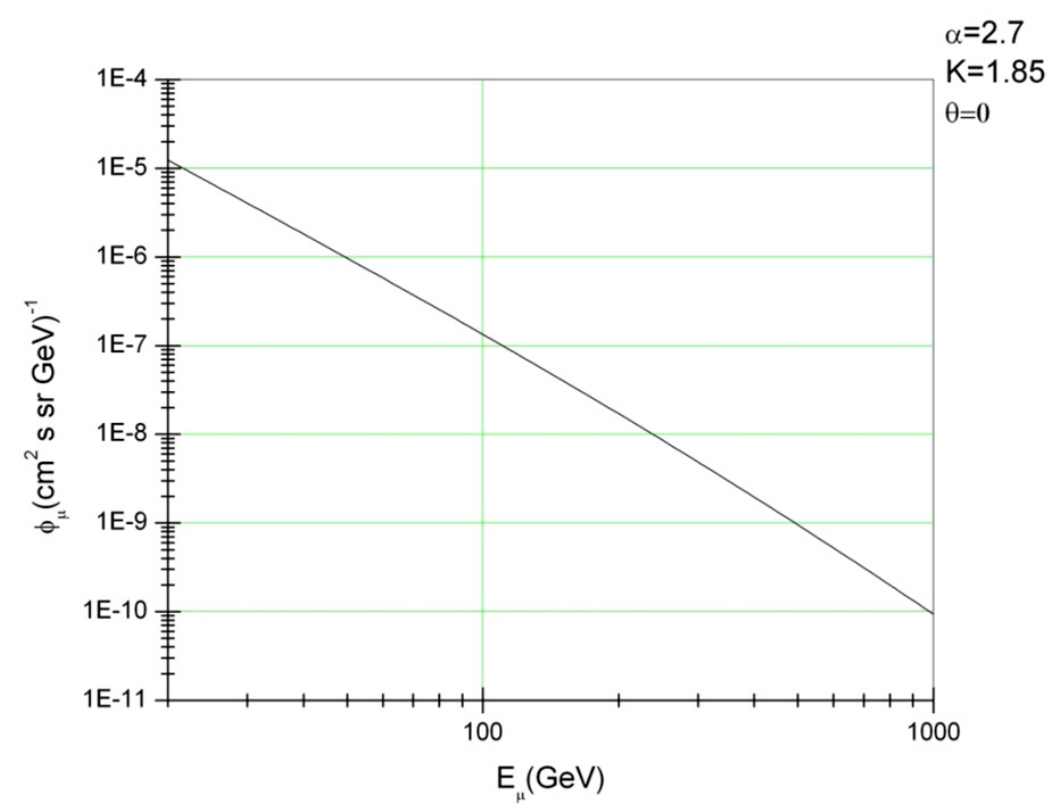
atmosfera.

Fig. 41: Fluxo de múons no solo, produzidos por raios cósmicos Galácticos no topo da

O resultado foi consistente com o de Gaisser (Gaisser 1992), e de bom acordo com os dados experimentais para altas energias $(\mathrm{E}>20 \mathrm{GeV})$, por não levar em conta o decaimento de secundários. 
Como ainda não tratamos do possível espectro em energia que um CRJ proveniente de um GRB teria, iremos usar os dados fornecidos por Dar (Dar, Laor et al. 1998), o qual trabalha com um fluxo monocromático, com energia típica por nucleon de $1 \mathrm{TeV}$, em comparação à energia típica de $1 \mathrm{GeV} /$ nucleon dos raios cósmicos normais .

A produção de múons seguirá a equação já apresentada anteriormente (Eq 21).

Usando a energia de $1 \mathrm{TeV} /$ nucleon para os primários e um fluxo primário de $10^{7} \mathrm{erg} / \mathrm{cm}^{2} \cong 10^{8} \mathrm{TeV} / \mathrm{cm}^{2}$, obteríamos o seguinte fluxo ao nível do mar, conforme mostrado na Fig.42.

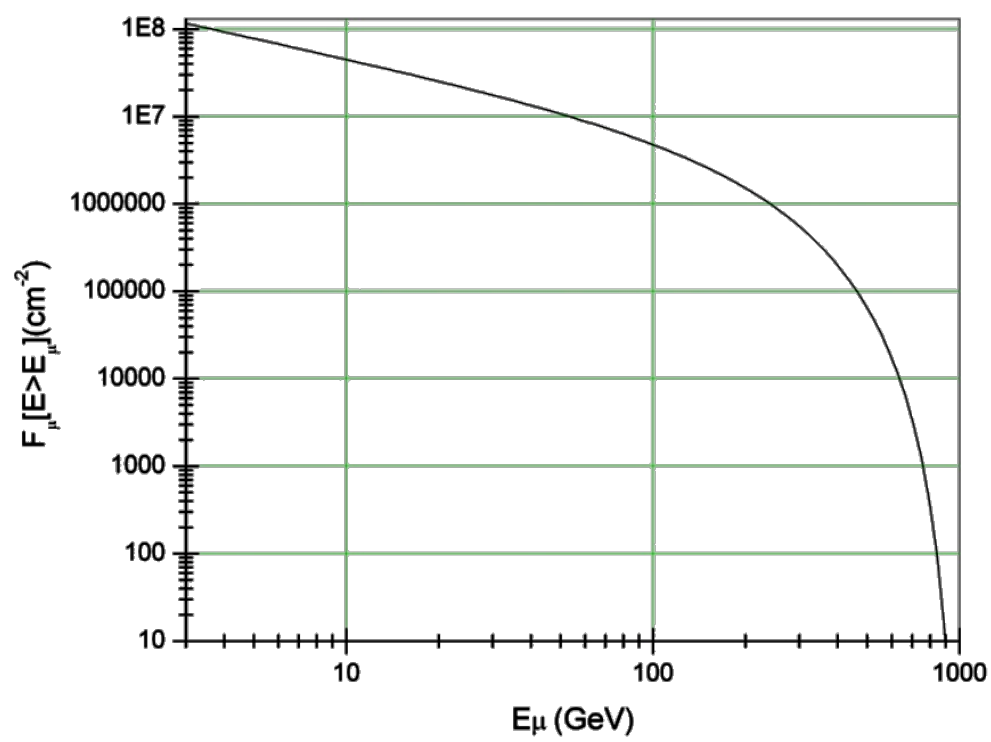
GRB.

Fig. 42: Fluxo de múons no solo, produzidos por um evento de CRJ proveniente de um

Lembrando que o fluxo mostrado na Fig. 42 é o fluxo de múons com energia maior que $\mathrm{E}_{\mu}$. Como já mostramos, a deposição de energia é constante em um grande intervalo de energias (de $\mathrm{GeV}$ até $\mathrm{TeV}$ ), portanto, podemos usar o fluxo diretamente do gráfico, como se fosse monocromático. Usando o fluxo acima de $20 \mathrm{GeV}$ (para garantir a validade de nossas fórmulas e consistência da análise, que levou em conta apenas o limite de alta energia), obteríamos $F_{\mu}\left(E_{\mu}>20 \mathrm{GeV}\right) \cong 10^{7} \mathrm{~cm}^{-2}$.

Para o caso de uma E.coli, cuja área aproximada é de $3 \mu \mathrm{m}^{2}$, teríamos a seguinte dose de energia depositada (Eq. 24), utilizando os dados do Apêndice 1:

$$
\frac{d E}{d x}=2.58 \frac{\mathrm{MeV}}{\mathrm{gcm}^{2}} \times 3 \mathrm{um}^{2} \times 10^{-8} \frac{\mathrm{cm}^{2}}{{\mu \mathrm{m}^{2}}^{2}}=7.74 \times 10^{-8} \mathrm{MeV} / \mathrm{g}=7.74 \times 10^{-6} \mathrm{~Gy}
$$

Eq. 24: Dose de energia depositada, para o caso da E.coli. 
Com o fluxo de múons de alta energia calculado na Fig. 41, a dose depositada por ionização seria $D_{\text {ioniz }}=77.4 G y$. A dose para $90 \%$ de depleção para E.coli por radiação ionizante é de aproximadamente $0.7 \mathrm{kGy}$ e $11 \mathrm{kGy}$ para D.radiodurans. Essas bactérias sobreviveriam a fluxos de $2 \times 10^{16}$ muons $/ \mathrm{m}^{2}$ e $3 \times 10^{17} \mathrm{muons} / \mathrm{m}^{2}$, respectivamente. Traduzindo em distâncias, teríamos que as distâncias máximas para que ocorresse a deposição de uma dose capaz de eliminar 90\% da população seriam de 48 pc para E.coli e 12 pc para D.radiodurans.

Além disso, essa dose seria diluída, pois a duração do CRJ é muito superior à do surto $\gamma$ (Dar, Laor et al. 1998), da ordem de:

$$
\delta t \approx D / 2 c \Gamma^{2} \approx 10 \text { dias }-20 \text { meses, para } 1000<\Gamma<100
$$

Assim, a população seria submetida a um nível relativamente baixo de radiação, não letal, a priori, mas por um longo período, superior a um ano. Essa irradiação pode ter conseqüências ecológicas, devido ao aumento das taxas de mutação e de mortalidade além alteração da química atmosférica.

Resumimos as distâncias para uma depleção de $90 \%$ da população desses organismos na Tabela 4, onde estão separados os diversos efeitos do GRB.

Tabela 4: Distâncias para depleção de $90 \%$ da população pelos 4 efeitos dos GRB, mostrando os grandes alcances para o flash de UV. Os intervalos nas distâncias refletem as incertezas na taxa de conversão $\gamma$ para UV.

\begin{tabular}{|c|c|c|c|}
\hline \multirow{2}{*}{$\begin{array}{c}\text { Efeito } \\
\text { planetário }\end{array}$} & \multirow{2}{*}{ Organismo teste } & \multicolumn{2}{|c|}{$D_{10}(k p c)$} \\
\hline & & Atmosfera fina & Atmosfera atual \\
\hline \multirow{2}{*}{ Flash $\gamma$} & E.coli & 0.39 & $-^{*}$ \\
\hline & D.radiodurans & 0.10 & $-^{*}$ \\
\hline \multirow{2}{*}{ Flash UV } & E.coli & $48-152$ & $21-96$ \\
\hline & D.radiodurans & $10-31$ & $4-19$ \\
\hline \multirow{2}{*}{$\begin{array}{c}\text { Depleção de } \\
\mathrm{O}_{3}\end{array}$} & E.coli & $-^{*}$ & $-^{*}$ \\
\hline & D.radiodurans & $-^{*}$ & 12 \\
\hline \multirow{2}{*}{ CRJ } & E.coli & $-^{*}$ & 0.05 \\
\hline & D.radiodurans & $-^{*}$ & 0.01 \\
\hline
\end{tabular}

*Depleção de $\mathrm{O}_{3}$ e CRJ não são relevantes para o caso de atmosfera fina, nem a distância para E.coli para depleção de $\mathrm{O}_{3}$, pois sua dose letal já está abaixo do fluxo normal sem o surto. $\mathrm{O}$ flash $\gamma$ também não é capaz de se propagar em atmosferas espessas, por isso esse efeito é desprezado. 
É interessante notar que o mecanismo mais eficiente, o que pode depositar a dose de radiação na superfície de um planeta de mais longe, é o flash UV, podendo chegar a distâncias de até centenas de kpc. No entanto, os danos gerados por esse evento são de curta duração, cerca de 10s, podendo ter poucas implicações em longo prazo. Em contrapartida, os efeitos da depleção de $\mathrm{O}_{3}$ poderiam durar anos, tendo assim um forte impacto sobre a ecologia global. Notamos que é possível causar um evento de depleção mesmo como surto localizado a $12 \mathrm{kpc}$. Ou seja, um surto que ocorrer em qualquer lugar da Galáxia, direcionado para a Terra, poderia causar danos significativos, incluindo a mortalidade de grande parte dos organismos vivos expostos na superfície dos continentes e mares, incluindo o fitoplâncton.

O valor que utilizamos para a depleção da população após a irradiação, de $90 \%$, foi arbitrário, escolhido apenas como uma forma de comparar os danos aos diferentes organismos. Os efeitos ecológicos em grande escala de uma súbita alteração em um sistema biológico complexo são difíceis de modelar, e, em especial, de generalizar de maneira que não seja espécie-específico. Estamos trabalhando nesse tipo de problema (Robersy, Cardenas et al. 2008), pois queremos desenvolver uma metodologia para trabalhar com as não linearidades naturas dos sistemas biológicos, de maneira a compreender os efeitos das grandes perturbações causadas por catástrofes globais, como a irradiação por um surto.

\subsubsection{Atmosfera primitiva}

Conforme apresentamos na seção 3.3.1, fizemos uma tentativa de simular uma atmosfera primitiva simplesmente diminuindo a densidade de coluna da mesma, mas não variamos sua composição.

A composição da atmosfera primitiva é ainda controversa. O paradigma de atmosfera fortemente redutora, por exemplo, como o adotado nos experimentos de Miller e Urey (Miller and Urey 1959) hoje não é mais um consenso. Admite-se ainda que a atmosfera foi anóxica até cerca de 2 bilhões de anos atrás, quando ocorreu o início do acúmulo desse gás, culminando na chamada "Grande Oxidação", vista no registro geológico como a formação de grandes depósitos de óxidos (Dole 1949; Kasting 1993; Canfield, Habicht et al. 2000). Esse evento está relacionado com a saturação dos sorvedouros de $\mathrm{O}_{2}$ do planeta (minerais que foram oxidados), os quais consumiam o $\mathrm{O}_{2}$ 
gerado pelos primeiros organismos fotossintetizantes (Catling, Zahnle et al. 2001; Catling and Claire 2005), e com o surgimento dos organismos eucariotos (Knoll 1992). A história da química da atmosfera na Terra está esquematizada na Fig. 43.

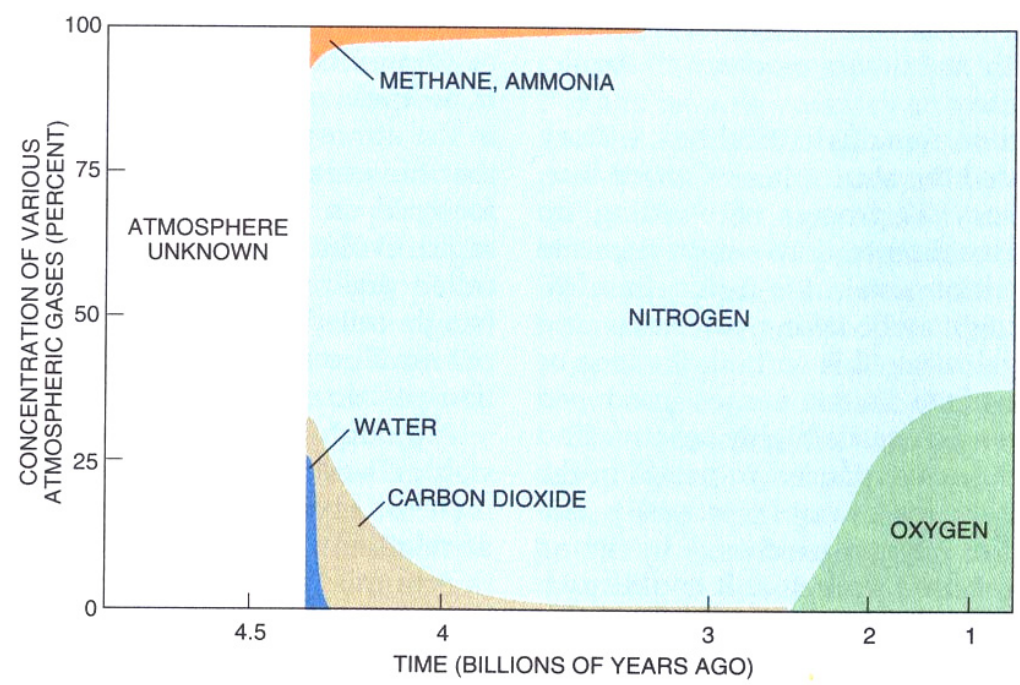

Fig. 43: Variação na composição atmosférica durante a história da Terra. Observa-se o aumento recente nos níveis de $\mathrm{O}_{2}$, o que ocorreu de forma simultânea ao surgimento dos organismos eucariontes. Ainda se conhece pouco sobre o estado da atmosfera primitiva (Kasting 1993).

$\mathrm{Na}$ tentativa de formarmos um quadro mais realista dos efeitos de um GRB sobre a Terra, temos de considerar os efeitos da diferente composição atmosférica, uma vez que a oxidação ocorreu recentemente, em termos geológicos. Nessas condições, os efeitos da irradiação sobre os organismos vivos provavelmente seria mais intenso que depois de protegidos por uma atmosfera espessa (Scalo and Wheeler 2002).

Dentre os efeitos que propomos para um GRB, o que mais será sensível à alteração da composição será a o flash UV, pois ele ocorrer pela interação dos fótons energéticos do surto com as moléculas atmosféricas, as quais os reemitem em menor energia.

Nosso modelo (Martin, Cardenas et al. 2009) consiste em uma atmosfera fina, da qual retiramos progressivamente $\mathrm{O}_{2}$, substituindo-o por $\mathrm{CO}_{2}$, de maneira a manter a pressão constante. Essa estratégia é válida, pois $\mathrm{CO}_{2}$ provavelmente foi o gás dominante da atmosfera primitiva, após o $\mathrm{N}_{2}$. Sobre essa atmosfera incidimos o fluxo proveniente de um GRB, utilizando um espectro de Band para a energia, o qual integramos entre $50 \mathrm{keV}$ e $3 \mathrm{MeV}$. 
A atmosfera foi dividida em camadas, as quais reemitem a radiação nelas depositadas segundo (Smith, Scalo et al. 2004), como mostrado na Eq. 25:

$$
\frac{d F_{U V, i}}{d \lambda}=\frac{F_{\text {dep }, i}}{\lambda\left(\frac{\lambda_{\max }}{\lambda_{\min }}\right)}
$$

Nessa equação, $F_{d e p, i}$ é a energia total depositada na i-ésima camada, e $\lambda_{\max } \mathrm{e}$ $\lambda_{\min }$ estão associados com os limites das bandas do nitrogênio, sendo fixados em $130 \mathrm{e}$ $600 \mathrm{~nm}$. Para o cálculo da energia depositada em cada camada, foram levados em conta processos de foto absorção e espalhamento Rayleigh. A emissão UV total foi calculada somando-se o resultado de todas as camadas atmosféricas.

A pressão parcial em relação à atmosfera atual de $\mathrm{O}_{2}$ foi variada de $10^{0}$ até $10^{-5}$, associando-se com eras geológicas específicas (Tabela 5):

Tabela 5: Associação da pressão parcial de oxigênio (em unidades de pal = present atmospheric level) com as eras geológicas, onde $\mathrm{Ga}=10^{9}$ anos.

\begin{tabular}{|c|c|}
\hline $\mathbf{O}_{2}$ pal & Era Geológica \\
\hline $10^{0}$ & $\begin{array}{c}\text { Proterozóico tardio e Fanerozóico } \\
(0.8 \text { Ga anos até presente) }\end{array}$ \\
\hline $10^{-1}-10^{-2}$ & $\begin{array}{c}\text { Protesozóico intermediário } \\
(2.3 \mathrm{Ga}-0.8 \mathrm{Ga})\end{array}$ \\
\hline $10^{-3}-10^{-5}$ & Arcaea e Proterozoico Archean eon and Early Proterozoic era \\
$(3.8 \mathrm{Ga}-2.5 \mathrm{Ga})$
\end{tabular}

Os fluxos UV no solo foram assim calculados conforme mostrado na Fig. 44. 


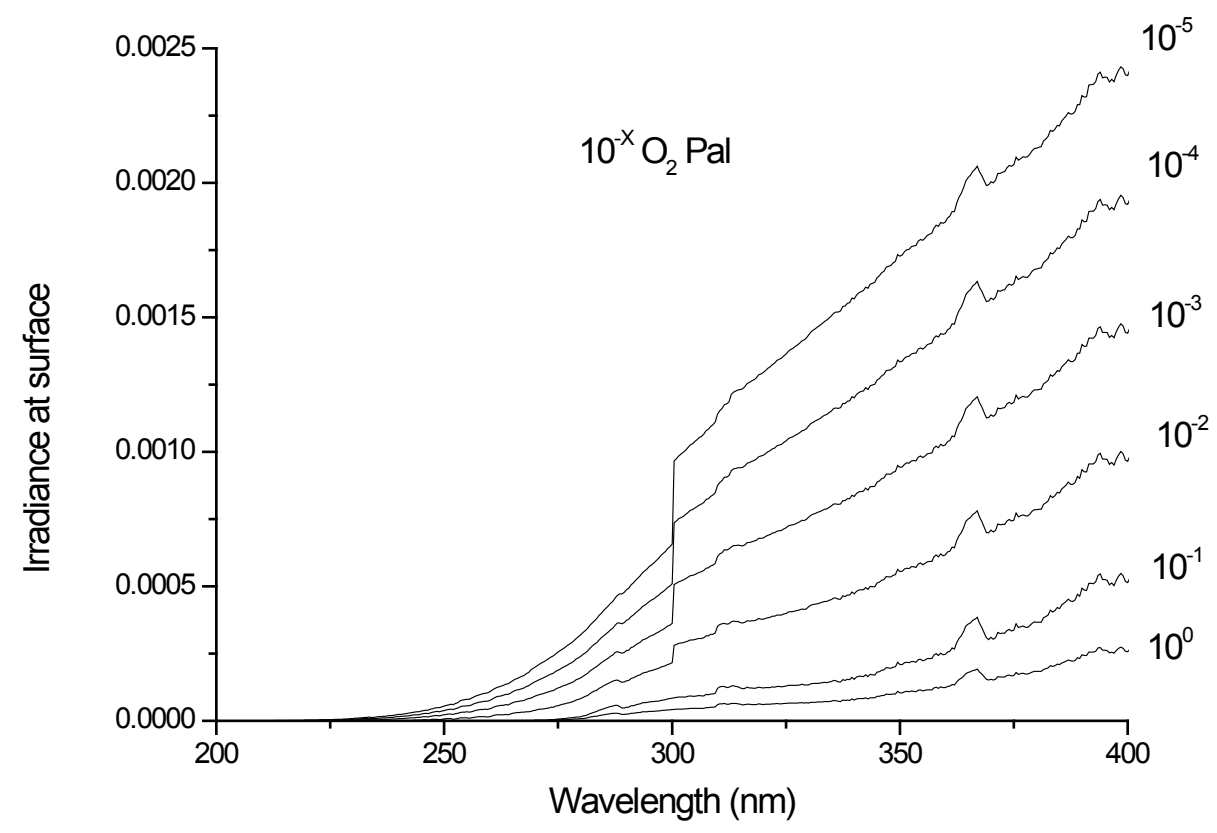

Fig. 44: Fluxo UV no solo, normalizado pelo fluxo do GRB no topo da atmosfera, para diversas pressões parciais de $\mathrm{O}_{2}$.

Nota-se claramente o aumento do fluxo de radiação sendo transmitida na região do UV, o qual é biologicamente muito ativo, conforme diminui a quantidade de $\mathrm{O}_{2}$ na atmosfera. Dessa maneira, surtos atingindo atmosferas mais anóxicas seriam mais danosos à biosfera.

\subsection{Soft-gamma repeaters}

\subsubsection{Efeitos sobre um planeta}

Nesta seção iremos utilizar a sistemática que desenvolvemos para o estudo da interação de GRBs com um planeta para outra fonte de radiação de alta energia, os SoftGamma Repeaters - SGR (Galante and Horvath 2007).

Essas fontes astrofísicas emitem pulsos regulares em raios-X, estando normalmente associadas a estrelas de nêutrons fortemente magnetizadas em rotação (magnetares) (Woods 2004). Todas as fontes, no entanto, apresentaram atividade esporádica muito mais intensa que a emissão regular, em eventos conhecidos como flares ou giant flares. A duração do evento de pico é de cerca de $0.2 \mathrm{~s}$, com uma fase de decaimento de cerca de $400 \mathrm{~s}$, modulada com periodicidade de cerca de $1 \mathrm{~s}$, associada à 
rotação da estrela de nêutrons. A emissão durante o pico é muito mais dura que na fase de decaimento, chegando a $175 \mathrm{keV}$, em comparação com $10 \mathrm{keV}$ da cauda.

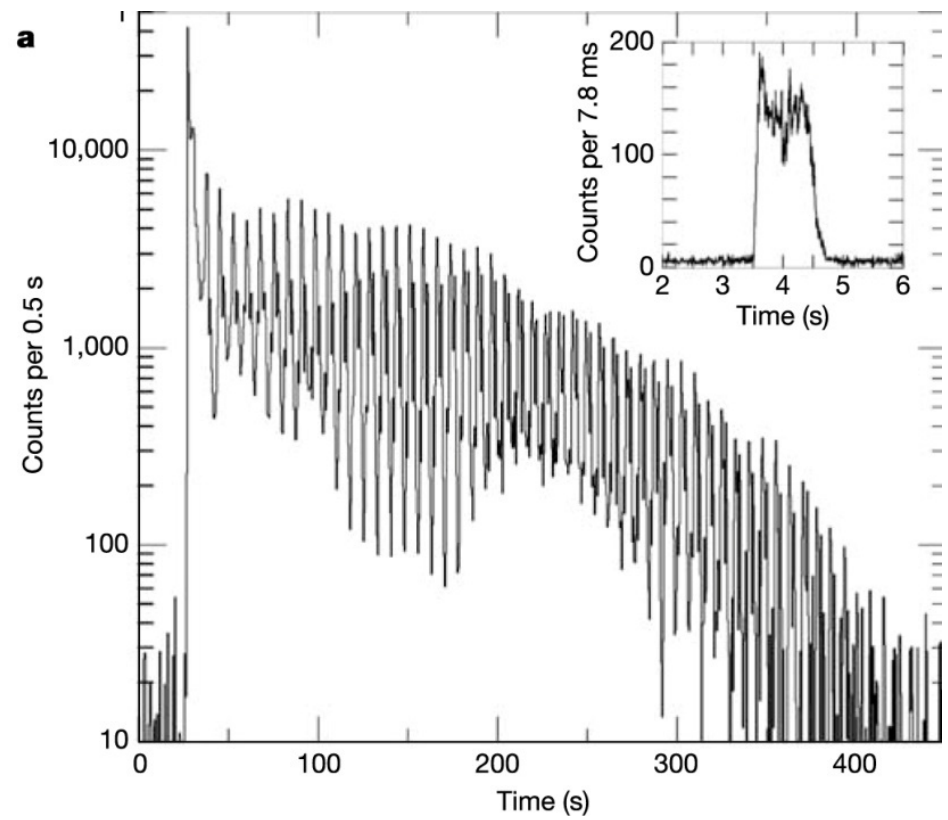

Fig. 45: Curva de luz do SGR 1806-20 durante seu episódio de giant flare em 27/12/2004 (Hurley, Boggs et al. 2005).

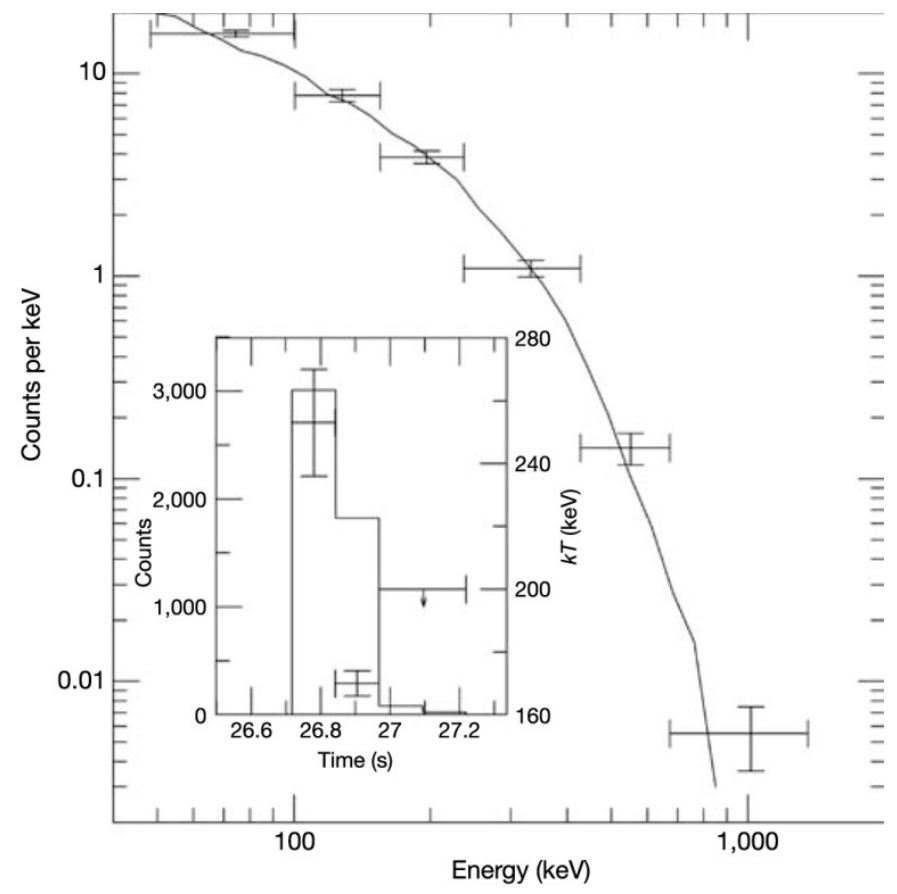

Fig. 46: Espectro em energia da emissão durante o flare do SGR 1806-20 (Hurley, Boggs et al. 2005).

Quatro desses eventos foram observados até o momento na Galáxia e Grande Nuvem de Magalhães (SGR 1627-41, SGR 1900+14, SGR 0526-66, SGR 1806-20). 
A emissão de energia está ligada ao decaimento do forte campo magnético do magnetar $\left(\sim 10^{15} \mathrm{G}\right)$, tendo sido observados com intervalo de $\sim 10$ anos.

Iremos utilizar como referência o evento de giant flare do SGR 1806-20, cuja curva de luz e espectro da emissão inicial estão apresentados nas Fig. 45 e 46 . A energética do surto pode ser resumida como:

- Fluxo no pico: $\mathrm{F}_{\text {peak }}>0.3 \mathrm{erg} / \mathrm{cm}^{2}$ (Nakar, Piran et al. 2005)

- Distância estimada: $6.4 k p c<\mathrm{D}<9.8 \mathrm{kpc}$ (Cameron, Chandra et al. 2005)

- Ângulo de colimação: $\Delta \Omega \sim 0.03 \operatorname{sr}$ (Yamazaki, Ioka et al. 2005)

- Luminosidade isotrópica $\gamma: 1.5 \times 10^{45} \mathrm{erg} \leq L_{\text {peak }}^{\text {iso }} \leq 3.5 \times 10^{45} \mathrm{erg}$

- Luminosidade $\gamma$ colimada: $3.5 \times 10^{43} \mathrm{erg} \leq L_{\text {peak }}^{\text {beam }} \leq 0.8 \times 10^{44} \mathrm{erg}$

A principal contribuição do estudo destas fontes é que suas distâncias são conhecidas e as curvas de luz quase idênticas, permitindo uma "calibração" dos efeitos biológicos muito mais confiável que aquela obtida para os GRB clássicos. Temos a vantagem de conhecermos suas fontes, apesar de ainda não sabermos se o evento de flare é único ou recorrente na vida de um magnetar. Adotando a mesma sistemática usada na seção 3.3 para GRB, podemos calcular as distâncias $D_{10}$ para esse evento. Os resultados desses cálculos estão apresentados na Tabela 6 . 
Tabela 6: Distâncias para depleção de $90 \%$ da população pelos 4 efeitos descritos para GRB extrapolados para o evento de flare do SGR 1806-20, mostrando os maiores alcances para o flash de UV. Os intervalos nas distâncias refletem as incertezas na taxa de conversão $\gamma$ para UV.

\begin{tabular}{|c|c|c|c|}
\hline \multirow{2}{*}{$\begin{array}{c}\text { Efeito } \\
\text { planetário }\end{array}$} & \multirow{2}{*}{ Organismo teste } & \multicolumn{2}{|c|}{$\mathbf{D}_{\mathbf{1 0}}$ (pc) } \\
\cline { 3 - 4 } & & Atmosfera fina & Atmosfera atual \\
\hline \multirow{2}{*}{ Flash $\gamma$} & E.coli & $0.06-0.09$ & $-^{*}$ \\
\cline { 2 - 4 } & D.radiodurans & $0.01-0.02$ & $-^{*}$ \\
\hline \multirow{2}{*}{ Flash UV } & E.coli & $7-35$ & $3-22$ \\
\cline { 2 - 4 } & D.radiodurans & $1-7$ & $1-4$ \\
\hline Depleção de & E.coli & $-^{*}$ & $-^{*}$ \\
\cline { 2 - 4 } O $_{3}$ & D.radiodurans & $-^{*}$ & $2-3$ \\
\hline \multirow{2}{*}{ CRJ } & E.coli & $-^{*}$ & 0.01 \\
\cline { 2 - 4 } & D.radiodurans & $-^{*}$ & negligible \\
\hline
\end{tabular}

* Depleção de $\mathrm{O}_{3}$ e CRJ não são relevantes para o caso de atmosfera fina, nem a distância para E.coli para depleção de $\mathrm{O}_{3}$, pois sua dose letal já está abaixo do fluxo normal sem o surto. $\mathrm{O}$ flash $\gamma$ é também desprezado para atmosferas espessas.

Esses eventos apresentam uma emissão muito semelhante à dos GRBs, porém deslocado para energias menores e com menor luminosidade total (Nakar, Piran et al. 2005). Eles são de interesse astrobiológico por estarem, de fato, localizados na Galáxia, e não em distâncias cosmológicas. Mesmo o evento SGR 1806-20, distante de alguns kpc da Terra foi capaz de afetar a ionosfera terrestre de modo mensurável (Campbell, Hill et al. 2005).

Pelos nossos cálculos da Tabela 6, eventos ocorrendo até dezenas de parsecs poderiam ter grande efeito sobre a biosfera terrestre.

\subsubsection{Estatística}

Com o propósito de avaliar a ocorrência de eventos de SGR próximos, calculamos a probabilidade de ocorrência de um flare em distâncias suficientemente pequenas para causar impacto na biologia da Terra, segundo a Tabela 6 (Galante and Horvath 2009).

Para isto foi realizado um cálculo Monte Carlos associando os eventos de flare aos seus possíveis progenitores, estrelas de nêutrons com alto campo magnético. Distribuímos as estrelas com as seguintes densidades: 


$$
\begin{array}{ll}
N(R)=N_{0}^{R} e^{-\frac{R}{R_{e}}} & \left(\mathrm{R}_{\mathrm{e}}=3800 \mathrm{pc}\right) \\
N(Z)=N_{0}^{Z} e^{-\frac{Z}{Z_{e}}} & \left(\mathrm{Z}_{\mathrm{e}}=70 \mathrm{pc}\right)
\end{array}
$$

Onde $N(R)$ é o número de estrelas em determinado raio galáctico e $N(Z)$ o número de estrelas em determinada altura do plano Galáctico, $R_{e}$ e $Z_{e}$ são as escalas de raio e altura, ou seja, onde o número de estrelas cai para 1/e do valor inicial.

Supusemos uma população estacionária de 15 fontes na Galáxia, com tempo de vida médio de $10^{5}$ anos. O código sorteia novas fontes ao final desse tempo de vida, seguindo a distribuição de estrelas de nêutrons.

Usamos três diferentes distâncias da Terra para contabilizar os flares de importância biológica: 20, 50 e 100pc. Sempre que um evento ocorresse dentro de uma dessas esferas ele era contabilizado. Os resultados estão apresentados nas Fig. 47, 48 e 49. 


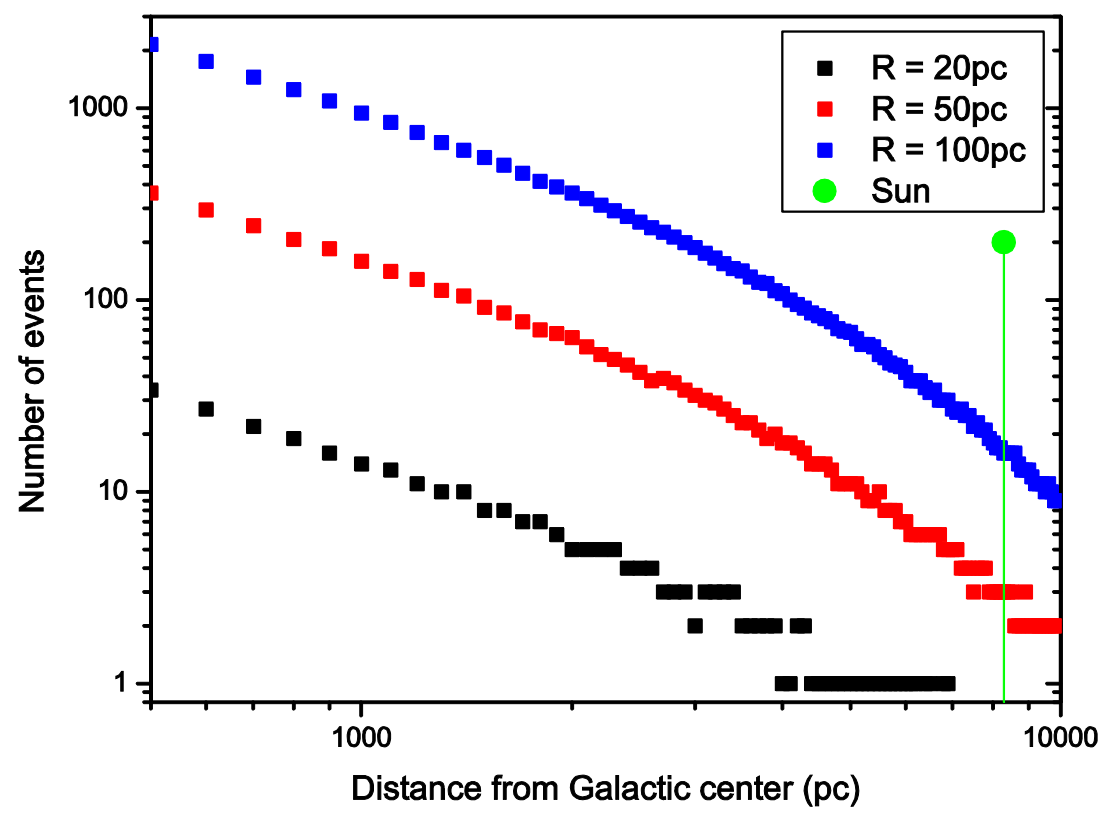

Fig. 47: Em azul estão os eventos ocorrendo a até 100pc de distância do planeta, em vermelho a até $50 \mathrm{pc}$ e em preto a até $20 \mathrm{pc}$, sendo a altura no plano Galáctico fixa o raio variável.

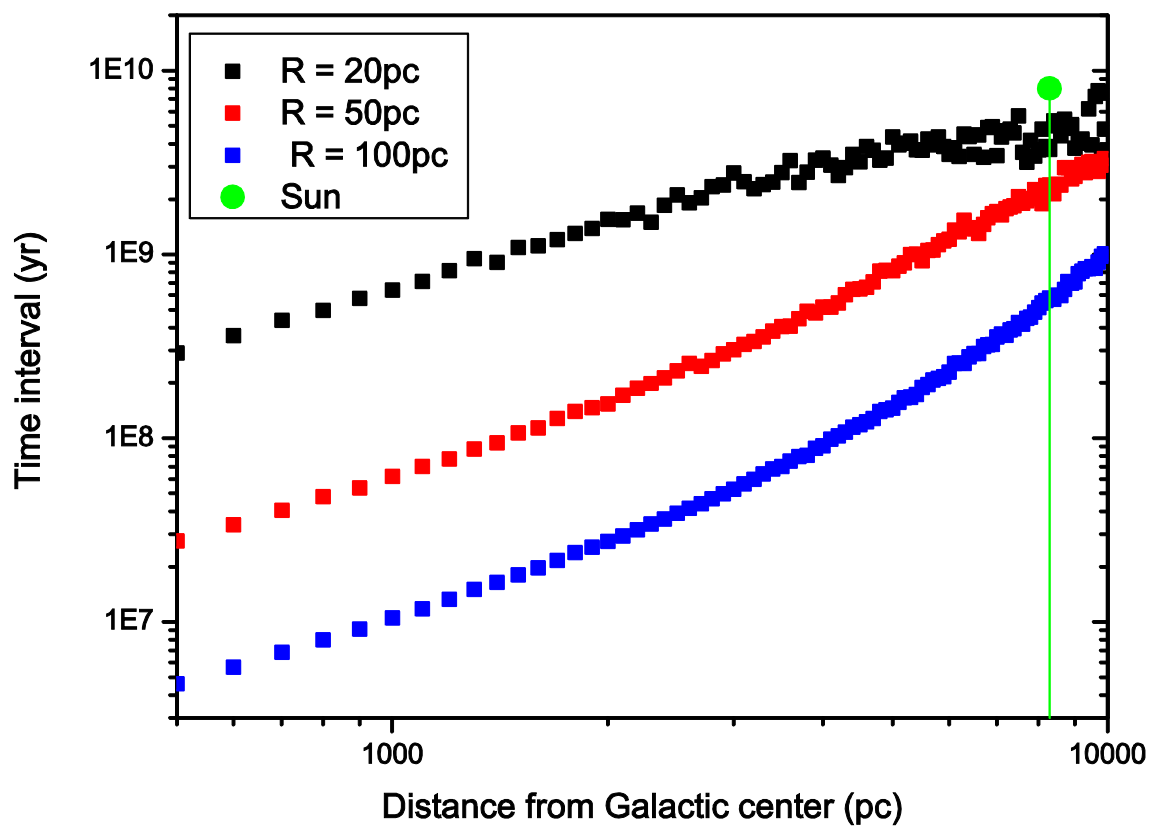

Fig. 48: Com altura fixa, o intervalo entre eventos como função do raio Galáctico, para as distâncias de 100 (azul), 50 (vermelho) e 20pc (preto). 

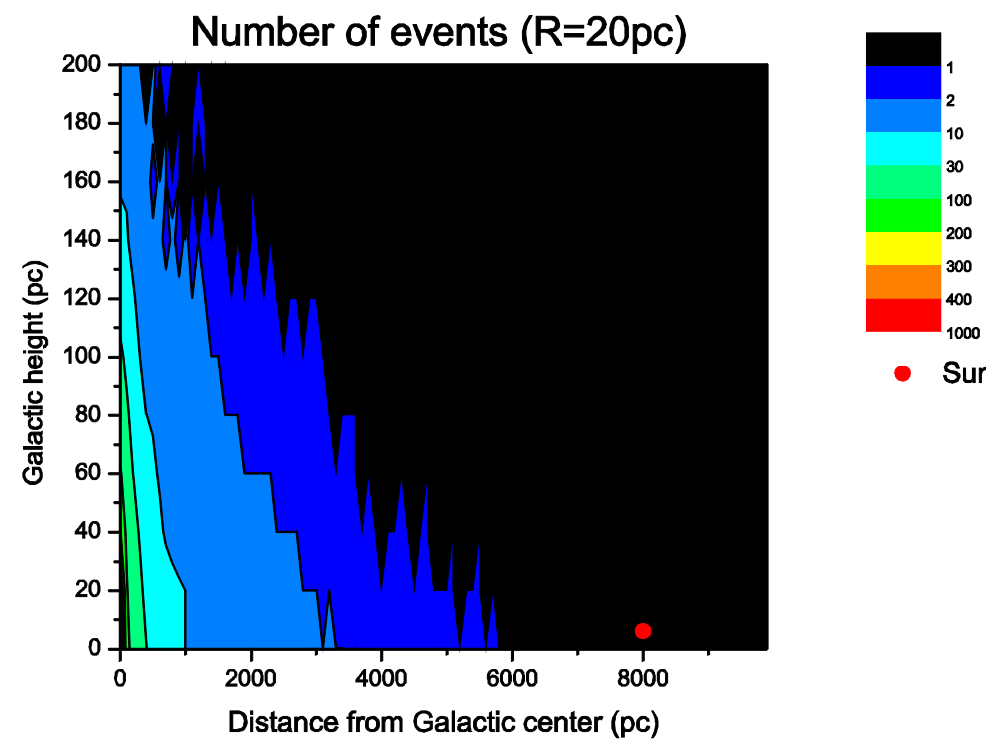

- Sun
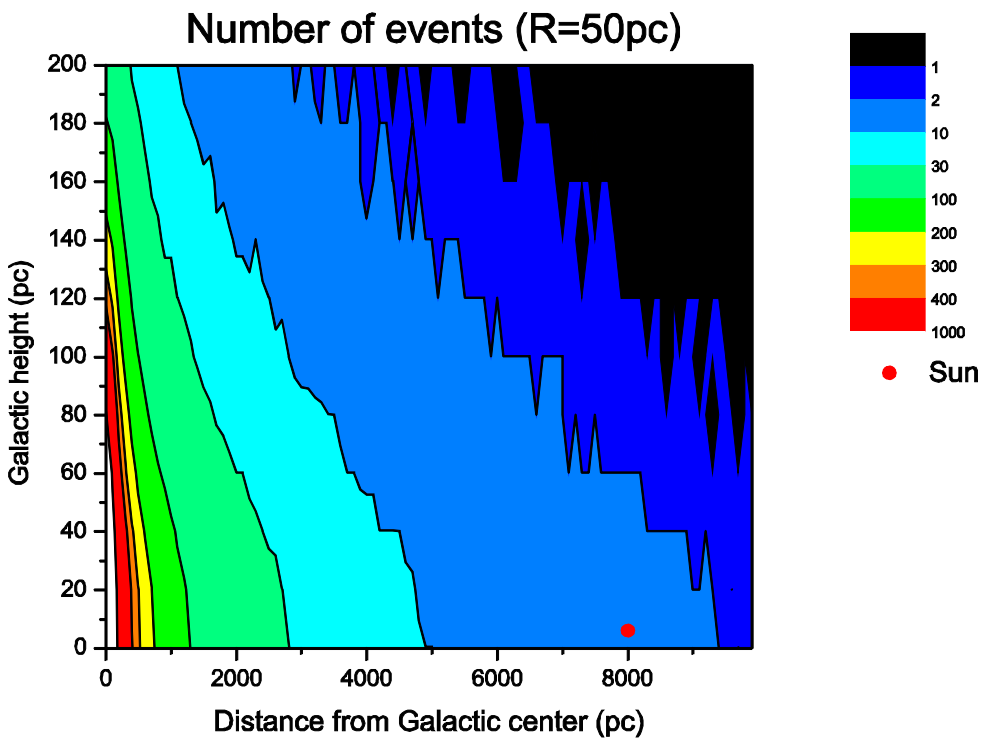

- Sun
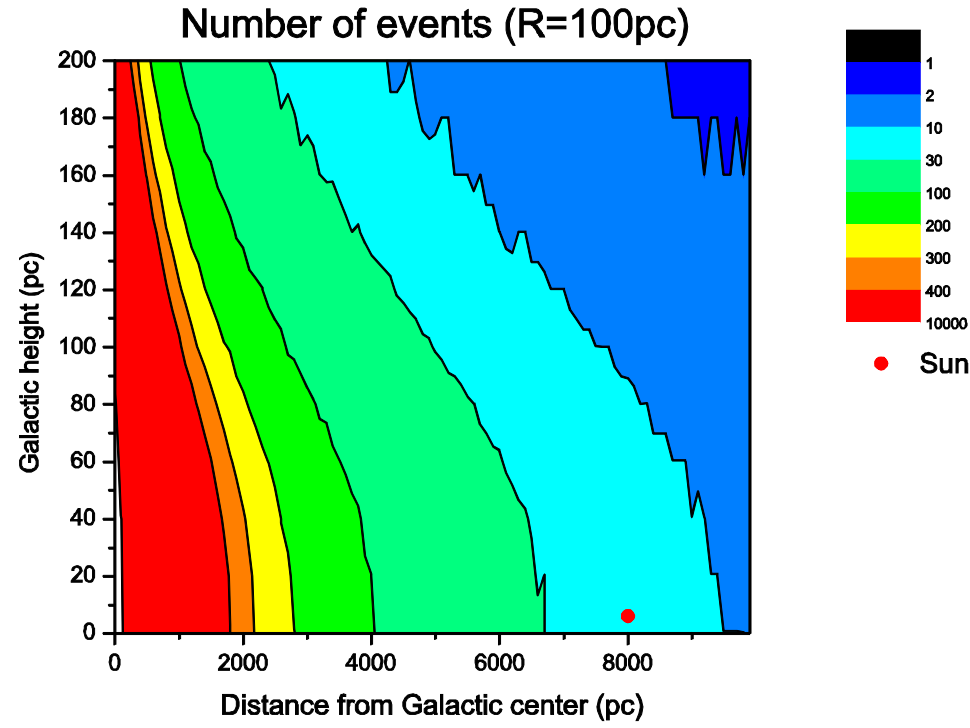

- Sun

Fig. 49: Número de eventos em distâncias menores que 20, 50 e 100pc, variando-se raio e altura Galácticos. 
Na Fig. 47 variamos a posição radial de nosso observador, porém o deixamos fixo na altura Galáctica. Para regiões próximas às do Sol, distante de $8 \mathrm{kpc}$ do centro Galáctico o número de fontes seria é baixo. Praticamente nenhum evento ocorreria a $20 \mathrm{pc}$ da Terra em uma escala de tempo de bilhões de anos. No entanto, expandindo o raio para 100pc já podemos esperar algumas dezenas de eventos.

A Fig. 48 apresenta o intervalo entre eventos ocorrendo em distâncias menores que os raios estabelecidos, novamente mantendo-se a altura fixa e variando o raio. Novamente, para o raio de $20 \mathrm{pc}$ na posição solar seria muito improvável a ocorrência de um evento com intervalos menores que 1 bilhão de anos.

A Fig. 49 apresenta o número de eventos ocorrendo dentro da esfera agora variando raio e altura Galáctica.

Apesar de a Terra estar em uma região praticamente livre das fontes, outros planetas situados em regiões mais interiores da Galáxia poderiam sofrer vários flares em sua proximidade durante o tempo de vida Galáctico. 


\section{Conclusões e perspectivas}

Desde o início, o projeto de tese enfrentou o desafio de ter que compreender os efeitos da radiação de alta energia emitida por Gamma-Ray Bursts desde sua região de emissão, em escalas de parsecs, até um distante planeta, a distâncias Galácticas.

Naturalmente, e além das incertezas intrínsecas, trabalhar num escopo amplo assim nos forçou a identificar algumas questões realmente novas, as quais procuramos responder utilizando ferramentas fenomenológicas e cálculos adequados. Algumas destas questões astronômicas abordadas compreenderam:

Progenitores;

Estatística de eventos;

Energia e colimação;

Efeitos observáveis sobre o ISM e remanescentes.

Na outro extremo do problema, sobre efeitos biológicos dos GRB, podemos destacar:

Probabilidade real de ocorrência;

Efeitos sobre a química atmosférica

Evidências observáveis de um evento ter ocorrido;

Efeitos microscópicos da radiação de alta energia;

Efeitos macroscópicos, ecológicos - extinção ou especiação?

No capítulo 2 trabalhamos com os efeitos da radiação sobre o meio interestelar circundante ao surto. $\mathrm{O}$ objetivo era buscar formas de distinguir o cenário de múltiplas supernovas de um GRB como progenitor das maiores supershells.

Usualmente, a radiação eletromagnética em cenários astrofísicos tem papel apenas de excitar estados eletrônicos ou ionizar átomos. Não há grande quantidade de fótons de alta energia disponíveis nas fontes astrofísicas. GRBs podem ser a exceção. Os fótons gerados por radiação síncrotron nos choques internos do jato (ou envelope) em expansão relativística têm energia suficiente para interagir diretamente com os 
núcleos dos átomos ao seu redor, causando a emissão de nêutrons, produzindo assim núcleos-filho ricos em prótons os quais decaem, alterando a distribuição de elementos e isótopos original.

Apesar da seção de choque extremamente baixa para a ocorrência dessas reações fotonucleares, a densidade de fótons gerado no surto com energia na região da ressonância gigante $(\sim 15 \mathrm{MeV})$ é grande o suficiente para que haja uma compensação. Além disso, as regiões de formação estelar, com densidades superiores às do ISM padrão, podem fornecer número suficiente de núcleos para que os fótons $\gamma$ interajam antes de escaparem. Dessa maneira, pudemos calcular algumas alterações para o caso de stripping de 2 nêutrons para os elementos até o ferro, incluindo algumas variações isotópicas, às quais estão listadas no final do capítulo 2. Infelizmente a seção de choque fotonuclear na ressonância é maior para núcleos mais pesados, mas esses são menos abundantes. Além disso, quanto mais pesado o núcleo, mais a ressonância se desloca para energias menores, onde os fótons são mais abundantes. Uma região privilegiada para reações fotonucleares seria, portanto, um GRB envolto por gás rico em metais. No entanto, parece haver uma preferência pela ocorrência de surtos em regiões pobres em metais, pela necessidade de progenitores massivos. Iremos prosseguir com os cálculos de maneira a incluir os eventos menos prováveis de stripping de $1 \mathrm{n}$, bem como utilizando diferentes espectros de abundância além da solar. Também incluiremos os fótons de menor energia responsáveis por aquecer, excitar e ionizar o gás do remanescente, criando outros possíveis diagnósticos espectroscópicos.

Apesar de sugestivos, esses cálculos não passam de exemplos que mostram a sua viabilidade, só tendo valor após observações serem feitas, sendo esse modelo comprovado ou refutado.

No capítulo 3 enfrentamos um problema novo sem tratamento específico na literatura: a interação entre eventos astrofísicos e sistemas biológicos. Trabalhar com problemas que envolvem mais de um ramo da Ciência é extremamente desafiador no modelo acadêmico da atualidade. No entanto, tivemos a oportunidade de participar de uma comunidade científica nascente, no Brasil e no mundo, a dos Astrobiológos que procura reatar essa comunicação para poder lidar com inevitáveis questões científicas que estão na interface de áreas, e que talvez sejam as questões mais difíceis que a Ciência tenha se proposto a resolver até hoje. Só o tempo, e o financiamento, dirá se essa empreitada dará frutos. 
A pergunta colocada nesse capítulo foi: GRB podem afetar a vida em um planeta? Quais as condições necessárias para que isso ocorra?

O resultado de nosso trabalho leva a pensar que, se um planeta for realmente iluminado pela irradiação $\gamma$ de um surto estando em distâncias de até $\sim 10 \mathrm{kpc}$, sua biosfera será seriamente alterada. Os efeitos começariam pela transmissão de parte do fluxo g diretamente através da atmosfera. Esse caso só é significativo se a atmosfera do planeta for rarefeita o suficiente para não absorver completamente os fótons, que, do contrário, acabariam por dissipar sua energia na forma de calor na atmosfera. A atmosfera primitiva terrestre é um exemplo de sistema que permitiria que fração significativa da radiação inicial atingisse o solo. Como a Terra teve atmosfera rarefeita por cerca de 3 bilhões de anos de sua existência, esse é a priori o caso mais importante.

Parte dos fótons $\gamma$ é reprocessada e reemitida na atmosfera em radiação auroreal, na região do UV e visível. Durante o surto, todo um hemisfério do planeta brilharia intensamente devido a esse processo, re-irradiando o solo com grandes doses de radiação. A radiação UV é altamente absorvida pelo DNA dos seres vivos expostos, causando danos talvez irreparáveis e uma grande destruição da vida, em especial dos organismos obrigatoriamente expostos à radiação, como o fitoplâncton marinho, base da cadeia alimentar. Mesmo a água dos mares pode não fornecer uma boa blindagem à radiação, pois ela pouco absorve a faixa de energia que mais danifica o DNA. Talvez até mesmo a vários de metros de profundidade os organismos marinhos poderiam ser comprometidos, alterando profundamente a cadeia alimentar e o equilíbrio ecológico.

Como essa rápida depleção na população de um tipo de organismo, como os fotossintetizantes marinhos, afetaria a ecologia global é um problema que não pudemos resolver, apesar de ter sido uma das questões a que nos havíamos proposto. Será abordado um trabalho futuro.

A deposição dos fótons ionizantes na atmosfera gera alterações químicas, sendo a mais estudada a depleção da camada de ozônio. Atualmente, há um consenso que ocorreria uma diminuição substancial diminuição na densidade deste gás na atmosfera após a iluminação pelo surto, a qual poderia perdurar por alguns anos. Essa diminuição causaria um aumento do fluxo UV solar no solo, sendo especialmente prejudicial aos organismos expostos.

Não é claro ainda se o excesso de NO produzido aumentaria a absorção da radiação solar, impedindo-a de chegar ao solo e fazendo com que a temperatura do planeta caia em um curto espaço de tempo, em uma espécie de inverno nuclear. Há 
sugestões que o resfriamento poderia mesmo disparar um evento de era do gelo global, conhecido com "Terra bola de neve" (Hoffman, Kaufman et al. 1998). Há ainda a possibilidade do $\mathrm{NO}$ em excesso ter atuado fertilizando os continentes e possibilitando sua colonização pela flora terrestre (Thomas, Melott et al. 2005).

Foi também estudada a possibilidade de aceleração massiva de raios cósmicos nos surtos, os quais atingiriam a atmosfera produzindo um chuveiro de partículas secundárias. Em especial, nos preocupamos com a geração de múons pelos prótons acelerados, pois essas partículas têm grande capacidade de penetração, poderiam, portanto, afetar os organismos mesmo no fundo dos mares e da terra. No entanto, a deposição de energia por essas partículas é muito baixa, e o efeito só seria relevante caso o surte ocorrer muito próximo ao planeta, contrariando o afirmado por Dar, Laor e Shaviv (1998) que propuseram esse mecanismo.

Em resumo, a radiação de um GRB poderia afetar a vida em um planeta tipoterrestre de forma significativa. Provavelmente não seria capaz de criar um cenário apocalíptico, com a esterilização global da vida, pois sempre haverá nichos onde microorganismos poderiam se abrigar da radiação e recolonizar o planeta após o surto. No entanto, GRBs e outros eventos astrofísicos energéticos poderiam estar associados a eventos de extinção em grande escala, como os observados no registro fóssil (Melott, Thomas et al. 2005). E GRBs tem a capacidade de depositar doses suficientes para eliminar grande parte dos organismos expostos mesmo estando em distâncias de dezenas de kpc, ou seja, mesmo estando em qualquer ponto da Galáxia.

Um dos grandes problemas para os GRBs é sua estatística. Observa-se uma taxa de ocorrência de cerca de 1 a cada milhão de anos por galáxia e, mesmo se ocorresse, como a emissão parece ser altamente colimada, a probabilidade do evento estar exatamente direcionado para o planeta torna-se pequena. GRBs longos têm origem cosmológica, e as galáxias jovens e pobres em metal, com forte taxa de formação estelar são locais privilegiados para sua ocorrência, o que não é o caso da Via Láctea. No entanto, no passado a Galáxia já foi mais ativa, podendo ter havido um surto. Além disso, surtos curtos não estão relacionados com estrelas massivas, mas sim com objetos compactos em coalescência, tornando-os possíveis fontes na Galáxia. Acreditamos que em escalas de tempo de $10^{9}$ anos torna-se estatisticamente possível que um evento de GRB tenha ocorrido na Galáxia, e talvez atingido o planeta. Talvez o registro desse evento esteja ainda no registro geológico, por alguma alteração isotópica sutil, como nós propomos no capítulo 2, ou até mesmo na Lua, onde os processos erosivos são mais 
lentos; ou ainda, esse registro pode estar incluído na história genética dos organismos vivos do planeta: um evento de irradiação global poderia ser uma força evolutiva instantânea - grande parte dos organismos com sistemas genéticos de reparação de danos por radiação, ou de proteção pouco eficientes seria imediatamente eliminada. Após essa grande liberação de nicho ecológico, os organismos sobreviventes recolonizariam o planeta e talvez essa forte pressão evolutiva tenha ficado gravada na memória genética como um gargalo em sua árvore filogenética, quando feita a partir de genes de proteção ou reparo de danos de radiação. E talvez possa eventualmente ser relacionada com um evento de extinção no registro fóssil.

Esperamos continuar contribuindo propondo testes e evidências da iluminação da Terra por surto. Para isso, continuaremos trabalhando no problema das reações fotonucleares para buscar evidências de variações isotópicas induzidas pelo fluxo $\gamma \mathrm{e}$ existe a idéia de prosseguirmos no desenvolvimento de um estudo filogenético que possa rastrear a origem dos sistemas de reparo de danos por radiação.

Na última seção do terceiro capítulo utilizamos a sistemática desenvolvida para os GRBs em outro evento astrofísico de alta energia, os giant flares de soft-gamma repeaters. Apesar de menos energéticos que GRBs, esses eventos possuem progenitores razoavelmente bem conhecidos, sendo estrelas de nêutrons com forte campo magnético, conhecidas como magnetares. Foram observados, até o momentos, 4 eventos desse tipo na Galáxia e na Nuvem de Magalhães, sendo que a radiação de um deles, SGR 2806-20 afetou de forma mensurável a ionosfera terrestre. Propomos que, ocorrendo a dezenas de parsecs, esses eventos possam causar grandes danos à biologia terrestre. Baseado em nosso modelo estatístico, um planeta na posição da Terra demoraria cerda de 1 bilhão de anos para que um eventos como esses acontecesse a essa distância.

Como conclusão final, percebemos que é possível que a vida no planeta seja afetada por eventos astrofísicos radiativos e que esses teriam grande impacto na ecologia do planeta, provavelmente causando um processo de extinção em massa, porém não de esterilização global. No entanto, a escala temporal para a ocorrência desse tipo de evento de alta energia deve ser de cerca de 1 bilhão de anos. Eventualmente, pode ser que ao menos um desses eventos tenha realmente afetado a Terra em sua história, o que é um incentivo para continuarmos trabalhando para propor maneiras de testar essa teoria. Por outro lado, em regiões em atividade de formação estelar as escalas de tempo seriam muito menores e os eventos de alta energia poderiam agir eliminando a vida que tenha surgido em planetas nessas regiões. 


\section{Referências}

Abbott, B., R. Abbott, et al. (2008). "Implications for the origin of GRB 070201 from LIGO observations." Astrophysical Journal 681(2): 1419-1430.

Abraham, J., M. Aglietta, et al. (2004). "Properties and performance of the prototype instrument for the Pierre Auger Observatory." Nuclear Instruments \& Methods in Physics Research Section a-Accelerators Spectrometers Detectors and Associated Equipment 523(1-2): 50-95.

Alvarez, L. W., W. Alvarez, et al. (1980). "Extraterrestrial Cause for the CretaceousTertiary Extinction." Science 208(4448): 1095-1108.

Alvarez, W., E. G. Kauffman, et al. (1984). "Impact Theory of Mass Extinctions and the Invertebrate Fossil Record." Science 223(4641): 1135-1141.

Anders, E. and N. Grevesse (1989). "ABUNDANCES OF THE ELEMENTS - METEORITIC AND SOLAR." Geochimica Et Cosmochimica Acta 53(1): 197-214.

Annis, J. (1999). "An astrophysical explanation fot "the great silence"." Journal of the British Interplanetary Society 52: 19-22.

Arrhenius, S. (1980). The Quest for Extraterrestrial Life [transl. by Goldsmith, D. die Untschau 7, 481 (1903)], University Science Books: 32-33.

Arzoumanian, Z., D. F. Chernoff, et al. (2002). "The velocity distribution of isolated radio pulsars." Astrophysical Journal 568(1): 289-301.

Atkins, R., W. Benbow, et al. (2003). "The high-energy gamma-ray fluence and energy spectrum of GRB 970417a from observations with Milagrito." Astrophysical Journal 583(2): 824-832.

Atkins, R., W. Benbow, et al. (2000). "Evidence for TeV emission from GRB 970417a." Astrophysical Journal 533(2): L119-L122.

Atoyan, A., J. Buckley, et al. (2006). "A gamma-ray burst remnant in our galaxy: HESS J1303-631." Astrophysical Journal 642(2): L153-L156.

B. Paczynski, P. H. (2005). "Gamma-ray bursts from quark stars." Monthly Notices of the Royal Astronomical Society: Letters 362(1): L4-L7.

Band, D., J. Matteson, et al. (1993). "BATSE OBSERVATIONS OF GAMMA-RAY BURST SPECTRA .1. SPECTRAL DIVERSITY." Astrophysical Journal 413(1): 281-292. 
Battista, J. R. (1997). "Against all odds: The survival strategies of Deinococcus radiodurans." Annual Review of Microbiology 51: 203-224.

Becquerel, H. (1901). "On some chemical effects produced by radium radiation." Comptes Rendus Hebdomadaires Des Seances De L Academie Des Sciences 133: 709-712.

Becquerel, H. (1901). "The radioactivity of uranium." Comptes Rendus Hebdomadaires Des Seances De L Academie Des Sciences 133: 977-980.

Becquerel, H. and P. Curie (1901). "The physiological action of radium rays." Comptes Rendus Hebdomadaires Des Seances De L Academie Des Sciences 132: 12891291.

Benitez, N., J. Maiz-Apellaniz, et al. (2002). "Evidence for nearby supernova explosions." Physical Review Letters 88(8): 4.

Bhargavi, S. G., J. Rhoads, et al. (2003). Searching for GRB remnants in nearby galaxies. Gamma-Ray Burst Symposium, Santa Fe, NM, Amer Inst Physics.

Biermann, Peter L., G. Medina Tanco, et al. (2004). "The Last Gamma Ray Burst in Our Galaxy? On the Observed Cosmic Ray Excess at Particle Energy $1018 \mathrm{eV} . "$ The Astrophysical Journal Letters 604(1): L29-L32.

Blandford, R. D. and R. L. Znajek (1977). "ELECTROMAGNETIC EXTRACTION OF ENERGY FROM KERR BLACK-HOLES." Monthly Notices of the Royal Astronomical Society 179(2): 433-456.

Bloom, J. S., D. A. Frail, et al. (2003). "Gamma-ray burst energetics and the gamma-ray burst Hubble diagram: Promises and limitations." Astrophysical Journal 594(2): 674-683.

Bloom, J. S., S. C. Odewahn, et al. (1999). "The host galaxy of GRB 990123." Astrophysical Journal 518(1): L1-L4.

Bok, B. J. (1966). "Magellanic Clouds." Annual Review of Astronomy and Astrophysics 4(1): 95-144.

Bond, J. R., W. D. Arnett, et al. (1984). "THE EVOLUTION AND FATE OF VERY MASSIVE OBJECTS." Astrophysical Journal 280(2): 825-847.

Bregman, J. N. (1980). "THE GALACTIC FOUNTAIN OF HIGH-VELOCITY CLOUDS." Astrophysical Journal 236(2): 577-591. 
Briggs, M. S. (2009). "BATSE Skymap." Retrieved 30/03/2009, from http://www.batse.msfc.nasa.gov/batse/grb/skymap/.

Briggs, M. S., D. L. Band, et al. (1999). "Observations of GRB 990123 by the Compton Gamma Ray Observatory." Astrophysical Journal 524(1): 82-91.

Briggs, M. S., W. S. Paciesas, et al. (1996). "BATSE observations of the large-scale isotropy of gamma-ray bursts." Astrophysical Journal 459(1): 40-63.

Bromm, V., P. S. Coppi, et al. (2002). "The formation of the first stars. I. The primordial star-forming cloud." Astrophysical Journal 564(1): 23-51.

Bromm, V. and A. Loeb (2006). "High-redshift gamma-ray bursts from population III progenitors." Astrophysical Journal 642(1): 382-388.

Brown, B. A. and B. H. Wildenthal (1988). "STATUS OF THE NUCLEAR SHELL-MODEL." Annual Review of Nuclear and Particle Science 38: 29-66.

Bruhweiler, F. C., M. A. Fitzurka, et al. (1991). "A LARGE SUPERSHELL H-II REGION COMPLEX IN THE LARGE MAGELLANIC CLOUD AND THE INTERSTELLAR ENVIRONMENT OF SN-1987A." Astrophysical Journal 370(2): 551-\&.

Bruhweiler, F. C., T. R. Gull, et al. (1980). "STELLAR WINDS, SUPER-NOVAE, AND THE ORIGIN OF THE H-I SUPERSHELLS." Astrophysical Journal 238(1): L27-L30.

Cameron, P. B., P. Chandra, et al. (2005). "Detection of a radio counterpart to the 27 December 2004 giant flare from SGR 1806-20." Nature 434(7037): 1112-1115.

Campbell, P., M. Hill, et al. (2005) "SGR1806: Detection of a Sudden Ionospheric Disturbance. GCN Circ. 2932." http://gcn.gsfc.nasa.gov/gen/gen3/2932.gen3.

Canfield, D. E., K. S. Habicht, et al. (2000). "The Archean Sulfur Cycle and the Early History of Atmospheric Oxygen." Science 288(5466): 658-661.

Catling, D. C. and M. W. Claire (2005). "How Earth's atmosphere evolved to an oxic state: A status report." Earth and Planetary Science Letters 237(1-2): 1-20.

Catling, D. C., K. J. Zahnle, et al. (2001). "Biogenic methane, hydrogen escape, and the irreversible oxidation of early Earth." Science 293(5531): 839-843.

Chevalier, R. A. (1974). "The Evolution of Supernova Remnants. Spherically Symmetric Models." Astrophysical Journal 188: 501-516.

Chevalier, R. A. and J. Gardner (1974). "The Evolution of Supernova Remnants. 11. Models of an Explosion in a Plane-Stratified Medium." Astrophysical Journal 192: $457-464$. 
Chomaz, P. (1997). Collective excitations in nuclei. Ecole Internationale Joliot Curie STRUCTURE NUCLEAIRE : un nouvel horizon GANIL (Caen, France).

Christlieb, N., M. S. Bessell, et al. (2002). "A stellar relic from the early Milky Way." Nature 419(6910): 904-906.

Chyba, C. F., P. J. Thomas, et al. (1990). "COMETARY DELIVERY OF ORGANICMOLECULES TO THE EARLY EARTH." Science 249(4967): 366-373.

Cline, T. L., U. D. Desai, et al. (1973). "ENERGY SPECTRA OF COSMIC GAMMA-RAY BURSTS." Astrophysical Journal 185(1): L1-L5.

Cockell, C. S. (1998). "Biological effects of high ultraviolet radiation on early Earth - a theoretical evaluation." Journal of Theoretical Biology 193(4): 717-729.

Cockell, C. S. (2000). "The ultraviolet history of the terrestrial planets - implications for biological evolution." Planetary and Space Science 48(2-3): 203-214.

Cockell, C. S. (2000). "Ultraviolet radiation and the photobiology of earth's early oceans." Origins of Life and Evolution of the Biosphere 30(5): 467-499.

Cockell, C. S. (2002). "Photobiological uncertainties in the Archaean and post-Archaean world." International Journal of Astrobiology 1(01): 31-38.

Cockell, C. S. and G. Horneck (2001). "The history of the UV radiation climate of the earth - Theoretical and space-based observations." Photochemistry and Photobiology 73(4): 447-451.

Cockell, C. S., P. Rettberg, et al. (2003). "Measurements of microbial protection from ultraviolet radiation in polar terrestrial microhabitats." Polar Biology 26(1): 6269.

Cohen, E. and T. Piran (1995). "THE DISTRIBUTION OF COSMOLOGICAL GAMMA-RAY BURSTS." Astrophysical Journal 444(1): L25-L28.

Costa, E., F. Frontera, et al. (1997). "Discovery of an X-ray afterglow associated with the gamma-ray burst of 28 February 1997." Nature 387(6635): 783-785.

Crutzen, P. J. and C. Bruhl (1996). "Mass extinctions and supernova explosions." Proceedings of the National Academy of Sciences of the United States of America 93(4): 1582-1584.

Curie, P. and A. Laborde (1903). "On heat spontaneously extricated by salts of radium." Comptes Rendus Hebdomadaires Des Seances De L Academie Des Sciences 136: 673-675. 
Cusumano, G., V. Mangano, et al. (2006). "Gamma-ray bursts: Huge explosion in the early Universe." Nature 440(7081): 164-164.

Dar, A. and A. De Rujula (2004). "Towards a complete theory of gamma-ray bursts." Physics Reports-Review Section of Physics Letters 405(4): 203-278.

Dar, A., A. Laor, et al. (1998). "Life Extinctions by Cosmic Ray Jets." Physical Review Letters 80(26): 5813.

Day, T. A. and P. J. Neale (2002). "Effects of UV-B radiation on terrestrial and aquatic primary producers." Annual Review of Ecology and Systematics 33: 371-396.

De La Vega, U. P., P. Rettberg, et al. (2005). "Sensitivity to polychromatic UV-radiation of strains of deinococcus radiodurans differing in their DNA repair capacity." International Journal of Radiation Biology 81(8): 601 - 611.

Dole, M. (1949). "The History of Oxygen." Science 109(2822): 77-96.

Efremov, Y. N. (1999). "Stellar arcs and gamma-ray bursts." Astronomy Letters-a Journal of Astronomy and Space Astrophysics 25(2): 74-79.

Eichler, D., M. Livio, et al. (1989). "NUCLEOSYNTHESIS, NEUTRINO BURSTS AND GAMMA-RAYS FROM COALESCING NEUTRON STARS." Nature 340(6229): 126128.

Elliott, J. P. (1958). "COllective MOtiON IN THE NUCLEAR SHELL MODEL .1. CLASSIFICATION SCHEMES FOR STATES OF MIXED CONFIGURATIONS." Proceedings of the Royal Society of London Series a-Mathematical and Physical Sciences 245(1240): 128-145.

Elliott, J. P. (1958). "COlLeCTIVE MOTION IN THE NUCLEAR SHELL MODEL .2. THE INTRODUCTION OF INTRINSIC WAVE-FUNCTIONS." Proceedings of the Royal Society of London Series a-Mathematical and Physical Sciences 245(1243): 562581.

Ellis, J. and D. N. Schramm (1995). "COULD A NEARBY SUPERNOVA EXPLOSION HAVE CAUSED A MASS EXTINCTION." Proceedings of the National Academy of Sciences of the United States of America 92(1): 235-238.

Ferrière, K. M. (2001). "The interstellar environment of our galaxy." Reviews of Modern Physics 73(4): 1031.

Fishman, G. J., C. A. Meegan, et al. (1994). "THE 1ST BATSE GAMMA-RAY BURST CATALOG." Astrophysical Journal Supplement Series 92(1): 229-283. 
Frail, D. A., S. R. Kulkarni, et al. (1997). "The radio afterglow from the gamma-ray burst of 8 May 1997." Nature 389(6648): 261-263.

Frail, D. A., S. R. Kulkarni, et al. (2001). "Beaming in gamma-ray bursts: Evidence for a standard energy reservoir." Astrophysical Journal 562(1): L55-L58.

Fryer, C. L., S. E. Woosley, et al. (1999). "Formation rates of black hole accretion disk gamma-ray bursts." Astrophysical Journal 526(1): 152-177.

Gaisser, T. (1992). Cosmic Rays and Particle Physics, Cambridge University Press.

Galama, T. J., P. M. Vreeswijk, et al. (1998). "An unusual supernova in the error box of the [gamma]-ray burst of 25 April 1998." Nature 395(6703): 670-672.

Galama, T. J., R. Wijers, et al. (1998). "Radio-to-X-ray spectrum of GRB 970508 on 1997 May 21.0 UT." Astrophysical Journal 500(2): L97-L100.

Galante, D. and J. E. Horvath (2007). "Biological effects of gamma-ray bursts: distances for severe damage on the biota." International Journal of Astrobiology 6(01): 19-26.

Galante, D. and J. E. Horvath (2009). "Biological relevance of giant flares from SoftGamma Repeaters (accepted)." Astrobiology.

Gascón, J., A. Oubiña, et al. (1995). "Sensitivity of selected bacterial species to UV radiation." Current Microbiology 30(3): 177-182.

Gascon, J., A. Oubina, et al. (1995). "SENSITIVITY OF SELECTED BACTERIAL SPECIES TO UV-RADIATION." Current Microbiology 30(3): 177-182.

Gehrels, N., G. Chincarini, et al. (2004). "The Swift Gamma-Ray Burst Mission." The Astrophysical Journal 611(2): 1005-1020.

Gehrels, N., C. M. Laird, et al. (2003). "Ozone depletion from nearby supernovae." Astrophysical Journal 585(2): 1169-1176.

Ghirlanda, G., G. Ghisellini, et al. (2006). "Gamma-ray bursts as standard candles to constrain the cosmological parameters." New Journal of Physics 8: 37.

Ghosal, D., M. V. Omelchenko, et al. (2005). "How radiation kills cells: Survival of Deinococcus radiodurans and Shewanella oneidensis under oxidative stress." Fems Microbiology Reviews 29(2): 361-375.

Goodman, J. (1986). "ARE GAMMA-RAY BURSTS OPTICALLY THICK." Astrophysical Journal 308(2): L47-L50. 
Grindlay, J., S. P. Zwart, et al. (2006). "Short gamma-ray bursts from binary neutron star mergers in globular clusters." Nat Phys 2(2): 116-119.

Hader, D. P. and F. L. Figueroa (1997). "Photoecophysiology of marine macroalgae." Photochemistry and Photobiology 66(1): 1-14.

Hader, D. P. and R. P. Sinha (2005). "Solar ultraviolet radiation-induced DNA damage in aquatic organisms: potential environmental impact." Mutation ResearchFundamental and Molecular Mechanisms of Mutagenesis 571(1-2): 221-233.

Hader, D. P. and R. C. Worrest (1991). "EFFECTS OF ENHANCED SOLAR ULTRAVIOLETRADIATION ON AQUATIC ECOSYSTEMS." Photochemistry and Photobiology 53(5): 717-725.

Harrison, F. A., J. S. Bloom, et al. (1999). "Optical and radio observations of the afterglow from GRB 990510: Evidence for a jet." Astrophysical Journal 523(2): L121-L124.

Hearn, A. G. (1961). "ABSORPTION OF OZONE IN ULTRA-VIOLET AND VISIBLE REGIONS OF SPECTRUM." Proceedings of the Physical Society of London 78(504): 932-\&.

Heger, A., C. L. Fryer, et al. (2003). "How massive single stars end their life." Astrophysical Journal 591(1): 288-300.

Heiles, C. (1979). "H-I SHELLS AND SUPERSHELLS." Astrophysical Journal 229(2): 533-\&. Heiles, C. (1987). "SUPERNOVAE VERSUS MODELS OF THE INTERSTELLAR-MEDIUM AND THE GASEOUS HALO." Astrophysical Journal 315(2): 555-566.

Hillas, A. M. (1971). Proc 17th ICRC 8: 193.

Hjorth, J., J. Sollerman, et al. (2003). "A very energetic supernova associated with the gamma-ray burst of 29 March 2003." Nature 423(6942): 847-850.

Hoffman, P. F., A. J. Kaufman, et al. (1998). "A Neoproterozoic snowball earth." Science 281(5381): 1342-1346.

Hogg, D. W. (1999). "Distance measures in cosmology." arXiv:astro-ph/9905116v4.

Hollaender, A. and C. P. Swanson (1946). "THE SUN AS A SOURCE OF MUTATION PRODUCING RADIATION." American Journal of Botany 33(10): 830-830.

Horneck, G., P. Rettberg, et al. (2001). "Protection of bacterial spores in space, a contribution to the discussion on Panspermia." Origins of Life and Evolution of the Biosphere 31(6): 527-547. 
Hunter, D. A. (1994). "IMAGING AND SPECTROSCOPY OF IONIZED SHELLS AND SUPERSHELLS IN THE LARGE MAGELLANIC CLOUD." Astronomical Journal 107(2): 565-581.

Hurley, K., S. E. Boggs, et al. (2005). "An exceptionally bright flare from SGR 1806-20 and the origins of short-duration gamma-ray bursts." Nature 434(7037): 10981103.

IAEA (2000). "IAEA-TECDOC-1178, Handbook of photonuclear data for applications: Cross sections and spectra."

Igumentshchev, I. V., B. M. Shustov, et al. (1990). "DYNAMICS OF SUPERSHELLS BLOW-OUT." Astronomy and Astrophysics 234(1-2): 396-402.

Ishkhanov, B. S., N. P. Yudin, et al. (2000). "Giant resonances in atomic nuclei." Physics of Particles and Nuclei 31(2): 149-169.

Kamerdzhiev, S. P. and S. F. Kovalev (2006). "Photonuclear data and modern physics of giant resonances." Physics of Atomic Nuclei 69(3): 418-432.

Kasting, J. F. (1993). "EARTHS EARLY ATMOSPHERE." Science 259(5097): 920-926.

Kasting, J. F., D. P. Whitmire, et al. (1993). "HABITABLE ZONES AROUND MAINSEQUENCE STARS." Icarus 101(1): 108-128.

Kawabata, K. S., J. Deng, et al. (2003). "On the spectrum and spectropolarimetry of type Ic hypernova SN 2003dh/GRB 030329." Astrophysical Journal 593(1): L19L22.

Kennicutt, R. C., B. K. Edgar, et al. (1989). "PROPERTIES OF H-II REGION POPULATIONS IN GALAXIES .2. THE H-II REGION LUMINOSITY FUNCTION." Astrophysical Journal 337(2): 761-781.

Klebesadel, R., I. B. Strong, et al. (1973). "OBSERVATIONS OF GAMMA-RAY BURSTS OF COSMIC ORIGIN." Astrophysical Journal 182(2): L85-L88.

Knauf, G. M. (1959). "RADIATION PROBLEMS RELATED TO SPACE FLIGHT." Journal of Investigative Dermatology 32(2): 157-163.

Knoll, A. H. (1992). "THE EARLY EVOLUTION OF EUKARYOTES - A GEOLOGICAL PERSPECTIVE." Science 256(5057): 622-627.

Kosugi, G., Y. Mizumoto, et al. (2004). "Spectral evolution of the GRB 030329 afterglow: Detection of the supernova nebular phase emissions." Publications of the Astronomical Society of Japan 56(1): 61-68. 
Kotzur, I. (1994). "W.C. Rontgen: a new type of ray." Radiology 193(2): 329-332.

Kouveliotou, C., C. A. Meegan, et al. (1993). "IDENTIFICATION OF 2 CLASSES OF GAMMA-RAY BURSTS." Astrophysical Journal 413(2): L101-L104.

Kroupa, P. (2002). "The Initial Mass Function of Stars: Evidence for Uniformity in Variable Systems." Science 295(5552): 82-91.

Kulkarni, S. R., S. G. Djorgovski, et al. (1998). "Identification of a host galaxy at redshift $z=3.42$ for the [gamma]-ray burst of 14 December 1997." Nature 393(6680): 35-39.

Lamb, D. Q., T. Q. Donaghy, et al. (2005). "A unified jet model of X-ray flashes, X-rayrich gamma-ray bursts, and gamma-ray bursts. I. Power-law-shaped universal and top-hat-shaped variable opening angle jet models." Astrophysical Journal 620(1): 355-378.

Lipari, P. (1993). "Tev muons in hadronic showers." Astroparticle Physics 1(4): 399-415.

Lodders, K. (2003). "Solar system abundances and condensation temperatures of the elements." Astrophysical Journal 591(2): 1220-1247.

Loeb, A. and R. Perna (1998). "Are H I supershells the remnants of gamma-ray bursts?" Astrophysical Journal 503(1): L35-L37.

Lowe, D. R. (1980). "Stromatolites 3,400-Myr old from the Archean of Western Australia." Nature 284(5755): 441-443.

Lugones, G., C. R. Ghezzi, et al. (2002). "Asymmetric core combustion in neutron stars and a potential mechanism for gamma-ray bursts." Astrophysical Journal 581(2): L101-L104.

Maciejewski, W., E. M. Murphy, et al. (1996). "The aquila supershell: A remnant of multiple supernovae." Astrophysical Journal 469(1): 238-\&.

Maclow, M. M. and R. McCray (1988). "SUPERBUBBLES IN DISK GALAXIES." Astrophysical Journal 324(2): 776-785.

Madronich, S., R. L. McKenzie, et al. (1998). "Changes in biologically active ultraviolet radiation reaching the Earth's surface." Journal of Photochemistry and Photobiology B-Biology 46(1-3): 5-19.

Martin, O., R. Cardenas, et al. (2009). "Short-term effects of Gamma Ray Bursts on habitable Earth-like Planets (accepted)." Astrophysics and Space Science. 
Matheson, T., P. M. Garnavich, et al. (2003). "Photometry and spectroscopy of GRB 030329 and its associated supernova 2003dh: The first two months." Astrophysical Journal 599(1): 394-407.

McCray, R. and M. Kafatos (1987). "SUPERSHELLS AND PROPAGATING STAR FORMATION." Astrophysical Journal 317(1): 190-196.

Melioli, C., F. Brighenti, et al. (2008). "Hydrodynamical simulations of Galactic fountains - I. Evolution of single fountains." Monthly Notices of the Royal Astronomical Society 388(2): 573-586.

Melosh, H. J. (1988). "THE ROCKY ROAD TO PANSPERMIA." Nature 332(6166): 687-688.

Melott, A. L., B. S. Lieberman, et al. (2004). "Did a gamma-ray burst initiate the late Ordovician mass extinction?" International Journal of Astrobiology 3(01): 55-61.

Melott, A. L., B. C. Thomas, et al. (2005). "Climatic and biogeochemical effects of a galactic gamma ray burst." Geophysical Research Letters 32(14): 5.

Meszaros, P. (2001). "Gamma-ray bursts: Accumulating afterglow implications, progenitor glues, and prospects." Science 291(5501): 79-84.

Meszaros, P. (2006). "Gamma-ray bursts." Reports on Progress in Physics 69(8): 22592321.

Meszaros, P. and M. J. Rees (1997). "Poynting jets from black holes and cosmological gamma-ray bursts." Astrophysical Journal 482(1): L29-L32.

Metzger, M. R., S. G. Djorgovski, et al. (1997). "Spectral constraints on the redshift of the optical counterpart to the gamma-ray burst of 8 May 1997." Nature 387(6636): 878-880.

Miller, G. E. and J. M. Scalo (1979). "INITIAL MASS FUNCTION AND STELLAR BIRTHRATE IN THE SOLAR NEIGHBORHOOD." Astrophysical Journal Supplement Series 41(3): 513-547.

Miller, S. L. and H. C. Urey (1959). "ORGANIC COMPOUND SYNTHESIS ON THE PRIMITIVE EARTH." Science 130(3370): 245-251.

Mix, L. J., J. C. Armstrong, et al. (2006). "The astrobiology primer: An outline of general knowledge - Version 1, 2006." Astrobiology 6(5): 735-813.

Nakamura, F. and M. Umemura (1999). "On the mass of Population III stars." Astrophysical Journal 515(1): 239-248. 
Nakamura, F. and M. Umemura (2002). "The stellar initial mass function in primordial galaxies." Astrophysical Journal 569(2): 549-557.

Nakar, E., T. Piran, et al. (2005). "Pure and loaded fireballs in soft gamma-ray repeater giant flares." Astrophysical Journal 635(1): 516-521.

Naoz, S. and O. Bromberg (2007). "An observational limit on the earliest gamma-ray bursts." Monthly Notices of the Royal Astronomical Society 380(2): 757-762.

Nealson, K. H. and P. G. Conrad (1999). "Life: past, present and future." Philosophical Transactions of the Royal Society of London Series B-Biological Sciences 354(1392): 1923-1939.

Newell, H. E. and J. E. Naugle (1960). "RADIATION ENVIRONMENT IN SPACE." Science 132(3438): 1465-1472.

Paczynski, B. (1986). "GAMMA-RAY BURSTERS AT COSMOLOGICAL DISTANCES." Astrophysical Journal 308(2): L43-L46.

Paczynski, B. (1998). "Are gamma-ray bursts in star-forming regions?" Astrophysical Journal 494(1): L45-L48.

Padoan, P., A. Nordlund, et al. (1997). "The universality of the stellar initial mass function." Monthly Notices of the Royal Astronomical Society 288(1): 145-152.

Pak, S., D. T. Jaffe, et al. (1998). "Molecular cloud structure in the magellanic clouds: Effect of metallicity." Astrophysical Journal 498(2): 735-756.

Panaitescu, A., P. Meszaros, et al. (2006). "Evidence for chromatic X-ray light-curve breaks in Swift gamma-ray burst afterglows and their theoretical implications." Monthly Notices of the Royal Astronomical Society 369(4): 2059-2064.

Peak, M. J., J. G. Peak, et al. (1984). "ULTRAVIOLET ACTION SPECTRA FOR DNA DIMER INDUCTION, LETHALITY, AND MUTAGENESIS IN ESCHERICHIA-COLI WITH EMPHASIS ON THE UVB REGION." Photochemistry and Photobiology 40(5): 613620.

Perna, R. and B. M. Gaensler (2004). "Are supershells powered by multiple supernovae? Modeling the radio pulsar population produced by $O B$ associations." Astrophysical Journal 606(1): 326-332.

Perna, R. and J. Raymond (2000). "Testing the multiple supernovae versus gamma-ray burst scenarios for giant HI supershells." Astrophysical Journal 539(2): 706-711. 
Perna, R., J. Raymond, et al. (2000). "Identifying gamma-ray burst remnants in nearby galaxies." Astrophysical Journal 533(2): 658-669.

Piran, T. and S. Ayal (2001). GRB remnants. Workshop Celebrating the First Year of the HETE Mission, Woods Hole, Ma, Amer Inst Physics.

Plume, R., D. T. Jaffe, et al. (1997). "Dense gas and star formation: Characteristics of cloud cores associated with water masers." Astrophysical Journal 476(2): 730749.

Powell, R. (2009). "The Hertzsprung Russel Diagram." Retrieved 30/03/2009, from http://www.atlasoftheuniverse.com/hr.html.

Project, T. H. H. (2007). Eta Carinae Nebula.

Razzaque, S., P. Meszaros, et al. (2004). "GeV and higher energy photon interactions in gamma-ray burst fireballs and surroundings." Astrophysical Journal 613(2): 1072-1078.

Rees, M. J. (2000). "A Review of Gamma Ray Bursts." Nuclear Physics A 663-664: 42c$55 c$.

Rhoads, J. E. (1997). "How to tell a jet from a balloon: A proposed test for beaming in gamma-ray bursts." Astrophysical Journal 487(1): L1-L4.

Rhoads, J. E. (1999). "The dynamics and light curves of beamed gamma-ray burst afterglows." Astrophysical Journal 525(2): 737-749.

Richard-Serre, C. (1971). CERN Report 71: 18.

Robersy, S., R. Cardenas, et al. (2008). Biological insights of population depletion under different radiation backgrounds

Rosswog, S. (2003). Gamma-ray bursts and their central engines. NATO Advanced Research Workshop on Superdense QCD Matter and Compact Stars, Yerevan, ARMENIA.

Rowan-Robinson, M. (2001). "The star formation history of the universe: An infrared perspective." Astrophysical Journal 549(2): 745-758.

Rozema, J., L. O. Bjorn, et al. (2002). "The role of UV-B radiation in aquatic and terrestrial ecosystems - an experimental and functional analysis of the evolution of UV-absorbing compounds." Journal of Photochemistry and Photobiology B-Biology 66(1): PII S1011-1344(01)00269-X. 
Ruderman, M. (1975). "THEORIES OF GAMMA-RAY BURSTS." Annals of the New York Academy of Sciences 262(OCT15): 164-180.

Ruderman, M. A. (1974). "POSSIBLE CONSEQUENCES OF NEARBY SUPERNOVA EXPLOSIONS FOR ATMOSPHERIC OZONE AND TERRESTRIAL LIFE." Science 184(4141): 1079-1081.

Rybicki, G. B. and A. P. Lightman (1979). Radiative processes in astrophysics. New York, Wiley.

Salpeter, E. E. (1955). "THE LUMINOSITY FUNCTION AND STELLAR EVOLUTION." Astrophysical Journal 121(1): 161-167.

Scalo, J. and J. C. Wheeler (2002). "Astrophysical and astrobiological implications of gamma-ray burst properties." Astrophysical Journal 566(2): 723-737.

Schaefer, H. J. (1952). "EXPOSURE HAZARD FROM COSMIC RADIATION AT EXTREME ALTITUDE AND IN FREE SPACE." Journal of the American Rocket Society 22(5): 277-283.

Shklovski, I. S. (1961). "ULTRAVIOLET RADIATION AND SOFT X-RAYS FROM THE SUN." Uspekhi Fizicheskikh Nauk 75(2): 351-\&.

Shu, F. H., F. C. Adams, et al. (1987). "STAR FORMATION IN MOLECULAR CLOUDS OBSERVATION AND THEORY." Annual Review of Astronomy and Astrophysics 25: $23-81$.

Silich, S., F. Elias, et al. (2008). "On the origin of the neutral hydrogen supershells: The ionized progenitors and the limitations of the multiple supernovae hypothesis." Astrophysical Journal 681(2): 1327-1333.

Sinha, R. P., M. Klisch, et al. (2001). "Responses of aquatic algae and cyanobacteria to solar UV-B." Plant Ecology 154(1-2): 219-+.

Sinha, R. P., H. D. Kumar, et al. (1995). "EFFECTS OF UV-B IRRADIATION ON GROWTH, SURVIVAL, PIGMENTATION AND NITROGEN-METABOLISM ENZYMES IN CYANOBACTERIA." Acta Protozoologica 34(3): 187-192.

Smith, D. S., J. Scalo, et al. (2004). "Transport of ionizing radiation in terrestrial-like exoplanet atmospheres." Icarus 171(1): 229-253.

Sollerman, J., G. Östlin, et al. (2005). "On the nature of nearby GRB/SN host galaxies." New Astronomy 11(2): 103-115. 
Stanek, K. Z., O. Y. Gnedin, et al. (2006). "Protecting life in the Milky Way: Metals keep the GRBs away." Acta Astronomica 56(4): 333-345.

Steinwedel, H. and J. H. D. Jensen (1950). "HYDRODYNAMIK VON KERNDIPOLSCHWINGUNGEN." Zeitschrift Fur Naturforschung Section a-a Journal of Physical Sciences 5(8): 413-420.

Tajima, T. and H. Ejiri (2003). Photonuclear Reactions and Nuclear Transmutation.

Tenorio-Tagle, G. and P. Bodenheimer (1988). "Large-Scale Expanding Superstructures in Galaxies." Annual Review of Astronomy and Astrophysics 26(1): 145-197.

Thomas, B. C., C. H. Jackman, et al. (2005). "Terrestrial ozone depletion due to a milky way gamma-ray burst." Astrophysical Journal 622(2): L153-L156.

Thomas, B. C., A. L. Melott, et al. (2005). "Gamma-ray bursts and the earth: Exploration of atmospheric, biological, climatic, and biogeochemical effects." Astrophysical Journal 634(1): 509-533.

Thorsett, S. E. (1995). "TERRESTRIAL IMPLICATIONS OF COSMOLOGICAL GAMMA-RAY BURST MODELS." Astrophysical Journal 444(1): L53-L55.

Tobias, C. A. (1959). "RADIATION AND LIFE IN SPACE." Federation Proceedings 18(4): 1242-1249.

Vanhala, H. A. T. and A. G. W. Cameron (1998). "Numerical simulations of triggered star formation. I. Collapse of dense molecular cloud cores." Astrophysical Journal 508(1): 291-307.

vanParadijs, J., P. J. Groot, et al. (1997). "Transient optical emission from the error box of the gamma-ray burst of 28 February 1997." Nature 386(6626): 686-689.

Vietri, M., D. De Marco, et al. (2003). "On the generation of ultra-high-energy cosmic rays in gamma-ray bursts: A reappraisal." Astrophysical Journal 592(1): 378-389.

Weaver, R., R. McCray, et al. (1977). "Interstellar bubbles. II - Structure and evolution." Astrophysical Journal 218: 377-395.

Weaver, T. A., G. B. Zimmerman, et al. (1978). "PRE-SUPERNOVA EVOLUTION OF MASSIVE STARS." Astrophysical Journal 225(3): 1021-1029.

Weber, P. and J. M. Greenberg (1985). "CAN SPORES SURVIVE IN INTERSTELLAR SPACE." Nature 316(6027): 403-407.

Wheaton, W. A., M. P. Ulmer, et al. (1973). "DIRECTION AND SPECTRAL VARIABILITY OF A COSMIC GAMMA-RAY BURST." Astrophysical Journal 185(3): L57-L61. 
Whitten, R. C., J. Cuzzi, et al. (1976). "EFFECT OF NEARBY SUPERNOVA EXPLOSIONS ON ATMOSPHERIC OZONE." Nature 263(5576): 398-400.

Wijers, R., M. J. Rees, et al. (1997). "Shocked by GRB 970228: the afterglow of a cosmological fireball." Monthly Notices of the Royal Astronomical Society 288(4): L51-L56.

Winkler, C., T. J. L. Courvoisier, et al. (2003). "The INTEGRAL mission." Astronomy \& Astrophysics 411(1): L1-L6.

Wood, R. D. (1996). "DNA repair in eukaryotes." Annual Review of Biochemistry 65: 135-167.

Woods, P. M. (2004). "Soft Gamma Repeaters and Anomalous X-ray Pulsars: Magnetar Candidates." arXiv:astro-ph/0406133v3.

Woosley, S. E. and T. A. Weaver (1986). "THE PHYSICS OF SUPERNOVA EXPLOSIONS." Annual Review of Astronomy and Astrophysics 24: 205-253.

Yamazaki, R., K. loka, et al. (2005). "Giant flare of SGR 1806-20 from a relativistic jet." Publications of the Astronomical Society of Japan 57(3): L11-L15.

Yang, T. C., M. Mei, et al. (1994). Oncogenic and mutagenic effects of UV in mammalian cells. F3 1/F3 4/F2 4/F3 8 Symposia of COSPAR ScientificCommission-F on Life Sciences - Space and Mars Recent Results, at the 30th COSPAR Scientific Assembly, Hamburg, Germany, Pergamon Press Ltd.

Zhang, B., X. Dai, et al. (2004). "Quasi-universal Gaussian Jets: A Unified Picture for Gamma-Ray Bursts and X-Ray Flashes." The Astrophysical Journal Letters 601(2): L119-L122.

Zhang, B. and P. Meszaros (2004). "Gamma-ray bursts: Progress, problems \& prospects." International Journal of Modern Physics A 19(15): 2385-2472. 


\section{Anexo 1: Tabela de abundâncias}

\begin{tabular}{|c|c|c|c|}
\hline Elemento & $\begin{array}{c}\text { Abundância } \\
\text { Recomendada (N) }\end{array}$ & Condritos (N) & Espectroscopia (N) \\
\hline $\mathrm{H}$ & $2.884 \times 10^{10}$ & $5.498 \times 10^{6}$ & $2.884 \times 10^{10}$ \\
\hline $\mathrm{He}$ & $2.888 \times 10^{9}$ & 0.6040 & $2.888 \times 10^{9}$ \\
\hline $\mathrm{Li}$ & 55.47 & 55.47 & 0.3631 \\
\hline $\mathrm{Be}$ & 0.7374 & 0.7374 & 0.4074 \\
\hline $\mathrm{B}$ & 17.32 & 17.32 & 14.45 \\
\hline $\mathrm{C}$ & $7.079 \times 10^{6}$ & $7.724 \times 10^{5}$ & $7.079 \times 10^{6}$ \\
\hline $\mathrm{N}$ & $1.950 \times 10^{6}$ & $5.535 \times 10^{4}$ & $1.950 \times 10^{6}$ \\
\hline 0 & $1.413 \times 10^{7}$ & $7.552 \times 10^{6}$ & $1.413 \times 10^{7}$ \\
\hline $\mathrm{F}$ & 841.1 & 841.1 & 1047 \\
\hline $\mathrm{Ne}$ & $2.148 \times 10^{6}$ & $2.355 \times 10^{-3}$ & $2.148 \times 10^{6}$ \\
\hline $\mathrm{Na}$ & $5.751 \times 10^{4}$ & $5.747 \times 10^{4}$ & $5.754 \times 10^{4}$ \\
\hline $\mathrm{Mg}$ & $1.020 \times 10^{6}$ & $1.040 \times 10^{6}$ & $1.000 \times 10^{6}$ \\
\hline $\mathrm{Al}$ & $8.410 \times 10^{4}$ & $8.308 \times 10^{4}$ & $8.511 \times 10^{4}$ \\
\hline $\mathrm{Si}$ & $\equiv 1.000 \times 10^{6}$ & $\equiv 1.00 \times 10^{6}$ & $\equiv 1.00 \times 10^{6}$ \\
\hline$P$ & 8373 & 7833 & 8913 \\
\hline$S$ & $4.449 \times 10^{5}$ & $4.449 \times 10^{5}$ & $4.634 \times 10^{5}$ \\
\hline $\mathrm{Cl}$ & 5237 & 5237 & 9120 \\
\hline $\mathrm{Ar}$ & $1.025 \times 10^{5}$ & $9.622 \times 10^{-3}$ & $1.025 \times 10^{5}$ \\
\hline $\mathrm{K}$ & 3692 & 3582 & 3802 \\
\hline $\mathrm{Ca}$ & $6.287 \times 10^{4}$ & $5.968 \times 10^{4}$ & $6.607 \times 10^{4}$ \\
\hline Sc & 34.20 & 34.20 & 42.66 \\
\hline $\mathrm{Ti}$ & 2422 & 2422 & 3020 \\
\hline $\mathrm{V}$ & 288.4 & 288.4 & 288.4 \\
\hline $\mathrm{Cr}$ & $1.286 \times 10^{4}$ & $1.313 \times 10^{4}$ & $1.259 \times 10^{4}$ \\
\hline $\mathrm{Mn}$ & 9168 & 9168 & 7079 \\
\hline $\mathrm{Fe}$ & $8.380 \times 10^{5}$ & $8.632 \times 10^{5}$ & $8.128 \times 10^{5}$ \\
\hline Co & 2323 & 2246 & 2399 \\
\hline $\mathrm{Ni}$ & $4.780 \times 10^{4}$ & $4.780 \times 10^{4}$ & $4.780 \times 10^{4}$ \\
\hline $\mathrm{Cu}$ & 527.0 & 527.0 & 467.7 \\
\hline $\mathrm{Zn}$ & 1226 & 1250 & 1202 \\
\hline $\mathrm{Ga}$ & 35.97 & 35.97 & 21.88 \\
\hline $\mathrm{Ge}$ & 120.6 & 120.6 & 109.6 \\
\hline As & 6.089 & 6.089 & $\ldots$ \\
\hline $\mathrm{Se}$ & 65.79 & 65.79 & $\ldots$ \\
\hline $\mathrm{Br}$ & 11.32 & 11.32 & $\ldots$ \\
\hline $\mathrm{Kr}$ & 55.15 & $1.643 \times 10^{-4}$ & 55.15 \\
\hline $\mathrm{Rb}$ & 6.572 & 6.572 & 11.48 \\
\hline $\mathrm{Sr}$ & 23.64 & 23.30 & 23.99 \\
\hline$Y$ & 4.608 & 4.538 & 4.677 \\
\hline $\mathrm{Zr}$ & 11.33 & 11.45 & 11.22 \\
\hline $\mathrm{Nb}$ & 0.7554 & 0.7522 & 0.7586 \\
\hline Mo & 2.601 & 2.804 & 2.399 \\
\hline Tc & $\ldots$ & $\ldots$ & $\ldots$ \\
\hline $\mathrm{Ru}$ & 1.900 & 1.806 & 1.995 \\
\hline
\end{tabular}




\begin{tabular}{|c|c|c|c|}
\hline $\mathrm{Rh}$ & 0.3708 & 0.3613 & 0.3802 \\
\hline $\mathrm{Pd}$ & 1.435 & 1.457 & 1.413 \\
\hline $\mathrm{Ag}$ & 0.4913 & 0.4913 & $(0.251)$ \\
\hline $\mathrm{Cd}$ & 1.584 & 1.584 & 1.698 \\
\hline In & 0.1810 & 0.1810 & 1.047 \\
\hline Sn & 3.733 & 3.733 & 2.884 \\
\hline $\mathrm{Sb}$ & 0.3292 & 0.3292 & 0.2884 \\
\hline $\mathrm{Te}$ & 4.815 & 4.815 & $\ldots$ \\
\hline 1 & 0.9975 & 0.9975 & $\ldots$ \\
\hline $\mathrm{Xe}$ & 5.391 & $3.495 \times 10^{-4}$ & 5.391 \\
\hline Cs & 0.3671 & 0.3671 & $\ldots$ \\
\hline $\mathrm{Ba}$ & 4.351 & 4.436 & 4.266 \\
\hline La & 0.4405 & 0.4405 & 0.3890 \\
\hline $\mathrm{Ce}$ & 1.169 & 1.169 & 1.096 \\
\hline $\mathrm{Pr}$ & 0.1737 & 0.1737 & 0.1479 \\
\hline $\mathrm{Nd}$ & 0.8355 & 0.8355 & 0.912 \\
\hline $\mathrm{Pm}$ & $\ldots$ & $\ldots$ & $\ldots$ \\
\hline Sm & 0.2542 & 0.2542 & 0.2818 \\
\hline $\mathrm{Eu}$ & 0.09513 & 0.09475 & 0.09550 \\
\hline $\mathrm{Gd}$ & 0.3321 & 0.3321 & 0.3802 \\
\hline $\mathrm{Tb}$ & 0.05907 & 0.05907 & 0.05495 \\
\hline Dy & 0.3862 & 0.3862 & 0.3981 \\
\hline $\mathrm{Ho}$ & 0.08986 & 0.08986 & 0.09772 \\
\hline $\mathrm{Er}$ & 0.2554 & 0.2554 & 0.2455 \\
\hline $\mathrm{Tm}$ & 0.03700 & 0.03700 & $(0.0288)$ \\
\hline $\mathrm{Yb}$ & 0.2484 & 0.2484 & 0.3467 \\
\hline Lu & 0.03572 & 0.03572 & 0.03311 \\
\hline $\mathrm{Hf}$ & 0.1699 & 0.1699 & 0.2188 \\
\hline $\mathrm{Ta}$ & 0.02099 & 0.02099 & $\ldots$ \\
\hline $\mathrm{W}$ & 0.1277 & 0.1277 & $(0.372)$ \\
\hline $\mathrm{Re}$ & 0.05254 & 0.05254 & $\ldots$ \\
\hline Os & 0.6738 & 0.6738 & 0.8128 \\
\hline Ir & 0.6448 & 0.6448 & 0.6918 \\
\hline $\mathrm{Pt}$ & 1.357 & 1.357 & 1.585 \\
\hline $\mathrm{Au}$ & 0.1955 & 0.1955 & $(0.295)$ \\
\hline $\mathrm{Hg}$ & 0.4128 & 0.4128 & $\ldots$ \\
\hline $\mathrm{Tl}$ & 0.1845 & 0.1845 & $(0.15-0.36)$ \\
\hline $\mathrm{Pb}$ & 3.258 & 3.258 & 2.884 \\
\hline $\mathrm{Bi}$ & 0.1388 & 0.1388 & $\ldots$ \\
\hline Th & 0.03512 & 0.03512 & $\ldots$ \\
\hline$U$ & $9.306 \times 10^{-3}$ & $9.306 \times 10^{-3}$ & $<9.772 \times 10^{-3}$ \\
\hline
\end{tabular}

Dados de (Lodders 2003). 


\section{Apêndice 1: Deposição de energia}

Para calcular a dose depositada de energia por ionização nos organismos, fizemos uso de uma forma analítica simplificada da fórmula de Bethe-Bloch, a partir do trabalho de Richard-Serre (Richard-Serre 1971), a qual vale para $\mathrm{E}>10 \mathrm{GeV}$, por tratar os efeitos da densidade de forma assintótica:

$$
\left(\frac{d E}{d x}\right)_{\text {ioniz }}=\frac{Z}{A}\left[4.55+2.34 \times 10^{-4} \eta-2.62 \times 10^{-8} \eta^{2}-0.1535 \ln \left(\rho \frac{Z}{A}\right)\right],
$$

onde $\eta=\beta \gamma=\left[\left(\frac{E}{M_{\mu} c^{2}}-1\right) \frac{E}{M_{\mu} c^{2}}\right]^{1 / 2}$

A perda de energia é dada em $\mathrm{MeV} / \mathrm{g} / \mathrm{cm}^{2}$. Para calcularmos a deposição de energia em $\mathrm{MeV} / \mathrm{g}$ temos de saber a área do alvo.

Suporemos que o material onde será depositada a energia é basicamente água. A perda total de energia por ionização será então:

$$
\left(\frac{d E}{d x}\right)_{\text {moléc }}=\sum_{i} N_{i}\left(\frac{d E}{d x}\right)_{i}
$$

onde o peso $\mathrm{N}_{\mathrm{i}}$ de cada átomo da molécula é dado por $N_{i}=M_{i} \frac{A_{i}}{A_{\text {molec }}}$. Portanto:

$$
\left(\frac{d E}{d x}\right)_{\text {água }}=\frac{1}{9}\left(\frac{d E}{d x}\right)_{H}+\frac{8}{9}\left(\frac{d E}{d x}\right)_{O}
$$




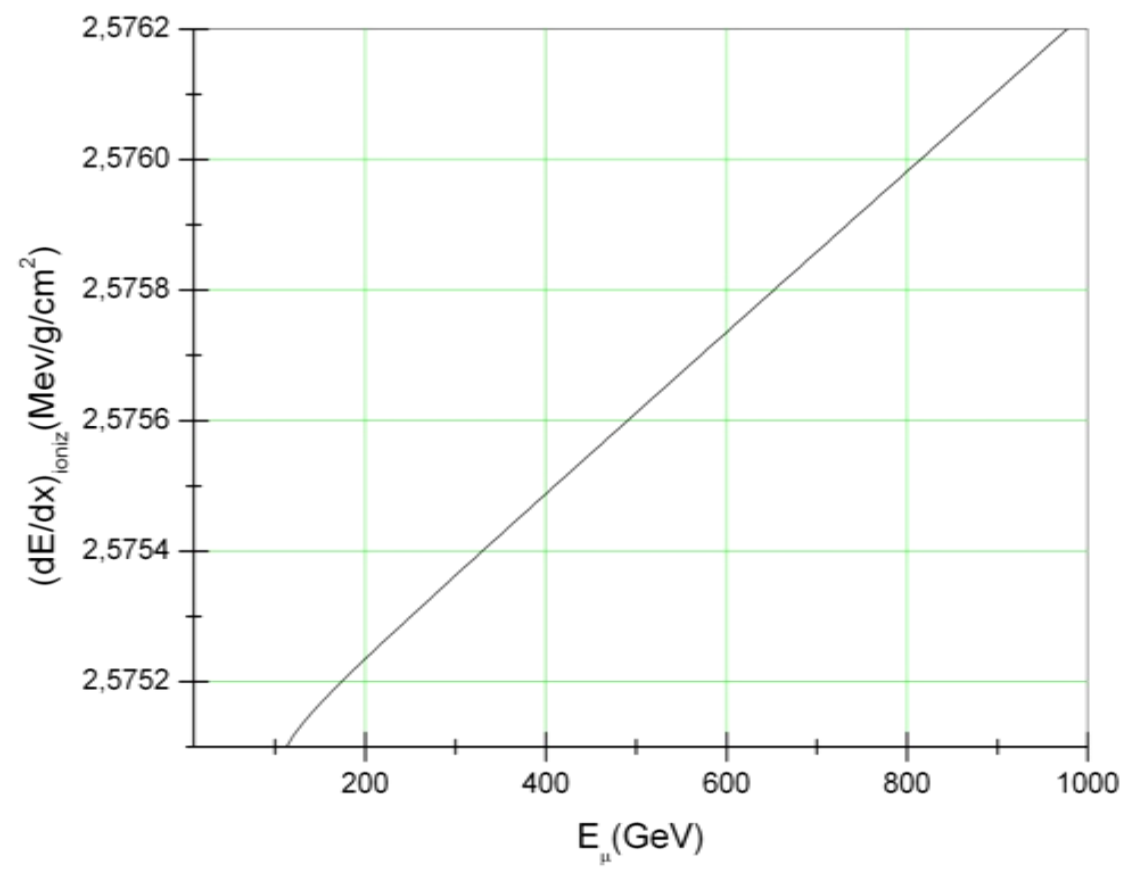

Fig. 50: Taxa de deposição de energia de múons em água, como função da energia dos múons.

Como vemos, a perda de energia por ionização é praticamente constante em um grande intervalo de energias, e muito próximo ao valor fornecido por Dar (Dar, Laor et al. 1998), portanto aproximaremos por $\left(\frac{d E}{d x}\right)_{\text {agua }} \cong 2.58 \mathrm{MeV} / \mathrm{g} / \mathrm{cm}^{2}$. 
Apêndice 2: Artigos 


\title{
Biological effects of gamma-ray bursts: distances for severe damage on the biota
}

\author{
Douglas Galante and Jorge Ernesto Horvath \\ Instituto de Astronomia, Geofisica e Ciências Atmosféricas, Universidade de São Paulo, São Paulo, Brazil \\ e-mail:douglas@astro.iag.usp.br
}

\begin{abstract}
In this paper we present a unified, quantitative synthesis of analytical and numerical calculations of the effects that could be caused on Earth by a gamma-ray burst (GRB), considering atmospheric and biological implications. The main consequences of the illumination by a GRB are grouped into four distinct classes and analysed separately, namely: direct $\gamma$ flash, UV flash, $\mathrm{O}_{3}$ layer depletion and cosmic rays. The effectiveness of each of these classes is compared and distances for significant biological damage are given for each one. We find that the first three effects have the potential to cause global environmental changes and biospheric damage, even if the source is located at galactic distances or even farther afield (up to $150 \mathrm{kpc}$, where 1 parsec $=3.09 \times 10^{16} \mathrm{~m}$, about five times the Galactic diameter of $30 \mathrm{kpc}$ ). Instead, cosmic rays would only be a serious threat for close sources (of the order of a few parsecs).

As a concrete application from a well-recorded event, the effects on the biosphere of an event identical to the giant flare of SGR1806-20 on 27 December 2004 have been calculated. In spite of not belonging to the so-called 'classical' GRBs, most of the parameters of this recent flare are quite well known and have been used as a calibration for our study. We find that a giant flare impinging on Earth is not a threat for life in all practical situations, mainly because it is not as energetic, in spite of being much more frequent than GRBs, unless the source happens to be extremely close.
\end{abstract}

Received 9 May 2006, accepted 7 November 2006

Key words: gamma-ray burst, life extinction, ozone depletion, UV flash.

\section{Introduction}

The implications of astrophysical events on Earth and Earthlike planets are an increasingly active field of research in many distinct areas of knowledge, such as Astronomy, Geology, Meteorology and Biology. Several sources of cosmic catastrophes have been proposed over the years. Recently, gamma-ray bursts (GRBs) were recognized as some of the most energetic astrophysical events since the Big Bang, releasing in just a few seconds as much energy as a supernova, of the order of $10^{44} \mathrm{~J}$ but concentrated in hard X-rays and $\gamma$ radiation. Thorsett (1995) was the first to acknowledge the potential destructive effects of a GRB illuminating the Earth. The question of vital statistics (rates, beaming, etc.) of the bursts is currently being studied, but it is undeniable that damage to the biota could be severe if a burst strikes (or has struck) the planet. Therefore, it is important to understand the various dangerous effects, and in particular their relative importance as a function of the distance for realistic physical inputs, in order to assess the actual threat to living organisms. It is the purpose of this work to present a unified synthesis of numerical and analytical calculations on the atmospheric and biological effects that a GRB might have if directed towards Earth or to a planet with an Earth-like atmosphere.

It is not unlikely that GRBs (as well as supernovae) have had a great impact on Earth, at least in the last billion years (Melott et al. 2004). Their effects range from a direct transmission of the high-energy $\gamma$ radiation through the atmosphere to chemical alterations on it, such as $\mathrm{NO}_{x}$ rise and $\mathrm{O}_{3}$ layer depletion. GRBs may also be associated (Vietri et al. 2003) with the acceleration of high-energy cosmic rays, which were taken into account by considering the effects of a massive flux of particles, in the form of a cosmic-ray jet (CRJ), as proposed by Dar et al. (1998).

As demonstrated below, our results suggest that 'classical' GRBs can have a radius of biological influence as large as $150 \mathrm{kpc}$. This distance is greater than the galactic radius, and therefore a burst occurring anywhere in the Galaxy could directly affect the biosphere of a planet lying within its beaming cone. It is naively expected that galaxies with strong star formation should be more prone to the occurrence of GRBs, owing to the greater proportion of massive stars, which are considered to be the progenitors of long-duration bursts in most models. Any occurrence of life might have been 'reset' by a GRB (Annis 1999), or it may even have 
received an evolutionary boost. Irregular galaxies with low metallicity may also be associated with GRBs (Stanek 2006), but these systems are less interesting for astrobiology, because it is still unclear if planets could be formed on them at all.

\section{Basic assumptions}

The model adopted for a long-duration GRB consists of a 'standard' $\gamma$ energy release of $5 \times 10^{43} \mathrm{~J}$, beamed within a solid angle $\Delta \Omega \sim 0.01 \mathrm{sr}$ (Frail et al. 2001) and peak duration of approximately $10 \mathrm{~s}$. The emission is generally well-fitted by a broken power law, known as a Band spectrum, with its main energy being released in the hundreds of $\mathrm{keV}$ range (Band et al. 1993), where $1 \mathrm{eV}=1.6 \times 10^{-19} \mathrm{~J}$. Absorption by the interstellar medium (ISM) was neglected because the later is almost completely transparent to high-energy photons, and thus the flux at a distance $D$ should behave as

$F=\frac{L}{\Delta \Omega D^{2}}$

where $L$ is the $\gamma$ luminosity and $\Delta \Omega$ is the beaming solid angle.

Since we shall only be using the observational characteristics of long bursts, we will not take into account the differences of the progenitors which may lead to the event itself, or the different models for explaining the formation of the $\gamma$ radiation (the Fireball and the Cannonball models being the most popular). The Fireball model associates this kind of burst with very energetic Ic $\mathrm{SNe}$, occasionally dubbed hypernovae events (van Paradijs et al. 2000). In this model the $\gamma$ radiation is produced by synchrotron emission during the collision of highly relativistic conical shells ejected during the explosion. In the Cannonball model (Dar \& De Rújula 2004), the $\gamma$ emission is produced by inverse Compton scattering on a bipolar jet made of chunks of ordinary material from a common core-collapsed supernovae, which is ejected when material from an accreting torus falls down on the compact object. In spite of being important for other purposes, these differences do not affect our conclusions, which are insensitive to the specific GRB model.

Some previous works have already made quantitative estimates on individual effects; for example, Thomas et al. $(2005 \mathrm{a}, \mathrm{b})$ made a study of the ozone depletion produced by a GRB using several initial conditions. Since we seek here to build a more complete picture of the problem, we have also considered the effects of transmission of the $\gamma$ radiation by the atmosphere (Smith et al. 2004) and the energy deposited by cosmic rays accelerated within the burst. Thus, for the sake of a clear identification of the different harmful thresholds for the biota related to each effect, we have divided them into four classes: $\gamma$ flash, UV flash, $\mathrm{O}_{3}$ layer depletion and CRJs, which will be further discussed and quantified.

After an evaluation of the physical conditions of the photon transfer, two unicellular organisms were used as fiducial biological probes for their effects: the well-known Escherichia coli (E. coli), an internal, radiation-sensitive (in particular to UV) bacterium, and Deinococcus radiodurans (D. radiodurans), classified as a polyextremophyle owing to its
Table 1. Doses and fluxes for a $10 \%$ survival for the bacteria E. coli and D. radiodurans for ionizing (Ghosal et al. 2005) and UV radiation (Gascón et al. 1995)

\begin{tabular}{lcll}
\hline Test organism & $D_{10}^{\text {ion }}(\mathrm{kGy})$ & $F_{10}^{\text {ion }}\left(\mathrm{J} \mathrm{m}^{-2}\right)$ & $F_{10}^{\mathrm{UV}}\left(\mathrm{J} \mathrm{m}^{-2}\right)$ \\
\hline E. coli & 0.7 & $3.50 \times 10^{5}$ & 22.6 \\
D. radiodurans & 11 & $5.50 \times 10^{6}$ & $5.53 \times 10^{2}$ \\
\hline
\end{tabular}

resistance to many external agents such as UV and ionizing radiation, organic peroxides and desiccation. They represent two extremes of radiation resistance, defining a pragmatic 'surviving zone for life'. We are not claiming that these organisms are representative of the primordial prokaryotic fauna on Earth, but they happen to be useful as biological standards because of the vast amount of available data on their biology. Their radiation resistances are summarized in Table 1 and a discussion on the population dynamics is given in Appendix A.

\section{Evaluation of $D_{10}$ distances}

\section{Direct $\gamma$ flash}

As discussed in the literature, for example in the recent numerical simulations by Smith et al. (2004), $\gamma$ photons with energies of the order of hundreds of $\mathrm{keV}$ lose energy primarily by Compton scattering over the electrons on the atmosphere. During the transmission through the atmosphere, these photons lose energy, with a characteristic energy decrease from around $250 \mathrm{keV}$ to $20 \mathrm{keV}$.

Following the calculations of Smith et al., a thin atmosphere, such as the one present on the primordial Earth, with $\rho<100 \mathrm{~g} \mathrm{~cm}^{-2}$ would transmit around $1 \%$ of the initial $\gamma$ radiation to the ground, while the present atmosphere (a much thicker one at $\rho \sim 1024 \mathrm{~g} \mathrm{~cm}^{-2}$ ) would transmit only around $10^{-28}$ of the initial $\gamma$ fluence $\left(6 \times 10^{-29} \mathrm{~J}\right)$. This means that practically all of the $\gamma$ energy of the burst would be deposited on a thick atmosphere, while on a thin one a significant fraction of the radiation would still reach the ground, affecting just the illuminated hemisphere owing to the short duration of the burst (typically around $10 \mathrm{~s}$ ), which is certainly much shorter than the rotation of the Earth.

The main biological effect of $\gamma$ radiation of this range of energy is free radical production by ionization, which has toxic effects on the cell. The $D_{10}^{\text {ion }}$ dose for $E$. coli is $D_{10}^{\text {ion }}=0.7 \mathrm{kGy}$ where $D_{10}^{\text {ion }}$ stands for the necessary dose of ionizing radiation for a $10 \%$ survival. For $D$. radiodurans, the $D_{10}^{\text {ion }}$ is much higher at $D_{10}^{\text {ion }}=11 \mathrm{kGy}$. These doses can be converted to fluxes by using the energy losses on water. For E. coli, we have $F_{10}^{\text {ion }}=3.5 \times 10^{5} \mathrm{~J} \mathrm{~m}^{-2}$ and for $D$. radiodurans $F_{10}^{\text {ion }}=5.5 \times 10^{6} \mathrm{~J} \mathrm{~m}^{-2}$ of $\gamma$ flux. In order to obtain such fluxes on the surface of the planet, we have to consider the transparency of the atmosphere to the $\gamma$ radiation, as stated above.

For $E$. coli with a thin atmosphere, the maximum distance at which the $\gamma$ flash would deliver a $D_{10}^{\text {ion }}$ dose at the surface of the planet was calculated to be $390 \mathrm{pc}$, and for D. radiodurans the corresponding figure was $100 \mathrm{pc}$. As previously stated, for the thick atmosphere this mechanism would be very 
inefficient as the $\gamma$ radiation would be deposited on the atmosphere itself.

\section{UV flash}

The same Compton mechanism blocking the direct irradiation provokes a large fraction of the high-energy $\gamma$ photons to have its energy lowered to the UV range.

Smith et al. (2004) calculated that, for a thin atmosphere, $1-10 \%$ of the initial $\gamma$ flux would be converted to UV flux, while for a thick atmosphere the fraction is in the range $2 \times 10^{-3}-40 \times 10^{-3}$. We observe that these calculations were performed without considering the presence of aerosols or clouds, which could quite effectively block the UV radiation. As this effect would last for just a few seconds, this means that the instantaneous condition of the atmosphere might substantially change the amount of radiation arriving on the ground.

The biological effectiveness of the UV radiation as a harmful factor comes from the fact that DNA and RNA strongly absorb in this range of energy, suffering mainly from nucleotide dimerization, especially on the pirimidines (Häder \& Sinha 2005). In fact, the UV flux necessary to deposit a $D_{10}^{\mathrm{UV}}$ dose on $E$. coli is $F_{10}^{\mathrm{UV}}=22.6 \mathrm{~J} \mathrm{~m}^{-2}$ (Gascón et al. 1995), a value $10^{4}$ times lower than from ionizing radiation. Again, for $D$. radiodurans, this value is higher, $F_{10}^{\mathrm{UV}}=5.53 \times 10^{2} \mathrm{~J} \mathrm{~m}^{-2}$ (Ghosal et al. 2005). These fluxes can be also translated into distances. Using the same procedure as before and considering the $\gamma$ to UV conversion efficiencies given by Smith et al. (2004), the $\gamma$ flux on the top of the atmosphere to deliver a $D_{10}^{\mathrm{UV}}$ dose on the ground should be 10-100 times greater than the $F_{10}^{\mathrm{UV}}$ of each organism, which implies maximum distances of 48-152 kpc for E. coli and 10-31 kpc for D. radiodurans, both for thin atmospheres. For the thick atmosphere case, the range is 21-96 kpc for E. coli and 4-9 kpc for D. radiodurans. These distance ranges arise from the uncertainty on the $\gamma$ to UV conversion, as presented above.

\section{$\mathrm{O}_{3}$ layer depletion}

The $\gamma$ radiation may alter the chemistry of the atmosphere, the most relevant change to our study being a rise in the concentration of $\mathrm{NO}_{x}$, which can act as a catalyser for $\mathrm{O}_{3}$ degradation. This problem has already been addressed by Ruderman (1979) in relation to the effects of SN explosions on the atmosphere.

Ruderman's calculations are based on the catalytic destruction of $\mathrm{O}_{3}$ by $\mathrm{NO}$ :

$\mathrm{NO}+\mathrm{O}_{3} \rightarrow \mathrm{NO}_{2}+\mathrm{O}_{2}$,

$\mathrm{NO}_{2}+\mathrm{O} \rightarrow \mathrm{NO}+\mathrm{O}_{2}$.

The kinematics of the reaction was modelled in a simplified manner by the equation

$\frac{\left[\mathrm{O}_{3}\right]}{\left[\mathrm{O}_{3}\right]_{0}}=\frac{\sqrt{19+9 X^{2}}-3 X}{2}$,

$X=\frac{\left[\mathrm{NO}_{X}\right]}{\left[\mathrm{NO}_{X}\right]_{0}}$.
Ruderman's work included the following assumptions:

- the oxidation of $\mathrm{NO}_{2}$ by $\mathrm{O}$ is the limiting step of the cycle;

- the $[\mathrm{O}] /\left[\mathrm{O}_{3}\right]$ ratio is taken to be constant.

During the $\gamma$ irradiation, the $\left[\mathrm{NO}_{x}\right]$ rises owing to the production of free $\mathrm{N}$ atoms

$\mathrm{N}^{*}+\mathrm{O}_{2} \rightarrow \mathrm{NO}+\mathrm{O}$.

If we consider all the $\mathrm{NO}_{x}$ to be $\mathrm{NO}$, the production rate is given by

$\frac{10}{(10+y)}=\frac{\text { NO molecules }}{\text { ion pair }}$

where $y$ is the initial concentration in parts per billion (ppb), which will be taken to be $3 \mathrm{ppb}$.

Using Ruderman's figures (Ruderman 1979), we have that $1 \mathrm{~J}$ of $\gamma$ radiation produces $2.8 \times 10^{17}$ ion pairs. The rate of production of $\mathrm{NO}$ molecules is then

$$
\begin{aligned}
R_{\mathrm{NO}}= & \phi \times 2.8 \times 10^{17}\left(\frac{\text { ion pairs }}{J}\right) \\
& \times\left(\frac{10}{10+y}\right)\left(\frac{\text { NO molecules }}{\text { ion pairs }}\right) \times \frac{10^{9}}{5 \times 10^{27}}
\end{aligned}
$$

where $\phi$ is in units of $\left(\mathrm{J} \mathrm{m}^{-2}\right) \mathrm{s}^{-1}$. Simplifying and integrating over the duration of the burst yields (in ppb)

$R_{\mathrm{NO}}=0.43 \phi$

where $\phi$ is in units of $\mathrm{J} \mathrm{m}^{-2}$. Using the definition (3) with $[\mathrm{NO}]_{0}=3 \mathrm{ppb}$, we finally obtain

$X=\frac{[\mathrm{NO}]}{[\mathrm{NO}]_{0}}=1+\frac{R_{\mathrm{NO}}}{[\mathrm{NO}]_{0}}$,

$X(\phi)=1+0.67 \times 10^{-2} \phi$.

where $\phi$ is in units of $\mathbf{J ~ m}^{-2}$. The NO thus produced has a dynamical time of residence in the atmosphere of the order of 2-6 yr (Ruderman 1979). Using Eq. (2), we may obtain the ozone depletion as a function of the $\gamma$ fluence on the top of the atmosphere, as presented in Fig. 1. Ellis \& Schramm (1995) later considered the same problem, with the addition of the effect of charged particles produced by the SN event, considering its ionizing power to be the same as the electromagnetic component. Their results are even more dramatic and may be adapted immediately for a GRB.

Recently, Gehrels et al. (2003) produced a more sophisticated treatment for the problem, using a 2D atmospheric simulation code developed at the Goddard Space Flight Center, and using an input spectrum from SN1987a, with a total energy release of $9 \times 10^{39} \mathrm{~J}$. Running the simulation at $10,20,50$ and $100 \mathrm{pc}$, their results suggest a tendency for ozone depletion to scale as $D_{\mathrm{SN}}^{-n}$, where $1.3<n<1.9$. In our calculations we used a mean value of $n=1.6$.

We calculated the mean ozone depletion at $10 \mathrm{pc}$ using the latest results from Gehrels et al. (2003) to be $22.6 \%$, and from this value we scaled to the effects of interest, obtaining the depletion of $\mathrm{O}_{3}$ (see Fig. 1):

$\frac{\left[\mathrm{O}_{3}\right]}{\left[\mathrm{O}_{3}\right]_{0}}=1-7.2 \times 10^{-4.6} \phi^{0.8}$

where $\phi$ is in units of $\mathrm{J} \mathrm{m}^{-2}$. 


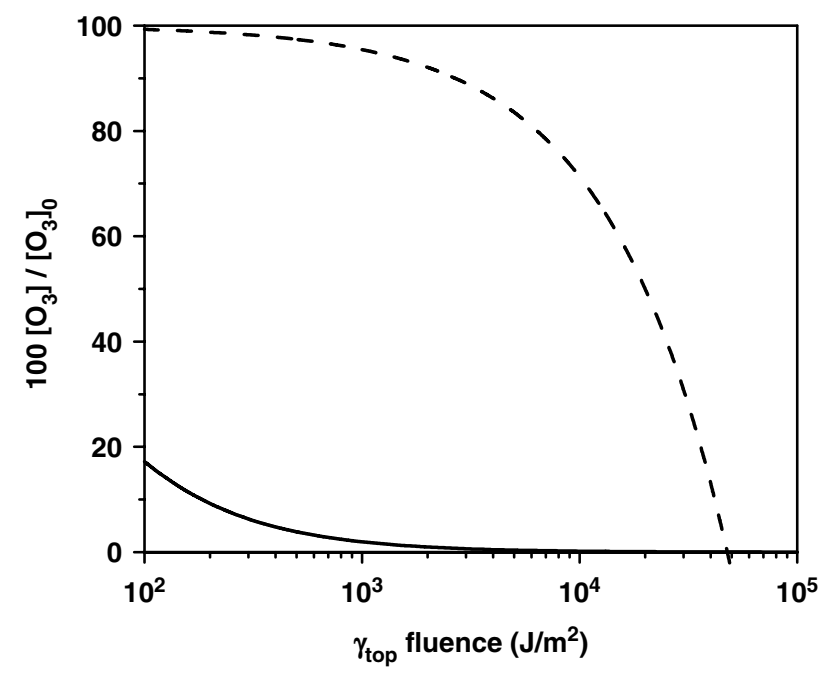

Fig. 1. Atmospheric ozone depletion as a function of the initial $\gamma$ fluence, as calculated by Ruderman (1979) (solid line), using an analytical simplified approach, and by Gehrels et al. (2003) (dashed line) using numerical simulations.

Comparing Ruderman's results with those of Gehrels et al., we appreciate the large differences between both approximations. Ruderman's results indicate that with fluences of $10^{3} \mathrm{~J} \mathrm{~m}^{-2}$ essentially all the $\mathrm{O}_{3}$ would be destroyed, while the recent simulations show that a modest fraction remains. This is caused by the strong simplifications adopted in Ruderman's work, in particular the simplifications to the chemical reactions and the fact that atmospheric mixing is neglected, so that the problem could be solved analytically (Crutzen \& Brühl 1996). We have thus adopted the milder scenario presented by Gehrels et al. (2003). In particular, Thomas et al. $(2005 \mathrm{a}, \mathrm{b})$ repeated the calculations using the same code but with an input spectrum of a GRB, which has a much shorter time scale than SNe. However, their results did not change our conclusions significantly.

To calculate the increase of the solar UV caused by the depletion of the $\mathrm{O}_{3}$ layer, we used a Beer-Lambert law

$\phi_{\mathrm{UV}}=\left(\phi_{\mathrm{UV}}\right)_{0} e^{-\sigma N}$

where $\sigma$ is the $\mathrm{O}_{3}$ cross-section and $N$ is the column density of $\mathrm{O}_{3}$. In this approximation we ignore other UV absorbers, such as water vapour and scattering particles, which are not expected to dominate. The initial mean value for the column density of $\mathrm{O}_{3}$ used was $350 \mathrm{DU}$, or equivalently $9.4 \times 10^{22}$ molecules $\mathrm{m}^{-2}$.

We may now introduce the depletion factor from Eq. (10) into Eq. (11), and thus obtain the solar $\mathrm{UV}_{\mathrm{B}}$ flux on the ground already increased by the depletion of the $\mathrm{O}_{3}$ layer as a result of the $\gamma$ flux from the GRB:

$\phi_{\text {sup }}=\phi_{0} \exp \left[-\left(\sigma \frac{\left[\mathrm{O}_{3}\right]}{\left[\mathrm{O}_{3}\right]_{0}} N\right)\right]$

where $\phi_{\text {sup }}$ is in units of $\left(\mathrm{J} \mathrm{m}^{-2}\right) \mathrm{s}^{-1}$. The results are depicted in Fig. 2. The $D_{10}^{\mathrm{UV}}$ distance for D. radiodurans is $12 \mathrm{kpc}$, or essentially the Galactic radius. Closer bursts increase

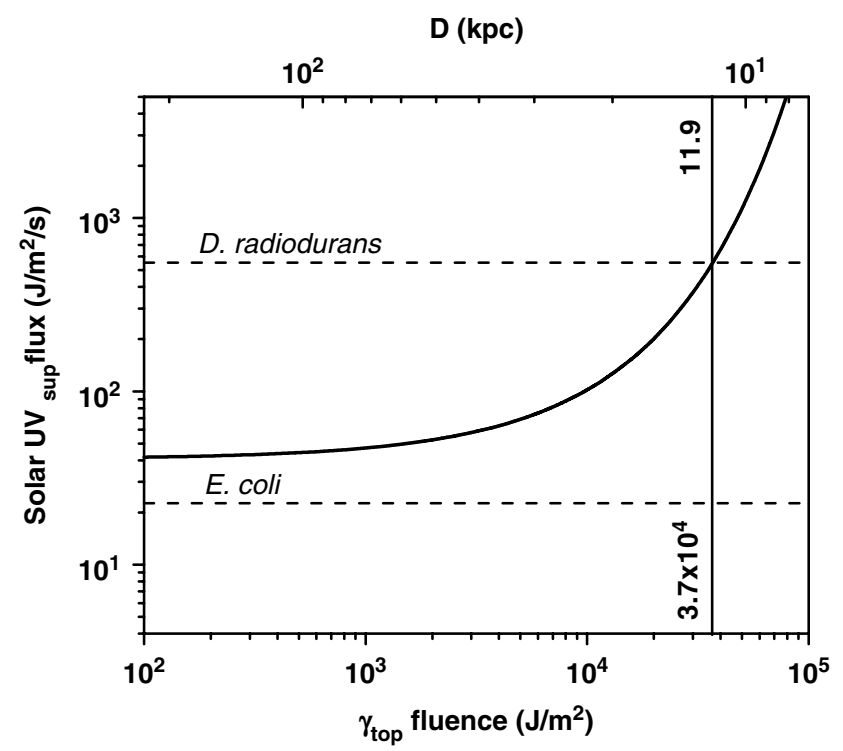

Fig. 2. Calculated solar UV flux reaching sea level, attenuated by the depleted ozone layer, as a function of the initial $\gamma_{\text {top }}$ fluence (lower scale) and distance to the standard GRB (upper scale). The $F_{10}^{\mathrm{UV}}$ for E. coli and D. radiodurans are also plotted.

dramatically the mortality for almost all types of exposed unicellular organisms. The $E$. coli $F_{10}^{\mathrm{UV}}$ is below the actual solar UV flux on the ground, even without ozone depletion, which is consistent with $E$. coli being an internal microorganism and does not result in a useful limit.

\section{Cosmic-ray jets}

This is the last effect to be considered in our work. Being an explosive phenomenon, Dar et al. (1998) proposed that a GRB may be associated with a massive acceleration of cosmic rays, which could be beamed into a jet and reach great distances from the source, called the cosmic-ray jet (CRJ). Although still very speculative, it is worth taking a serious look into this hypothesis and in particular to the consequences regarding to planet illumination by the GRB, since it could also be struck by the jet, but with a substantial time delay.

It is generally assumed in the calculations that the same amount of energy seen in $\gamma$ radiation is used to accelerate the particles (termed the equipartition hypothesis; see, e.g., Vietri et al. (2003)), which we shall consider to be protons. This way, we considered a jet of protons with $5 \times 10^{43} \mathrm{~J}$ of kinetic energy and assume the same collimation angle inferred for the photons, $\Delta \Omega=1 / \Gamma$, with $\Gamma \approx 100$.

Hitting the upper atmosphere, the CRJ would produce a shower of secondary particles. We have focused our attention on the muons, which could arrive on the ground and even underground or deep underwater, unlike UV or $\gamma$ radiation which is restricted to the surface. In fact this is one of the main arguments given by Dar et al. (1998) for why CRJs could potentially have a major impact on life.

The production of muons in the atmosphere occurs when a proton interacts with a nucleus in the following sequence:

$\mathrm{p}+\mathrm{N} \rightarrow \pi+\mathrm{K} \rightarrow \mu+v$. 


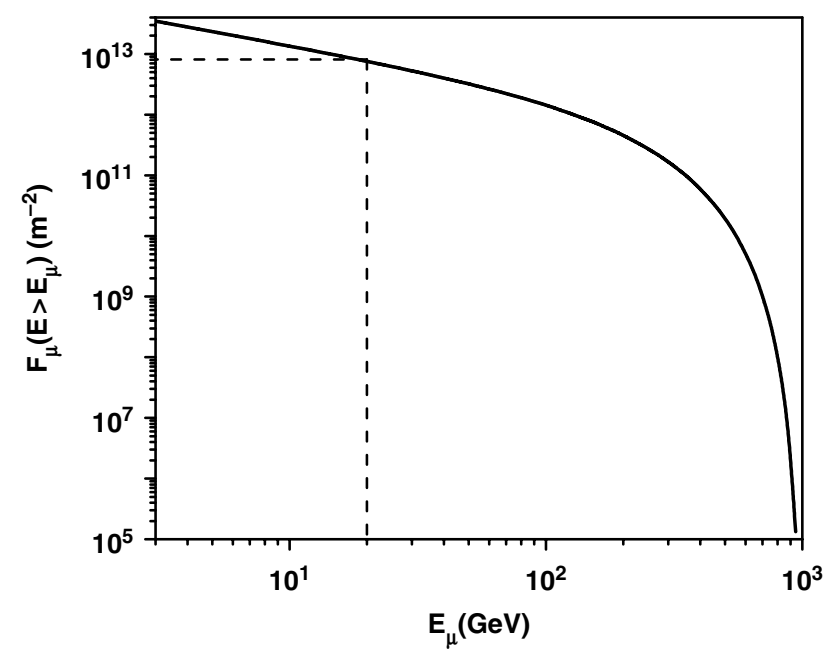

Fig. 3. Muon flux on sea level produced by the interactions of $1 \mathrm{TeV}$ protons on top of the atmosphere, not considering muon decay. For muons over $20 \mathrm{GeV}$, the expected muon flux is of the order of $10^{13} \mathrm{~m}^{-2}$.

In the case of a monochromatic primary flux, we can use the simplified formula (Dar et al. 1998)

$\left\langle N_{\mu}\right\rangle \cong \frac{\left(0.0145 E_{\mathrm{p}}\right)}{\cos \theta}\left(E_{\mathrm{p}} / E_{\mu}\right)^{0.757}\left(1-\left(E_{\mu} / E_{\mathrm{p}}\right)\right)^{5.25}$

where $E_{\mathrm{p}}$ is in units of $\mathrm{TeV}$. This gives the mean number of high-energy muons $\left(E>E_{\mu}\right)$ produced by nucleons of energy $E_{\mathrm{p}}$, which do not decay in the atmosphere and reach the sea level with zenithal angle $\theta<\pi / 2$.

To introduce the incident spectrum of the primaries, we can use the equation given by Lipari (1993), deducible using standard physics (e.g. Gaisser 1992):

$$
\begin{aligned}
\phi_{\mu}(E, \theta)= & {\left[L_{\pi}(\alpha)\left(1+\frac{L_{\pi}(\alpha)}{H_{\pi}(\alpha)} \frac{E \cos \theta}{\varepsilon_{\pi}}\right)^{-1}+L_{\mathrm{K}}(\alpha)\right.} \\
& \left.\times\left(1+\frac{L_{\mathrm{K}}(\alpha)}{H_{\mathrm{K}}(\alpha)} \frac{E \cos \theta}{\varepsilon_{\mathrm{K}}}\right)^{-1}\right] K E^{-\alpha} .
\end{aligned}
$$

These formulae are strictly valid for muon energies greater than $20 \mathrm{GeV}$, because muon decay processes are not taken into account. The input spectrum is characterized by the index square and the constant $K$ (these parameters were taken from the work of Lipari (1993)). This formula was tested successfully using the usual cosmic-ray background $(\alpha=2.7$ and $K=1.85$ ) reproducing the actual flux, except at low energies where the Solar wind and other effects are important.

The main process of energy loss for high-energy muons on matter is ionization. To calculate the ionization losses, we used a simplified well-known version of the Bethe-Bloch equation (Richard-Serre 1971), which is valid strictly for energies above $10 \mathrm{GeV}$ :

$$
\begin{aligned}
\left(\frac{d E}{d x}\right)_{\text {ioniz }}= & \frac{Z}{A}\left[4.55+2.34 \times 10^{-4} \eta-2.62\right. \\
& \left.\times 10^{-8} \eta^{2}-0.1535 \ln \left(\rho \frac{Z}{A}\right)\right],
\end{aligned}
$$

Table 2. $D_{10}$ distances for the various effects following $a$ $G R B$, clearly showing the longer range for the UV Flash mechanism. The quoted ranges for the UV Flash reflect the uncertainty in the fraction of $\gamma$ to $U V$ conversion efficiency (see text). Nor the ozone depletion nor the CRJ effects is relevant on the thin atmosphere case, and for $\mathrm{E}$. coli, the $D_{10}$ distance is not calculated for ozone depletion because it is already below the $D_{10}$ threshold without the burst

\begin{tabular}{llll}
\hline & & \multicolumn{2}{l}{$\begin{array}{l}D_{10} \text { distance } \\
\left(\mathrm{kpc}=3 \times 10^{19} \mathrm{~m}\right)\end{array}$} \\
\cline { 3 - 4 } $\begin{array}{l}\text { Planetary } \\
\text { effect }\end{array}$ & $\begin{array}{l}\text { Test } \\
\text { organism }\end{array}$ & $\begin{array}{l}\text { Thin } \\
\text { atmosphere }\end{array}$ & $\begin{array}{l}\text { Thick } \\
\text { atmosphere }\end{array}$ \\
\hline$\gamma$ flash & E. coli & 0.39 & Negligible \\
UV flash & D. radiodurans & 0.10 & Negligible \\
$\mathrm{O}_{3}$ layer depletion & E. coli & $48-152$ & $21-96$ \\
CRJ & D. radiodurans & $10-31$ & $4-19$ \\
& E. coli & - & - \\
& D. radiodurans & - & 12 \\
\hline
\end{tabular}

$\eta=\beta \gamma=\left[\left(\frac{E}{M_{\mu} c^{2}}-1\right) \frac{E}{M_{\mu} c^{2}}\right]^{1 / 2}$

In water, Eq. (16) gives an approximate constant energy loss of $2.58\left(\mathrm{MeV} \mathrm{g}^{-1}\right) \mathrm{cm}^{-2}$, for muon energies up to $1 \mathrm{TeV}$.

In the absence of a firm evaluation of the spectrum, we have decided not to employ any specific one for the particles accelerated at the GRB, but rather a monochromatic flux of typical energy per nucleon of $1 \mathrm{TeV}$. The duration of the irradiation by these relativistic particles is estimated to be $\approx 2$ months (Dar et al. 1998).

For a primary energy flux of $10^{4} \mathrm{~J} \mathrm{~m}^{-2} \cong 10^{12} \mathrm{TeV} \mathrm{m}^{-2}$ in high-energy particles, which is the assumption for our standard burst at $10 \mathrm{kpc}$, we have calculated the muon flux at sea level, as shown in Fig. 3.

The lethal dose of ionizing radiation for humans is around $3 \mathrm{~Gy}$, which can be translated to a muon flux, at the $20 \mathrm{GeV}$ energy range, of about $10^{14} \mathrm{~m}^{-2}$. Our benchmark organisms $E$. coli and $D$. radiodurans are much more resistant, the $D_{10}^{\text {ion }}$ dose being $0.7 \mathrm{kGy}$ for $E$. coli and $11 \mathrm{kGy}$ for D. radiodurans. Consequently, these bacteria could stand higher muon fluxes, $2 \times 10^{16} \mathrm{~m}^{-2}$ for $E$. coli and $3 \times 10^{17} \mathrm{~m}^{-2}$ for D. radiodurans. These numbers set $D_{10}^{\text {ion }}$ distances for the burst source of $300 \mathrm{pc}$ for humans, $48 \mathrm{pc}$ for $E$. coli and $12 \mathrm{pc}$ for $D$. radiodurans.

\section{Discussion and conclusions}

As a summary of the above results, we present in Table 2 the $D_{10}$ distances for $E$. coli and D. radiodurans calculated for the various mechanisms presented. 
We can safely state that the most efficient damaging effect of GRB illumination is the UV flash, because it can deliver a $D_{10}$ dose for distances up to $150 \mathrm{kpc}$. However, this effect is limited to one hemisphere, and only over uncovered land and shallow waters. It may not have a direct global impact, although it may have an indirect long-term effect if a significant part of the planktonic organisms are killed during the irradiation. The non-linear effects on populations of a huge catastrophe such as the incidence of a nearby GRB are difficult to model and there is ample room to study scenarios addressing these issues.

The direct $\gamma$ flash seems not to be biologically important, because most of its energy would be absorbed by the atmosphere. For a thick atmosphere, the energy deposition would probably lead to an increase in temperature of a few degrees, but for a thin one the results could be even more dramatic. However, the climatic consequences of these are not totally clear and it would be interesting to model such a large disturbance in some detail.

The depletion of the ozone layer is the most obvious global and long-term effect. It can affect life for many years, probably making the surface of the planet an environment uninhabitable for its photosynthesizing biota. It can be effective for distances up to $12 \mathrm{kpc}$ for D. radiodurans, which means almost anywhere in the Galaxy, even for a radiation resistant organism, confirming the expectations of Thorsett (1995). In fact, it is difficult to imagine a fundamental ecosystem dependent on photosynthetic organisms not to be at least harmed by the occurrence of a directed GRB event closer than a few kpc. UV radiation has been proposed to have a role in extinctions on Earth (Cockell 1999), and it is important to consider GRBs as additional sources of ozone depletion.

Other consequences are expected as well, as pointed out by Thorsett (1995) and by Thomas et al. (2005b): the rise of the $\mathrm{NO}_{x}$ concentration in the atmosphere may have a global cooling effect, blocking visible sunlight and making photosynthesis inefficient. On the other hand, the residual nitrates of this process may make the soil more fertile after the end of this GRB winter, allowing lands to be populated by vegetation (see Thomas et al. (2005b)).

The cosmic-ray effect is still controversial, and it seems to be very inefficient unless the source is located in close proximity (of the order of a few pc) to the Earth. However, a non-lethal CRJ incidence could still be important for the biota, for example by providing a higher level of background radiation which could induce significant mutation rates. As its effect lasts for several months, these mutations might have time to accumulate on simple, fast replicating organisms, having a yet unknown evolutionary importance (Dermer \& Holmes 2005).

We conclude our unified study of the several effects of GRBs with a quantitative assessment of how destructive an event could be, leading to extermination of life or at least part of it. However, it is not impossible that it may work as an evolutionary kick inducer, in common with many
Table 3. $D_{10}$ distances for the various effects following a SGR. The quoted ranges reflect the uncertainty on the distance to the source and on the fraction of $\gamma$ to $U V$ conversion efficiency (see text). Nor the ozone depletion nor the CRJ effects is relevant on the thin atmosphere case, and for E. coli, the $D_{10}$ distance is not calculated for ozone depletion because the solar flux on the ground is already above the $D_{10}$ threshold without ozone loss

\begin{tabular}{llll}
\hline & & \multicolumn{2}{l}{$D_{10}$ distance $\left(\mathrm{pc}=3.1 \times 10^{16} \mathrm{~m}\right)$} \\
\cline { 3 - 4 } $\begin{array}{l}\text { Planetary } \\
\text { effect }\end{array}$ & $\begin{array}{l}\text { Test } \\
\text { organism }\end{array}$ & $\begin{array}{l}\text { Thin } \\
\text { atmosphere }\end{array}$ & $\begin{array}{l}\text { Thick } \\
\text { atmosphere }\end{array}$ \\
\hline$\gamma$ flash & E. coli & $0.06-0.09$ & Negligible \\
& D. radiodurans & $0.01-0.02$ & Negligible \\
UV flash & E. coli & $7-35$ & $3-22$ \\
& D. radiodurans & $1-7$ & $1-4$ \\
$\mathrm{O}_{3}$ layer depletion & E. coli & - & - \\
\multirow{2}{*}{ CRJ } & D. radiodurans & - & $2-3$ \\
& E. coli & - & 0.01 \\
& D. radiodurans & - & Negligible \\
\hline
\end{tabular}

other apparent catastrophic events that happened on Earth (Horvath 2003).

\section{Case study: SGR1806-20}

On 27 December 2004, a giant flare event from the soft gamma repeater SGR1806-20 was observed. The main characteristics of this event were as follows:

- peak flux: $F_{\text {peak }}>0.3 \times 10^{-3} \mathrm{~J} \mathrm{~m}^{-2}$ (Nakar et al. 2005);

- estimated distance: $6.4 \mathrm{kpc}<D<9.8 \mathrm{kpc}$ (Cameron et al. 2005);

- beaming angle: $\Delta \Omega \sim 0.03 \mathrm{sr}$ (Yamazaki et al. 2005);

- $\gamma$ isotropic luminosity: $1.5 \times 10^{38} \mathrm{~J}<L<3.5 \times 10^{38} \mathrm{~J}$

- $\gamma$ luminosity with beaming: $3.5 \times 10^{36} \mathrm{~J}<L<0.8 \times 10^{37} \mathrm{~J}$

This kind of event is thought to share many of its characteristics with classical GRBs, but scaled to lower energies (Nakar et al. 2005). Although different in origin they are of interest because there are another three currently known SGRs in the Galaxy, so that they are not of cosmological origin and might have more direct implications to life, even at present.

By applying the same method as previously used for the GRBs, we arrived at the $D_{10}$ distances for the effects studied. The results are summarized in Table 3. As in the case of GRBs, we found that the most effective mechanism is UV flash because it corresponds to the largest calculated $D_{10}$ distance. However, this type of event needs to occur very close to Earth to lead to any dramatic consequences, so close that in fact we do not expect to have had any progenitors in the history of the planet.

For the case of a CRJ, we do not expect to have any direct biological effect at all given the spreading of the particles by magnetic fields (Biermann et al. 2004) as, although the acceleration of high-energy particles by internal shocks in the SGR1806-20 is a possibility (as discussed by Asano et al. (2005)), it is not relevant for our purposes. 


\section{Acknowledgements}

We wish to acknowledge the partial financial support of FAPESP and CNPq Agencies (Brazil) in the form of research scholarships to the authors. The CAPES Federal Agency has funded a joint program with Santa Clara University (Cuba) from which this work has benefited.

\section{Appendix A. Population dynamics}

The use of the $D_{10}$ doses throughout this work is a way of employing a common standard for population damage; by no means should it be considered a general lethal or critical ecological threshold. For that, more complex population dynamics should be taken into account.

One approach to understanding what can be considered a significant population depletion, where by significant we mean that the population is at risk of extinction, is to define the concept of the minimum viable population (MVP). This concept was first introduced by Shaffer (1981), considering the ecological and economical problems of keeping natural reserves as small as possible and still retaining biodiversity. Therefore, it is a concept usually adopted for macroscopic populations. As Shaffer stated:

'A minimum viable population for any given species in any given habitat is the smallest isolated population having a $99 \%$ chance of remaining extant for 1000 years despite the foreseeable effects of demographic, environmental, and genetic stochasticity, and natural catastrophes.'

Shaffer considered it an ad hoc definition, because there is no special reason for the choices of $99 \%$ and $1000 \mathrm{yr}$. He makes clear the necessity of adapting this definition to the system of interest.

The concept seems valid for a variety of systems: if a population becomes too small, it may become extinct. The problem is how to assess such a number, which is strongly dependent on the system and its interactions with its surroundings. Shaffer proposes five ways of doing so.

- Experiments. The viability of doing experiments depends on the system, because it is necessary to find or create isolated populations and follow their persistence for a time scale relevant to that species.

- Biogeographic patterns. The observations of distribution patterns that occur on islands or fragmented regions can give a first insight into the minimum areas required for the populations and, by estimating the densities, one can calculate the MVP. This approach requires the species already to be in equilibrium on the isolated regions, and that the time of isolation is known (by geological clues, for instance). However, the estimates may not be promptly extrapolated because the interspecies and environmental interactions can be very distinct.

- Theoretical models. There are many theoretical models which can predict the probability of survival of a small population but these normally are not based on realistic biological hypothesis, being over-simplified, or they get into unsolved mathematical problems. The diffusion theory, as applied by many authors, can be used on totally unpredictable environments.

- Numerical simulations. By not suffering the limitations of the purely theoretical models, these can be the most useful way to calculate the MVP. They can be more realistic and accept many more parameters from the actual biological system, allowing their prompt modification, as well as their interdependencies. However, the simulations are extremely specific to the system being modelled, failing to give general conclusions. They also need accurate knowledge of the critical parameters to assure a realistic simulation.

- Genetic considerations. Many authors follow genetic and evolutionary arguments to recommend MVP. Franklin (1980) suggests that, to keep short-term fitness, the effective size of the population has to be greater than 50 individuals. He also proposes that, for an environment in alteration, in order to assure sufficient genetic variability for adaptation, the number must be around 500. These recommendations are based on generalized applications of basic genetic principles, and thus they may suffer from over-simplifications.

Following the tendency to concentrate MVP calculations for macroscopic species endangered by extinction, a great deal of models take into account the so-called Allee effect, i.e. the sensitivity of a population to a low density of individuals owing to the difficult in finding mating partners. Microorganisms, in contrast with sexually reproducing ones, are not subjected to the Allee effect. However, horizontal gene transfer (HGT) seems to be an essential mechanism on the prokaryotic domain of life (Allers \& Mervarech 2005), which may imply an analogue of the Allee effect to guarantee genetic variability. It is clear that understanding the full importance of HGT is fundamental to comprehending the evolutionary processes during the unicellular era of the Earth. We must emphasize that, by neglecting the HGT, models that intend to predict the MVP for unicellular organisms may be underestimating it. As some authors suggest that up to $30 \%$ of the prokaryotic genetic material may be of HGT origin (Allers \& Mervarech 2005) we must consider that the difference between a purely vertical gene transfer (VGT) model and a VGT/HGT hybrid model should be significant on the MVP calculation. Theses values are not yet present in the literature.

Similarly to Franklin (1980), other authors (Soule 1986; Nunney \& Campbell 1993) have arrived at a MVP of 10 for microorganisms. Chiba (1998) makes a systematic analytical study of the problems of calculating the MVP in a general way, using as an example an exponentially growing population, which is a good model for microorganisms, but also neglecting HGT. In a similar approach, McCarthy (2001) calculates the MVP using stochastic methods and Monte Carlo simulations, arriving at the important result that, although populations may float abruptly with the variation of the model parameters (as perturbations), as long as the MVP is not reached, extinction should not take place. He also demonstrated that the MVP changed gradually, not abruptly, 
with parameter variations. This result validates the concept of MVP for extinction models.

As an experimental test for the theoretical MVP for microorganisms, Quang (1998) showed that the smallest viable population of a few species of aquatic bacteria, during the period of the experiment, fluctuated around 10 cells $\mathrm{ml}^{-1}$.

\section{References}

Allers, T. \& Mevarech, M. (2005). Nat. Rev. Genet. 6, 58-73.

Annis, J. (1999). J. Brit. Interplanet. Soc. 52, 19-25.

Asano, K., Yamazaki, R. \& Sugiyama, N. (2005). astro-ph/0503335 (in press).

Band, D. et al. (1993). Astrophys. J. 413, 281-292.

Biermann, P.L., Tanco, G.M., Engel, R. \& Pugliese, G. (2004). Astrophys. J. 604, L29-L32.

Cameron, P.B. et al. (2005). Nature 434(7037), 1112-1115.

Chiba, S. (1998). Paleobiology 24(3), 336-348.

Cockel, C.S. (1999). Paleobiology 25(2), 212-225.

Crutzen, P.J. \& Brühl, C. (1996). Proc. Natl Acad. Sci. USA 93, 1582-1584.

Dar, A. \& De Rújula, A. (2004). Phys. Rep. 405, 203-278.

Dar, A., Laor, A. \& Shaviv, N.J. (1998). Phys. Rev. Lett. 80(26), 5813-5816. Dermer, C.D. \& Holmes J.M. (2005). Astrophys. J. Lett. 628, L21-L24. Ellis, J. \& Schramm, D.N. (1995). Proc. Natl Acad. Sci USA 92, 235-238.

Frail, D.A. et al. (2001). Astrophys. J. Lett. 562, L55-L58.

Franklin, I.R. (1980). Conservation Biology: An Evolutionary-Ecological Perspective, pp. 135-150. Sinauer, Sunderland, MA.

Gaisser, T. (1992). Cosmic Rays and Particle Physics. Cambridge University Press, Cambridge.

Gascón, J., Oubiña, A., Pérez-Lezaun, A. \& Urmeneta, J. (1995). Curr. Microbiol. 30, 177-182.
Gehrels, N., Laird, C.M., Jackman, C.H., Cannizzo, J.K., Mattson, B.J. \& Chen, W. (2003). Astrophys. J. 585, 1169-1176.

Ghosal, D. et al. (2005). FEMS Microbiol. Rev. 29, 361-375.

Häder, D. \& Sinha, R.P. (2005). Mutat. Res. 571, 221-233.

Horvath, J.E. (2003). astro-ph/0310034 (unpublished).

Lipari, P. (1993). Astropart. Phys. 1, 399-415.

McCarthy, M.A. \& Thompson, C. (2001). Anim. Conserv. 4, 351-355.

Melott, A.L., Lieberman, B.S., Laird, C.M., Martin, L.D., Medvedev, M.V., Thomas, B.C., Cannizzo, J.K., Gehrels, N. \& Jackman, C.H. (2004). Int. J. Astrobiol. 3, 55-61.

Nakar, E., Piran, T. \& Sari, R. (2005). Astrophys. J. 635, 516-521.

Nunney, L. \& Campbell, K.A. (1993). Tree 8(7), 234-239.

Quang, P.M. (1998). J. Microb. Method. 33, 203-210.

Richard-Serre, C. (1971). CERN Report 71, 18.

Ruderman, M.A. (1979). Science 184, 1079-1081.

Shaffer, M.L. (1981). Science 31(2), 131-134.

Smith, D., Scalo, J. \& Wheeler, C. (2004). Icarus 171(1), 229-253.

Soulé, M.E. (1986). Conservation Biology: the Science of Scarcity and Diversity. Sinauer, Sunderland, MA.

Stanek, K.Z., Gnedin, O.Y., Beacom, J.F., Gould, A.P., Johnson, J.A., Kollmeier, J.A., Modjaz, M., Pinsonneault, M.H., Pogge, R. \& Weinberg, D.H. (2006). astro-ph/0604113 (in press).

Thomas, B.C., Jackman, C.H., Melott, A.L., Laird, C.L., Stolarski, R.S., Gehrels, N., Cannizzo, J.K. \& Hogan, D.P. (2005a). Astrophys. J. Lett. 622, L153-L156.

Thomas, B.C., Melott, A.L., Jackman, C.H., Laird, C.M., Medvedev, M.V., Stolarski, R.S., Gehrels, N., Cannizzo, J.K., Hogan, D.P. \& Ejzak, L.M. (2005b). Astrophys. J. 634, 509-533.

Thorsett, S. (1995). Astrophys. J. Lett. 444, L53-L55.

van Paradijs, J., Kouvelioutou, C. \& Wijers, R.A.M.J. (2000). Ann. Rev. Astron. Astrophys. 38, 379-425.

Vietri, M., de Marco, D. \& Guetta, D. (2003). Astrophys. J. 592, 378-389.

Yamazaki, R., Ioka, K., Takahara, F. \& Shibazaki, N. (2005). Publ. Astron. Soc. Jap. 57, L11-L15. 


\section{Astrobiology}

Astrobiology Manuscript Central: http://mc.manuscriptcentral.com/astrobiology

\section{Biological relevance of giant flares from Soft-Gamma Repeaters}

\begin{tabular}{|r|l|}
\hline Journal: & Astrobiology \\
\hline Manuscript ID: & AST-2008-0328 \\
\hline Manuscript Type: & Research Articles (Papers) \\
\hline Date Submitted by the \\
Author: & 20 -Dec-2008 \\
\hline Complete List of Authors: & $\begin{array}{l}\text { Galante, Douglas; Universidade de Sao Paulo, Instituto de } \\
\text { Astronomia, Geofisica e Ciencias Atmosfericas } \\
\text { Horvath, Jorge; Universidade de Sao Paulo, Instituto de } \\
\text { Astronomia, Geofisica e Ciencias Atmosfericas }\end{array}$ \\
\hline Keyword: & $\begin{array}{l}\text { Habitability, Life In Extreme Environments, Radiation Resistance, } \\
\text { Ozone, UV Radiation }\end{array}$ \\
\hline
\end{tabular}

\section{(5) ScholarONE \\ Manuscript Central}


Biological relevance of giant flares from Soft-gamma Repeaters

Title: Biological relevance of giant flares from Soft-Gamma Repeaters

\author{
Authors: \\ Douglas Galante \\ Instituto de Astronomia, Geofísica e Ciências Atmosféricas \\ Universidade de São Paulo \\ R. do Matão 1226, Cidade Universitária \\ 05508-090 São Paulo - SP, Brazil \\ douglas@astro.iag.usp.br \\ Jorge Ernesto Horvath \\ Instituto de Astronomia, Geofísica e Ciências Atmosféricas \\ Universidade de São Paulo \\ R. do Matão 1226, Cidade Universitária \\ 05508-090 São Paulo - SP, Brazil \\ foton@astro.iag.usp.br
}

Corresponding author: Douglas Galante (same address as above) 


\begin{abstract}
With the possible exception of meteor impacts, astrophysical events, such as supernovae, gamma-ray bursts and flares are often not taken on account on biological and evolutionary studies due to their low rates of occurrence. We show that a class of these events, the so-called giant flares from soft-gamma repeaters (SGR), may occur at a distance at which their biological effects are non-negligible in a recurrence time scale of a few hundred million years, which is comparable to that of intense volcanic activity. A brief discussion of these events as a driving force of the biosphere is also given.
\end{abstract}

\title{
Keywords
}

Soft-gamma repeaters

Giant flares

Extinction

UV radiation

UV flash

Ozone depletion 


\section{Introduction}

Soft-gamma repeaters are x-ray sources which emit quasi-periodic pulsed radiation, believed to be highly magnetized spinning neutron stars (ref. 14). Some of these SGR exhibit, from time to time, a significant intensification of their outburst, an increase of around 10000 times on the amplitude, in an event called giant flare. Models (ref. 14) show that one possible mechanism able to produce such increase is mainly magnetic, being produced by a sudden release of energy stored in its dipolar curled field. The impact of energetic radiation on life is important to assess habitability of planets other than Earth (ref. 10), which is a core subject of biosignature search programs on exo-planets and on the Solar system.

Four SGR are currently known on our Galaxy and on the LMC (denominated by their catalogue numbers SGR 1627-41, SGR 1900+14, SGR 0526-66, SGR 1806-20), and the last three of them have shown giant flare activity so far. Although it is a small number, if it represents a stationary source of flares, the integrated number of events may be physically relevant. It is still a matter of debate if the giant flare event is unique on the history of a SGR or can be repeated, and if the emission is beamed. The work of Terasawa et al (ref.11) suggests that the beaming if mild, of the order of tens of degrees. 
Considering these characteristics, we discuss if some of the giant flares could have occurred close enough to Earth in order to cause a biological perturbation, either by direct effects on the exposed biota or by altering the atmospheric chemistry. During around 3 billion years of Earth`s history, the biosphere was dominated by unicellular marine organisms (ref. 1), so, in order to roughly quantify the direct damages of radiation on the biota, some benchmark organisms were chosen.

\section{Giant flares}

A general picture emergent from the three well-observed giant flares indicates a quite similar pattern for those events, at a nominal rate of $\sim 1 / 10 \mathrm{yr}^{-1}$. The giant flares consist of a very intense spike with duration $\approx 0.2 \mathrm{~s}$ and a long decaying phase lasting $\approx 100 \mathrm{~s}$. Very clear signals of periodicity (with periods of $\sim$ seconds) have been seen in the latter, naturally associated with the rotation of the underlying neutron star. The spectra of each component are quite different, ranging from a quasi-thermal high-temperature distribution ( $\mathrm{T}_{\text {spike }} \approx 175 \pm 25 \mathrm{keV}$ ) for the initial spike, and then dropping to a much softer one ( $\mathrm{T}_{\text {tail }} \approx 10 \mathrm{keV}$ ) which further drops by a factor of $\approx 3$ at the end of the modulated "tail" phase lasting $\approx 400 \mathrm{~s}$ (all numbers given here pertain to the 27 December 2004 giant flare from the source SGR 1806-20, see ref. 5). The total 
isotropic-equivalent radiated energy (mainly in the initial spike) has been estimated as $\mathrm{E} \approx 4 \times 10^{46} \mathrm{~d}_{15}^{2} \operatorname{ergs}($ ref. 5), possibly being a lower limit as estimated by the non-saturated data of the Geotail experiment (ref. 11).

\section{The model}

In order to simulate the radiation flux due to giant flares on a planet at different positions on the Galaxy it was used a toy model consisting of a sphere, in whose center the planet was placed. For the Galaxy, two models were used, a 1D (flat) and a 2D (thick) disc. On the flat model the sphere was moved across de radius of the Galaxy, from 50 to $10000 \mathrm{pc}$, at a height of $6 \mathrm{pc}$ from the Galactic plane, simulating the position of the Sun. On the thick disk model, the sphere was moved both on radius (50 to $10000 \mathrm{pc}$ ) and height ( 0 to $200 \mathrm{pc}$ ).

Spheres of 20, 50 and 100pc radii were used, each one representing different levels of radiation arriving on the ground of the planet. These spheres will be termed spheres of influence. 1000 synthetic populations of active sources, with a fixed total number of 15 for the entire Galaxy, were generated, assuming to follow the spatial distribution of neutron stars according to the exponential laws as described by equations (1) and (2).

$$
N(R)=N_{0}^{R} e^{-\frac{R}{R_{e}}} \quad\left(\mathrm{R}_{\mathrm{e}}=3800 \mathrm{pc}\right)
$$




$$
N(Z)=N_{0}^{Z} e^{-\frac{Z}{Z_{e}}} \quad\left(Z_{\mathrm{e}}=70 \mathrm{pc}\right)
$$

In each of these populations, the number of events happening inside the sphere of influence was counted. The greater the number, the more prone that region of the Galaxy was to deliver high doses of radiation to the planet ground due to the giant flares of SGR. Varying the radius of the sphere allowed us to test different thresholds of radiation, and, in and indirect way, to probe the population depletion caused by these irradiation events (ref. 3).

\section{Benchmark organisms}

To convert from radiation fluxes to mortality rates - or population depletion we must assume a benchmark organism. In Galante and Horvath (ref. 3), we used two bacteria: Escherichia coli and Deinococcus radiodurans, which represented extremes on the radiation resistance of the known microorganisms, and have already been extensively studied. E. coli is an internal bacterium, being very sensitive to radiation, while $D$. radiodurans is a polyextremophile, being extremely resistant to radiation. For comparison, in the present work we included the aquatic cyanobacteria Anabaena sp. to model the resistance, since Earth's biosphere was dominated by marine photosynthetic organisms for most of its history (ref. 1). Cyanobacteria are also probably the oldest fossilized organisms 
on Earth, as the microfossils from the Apex chert, Western Australia, dating back to 3.46 billion years suggest (ref. 8).

Being photosynthesizing organism, cyanobacteria depend directly of the exposition to sunlight, so they must cope with UV damage. Their strategies vary from species to species, but can be divided in passive and active mechanisms (ref. 12). The passive ones consist on the use of some kind of molecular shielding, like the UV screening mycosporin-like amino acids and derivatives (MAAs). Active ones comprise cellular motility, the migration of cells inside microbial mats in response to the radiation intensity, not only to avoid the harmful effects, but also to optimize photosynthetic irradiance. As expected, the UV radiation resistance of cyanobacteria is around 10 times greater than that of $E$. coli, but still inferior of $D$. radiodurans, as presented on Table 1.

TABLE 1

The $10 \%$ survivability rate is an arbitrary figure, chosen uniquely for easier comparison of data. It doesn't represent by itself an ecological threshold for extinction, but it is expected that such sudden population depletion of the primary producers of the marine food chain would have a direct impact on the whole ecosystem.

\section{Results and discussion}


Our statistical model generated reproducible data when it was run for several times, and the results averaged.

Using the 1D model, we could calculate the number of events happening inside the sphere of influence at different Galactic radii during the age of the Galaxy, as show in Fig. 1, for spheres of 20, 50 and 100pc of radii. Smaller spheres stand for higher doses on the ground, because the flare would happen closer to the planet, but it also stands for smaller probabilities of occurrence. We can see that, for a planet at the Galactic radius of the Sun, there would be no events at 20pc, around 2-3 events at 50pc and around 16 events at 100pc.

FIG 1

It was also calculated the interval between events, which is presented in Fig. 2. For this, the Galactic age was not used as a constraint. At the position of the Sun, with a 20pc radius, the interval between events would be above 5 billion years; with 50pc around 2 billion years and with 100pc around 600 million years, which is in agreement with the results from Fig. 1. This can give us a way of addressing the dynamics of these processes, how they can be compared to other catastrophic events, such as volcanism and meteor impacts.

FIG 2

Using the 2D version of the model, we could recalculate the number of events happening inside the spheres as a function of both the galactic radius and height. 
With solar coordinates, the number of events is, on average, zero for the $20 \mathrm{pc}$ sphere, 3-9 for the 50pc one and 12-41 for the 100pc one, as can be seen in Fig. 3.

FIG 3

It is important to note that, if we must include the beaming effect on our model, the number of events we have calculated should decrease by a factor of $\frac{4 \pi}{\theta(s r)}$, or, around $1 / 3$ of the original values using the current beaming scenario for the giant flares of soft gamma repeaters (ref. 11). Naturally, the time between events should be scaled with the inverse of the latter.

It was calculated (ref. 3) that D10 doses could be deposited on a planet at distances of around 20pc from a SGR. Altering the sphere radius allowed us to change the deposited dose and, consequently, the depletion of the population. From 20 to 50pc, the flux would drop by a factor of 6.25 , and from 50 to $100 \mathrm{pc}$ by another factor of 4 . However, the survival curve is characteristic of each species, and normally has an exponential dependence with the radiation flux. This would imply on population depletions of the order of $10 \%$ at $50 \mathrm{pc}$ and $1 \%$ at 100pc. Although the direct population depletions are small at such distances, the majority of the irradiated energy would be deposited on the atmosphere, causing disturbances on its chemistry, mainly on the ozone layer, which could have consequences for life on a temporal scale of years (ref. 7). 


\section{Conclusions}

Giant flares are astrophysical events that are starting to be understood but there is still much to be learned about their sources and statistics. Our work is intended to point out the consequences of such events around the Galaxy for existing life on nearby planets.

Giant flares have already shown their possibility of causing alterations on our planet, as happened in 2004, when one of these events from the source SGR 180620 , at a distance of $\geq 10 \mathrm{kpc}$, affected Earth's ionosphere in a measurable way (ref. 2). As discussed here and in our previous work (ref. 3), should an event like this happen closer, in the tens of parsecs range, it is expected to cause massive impacts on the biota of any planet harboring life.

It is important to note that giant flares of soft gamma repeaters are unlikely to cause a global sterilizing event. The time scale for one giant flare happening close enough to Earth for such effect is longer than the age of the Galaxy, and even if one would happen, it would only affect the surface of one hemisphere of the planet due to its short duration and to the limited penetration of photons. However, flares at distances of tens to hundreds of parsecs are statistically feasible on the time scale of hundreds of Myr, and able to deliver radiation fluxes orders of magnitudes higher than the Solar one, affecting directly life and altering the atmospheric chemistry. The ecological consequences of these sudden events are yet to be modeled. 
In comparison with other cataclysmic events, the time scale of occurrence of flares is of the same order of magnitude of the impact of meteors that create craters larger than $100 \mathrm{~km}$ in diameter, which is a $10^{8} \mathrm{yr}$ (ref. 9), but still much larger than the time scale of supervolcanoes' activity, which is of the order of $10^{5} \mathrm{yr}$ (ref. 13).

With the current results, we could estimate the time interval of these biologically impacting events as a function of the position on the Galaxy, which could be used as an additional parameter when defining a Galactic habitable zone.

\section{Acknowledgments}

The authors would like to acknowledge the financial support from FAPESP, CNPq and CAPES Agencies in the form of fellowships and grants.

\section{Author Disclosure Statement}

No competing financial interests exist, for both authors. 


\section{References}

1. Billings L, Cameron V, Claire M, Dick GJ, Domagal-Goldman SD, Javaux EJ, Johnson OJ, Laws C, Race MS, Rask J, Rummel JD, Schelble RT and Vance S (2006) The Astrobiology Primer: An Outline of General Knowledge. Astrobiology 6(5): 735-813.

2. Campbell P, Hill M, Howe R, Kielkopf JF, Lewis N, Mandaville J, McWilliams A, Moos W, Samouce D, Winkler G, Fishman GJ, Price A, Welch DL, Schnoor P, Clerkin A, and Saum D (2005) SGR1806: Detection of a Sudden Ionospheric Disturbance. GCN Circ. 2932, http://gcn.gsfc.nasa.gov/gcn/gcn3/2932.gcn3

3. Galante D and Horvath JE (2007) Biological effects of gamma-ray bursts: distances for severe damage on the biota. Int. Jour. Astrobiology 6, 19-26.

4. Gascón J, Oubiña, A, Pérez-Lezaum A and Urmeneta, J (1995) Sensitivity of selected bacterial species to UV radiation, J. Curr. Biology 30: 177-182.

5.Hurley K, Boggs SE, Smith DM, Duncan RC, Lin R, Zoglauer A, Krucker S, Hurford G, Hudson H, Wigger C, Hajdas W, Thompson C, Mitrofanov I, Sanin A, Boynton W, Fellows C, von Kienlin A, Lichti G, Rau A and Cline T (2005) An exceptionally bright flare from SGR 1806-20 and the origins of short-duration $\gamma$-ray bursts. Nature 434, 1098-1103.

6. Levine,E and Thiel T (1987) UV-Inducible DNA Repair in Cyanobacteria Anabaena sp., J. Bacteriol. 169 (9):3988-3993. 
7. Mellot AL, Lieberman BS, Laird CM, Martin LD, Medvedev MV, Thomas BC, Cannizzo JK, Gehrels N and Jackman CH (2004) Did a gamma-ray burst initiate the late Ordovician mass extinction?, Int. J. Astrobiol. 3: 55-61.

8. Schopf JW and Packer BM (1987) Early Archean (3.3 Billion to 3.5 Billion-Year-Old) Microfossils from Warrawoona Group, Australia, Science 237: $70-73$.

9. Shoemaker EM (1983) Asteroid and Comet Bombardment of the Earth, Ann.Rev.Earth Planet. Sci. 11:461-494.

10. Smith DS and Scalo J (2007) Solar X-ray Flares Hazards on the Surface of Mars, Planet. Space Sci. 55(4): 517-527.

11. Terasawa T, Tanaka YT, Takei Y, Kawai N, Yoshida A, Nomoto K, Yoshikawa I, Saito Y, Kasaba Y, Takashima T, Mukai T, Noda H, Murakami T, Watanabe K, Muraki Y, Yokoyama T, Hoshino M (2005) Repeated injections of energy in the first $600 \mathrm{~ms}$ of the giant flare of SGR 1806-20, Nature 434, 1110.

12. Whitton BA and Potts M (2000) The Ecology of Cyanobacteria: Their Diversity in Time and Space (Springer), pp 599-603.

13. Wilson CJN (2008) Supereruptions and Supervolcanoes: Processes and Producs, Elements 4(1): 29-34. 
14. Woods, P and Thompson, C (2006), in Compact Stellar X-ray Sources, eds. Lewin W and van der Klis M (Cambridge Astrophysics Series No39). 


\section{Figure legends}

Fig 1: number of events inside the sphere of influence as a function of the Galactic radius, for spheres of 20, 50 and 100pc of radius.

Fig 2: time interval between events inside the sphere of influence as a function of Galactic radius, for spheres of 20,50 and 100pc of radius.

Fig 3: results of a 2D model of the Galaxy, showing the number of events for spheres of 20, 50 and 100pc as a function of Galactic radius and height.

\section{Table legends}

Table 1: Radiation fluxes for a $10 \%$ survival of populations of D.radiodurans, E.coli (ref. 4) and Anabaena sp. (ref. 6) after UV irradiation. 


\begin{tabular}{|c|c|c|c|}
\hline & D.radiodurans & Anabaena sp. & E.coli \\
\hline$F_{10}^{U V}\left(\mathrm{~J} / \mathrm{m}^{2}\right)$ & 553 & 360 & 22.6 \\
\hline
\end{tabular}

Table 1

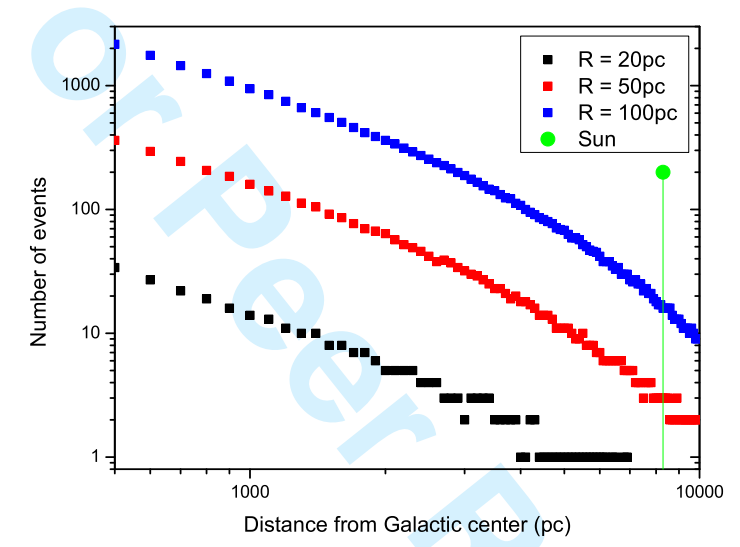

Fig 1

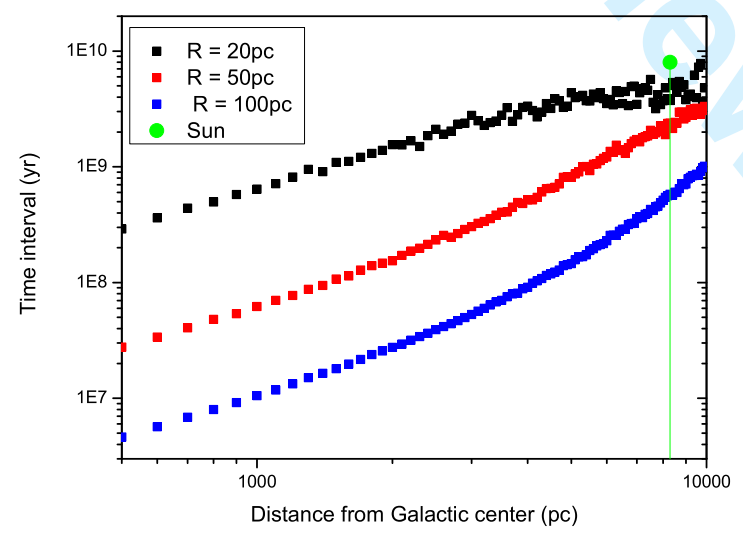

Fig 2 

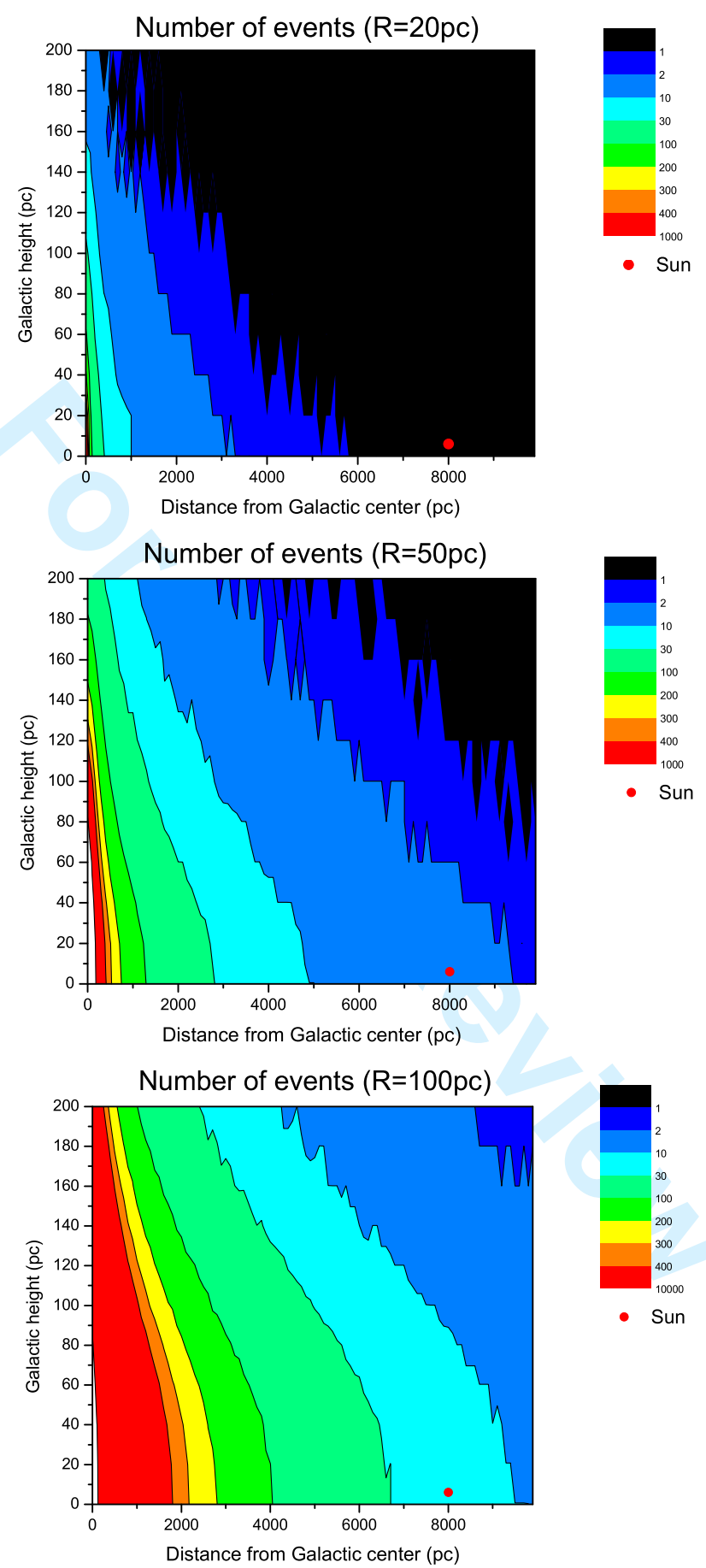

Fig 3 


\begin{tabular}{|c|c|c|c|}
\hline & D.radiodurans & Anabaena sp. & E.coli \\
\hline$F_{10}^{U V}\left(\mathrm{~J} / \mathrm{m}^{2}\right)$ & 553 & 360 & 22.6 \\
\hline
\end{tabular}

Table 1 


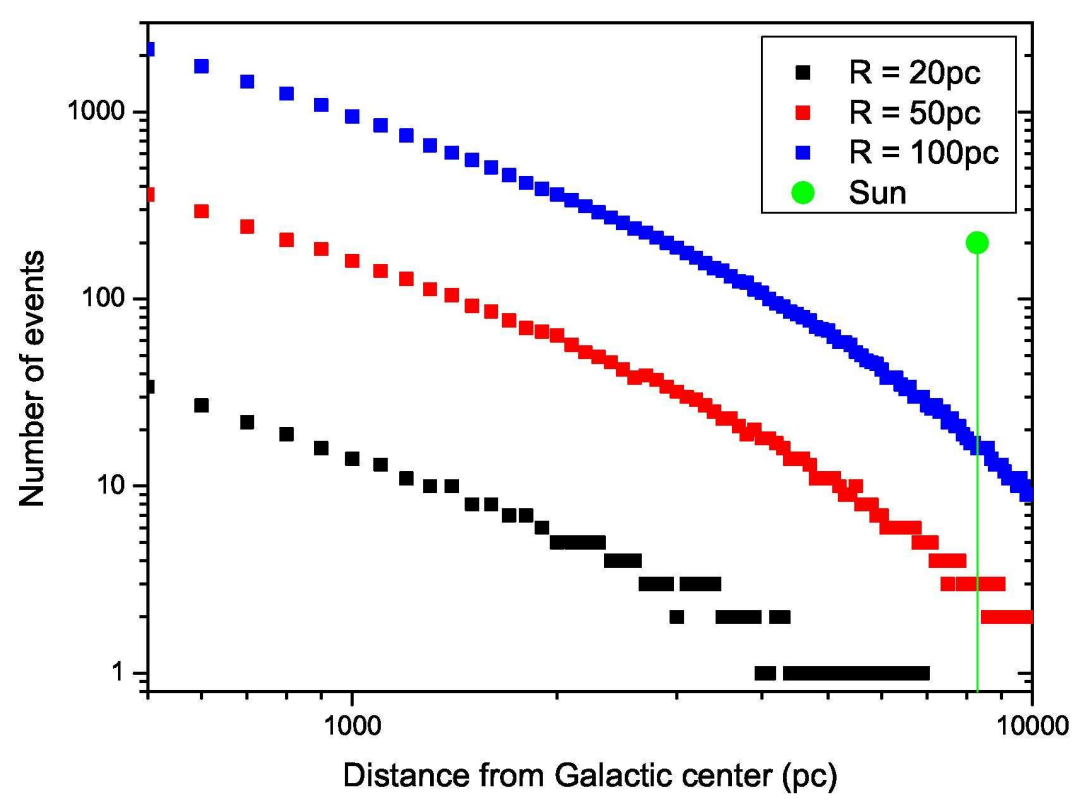

Number of events inside the sphere of influence as a function of the Galactic radius, for spheres of 20,50 and $100 \mathrm{pc}$ of radius.

$87 \times 62 \mathrm{~mm}(600 \times 600 \mathrm{DPI})$ 


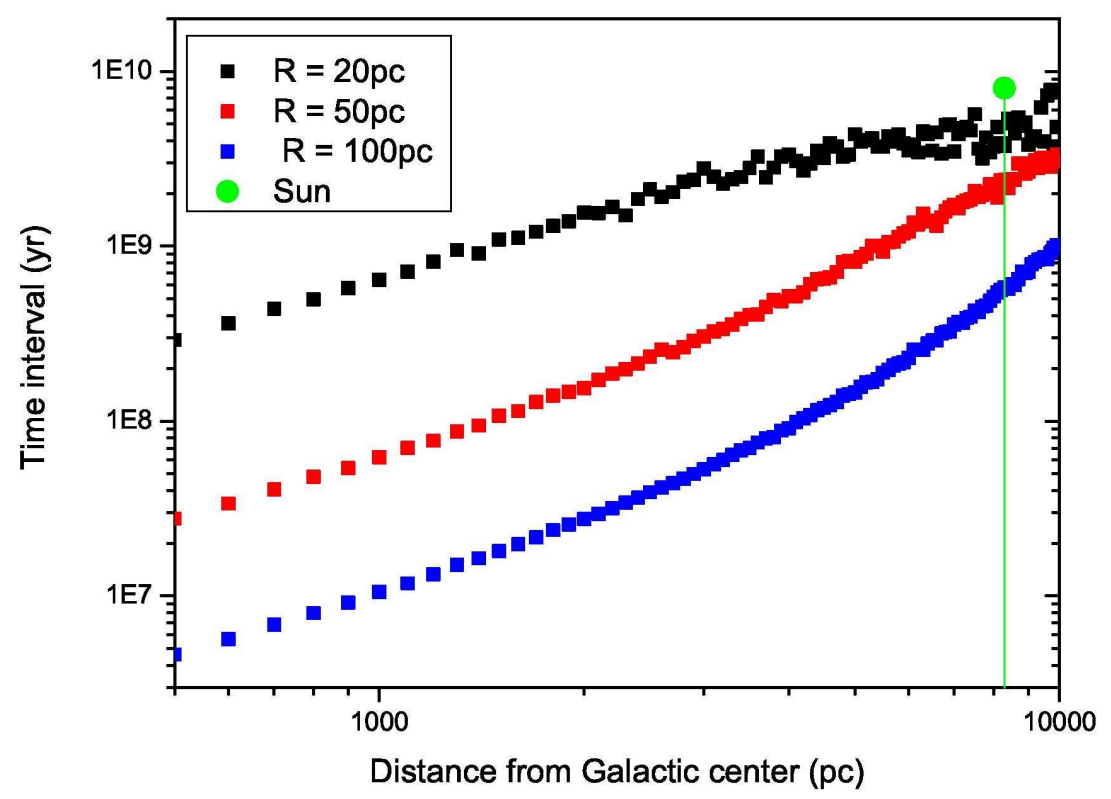

Time interval between events inside the sphere of influence as a function of Galactic radius, for spheres of 20,50 and $100 \mathrm{pc}$ of radius.

$87 \times 62 \mathrm{~mm}(600 \times 600 \mathrm{DPI})$ 

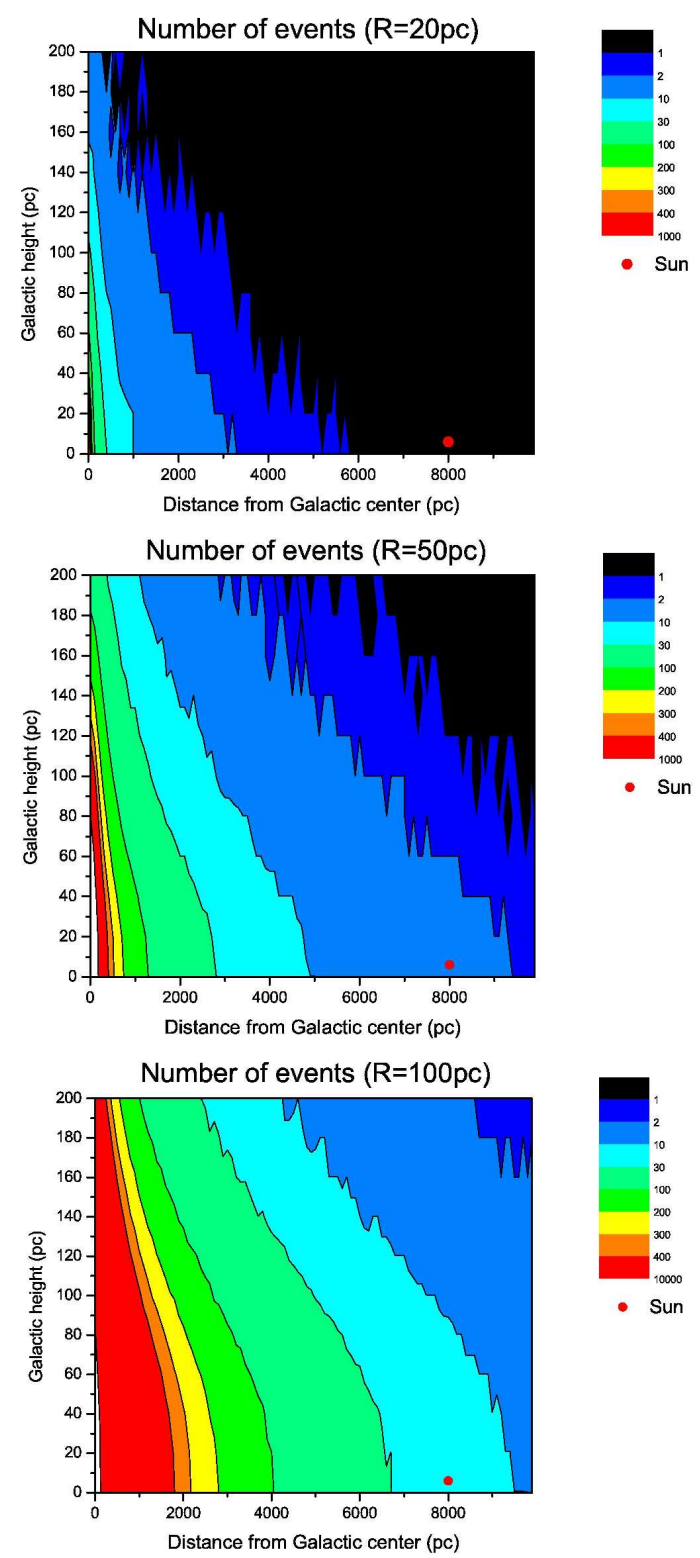

Results of a 2D model of the Galaxy, showing the number of events for spheres of 20,50 and 100pc as a function of Galactic radius and height. $87 \times 200 \mathrm{~mm}(600 \times 600$ DPI $)$ 
Short-term effects of Gamma Ray Bursts

\title{
Letter
}

\section{Short-term Effects of Gamma Ray Bursts on Earth}

\author{
Osmel Martín ${ }^{1}$, Douglas Galante ${ }^{2}$, Rolando Cárdenas ${ }^{3}$ and J.E. Horvath ${ }^{4}$ \\ ${ }^{1,3}$ Department of Physics, Universidad Central de Las Villas, Santa Clara, Cuba. \\ Phone 5342281109 Fax 5342281109 e-addresses: ${ }^{1}$ osmel@uclv.edu.cu; ${ }^{3}$ rcardenas@uclv.edu.cu \\ ${ }^{2,}{ }^{4}$ Department of Astronomy, Instituto de Astronomia, Geofisica e Ciências Atmosféricas, Universidade de \\ São Paulo,Brazil.e-addresses: ${ }^{2}$ douglas@astro.iag.usp.br; ${ }^{4}$ foton@astro.iag.usp.br
}

\begin{abstract}
The aim of the present work is to study the potential short-term atmospheric and biospheric influence of Gamma Ray Bursts on the Earth. We focus in the ultraviolet flash at planet's surface, which occurs as a result of the retransmission of the $\gamma$ radiation through the atmosphere. This would be the only important short-term effect on life. We mostly consider Archean and Proterozoic eons, and for completeness we also comment on the Phanerozoic. Therefore, in our study we consider atmospheres with oxygen levels ranging from $10^{-5}$ to 1 of the present atmospheric level, representing different moments in the oxygen rise history. Ecological consequences and some strategies to estimate their importance are outlined.
\end{abstract}

\section{I - Introduction}

During the Archean and Proterozoic eons the atmosphere of our planet evolved from very low oxygen content, perhaps lower than $10^{-5}$ of the present atmospheric level (pal) of $\mathrm{O}_{2}$, towards our modern Phanerozoic atmosphere with roughly $20 \% \mathrm{O}_{2}$. Many authors consider that the $\mathrm{O}_{2}$ rise in the Earth's atmosphere is intrinsically linked with the development of the first photosynthetic bacteria and with the termination of the chemical sinks which consumed it (Catling \& Clair, 2005; Catling, Zahnle \& McKay, 2001). Although many details on the evolution of our atmosphere remain controversial (Cockell, 2000; Cockell \& Raven, 2007), several authors accept that the irreversible increase of $\mathrm{O}_{2}$ took place around 2.3 billion of years ago, millions of years after the first evidences of photosynthetic life appeared in a global extension. Seemingly, this process was characterized by an abrupt increase of the $\mathrm{O}_{2}$ level from around $10^{-5} \mathrm{O}_{2}$ pal to around $10^{-1} \mathrm{O}_{2}$ pal in about 100 million of years. After this initial sudden rise, the oxygen levels have increased (with several fluctuations) up to the present value. Accordingly, we considered in the present study atmospheres with oxygen levels ranging from $10^{-5}$ to 1 of the present atmospheric level (pal), representing different moments in the oxygen rise history.

As we said above, many issues of the atmospheric composition and evolution during the Archean and Proterozoic are nowadays controversial. It is a big interdisciplinary challenge to make exact quantitative estimations on several issues in these eons. However, roughly speaking, we can consider that our studied atmospheres correspond with a reasonable approximation to past atmospheres and geologic times as we state in the Table 1 below. 


\begin{tabular}{|l|l|}
\hline $\begin{array}{l}\text { Oxygen content in present atmospheric } \\
\text { level }\left(\mathrm{O}_{2} \text { pal }\right)\end{array}$ & Geologic time \\
\hline 1 & $\begin{array}{l}\text { Late Proterozoic era and Phanerozoic eon } \\
(0.8 \text { Ga ago up to the present })\end{array}$ \\
\hline $10^{-1}$ or $10^{-2}$ & $\begin{array}{l}\text { Mid-Proterozoic era }(2.3 \mathrm{Ga}-0.8 \mathrm{Ga} \text { before } \\
\text { present })\end{array}$ \\
\hline $10^{-3}, 10^{-4}$ or $10^{-5}$ & $\begin{array}{l}\text { Archean eon and Early Proterozoic era }(3.8 \\
\mathrm{Ga}-2.5 \mathrm{Ga})\end{array}$ \\
\hline
\end{tabular}

Table 1 Model atmospheres studied and the geologic time in which they probably existed

During long periods of time, stochastic variation of the UV levels reaching the surface of Earth could have significantly influenced the evolution of life. Several astrophysical sources of radiation have been proposed, such as solar flares, supernovae explosions and Gamma-Ray Bursts (GRB) (Thorsett, 1995; Smith, Scalo \& Wheeler, 2004a; Thomas et al., 2005; Gehrels et al, 2003). For Earth-like planets with an atmospheric density $\rho>>100$ $\mathrm{g} / \mathrm{cm}^{3}$, the harmful influence is not directly associated to the primary ionizing flux, because the latter is strongly absorbed in the upper atmosphere. The most immediate effect on surface is the large UV reemission flux resulting from the interaction of primary radiation with the atmospheric constituents. This effect is usually called "UV-flash" and its biological relevance is related today mainly to the presence of UV blocking agents in the atmosphere, especially in the region of 200-310 nm. In this regard, oxygen plays a dual role in the atmosphere; the first is associated directly with its intrinsic absorption features mainly in the UV-C (100-280nm) band and the second in the ozone layer formation, which strongly absorbs in the UV-B (280-315nm) region.

However, the irradiation by energetic astrophysical sources could cause a massive depletion of the ozone layer resulting in an increase on the solar UV flux reaching the ground. This is likely to be the major impact on the UV radiation flux at a planet's surface if a significant ozone layer is present, as in today's Earth. The high-energy gamma rays from the burst should break apart $\mathrm{N}_{2}$ and $\mathrm{O}_{2}$, creating nitrogen oxides $\left(\mathrm{NO}_{\mathrm{x}}\right)$, which then catalyze ozone destruction. This, in turn, would allow more of the solar UV radiation to reach the planet's surface, which could remain enhanced for several years, until ozone layer recovers. Another planetary effects are likely to occur, and in general for a detailed modeling of the potential action of a GRB on the Phanerozoic Earth we recommend (Thomas et al, 2005) and references therein, while for a compact synthesis the work of Galante \& Horvath (2007) may be useful.

On the other hand, the atmosphere in Archean and Early-Proterozoic Earth presented low oxygen and, consequently, low ozone levels. A strong ozone UV shield, such as the one our planet had in the Phanerozoic eon, was absent. Thus, in our modeling, we have chosen not to take into account the effect of ozone depletion, and focused on the effect of UV retransmission only, the above mentioned "UV-flash". Basically, this would be the only important short-term effect on life. Warming of the atmosphere and alterations of its chemistry, with potential climatological and biological consequences, would be rather longterm influences. The detailed modeling of long-term effects of a GRB on these geologic 
times would entail a huge interdisciplinary challenge (Catling, 2008), and it is well beyond the scope of this study.

On the other hand, it has been suggested that the probability of direct effects from astrophysical events such as supernovae explosions or GRB's were potentially bigger during the early Earth (Scalo \& Wheeler, 2002), namely when atmospheric composition, climate and biosphere structure differed considerable from the present one. Events like GRB's should have had different consequences during the (seemingly) less protected life in the Archean or Early-Proterozoic Earth. No other efficient candidate to replace the ozone/oxygen screening properties in the atmosphere has been firmly established (Pavlov, Brown \& Kasting, 2001).

It can be argued that he retransmitted UV would play even a more important role in planets orbiting M stars, where flares are common in the first billion years of the star's life. These stars are the most common in our Galaxy and, if they are parent stars of planetary systems bearing life, they could induce stochastically varying mutation rates and frequent hypermutation episodes (Smith, Scalo \& Wheeler, 2004b).

\section{II - Basic assumptions}

\section{A - Spectrum of the Gamma Ray Burst}

The assumed broken power law for the GRB spectrum, and the parameterizations used in this work, were taken directly from (Smith, Scalo \& Wheeler, 2004a):

$$
\begin{aligned}
& \frac{d N}{d E}=k\left(\frac{E}{100 k e V}\right)^{\alpha} \exp \left(-E / E_{0}\right) \text { for } E \leq(\alpha-\beta) E_{0}, \\
& \frac{d N}{d E}=k\left[\frac{(\alpha-\beta) E_{0}}{100 k e V}\right]^{\alpha-\beta} e^{\beta-\alpha}\left(\frac{E}{100 k e V}\right)^{\beta} \text { for } E \geq(\alpha-\beta) E_{0},
\end{aligned}
$$

where $E_{0}=250 \mathrm{keV}, \alpha=-0.9$ and $\beta=-2.3$

The energy range considered was $50 \mathrm{keV}<\mathrm{E}<3 \mathrm{MeV}$. The original spectrum was split in 100 equal logarithmically spaced "monochromatic" energy bins with a corresponding value of mean energy and flux associated to each bin.

\section{B - Atmospheric Models}

For the atmospheric models, an exponential and well-mixed (except the ozone) atmosphere was considered. The main parameters used were

- Scale Height $(\mathrm{Ho})=8 \mathrm{~km}$

- $\operatorname{Density}(\rho)=1.3 \times 10^{-3} \mathrm{~g} / \mathrm{cm}^{3}$

First, we calculate the $\gamma$ energy deposition in the atmosphere and then, using these results, we compute the UV reemission. The actual composition of the atmosphere is quite 
irrelevant for $\gamma$ energy deposition studies, thus it was fixed to the present value without substantial error. However, atmospheric constituents are important for the UV reemission process and its consequent biological implications. Therefore, to estimate the UV radiation levels reaching the ground, our six different atmospheric compositions were used, respectively with $10^{-5}, 10^{-4}, 10^{-3}, 10^{-2}, 10^{-1}$ and $10^{0} \mathrm{O}_{2}$ pal. We then follow (Segura et al., 2003) in other aspects of our atmospheric models:

- We adopted their data for the ozone column.

- Ground atmospheric pressure was set to $1 \mathrm{~atm}$.

- We allowed $\mathrm{CO}_{2}$ to vary to fill in the rest of the atmosphere as oxygen is removed. This is important because $\mathrm{CO}_{2}$ was a dominant candidate gas in ancient environments and its spectroscopic characteristics can attenuate the radiation levels mainly in UV-C region (Cockell, 2000; Cnossen et al, 2007).

To implement the ozone column in each case, two procedures were applied. The first was a simple direct rescaling of the standard USA 76 atmosphere, and the second was a shift down of the entire ozone profile and then a rescaling of it to the appropriate case. It is well known that depletion of $\mathrm{O}_{2}$ tends not only to make the ozone layer thinner, but also closer to the troposphere (Segura et al, 2003; Kasting \&Catling, 2003). The second procedure attempts in a very rough way to mimic the latter effect.

\section{C - Interactions of Gamma rays with the atmosphere}

To study the interactions of $\gamma$ rays in the atmosphere we employed the general procedure described in Gehrels et al (2003). The atmosphere was splitted in 90 layers from 0 to 180 $\mathrm{km}$ and the wavelength range was splitted in 100 beams. Each normal incident energy beam was attenuated by an exponential Beer's law of the form $N_{i, j}=N_{i}^{0} e^{-\mu_{i} x_{j}}$ according to its own flux and mean energy, where $N_{i, j}$ is the photon flux remaining from the incident monoenergetic beam $N_{i}^{0} ; x_{j}$ is the column density (in $\mathrm{g} / \mathrm{cm}^{2}$ ) of the layer and $\mu_{i}$ is the corresponding mass attenuation coefficients taken from (Berger, M. et al, 2005). The energy deposited at each layer was determined using the difference between the total fluxes incident on adjacent layers:

$$
\text { Fdep, } i=\sum_{j=1}^{100}\left(N_{i, j}-N_{i, j-1}\right)
$$

For the UV-reemission treatment it was assumed that the emission follows roughly the law (Smith, Scalo \& Wheeler, 2004a):

$$
\frac{d F_{U V, i}}{d \lambda}=\frac{F d e p, i}{\lambda \ln \left(\lambda_{\max } / \lambda_{\min }\right)},
$$


where $F$ dep, $i$ is the total energy deposited in the $i$-th layer. The values $\lambda_{\max }$ and $\lambda_{\min }$ are associated to the typical limits of nitrogen bands and they were set to 130 and $600 \mathrm{~nm}$ respectively.

To compute the incident UV radiation fluxes on the surface of Earth, both photoabsorption and Rayleigh scattering were taken into account. The net effect at surface was computed as the sum of the emission effects of each layer.

\section{D - Biological Effects and critical Distances}

In this section we show how to calculate the critical distances of the GRB progenitors which would cause significant damages on the biota. To do this, we followed (Cockell, 2000; Cockell \& Raven, 2007), i. e., we use the action spectrum $e(\lambda)$ for DNA damage, convolve it with the incident UV flux density $E(\lambda)$, and calculate the effective biological irradiances or fluxes $E^{*}$ :

$$
E^{*}=\sum e(\lambda) E(\lambda) \Delta \lambda
$$

We then define and calculate the effective biological fluences $F^{*}$ :

$$
F^{*}=E^{*} \Delta t
$$

where $\Delta t$ is the exposure time to the UV radiation.

In what follows, the subscript $G R B$ will refer to the retransmitted UV radiation coming from the Gamma Ray Burst, and the subscript Sun will stand for the UV coming from the Sun. There is much variability between different species concerning their resistance to radiations, and therefore to define significant biological damage is a fuzzy problem. In our case, we modified the criterion used in (Thomas et al, 2005) for the action of a GRB on the Phanerozoic eon. Instead of using biological effective irradiances we introduce effective biological fluences (eq. 6), to describe the potential biological damage of UVR. We then assume the following condition for having significant marine mortality under the action of the UV flash:

$$
F_{G R B}^{*}=n F_{S u n}^{*}
$$

This means that in the exposure time of ten seconds to the UV flash, the organism would be exposed to an effective biological fluence which is $n$ times greater than the one they are used to receive in the whole day from the Sun. It seems reasonable to expect significant mortality of surface inhabitants of both the sea and land already for $n=1$, especially since in ten seconds the repair mechanisms will have very little time to act against such a huge effective biological fluence. Of course, mortality should not be expected to occur only during the exposure time, but also later as irreversible sequels take over. Another issue is the duration of a day in different eons. Although uncertainties remain concerning this, it seems that the length of the day in our planet has increased from some 15 hours in Early Archean up to our present 24 hours. We have adopted a median value of 20 hours and 
finally use its half (10 hours) for the actual daily exposition to the Sun. Differences in exposure time due to latitude or specific eon do not change appreciably the main results of this work.

To proceed we define a dimensionless effective biological irradiance $E^{*}{ }_{a d}$

$$
E_{a d}^{*}=\frac{E_{G R B}^{*}}{I_{G R B}^{t o p}}
$$

where $I_{G R B}^{t o p}$ is the full flux of the GRB at the top of the atmosphere. Combining eqs. (6-8) we obtain

$$
E_{a d}^{*} I_{G R B}^{t o p} \Delta t_{G R B}=n E_{S u n}^{*} \Delta t_{S u n}
$$

The fluence of the GRB at the top of the atmosphere is

$$
I_{G R B}^{\text {top }} \Delta t_{G R B}=\frac{E_{\gamma}}{\Delta \Omega \times D^{2}}
$$

In the above formula $E_{\gamma}=5 \times 10^{43} \mathrm{~J}$ is the gamma energy, $\Delta \Omega$ is the solid angle fixed to $0.01 \mathrm{sr}$ according to (Frail et al., 2001), and $D$ is the distance of the progenitor of the GRB. The absorption by the interstellar medium was not included in our analysis because it is almost completely transparent to high-energy photons.

Substituting eq. (10) into eq. (9) and solving for $D$ we obtain an expression to calculate the critical distances from which a GRB emission would cause significant surface mortality, as the condition given in eq. (7) is fulfilled

$$
D=\sqrt{\frac{E_{\gamma} \times E_{a d}^{*}}{\Delta \Omega \times \Delta t_{\text {Sun }} \times n \times E_{\text {Sun }}^{*}}}
$$

An issue here is to estimate $E^{*}$ Sun for our different atmospheres. We propose the following approximate procedure: we consider that the Archean atmosphere studied in (Cockell, 2000) corresponds to our $10^{-5}$ pal $\mathrm{O}_{2}$ atmosphere. From Fig. 5 of that paper it can be inferred approximate values of $80 \mathrm{~W} / \mathrm{m}^{2}$ and $20 \mathrm{~W} / \mathrm{m}^{2}$ for solar zenithal angles of $0^{\circ}$ and $60^{\circ}$ respectively. As a rough average we used $E^{*}{ }_{\text {Sun }}=50 \mathrm{~W} / \mathrm{m}^{2}$. Then we use Table 3 of (Segura et al, 2003), where $E^{*}$ Sun are normalized to the present value (in that reference paper the $E^{*}$ Sun have dimensions and are shown in Table 2). In that reference the authors only used the wavelength range (295-315) nm; so we are using this range as a proxy for all UV effects. This will imply some underestimation of $E^{*}$ sun because of the ozone absorption of the UV-C band in the range (200-280) nm. Therefore, the lesser the oxygen content of the atmosphere, the higher will be that underestimation. However, we consider that the errors introduced will be relatively small. 


\section{III - Results}

\section{A $-\underline{\text { Retransmitted ultraviolet radiation reaching the ground }}$}

The table below shows the UV energy reaching the ground, expressed as a fraction of the original incident gamma energy at the top of the atmosphere. In general, the fraction of the incident fluence which is retransmitted to UV is almost independent of the mean energy of the incident photons, because the number of secondary electrons available for molecule excitation only depends on the total energy of primary electrons. This last quantity depends on the total fluence of ionizing radiation, and not on the specific form of the spectrum of the GRB. Therefore, our reported values below are quite similar to those presented in Smith, Scalo and Wheler (2004b), actually a bit lower, as we replaced oxygen by $\mathrm{CO}_{2}$ and not by $\mathrm{N}_{2}$, as done in the mentioned reference.

\begin{tabular}{|c|c|c|c|c|}
\hline $\mathbf{O}_{2}$ pal & $\begin{array}{c}\text { UV-A } \\
\mathbf{3 1 5 - 4 0 0} \mathbf{~ n m}\end{array}$ & $\begin{array}{c}\text { UV-B } \\
\mathbf{2 8 0 - 3 1 5} \mathbf{~ n m}\end{array}$ & $\begin{array}{c}\text { UV-C } \\
\mathbf{1 3 0 - 2 8 0 ~} \mathbf{n m}\end{array}$ & $\begin{array}{c}\text { TOTAL } \\
\mathbf{1 3 0 - 6 0 0} \mathbf{~ n m}\end{array}$ \\
\hline $\mathbf{1 0}^{\mathbf{0}}$ & $2.330 \times 10^{-02}$ & $6.311 \times 10^{-04}$ & $3.043 \times 10^{-12}$ & $2.022 \times 10^{-01}$ \\
\hline $\mathbf{1 0}^{-1}$ & $5.867 \times 10^{-02}$ & $2.789 \times 10^{-03}$ & $2.418 \times 10^{-09}$ & $2.480 \times 10^{-01}$ \\
\hline $\mathbf{1 0}^{-2}$ & $6.484 \times 10^{-02}$ & $5.161 \times 10^{-03}$ & $4.817 \times 10^{-07}$ & $2.583 \times 10^{-01}$ \\
\hline $\mathbf{1 0}^{-3}$ & $6.598 \times 10^{-02}$ & $8.943 \times 10^{-03}$ & $5.802 \times 10^{-05}$ & $2.643 \times 10^{-01}$ \\
\hline $\mathbf{1 0}^{-4}$ & $6.616 \times 10^{-02}$ & $1.187 \times 10^{-02}$ & $2.338 \times 10^{-03}$ & $2.699 \times 10^{-01}$ \\
\hline $\mathbf{1 0}^{-5}$ & $6.617 \times 10^{-02}$ & $1.210 \times 10^{-02}$ & $2.933 \times 10^{-03}$ & $2.707 \times 10^{-01}$ \\
\hline
\end{tabular}

Table 2: UV energy reaching the ground expressed as fraction of the original incident gamma energy at the top of the atmosphere.

In order to make a better estimation of the biological damage of the GRB, we have also obtained the (more resolved) incident spectrum at the surface of the planet, as can be shown in Fig. 1. These UV irradiances are normalized to the full flux supplied by the GRB at the top of the atmosphere. The wavelengths below $200 \mathrm{~nm}$ were not considered, as they are almost totally absorbed in the atmosphere. 


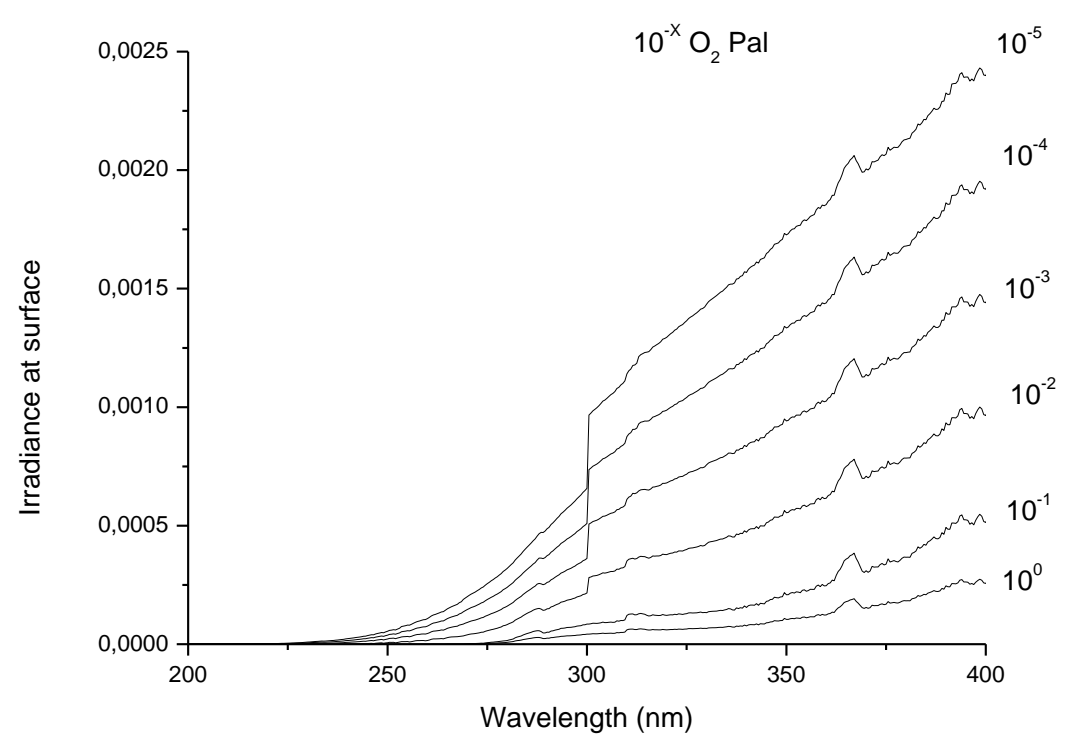

Fig. 1 UV irradiances reaching the ground for different atmospheres and wavelengths, normalized to the full flux of the GRB at the top of the atmosphere.

\section{B - Biological effective irradiances}

Applying the methodology described in subsection II-D, we convolved the above spectra with the action spectrum for DNA, to obtain the biological effective irradiances. Fig. 2 below shows the dimensionless irradiances for the studied atmospheres. As expected, the smaller the oxygen content, the greater the DNA damage caused by the GRB, as the atmosphere would have less ozone to shield the retransmitted UV.

We would like to comment on the relative importance of the flash here. Usually, the authors engaged in the modelling of the effects of GRB's on Earth tend to ignore the UV flash, largely based on the fact that the longer term effects are more important. In addition, in atmospheres having an oxygen-ozone shield, the UV-C band is almost totally absorbed, and its effective biological effect is relatively small, as can be seen in the two lower curves in Fig.2. However, with the decrease of the oxygen content, an important fraction of the very biologically damaging wavelengths below $280 \mathrm{~nm}$ pass through the atmosphere and reach the ground. Therefore, for atmospheres having from $10^{-3}$ to $10^{-5}$ pal (probably Archean and Early Proterozoic atmospheres), the peak of the effective biological irradiance is in the UV-C region, as can be seen in the upper three curves of the above figure. In our opinion, this makes worth to investigate the potential biological effects of the UV flash, especially for low-ozone atmospheres. 


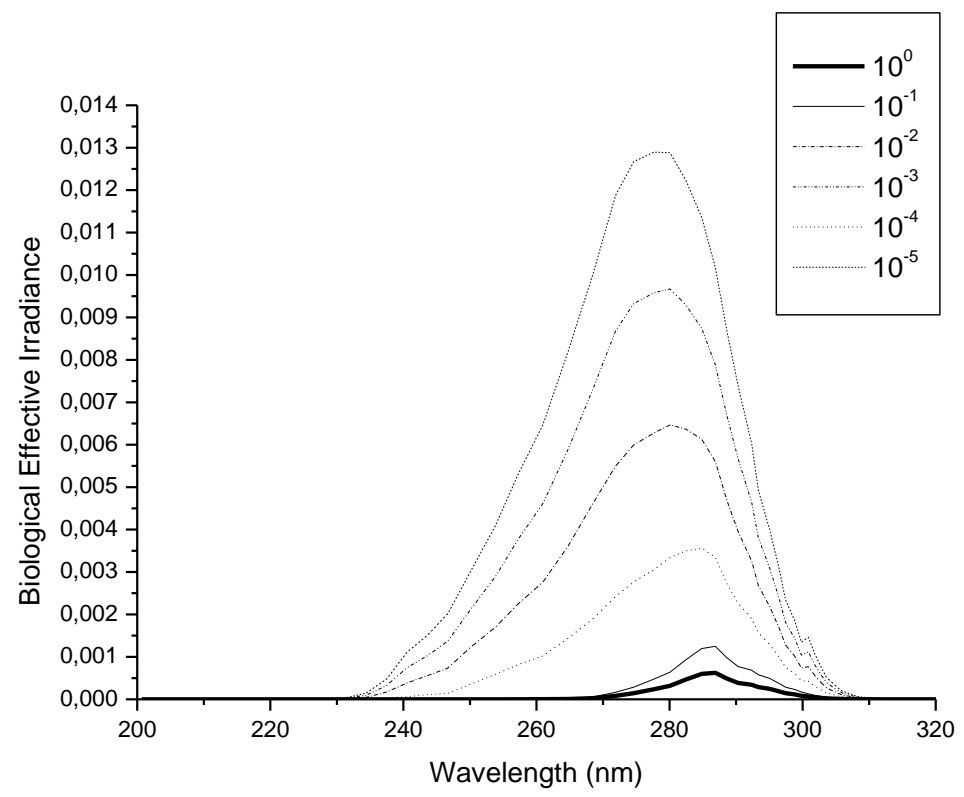

Fig. 2 Biological effective irradiances normalised to the full flux of the GRB at the top of the studied atmospheres. As expected, the lesser the oxygen content, the greater the DNA damage caused by the GRB.

\section{C-Critical Distances}

Applying the methodology described in subsection II-B, we have obtained the critical distances for our criteria for severe damage to the biota. We have several values for the parameter $n$ and have denoted correspondingly the critical distances $D_{n}$. Of course, the greater the value of $n$, the greater the biological damage. (Thomas et al, 2005) assumed that $n=2$ would cause significant marine mortality, especially in phytoplankton, which lives near the surface, as it needs light to make photosynthesis. However, we remind the reader that we have used effective biological fluences, while they used fluxes.

Also, as our work is concerned with several eons, we point out that having a greater instantaneous damage caused by the GRB (as seen in the former subsection) by no means imply a greater final or definitive damage, because we should also consider the solar UV instantaneous damage which the species is used to live with. Obviously, these two magnitudes increased with the reduction of the oxygen content, as seen in Table 3, which also shows a set of critical distances. 


\begin{tabular}{|l|l|l|l|l|l|l|}
\hline $\begin{array}{l}\mathrm{O}_{2} \text { content } \\
(\mathrm{pal})\end{array}$ & $\mathrm{E}^{*}{ }_{\mathrm{ad}}$ & $\begin{array}{l}\mathrm{E}^{*} \mathrm{Sun} \\
\left(\mathrm{W} / \mathrm{m}^{2}\right)\end{array}$ & $\mathrm{D}_{2}(\mathrm{kpc})$ & $\mathrm{D}_{4}(\mathrm{kpc})$ & $\mathrm{D}_{8}(\mathrm{kpc})$ & $\mathrm{D}_{16}(\mathrm{kpc})$ \\
\hline 1 & 0.005028 & 0.009158 & 4.45 & 3.14 & 2.22 & 1.57 \\
\hline $10^{-1}$ & 0.01006 & 0.01410 & 5.07 & 3.58 & 2.53 & 1.79 \\
\hline $10^{-2}$ & 0.042528 & 0.09561 & 4.00 & 2.83 & 2.00 & 1.42 \\
\hline $10^{-3}$ & 0.084888 & 1.9610 & 1.25 & 0.88 & 0.63 & 0.44 \\
\hline $10^{-4}$ & 0.1283 & 33.4535 & 0.37 & 0.26 & 0.18 & 0.13 \\
\hline $10^{-5}$ & 0.1719 & 50 & 0.35 & 0.25 & 0.17 & 0.12 \\
\hline
\end{tabular}

Table 3: Critical distances for the UV-flash to double the effective biological fluence caused by the solar UV. Note: $1 \mathrm{kpc}=3.1 \times 10^{19} \mathrm{~m}$

\section{IV - General discussion}

From above section we can infer:

1) Phanerozoic, Late- and Mid-Proterozoic biospheres would be, in the short-term, the more stressed by the UV flash of a GRB coming from several kpc. Note that even to potentially cause a damage 16 times greater than that of the solar UV (last column), the critical distances for those eras are namely the estimated for the "last typical nearest burst" potentially striking Earth in the last billion years, which is considered to have been emitted at one or two kpc from our planet. Thus, it could be interesting to include this effect in the very detailed modeling of long-term effects of a GRB on Phanerozoic eon (Thomas et al, 2005).

2) For a given distance to the GRB progenitor, the ecosystems living in $\sim 10^{-1}$ pal atmosphere would feel a greater immediate stress. This roughly corresponds to a Mid-Proterozoic atmosphere.

3) The last three rows of Table 3 indicate that the less protected ecosystems are not necessarily the more affected. They would certainly receive a higher biological fluence from a GRB, but they were somehow used to receive higher effective biological fluences from the everyday Sun. Therefore, it is appealing to think that during the Archean and Early Proterozoic the biota more resistant to radiations was on the land. Therefore, a GRB would affect it less than later biota used to live in milder photobiological environments, such as those from the Mid-Proterozoic up to the present.

\section{V - Conclusions}

In this work we have estimated the biological importance of the UV-flash which a GRB would deliver on our planet's surface, considering different model atmospheres, potentially representing the main stages of the geological and biological evolution of our planet. 
At first glance, one might think that the UV-flash is just a transient short -term effect, because a typical long burst only lasts from 10 seconds to a minute, thus affecting directly only one hemisphere during a small time. On above grounds, this effect is not usually considered. However, although the irradiation time is short, mortality of surface organisms can occur later as a result of irreversible DNA damages and other harmful biochemical effects in exposed cells. Phytoplankton, obliged to live in the light-exposed zone of aquatic ecosystems, would certainly be a primary target. We have defined an effective biological fluence to have a better account of biological damage, and we have shown that the brief UV-flashes from GRB's emitted at distances of the order of kpc are capable of doubling the solar UV effective biological fluence of a whole day (Table 3). The consequent damage on phytoplankton and other surface groups could be transmitted trophically to other ecological niches, creating longer-term detrimental effects on the biota. Actually, at the moment there is the hypothesis that the minor marine extinction of tropical mollusks around two million years ago was caused by a similar mechanism: radiation coming from a nearby supernova firstly affected phytoplankton and later this was trophically transmitted to low-mobility groups such as bivalve mollusks (Benítez, Maiz-Apellaniz \& Canelles, 2002). The aquatic ecosystems have always hosted an important fraction of global primary productivity in our planet. For instance, today the ocean accounts for about half of global primary productivity and, accordingly, half of $\mathrm{CO}_{2}$ fixation and $\mathrm{O}_{2}$ evolution (Behrenfeld et al, 2005). Thus, even modest effects on oceanic productivity could have major repercussions throughout the whole marine food chain and, through atmospheric effects, the global climate (Thomas, 2009).

We also would like to comment on another point now. Most times we expect Nature to respond linearly to small perturbations. However, ecologists are detecting abrupt changes in ecosystems due to small changes in a given parameter. This is quite analogous to phase transitions in physical systems. Seemingly, there are thresholds in many ecosystems, which determine the rapid shift to another state (van Nes \& Scheffer, 2004). There is some empirical evidence showing that several aquatic ecosystems have undergone relatively rapid phase shifts during the past century (Scheffer et al, 2001). Therefore, under some circumstances, a short-term perturbation can provoke a rapid phase shift of an entire ecosystem. We are now checking whether a brief UV-flash can cause abrupt phase transitions in aquatic ecosystems, and in some cases the answer has been affirmative. We will present this in a forthcoming paper.

We are aware of the fact that potential long-term effects, such as alterations of the atmospheric chemistry with its subsequent effects, should have priority when modeling the influence of a GRB on our planet. However, as new developments make the modeling more accurate, the inclusion of the UV-flash as an initial scenario to infer the long-term effects could shed more light on what a GRB would cause in our planet. Perhaps interesting surprises are waiting for the model builders.

\section{Acknowledgements}

The authors would like to acknowledge the financial support from FAPESP (Brazil), in the form of fellowships, and CAPES (Brazil), which has funded a joint program USP (Brazil)-Universidad Central de Las Villas, Santa Clara (Cuba). This work has received a very important benefit from this support. 


\section{References}

Behrenfeld, M., Boss, E., Siegel, D., \& Shea, D. 2005, Carbon-based ocean productivity and phytoplankton physiology from space, Global Biogeochem. Cy., 19, GB1006

Benítez, B., Maíz-Apellaniz, J., \& Canelles, M. 2002, Evidence for Nearby Supernova Explosions, Phys. Rev. Lett. 88, 081101

Berger, M., Hubbell, J., Seltzer, S., Chang, J., Coursey, J., Sukumar, R., \& Zucker, D. 2005 (last update), XCOM: Photon Cross Sections Database. http://physics.nist.gov/PhysRefData/Xcom/Text/XCOM.html

Catling, D., 2008. Personal communication

Catling, D., \& Claire, M. 2005, How Earth's atmosphere evolved to an oxic state: A status report, Earth and Planetary Science Letters, 237, 1-20

Catling, D., Zahnle, K., \& McKay C. 2001, Biogenic Methane, Hydrogen Escape, and the Irreversible Oxidation of Early Earth, Science, 293, 839-843

Cnossen, I., Sanz-Forcada, J., Favata, F., Witasse, O., Zegers, T., \& Arnold, N. 2007, Habitat of early life: Solar X-ray and UV radiation at Earth's surface 4-3.5 billion years ago, Journal of Geophysical Research, 112, E02008

Cockell, C. 2000, Ultraviolet radiation and the photobiology of Earth's early oceans, Origins of life and Evolution of the Biospheres, 30, 467-499

Cockell, C., \& Raven J. 2007, Ozone and life on the Archaean Earth, Phil. Trans. R. Soc. A, 365, 1889-1901

Frail, D., Kulkarni, S., Sari, R., Djorgovski, S., Bloom, J., Galama, T., Reichart, D., Berger, E., Harrison, F., Price, P., Yost, S., Diercks, A., Goodrich, R., Chaffee, F. 2001, Beaming in Gamma-Ray Bursts: Evidence for a Standard Energy Reservoir, Astrophys. J. Lett., 562, L55-L58.

Galante, D., \& Horvath J. 2007, Biological effects of gamma-ray bursts: distances for severe damage on the biota, International Journal of Astrobiology, 6, 19-26

Gehrels, N., Laird, C., Jackman, C., Cannizzo, J., Mattson, B., \& Chen, W. 2003, Ozone depletion from nearby supernovae, The Astrophysical Journal, 585, 1169-1176

Kasting, J., \& Catling, D. 2003, Evolution of a habitable planet, Annu.Rev.Astrophys, 41, 429-463

Pavlov, A., Brown, L., \& Kasting, J. 2001, UV shielding of $\mathrm{NH}_{3}$ and $\mathrm{O}_{2}$ by organic hazes in the Archean atmosphere, Journal of Geophysical Research 106, 1-21 
Scalo, J., \& Wheeler, J. 2002, Astrophysical and Astrobiological Implications of GammaRay Burst Properties, Astrophys. J., 566, 723-729

Scheffer, M., Carpenter, S., Foley, J., Folke, C. \& Walker, B. 2001, Catastrophic shifts in ecosystems, Nature 413, 591-596

Segura, A., Krelove K., Kasting J., Sommerlatt D., Meadows V., Crisp D., Cohen, M., \& Mlawer, E. 2003, Ozone concentrations and ultraviolet fluxes on Earth- like planets around other stars, Astrobiology 3(4), 689-708

Smith, D., Scalo J., \& Wheeler J. 2004a, Transport of ionizing radiation in terrestrial-like exoplanet atmospheres, Icarus, 171, 229-253

Smith, D., Scalo J., \& Wheeler J. 2004b, Importance of Biologically Active Aurora-like Ultraviolet Emission: Stochastic Irradiation of Earth and Mars by Flares and Explosions, Origins of Life and Evolution of the Biospheres, 34(5), 513-532

Thomas, B., 2009. Personal communication

Thomas, B., Melott, A., Jackman, C., Laird, C., Medvedev, M., Stolarski, R., Gehrels, N., Cannizzo, J., Hogan, D., Ejzak, L. 2005, Gamma-Ray Bursts and the Earth: Exploration of Atmospheric, Biological, Climatic and Biogeochemical Effects, Astrophys. J., 634, 509-533

Thorsett, S. 1995, Terrestrial Implications of Cosmological Gamma-Ray Burst Models, Astrophys. J., 444 (1995) L53

van Nes, E., \& Scheffer, M. 2004, Large species shifts triggered by small forces, Am. Nat., 164, 225-266 


\title{
Biological insights of population depletion under different radiation backgrounds
}

${ }^{1,2}$ Robersy Sanchez, ${ }^{3}$ Rolando Cardenas, ${ }^{4}$ Douglas Galante and ${ }^{4}$ Jorge Ernesto Horvath

${ }^{1}$ Research Institute of Tropical Roots, Tuber Crops and Bananas (INIVIT). Biotechnology Group. Santo Domingo. Villa Clara. Cuba.

${ }^{2}$ Center of Studies on Informatics. Central University of Las Villas. Santa Clara. Cuba. ${ }^{3}$ Astrobiology and Cosmology Group. Central University of Las Villas. Santa Clara. Cuba.

${ }^{4}$ Instituto de Astronomia, Geofísica e Ciências Atmosféricas, Universidade de São Paulo, São Paulo, Brazil

\begin{abstract}
We propose in this work a simple general model for radiation-induced damages to living populations of organisms. The model is shown to fit the radiation-induced dose response curves for several cases. Due to the enzymatic nature of repair system, the starting point to state the new model is the Michaelis-Menten kinetic model. Available published data are used to verify the statistical signification of the nonlinear regression. The proposed model is also embedded into more general ecological descriptions to study the stability of populations in varying radiation background environments. Our population dynamics models suggest that whenever the repair systems can keep the birth rate values going above the lethally rate, populations under radiation disturbance can survive reaching new stationary states.
\end{abstract}




\section{Introduction}

Radiations are ubiquitous in most parts of our Universe, so we expect that most life forms evolve in a radioactive environment. In Earth, we are under the influence of both a constant field of ionizing radiation from cosmic rays and radiations emitted from radioactive elements in our rocky planet, such as radium, plutonium, uranium, radon, ${ }^{14} \mathrm{C}$, and ${ }^{3} \mathrm{H}$. Ionizing radiation is in the air we breathe, the food we consume, the buildings we live in, and the soil we live on [1]. Mutations continuously occur in the genomes of all living organisms, at a very low frequency, which tends to be constant for a specific species. That frequency is increased when the living organism is exposed to higher doses of radiations. Highly efficient mechanisms of DNA repair explain the fact that in some areas with a relatively high level of radiation, harmful effects on the biota are not noticeable [2]. For an area in China dose rates of about 3-4 mGy/year have been reported $[3,4]$ and on the Southwest coast of India the doses from external radiation by monazite deposits is 5-6 mGy/year with maximal doses of up to $32.6 \mathrm{mGy} / \mathrm{year}$ [5]. Along certain beaches in Brazil, where monazite sand deposits are found, external radiation levels range up to $400 \mathrm{mGy} /$ year [6].

Some organisms have acquired a high resistance to radiation, either by direct selective pressure, in radiation rich environments, or by chance, as a by-product of other adaptations. The later is commonly accepted to be the case, for instance, of the species Deinococcus radiodurans. This organism beats most of the constraints for survival of life - radiation, cold, dormancy, oxidative damage, and other factors [7]. Its exceptional high radiation resistance is now associated with the gene irrE. It is possible that genes like irrE or similar sequences may also be found in mammals, as evidences suggest that DNA repair mechanisms have been preserved during evolution. Darwinian evolution is an economical process, and this explains why many of the human repair genes have 
already also been found on the ever expanding database of genetic sequences for model organisms [8]. A comprehensive list of DNA repair genes found in humans is presented in [8] and an interesting analysis of the expression patterns of DNA repair in higher plants can be found in [9].

Fingerprints of life extinction history could be found in the repair genes conserved during evolution. The exact biological signature of extinctions may be quite complicated and somewhat obscured in fossil records. A first examination of the fossils suggest, however, a clear correlation between the extinction pattern of different species, their vulnerability to ionizing radiation and the sheltering provided by their habitats and the environment they live in. For instance, insects, which are less vulnerable to radiation (by a factor of 10 or 20 respect to vertebrates), were extinct only in the greatest extinction: the end Permian, 251 Myr ago. Even then only 8 out of 27 orders were extinct compared with a global extinction rate of around 95\%. Mountain shadowing, canyons, caves, underground habitats, deep underwater habitats and high mobility may also explain why many species like crocodiles, turtles, frogs, snakes, deep sea organisms and birds were little affected in the Cretaceous/Tertiary boundary extinction which claimed the life of the big dinosaurs and pterosaurs [10].

The most frequently invoked extraterrestrial mechanisms for life extinctions in the geologic past are impacts (asteroids or comets) and radiation increasing events, such as supernovae [11,12], cosmic ray jets [10,13] and gamma ray bursts [14]. In this work we shall focus on the consequences of such an increase on the radiation background levels. The shockwave of impacts, the radiation joints from supernovae and gamma ray bursts and the energetic particles from cosmic ray jets may considerably deplete the ozone layer, resulting in higher levels of solar UV radiation on the ground. Cosmic ray jets, 
through their interaction with the atmosphere, may additionally produce a muon shower, capable of deep underwater and underground penetration, down to hundreds of meters. In this paper we present additional considerations on the survival/death probabilities of species exposed to high levels of radiation, considering the DNA repair mechanisms. It will be shown that dose-response curves can be explained in terms of kinetic considerations of the repair system and cellular susceptibility/resistance to radiation. In addition, the dose-response model was used in an interacting population models to study population depletion under different radiation backgrounds. Considering the fact that by 3500 million years ago, most of the principal biochemical pathways that sustain the modern biosphere must have already evolved and were global in scope [14], we think that our model can shed some more light on surviving chances on past and on present species exposed to high levels of radiation in the geological past.

\section{Dose-response models}

All organisms suffer a certain number of mutations as the result of normal cellular operations or random interactions with the environment. These are called spontaneous mutations; the rate at which they occur is characteristic for a particular species and is sometimes called the background level. So, all organisms have repair systems to protect themselves against damage from the environment or errors that may occur during replication. The repair systems are as complex as the replication apparatus itself, which indicates their importance for the survival of the cell. When a repair system reverses a change on DNA, there is no consequence. But a mutation may result when it fails to do so. The measured rate of mutation reflects a balance between the number of damaging events occurring in DNA and the number that have been corrected (or miscorrected) [15]. Thus, the subsequent action of DNA repair processes either removes the lesion(s) or misrepairs the induced damage. 
Spontaneous mutations that inactivate gene function occur in bacteriophages and bacteria at a relatively constant rate of $3-4 \times 10^{-3}$ per genome per replication [2]. A common mutation rate for different organisms suggests that this rate is the product of a selective pressure. Indeed, this rate must have been shaped in response to evolutionary forces of a very general nature, forces independent of kingdom and niche. There is not reliable measurement of the rate of mutation in eukaryotes, although usually it is thought to be somewhat similar to that of bacteria on a per-locus per-generation basis (see [17]). Next, it has been pointed out that the overall rate of mutation has been subject to selective forces that have balanced the deleterious effects of most mutations against the advantageous effects of some mutations. So, the background level of mutation describes the rate at which sequence changes accumulate in the genome of an organism. It reflects the balance between the occurrence of spontaneous mutations and their removal by repair systems, and is characteristic for any species $[17,18]$. This statement is strengthened by the analysis of spontaneous mutation in the thermoacidophilic archaeon Sulfolobus acidocaldarius. Under the harsh conditions of high temperature and acidity where this archaea lives, higher rates of spontaneous DNA damage might be expected than occurring in other organism under optimal conditions. Sulfolobus acidocaldarius does not show an elevated mutation rate, but in fact has an overall mutation rate just below the average range about $1.8 \times 10^{-3}$ mutations per genome per replication [16]. The balance between the occurrence of spontaneous mutations and their removal by repair systems is also manifested in the increased resistance to radiation damage in Drosophila sp. laboratory populations that have been exposed to radiation for a long time.

Now, let be $N_{D}$ the number (density) of DNA damages in organism resulting of normal cellular operations and random interactions with a given environment and $N_{M}$ the 
number of mutation remaining after the corrections of the repair systems on DNA. The $N_{D}$ value can be given as the number of mutations per base pair in the DNA molecule or the number of mutations per locus. Since the repair processes are achieved by enzymatic systems, it can be set out the general quasi-chemical equation:

$$
N_{D} \stackrel{\text { Enzymes }}{\longrightarrow} N_{M}
$$

At this point, in order to make possible a kinetic analysis the following assumptions are proposed

Assumption 1: The rate of DNA repair reactions $V_{\text {rep }}$ satisfy the Michaelis-Menten equation

$$
V_{\text {rep }}=\frac{V_{\max } N_{D}(t)}{K_{M}+N_{D}(t)}
$$

where $V_{\max }$ and $K_{M}$ are the maximal repair rate and the Michaelis-Menten constant, respectively.

Assumption 2: The rate of enzymatic DNA repair mechanisms is determined by the rate of the slowest enzymatic reaction and the $N_{M}$ value can be estimated as

$$
N_{M}=c \frac{V_{\max } N_{D}(t)}{K_{M}+N_{D}(t)}
$$

where the kinetic parameters $V_{\max }$ and $K_{M}$ characterizes the slowest repair step and $c$ is a proportionality constant.

In this study, radiations are considered the main source of DNA damage. The number of DNA damages due to spontaneous mutations is too small in respect of those due to radiations $\left(N_{R}\right)$ and the $N_{D}$ value can be approximated by $N_{R}$, i.e. $N_{D} \approx N_{R}$. In addition, the number of DNA damages due to radiations $\left(N_{R}\right)$ can be estimated as a function of radiation dosage, i.e.: $N_{R}=f(D)$. So, according to last assumptions, it can be written

$$
N_{M}=c \frac{V_{\max } f(D)}{K_{M}+f(D)}
$$


The term $c V_{\max }$ could be considered equal to the maximum number of DNA damages $N_{\max }$ that can be processed by the repair systems of a given organism, i.e. $c V_{\max }=N_{\max }$ and (3) can be rewritten as

$$
N_{M}=\frac{N_{\text {max }} f(D)}{K_{M}+f(D)}
$$

This equation leads us to two limit conditions. If $K_{M}>>f(D)$ equation (3*) becomes

$$
N_{M}=\frac{N_{\max }}{K_{M}} f(D)
$$

That is, the mutations frequency grows linearly with the radiation dosage in some interval $\{0, f(D)\}: 0 \leq f(D)<K_{M}$. Besides, there is an asymptotic behaviour as $f(D) \rightarrow \infty$

$$
N_{M}=c V_{\max }=N_{\max }
$$

Obviously, the form of function $f(D)$ depends on the biological effects of different types of radiation, such as X-rays and $\gamma$-rays, $\alpha$-particles, $\beta$-particles, neutrons and heavy ions. The magnitude of DNA damages for a given type of radiation usually is different for different biological systems (e.g. different organisms) or for different stages of the same system (e.g. stage in the growth cycle or other environmental factors, e.g. oxygen content) or for different types of tissues from the same organism. In particular, for different types of ionizing radiation the spatial density of ionizations produced per unit absorbed dose in the irradiated tissue is different. If every impact of the high energy photons or secondary ionizing particles produced by the photons hit the DNA and produce a different mutation, then, according to the "target hypothesis", we should expect

$$
N_{R}=f(D)=k D
$$


Nevertheless, if more than a single ionization were necessary to produce one different mutation then the $f(D)$ could be exponential or multiplicative. Here, we will use:

$$
N_{R}=f(D)=k D^{n}
$$

Or

$$
N_{R}=f(D)=c_{R} \operatorname{Exp}(k D)
$$

\subsection{The estimation of lethality}

Survival depends upon the ability of organisms to cope with varied environmental stress conditions, including fluctuating water availability, heat, osmotic stress, and radiation. Here, we only have taken into account radiation stress.

Let $L$ be the fraction of individuals with lethal mutations (lethality). Then the surviving fraction $S$ is $S=1-L$. The lethality is expected to increase with the increase of $N_{M}$. The simplest relationship between the lethality $L$ of irradiated organisms and the frequency of mutations $N_{M}$ is supposed in the following:

Assumption 3: The lethality $L$ is proportional to $N_{M}$, i.e.:

$$
L=c_{l} N_{M}=\frac{c_{l} N_{\max } f(D)}{K_{M}+f(D)}
$$

Here, $K_{M}$ is equal to the value of $N_{R}$ at which the lethality is half of maximal lethality $L_{\max }=c_{l} N_{\max }$, i.e. (9) can be written as

$$
L=\frac{L_{\max } f(D)}{K_{M}+f(D)}
$$

By construction, the maximal lethality is equal to $100 \%$. Obviously, a $100 \%$ of lethality in a small population does not mean that all possible lethal mutations happened in this population. In a large enough population, however, all possible induced mutations can take place at high radiation dose. Normally, a fraction of these mutations are miscorrected by the repair system giving rise to lethal mutations. The limiting behaviour 
of equation (10) is inherited from equation (3*). Now, if $K_{M}>>f(D)$ equation (10) becomes

$$
L=\frac{L_{\max }}{K_{M}} f(D)
$$

While, $L=L_{\max }$ as $f(D) \rightarrow \infty$.

\subsection{Experimental Confrontations}

In this section we show that the present data supports the model described by equations

(3) and (10) with the estimations of the DNA density damage according to particular cases of equations (6-8).

\subsubsection{Effect of gamma rays}

The equations ( $\left.3^{*}\right)$ and (4) have been confronted with data by Russell and Kelly [19] who used the mouse specific-locus method to detect mutations involving any of the seven gene loci in the first-generation offspring of the irradiated parent. The radiation used was $\gamma$-rays and a good agreement with equations ( $\left.3^{*}\right)$ and (4) has been found . The nonlinear regression analysis, according to equation (3*) and considering (4) leads us to the estimates $N_{\max }=14.97 \times 10^{5}$ (mutations per locus) and $K_{M}=25 \times 10^{5}, k=$ 1659.1 and the upper bound $k D / K_{M} \approx 0.57$. This means equation (6) can be combined with equation (4) to estimate $N_{M}$ (see Fig 1):

$$
N_{M}=7 \times 10^{-3} D \quad\left(\mathrm{R}_{\text {adjusted }}^{2}=0.92\right)
$$




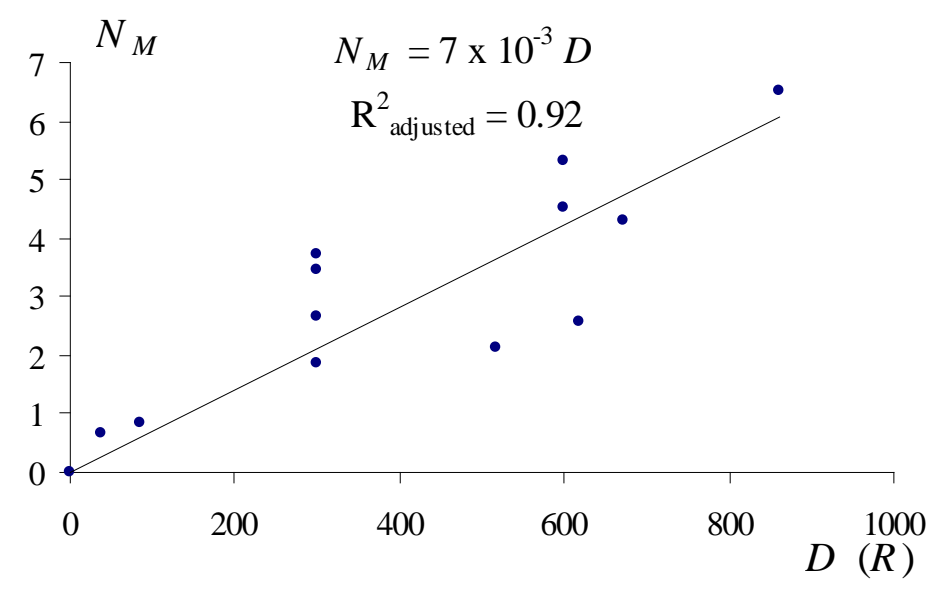

Figure 1. Graph of the regression analysis of the frequency of mutations $N$ versus dose $D$. The $N_{M}$ values correspond to the number of mutation $\times 10^{-5}$ per locus and the values $D$ are in Roentgens $(R)$. All data were taken from Table 1 of [19] and recalculated by correction with the mean of the control rates. The 95\% confidence interval for the regression coefficient is: lower bound equal to $5.77 \times 10^{-3}$ and upper bound equal to $8.33 \times 10^{-3}$.

The lethality of freshly hatched larvae of Trogoderma granarium everts irradiated with gamma radiation $\left({ }^{60} \mathrm{Co}\right)$ is described combining equations (10) and (8) [20]. That is, it can be well described by the equation:

$$
L=\frac{L_{\max } c_{R} \operatorname{Exp}(k D)}{K_{M}+c_{R} \operatorname{Exp}(k D)}
$$

Since $c_{R}$ is just a constant to provide the mutation unit, it can be fixed $c_{R}=1$ mutation, which correspond with the so-called parsimony model with three parameters. Next, taken into account this criterion and the last equation:

$$
L=\frac{L_{\max }}{1+\frac{K_{M}}{c_{R}} \operatorname{Exp}(-k D)}
$$


where $\frac{K_{M}}{c_{R}}$ is a dimensionless constant numerically equal to $K_{M}$. In this model $k$ represents the cell susceptibility/resistance to undergo radiation-induced mutations before the action of the repair system, while $\frac{K_{M}}{C_{R}}$ is a measure of the repair system capacity to process the DNA damage. The best-fit equation is

$$
L=\frac{92.758}{1+435.923 \operatorname{Exp}(-0.86 D)} \quad\left(\mathrm{R}_{\text {adjusted }}^{2}=0.99\right)
$$

The nonlinear regression is presented in Fig 2.

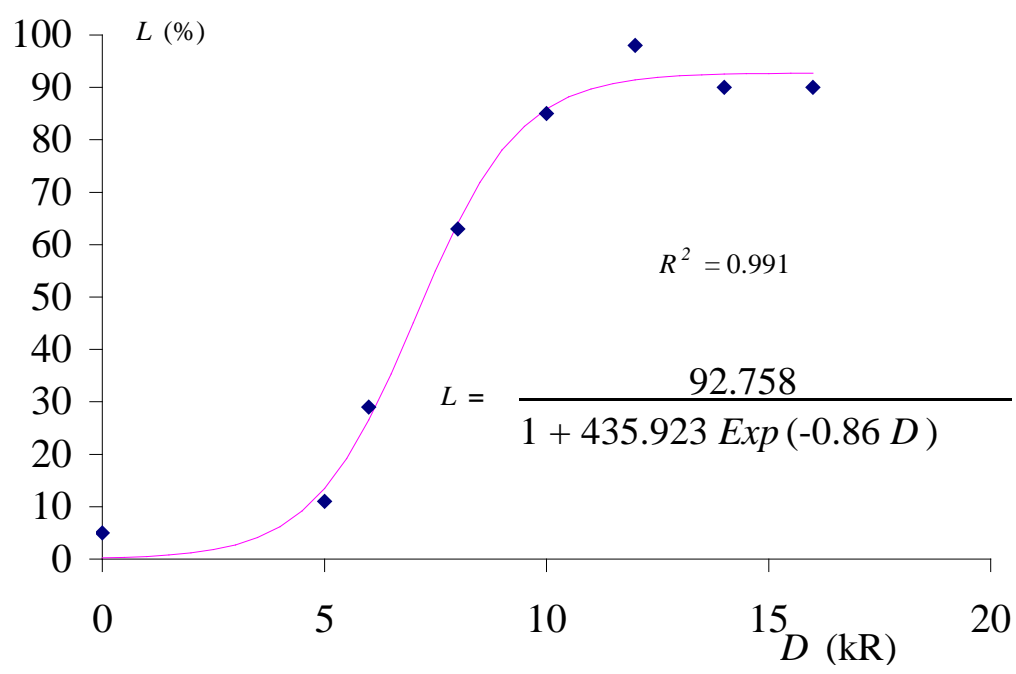

Figure 2. Nonlinear Regression analysis of the lethality $(L)$ of freshly hatched larvae of Trogoderma granarium everts versus gamma radiation dose $(D)$. Data were taken from [20].

For the lethality of Carica papaya explants, irradiated with gamma rays $\left({ }^{60} \mathrm{Co}\right)$, a satisfactory fit to equation (14) is also obtained,

$$
L=\frac{91.329}{1+107.049 \operatorname{Exp}(-0.145 D)} \quad\left(\mathrm{R}_{\text {adjusted }}=0.985\right)
$$

The nonlinear regression analysis of explants lethality versus inverse of dose is shown in Fig 3. 


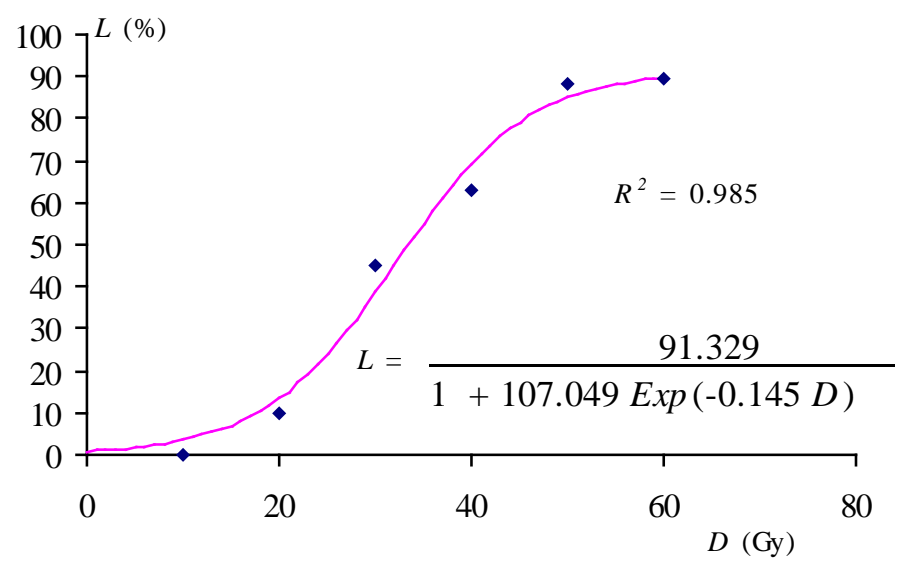

Figure 3. Regression analysis percent of the Carica papaya explants lethality $(L)$ versus dose $(D)$. The data were kindly supplied by the Biotechnology group from the Research Institute of Tropical Roots, Tuber Crops and Banana (INIVIT).

\subsubsection{Effects of UV radiation}

We discuss now a recent report [21] about the effect UV radiation on the bacteria of the surface of leaves, termed the phyllosphere, which can be described by equation (10). Phyllosphere microbial residents grow through the utilization of the limited resources available in this habitat. Jacobs and Sundin [21] pointed out that solar UV-B acts as a selective pressure altering the phyllosphere bacterial community composition and that UV tolerance is a prevalent phenotype late in the season. They selected Clavibacter michiganensis as a model of UV-tolerant epiphyte in their study. The experimental data was adjusted combining equations (10) and (7). The data exploration allows fixing the $n$ value in equation (7) equal to 9/5. Explicitly, if for the two C. michiganensis strains G7.1 and T5.1 is taken $N_{M}=f(D)=k D^{9 / 5}$ then the particular cases of equation (10) are:

$$
\text { G7.1: } \quad L=\frac{99.836 \times 0.0096 D^{9 / 5}}{10.262+0.0096 D^{9 / 5}} \quad \mathrm{R}_{\text {adjusted }}^{2}=0.995
$$




$$
\text { T5.1: } \quad L=\frac{100.846 \times 0.0197 D^{9 / 5}}{21.919+0.0197 D^{9 / 5}} \quad \mathrm{R}_{\text {adjusted }}^{2}=0.99
$$

Or equivalently, deriving from (10) $L=-\frac{K_{M}}{k} \frac{L}{D^{9 / 5}}+L_{\max }$, the linear regression turns out:

$$
\begin{array}{ll}
\text { G7.1: } \quad L=-1063.989 \frac{L}{D^{9 / 5}}+99.799 & \mathrm{R}_{\text {adjusted }}^{2}=0.996 \\
\text { T5.1: } \quad L=-1118.059 \frac{L}{D^{9 / 5}}+100.883 \quad \mathrm{R}_{\text {adjusted }}^{2}=0.992
\end{array}
$$

The graphs with the nonlinear regression analysis of Clavibacter michiganensis lethality under solar UV-C (254 $\mathrm{nm}$ ) radiation versus the UV-C radiation dosage is presented in Fig 4.
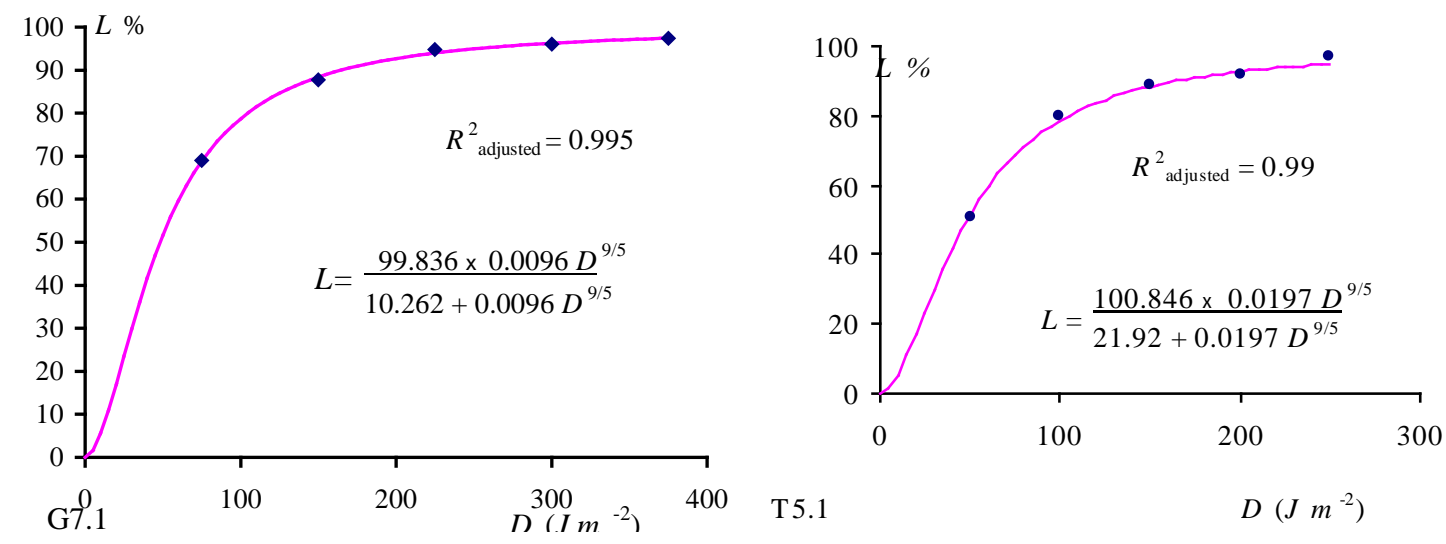

Figure 4. The nonlinear regression analyses of Clavibacter michiganensis lethality versus UV radiation dosage for the strains G7.1 and T5.1. The data were taken from Table 5 of [21].

\subsubsection{Effects of $X$-rays}

The relationship between X-ray doses and the rate of dominant lethals induced by irradiation of mouse spermatozoa was study by Leonard in 1966 [22]. The nonlinear 
regression of embryos lethality versus X-ray dosage is achieved combining equations (10) and (7). The best fitted equation is:

$$
L=\frac{103.795 \times 0.0131 D^{1.422}}{124.901+0.0131 D^{1.422}} \quad \mathrm{R}_{\text {adjusted }}^{2}=0.995
$$

The graph of this linear regression is presented Fig 4.

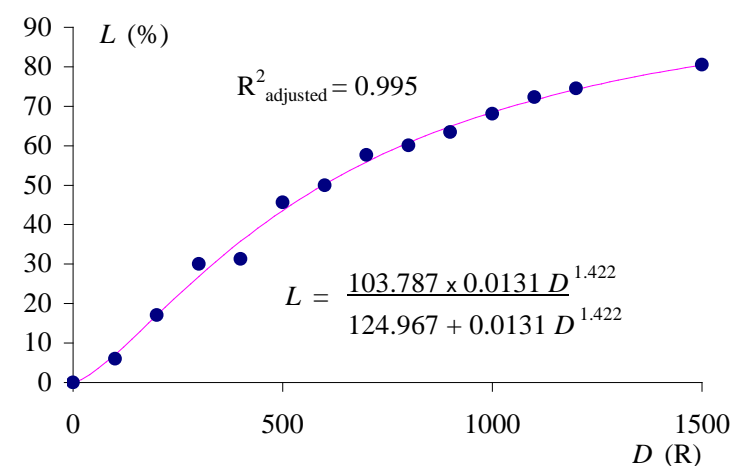

Figure 4. The nonlinear regression analyses of mouse embryos lethality versus X-ray dose. The data were taken from [22].

\subsubsection{Adaptation of Drosophila melanogaster populations}

Nothel [23] studied the evolutionary aspects of high mutation pressure in the laboratory populations of Drosophila melanogaster with irradiation histories up to 600 generations [23]. Hi can not explain the sigmoid dose-responses obtained in his experiments and so as to show that there is a fine-tuned evolutionary adjustment of mutation rates to irradiation levels appeals to probit regressions. By means of this nonparametric regression, Nothel [23] proved that the sensitivity to the genetic damage induction in immature oocytes decreases stepwise from the control population $(+\mathrm{K})$, to populations irradiated at $2 \mathrm{kR}$ per generation (RO I, RO II), to the population exposed to $4 \mathrm{kR}$ per generation (RO 4), to the population exposed to $8 \mathrm{kR}$ per generation ( $\left.\mathrm{RO} \mathrm{I}_{48}\right)$. 
Now, we shall show that, by means of nonlinear regression, the sigmoid dose-responses obtained by Nothel fit equation $L=\frac{L_{\max }}{1+\frac{K_{M}}{c_{R}} \operatorname{Exp}(-k D)}(14)-$ with $c_{R}=1-$ and, as a result, the adaptation of $D$. melanogaster population to high mutation pressure can be estimated by means of parameters $K_{M}$ and $k$. The parameter values of the nonlinear regression analysis are presented in Table 1 and the graph of these regressions in Fig. 5. The multivariate analysis of variance of curve parameters is in agreement with the Nothel results [23]. There is a statistical significant decrease of the sensitivity to the induction of genetic damage, now associated to the increase of $K_{M}$ and the decrease of $k$ (see Table 1). The increase of $K_{M}$ suggests the increase of the repair capacity by means of the synthesis of new enzymes. Meanwhile, the decrease on the $k$ parameter implies on an increase of the cell protection capacity against ionizing radiation, which is independent of the repair system.

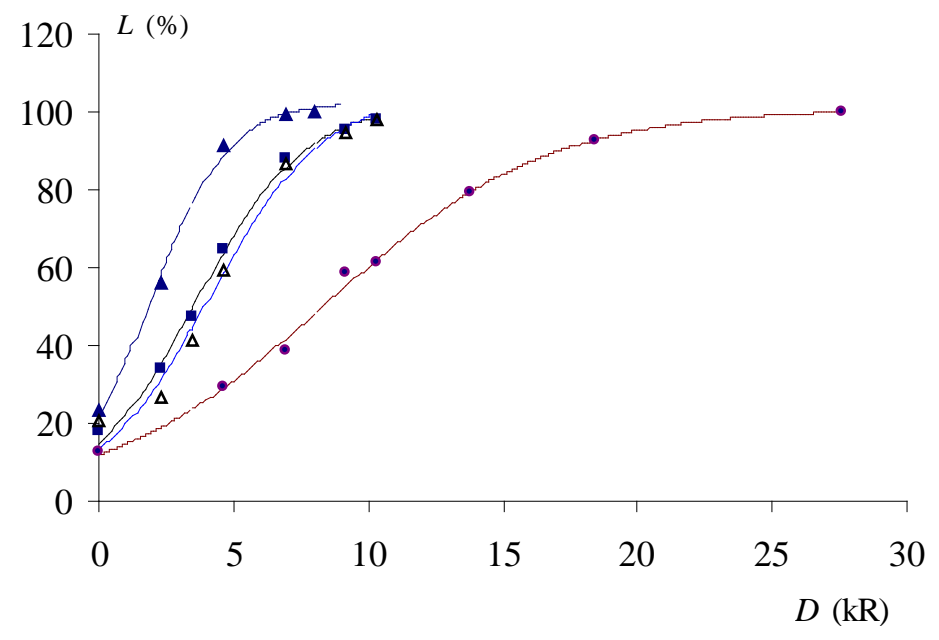

Figure 5. The nonlinear regression analysis of dose-response for the induction of dominant lethals in Drosophila melanogaster. In the graph are presented the adjusted curves for the control population $+\mathrm{K}(\oint)$, the populations irradiated at $2 \mathrm{kR}$ per generation RO I $(\circledR)$ and RO II ( $($ ) and for the population exposed to $8 \mathrm{kR}$ per 
generation $\mathrm{RO} \mathrm{I}_{48}(\mathrm{)})$. The parameters values corresponding to equation (14) are presented in Table 1. Data were taken from Table 1 of [23].

Table 1. Parameter values of the nonlinear regression analyses of dose-response for the induction of dominant lethals in Drosophila melanogaster.

\begin{tabular}{|c|c|c|c|c|c|c|c|c|}
\hline & \multirow{3}{*}{$L_{\max }$} & Std. & \multirow{3}{*}{$k$} & Std. & \multicolumn{3}{|c|}{ Std. } & \multirow{3}{*}{$\left({ }^{a}\right)$} \\
\hline & & & & & $K_{M}$ & & $\mathrm{R}_{\text {adjusted }}^{2}$ & \\
\hline & & Error & & Error & & Error & & \\
\hline$+\mathrm{K}$ & 102.54 & 2.54 & 0.69 & 0.07 & 3.74 & 0.53 & 0.993 & $\mathrm{a}$ \\
\hline RO II & 105.06 & 7.25 & 0.47 & 0.09 & 6.91 & 1.84 & 0.974 & $\mathrm{~b}$ \\
\hline RO I & 102.31 & 2.83 & 0.49 & 0.04 & 5.89 & 0.75 & 0.994 & $\mathrm{~b}$ \\
\hline $\mathrm{RO} \mathrm{I}_{48}$ & 100.91 & 1.99 & 0.24 & 0.01 & 7.58 & 0.83 & 0.996 & C \\
\hline
\end{tabular}

a The same letter means that in the multivariate analysis of variance it was not found statistical significant difference between the curves at $\alpha=0.01$. The parameters correspond to equation

(14): $L=\frac{L_{\max }}{1+K_{M} \operatorname{Exp}(-k D)}$. The experimental data for the nonlinear regression were taken from [23].

\section{Population dynamics under radiation disturbances}

The radiation-induced lethality model (9) allows the study of the implications of ionizing radiation from astrophysical events on population depletion and its risk of extinction. In this section, the effects will be analyzed over a single species and over two interacting species, using a standard first order differential equations approach, which already gives many insights on the behavior of the perturbed biological systems. 


\subsection{Single species depletion model}

As was shown above, the living organism populations can survive under hard environment radiation conditions. The plausible explanation to this phenomenon is the radiation induced synthesis of new molecules to increase cellular defense against radiation. According to the last section the surviving capacity of living organism against ionizing radiations is determined by two radiation induced factors: the enzymatic machinery of the repair system and the non-specific cellular response expressed in the cell sensibility to direct hits of ionizing radiation. These factors are characterized in equation (10), for instance, by the parameters $K_{M}$ and $k$ as appear in the particular case (13). Now, let us suppose given a single population with a population density $N(t)$ at time $t$ forced to live in an increasing background radiation condition. We can suppose the background radiation increases linearly every unit of time in one radiation unit. Likewise to the last experiment it can be supposed three levels in the molecular response against to the increasing background radiation, which correspond with parameters $K_{M_{i}}$ and $k_{i}(i=1,2,3)$. The lethality rate induced by radiation is given by the piecewise function:

$$
r_{L}(t)=r_{L_{0}}+\delta_{i} \frac{f_{i}(D(t))}{K_{M_{i}}+f_{i}(D(t))}
$$

where $f_{i}(D(t))$ could be given by equations (6) to (8), $r_{L_{0}}$ is the lineal lethality rate in absence of radiation, $L_{\max }=1$ and $\delta_{i}$

$$
\delta_{1}=\left\{\begin{array}{ll}
1 & \text { for } t<t_{1} \\
0 & \text { otherwise }
\end{array}, \delta_{2}=\left\{\begin{array}{ll}
1 & t_{1}<t<t_{2} \\
0 & \text { otherwise }
\end{array} \text { and } \delta_{3}= \begin{cases}1 & t_{2}<t \\
0 & \text { otherwise }\end{cases}\right.\right.
$$

Here, the $t_{i}$ constants are the time breakpoints. Next, as a single species model it can be considered: 


$$
\frac{d N(t)}{d t}=r_{B} N(t)\left(1-\frac{N(t)}{K_{E n v}}\right)-r_{L}(t) N(t)
$$

where $r_{B}$ is the linear birth rate of species, $K_{E n v}$ is the carrying capacity of the environment. The rate $r_{B}$ is, in a general case, function of radiation dosage. In a first approach, it is assumed that the $r_{B}$ is not affected by radiation. Notice that the new parameter $r_{L}$ estimates the overall population sensitivity or resistance to radiation and $r_{L} N(t)$ is the per capita rate of lethality. In equation (21), the first term of the right corresponds to the logistic growth model of Verhulst [24], while the piecewise sum corresponds to the lethality generated by ionizing radiation modulated by three distinguishable kinetic repair steps. Next, the steady states are derived of

$$
\frac{d N(t)}{d t}=0 \Rightarrow r_{B}\left(1-\frac{N(t)}{K_{E n v}}\right)=r_{L}(t)
$$

From this equation we have

$$
\frac{N(t)}{K_{E n v}}=1-\frac{r_{L}(t)}{r_{B}}
$$

The population can survive whenever the ratio $\frac{r_{L}(t)}{r_{B}}<1$; however, this ratio is a growing function of time and starting from a time $t_{e}$ the ratio will be $\frac{r_{L}(t)}{r_{B}}>1$ and the right term of $\left(22^{*}\right)$ will be zero, i.e. $\frac{N\left(t_{e}\right)}{K_{E n v}}=0$, which corresponds to equilibrium states where the population becomes extinct. These asserts can be also deduced from the graph of population density $N(t)$ versus time $t(D(t) / c)$ derived from the numerical solutions of (21) specifying parameters values and $f_{i}=\operatorname{Exp}\left(k_{i} D\right)$. The survival capacity enhance with the increase $K_{M_{i}}$ and the decrease of $k_{i}$ (see Fig $6 \mathrm{~A}$ and B). That is, the time to species extinction is delayed with the simultaneous increase of $K_{M}$ and decrease of $k$. 
Now, we shall assume that the birth rates of $r_{B}$ is also affected by radiation at high dose. In general, it could be expected that at high radiation background the frequency of sterility in female and in male subpopulations and non-viable embryos should increase. So, in a realistic model it should be taken into account this fact. In particular, in equation (21) it can be set

$$
r_{B}=r_{B_{0}}\left(1-\delta_{B} \delta_{i} \frac{f_{i}(D(t))}{K_{M_{i}}+f_{i}(D(t))}\right)
$$

, where $\delta_{B}=\left\{\begin{array}{ll}1 & \text { for } t_{B}<t \\ 0 & \text { otherwise }\end{array}\right.$ and $D\left(t_{B}\right)$ denote the threshold dose at which $r_{B}$ start to decrease. The numerical simulation under last constraint is presented in Fig 6 B. So, if the linear birth rates are affected at high radiation background then the population extinction go faster.
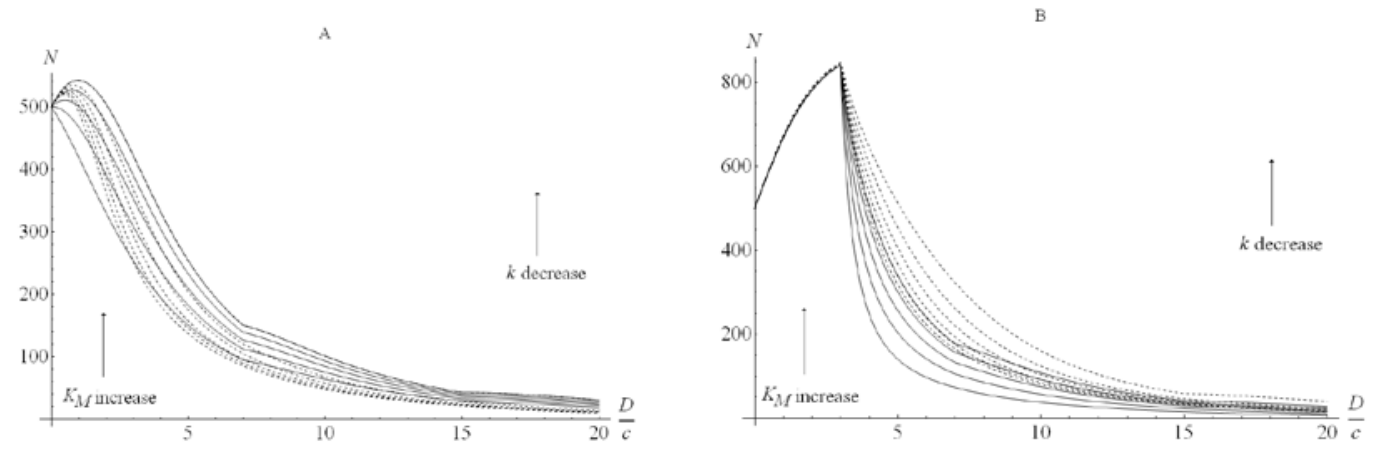

Figure 6. Numerical solutions of differential equation (20). Population density $N(t)$ versus time $t(D(t) / c)$. Here, $c=1$ (radiation unit/time unit), $N(0)=500, K_{E n v}=1000, r_{B}$ $=0.97$ and the breakpoints $t_{1}=7$ and $t_{2}=15$. A: The $r_{B}$ value is kept constant and $r_{L}$ is given by equation (20) with $r_{L_{0}}=0.1$. The dashed curves correspond to variations of $k_{i}$ starting with the values presented in Table $1(\Delta k=0.2)$, and the continuous lines to variations of $K_{M_{i}}\left(\Delta K_{M}=0.7\right)$. B: For $t>3$ both $r_{L}$ and $r_{B}$ (with $r_{B_{0}}=0.95$ ) are given by equations (20) and (23) respectively. 


\subsection{The interacting population depletion models}

In this section, we will use a very simple ecological model that could yield some insight into the ecological mechanisms of population extinction or survival under constant and increasing radiation background. Here, all models are described in term of predator-prey model and a lethality radiation induced function. Models of interacting or noninteracting species were used in the analysis of extinction patterns through the interplay of biotic and abiotic causes [25, 26, 27, 28, 29, 30, 31, 32]. These models are very simple but their dynamical outcomes can sometimes give unexpected results and provided a quantitative test to different scenarios of macroevolutionary dynamics. In our model, the cause of population depletion or extinction is determined by the radiation background and the fraction of individuals with lethal mutations is expressed introducing (10) as function of time and radiation dosage.

\subsubsection{The model at constant radiation background}

The model at constant radiation background is described in term of predator-prey model and a lethality radiation induced function derived from (10)

$$
\begin{aligned}
& \frac{d N(t)}{d t}=N(t)\left[r_{B N}\left(1-\frac{N(t)}{K_{E n v}}\right)-r_{N P} \frac{P(t)}{N(t)+K}-r_{L N}\right] \\
& \frac{d P(t)}{d t}=P(t)\left[r_{B P}\left(1-r_{P N} \frac{P(t)}{N(t)}\right)-r_{L P}\right]
\end{aligned}
$$

where $r_{L N}$ and $r_{L P}$ can be given by expressions analogous to equation (20) but independent of time:

$$
r_{L i}(t)=r_{L i_{0}}+\delta_{L j} \frac{f_{i j}\left(D\left(t_{L j}\right)\right)}{K_{M_{i j}}+f_{i j}\left(D\left(t_{L j}\right)\right)}
$$


, where $\delta_{L j}=\left\{\begin{array}{cc}1 & \text { for } t_{L j}<t \\ 0 & \text { otherwise }\end{array}(j=1,2,3)\right.$ and $D\left(t_{L j}\right)$ denote the threshold dose at which $r_{L i}$ $(i=N, P)$ start to decrease with the expression of the three enzymatic system.

At relatively low doses in equation (20) we can set $i=1$. The first term of the right corresponds to a predator-prey model well analyzed in [33].

The steady state conditions $\frac{d N(t)}{d t}=0$ and $\frac{d P(t)}{d t}=0$ leads to the nonlinear and nonhomogenous system

$$
\begin{aligned}
& \frac{N}{K_{N}}+\frac{r_{N P}}{r_{B N}} \frac{P}{N+K}=1-\frac{r_{L N}}{r_{B N}} \\
& r_{P N} \frac{P}{N}=1-\frac{r_{L P}}{r_{B P}}
\end{aligned}
$$

Since only the positive values of $N$ and $P$ haves biological meaning, the possible solutions are given for $\frac{r_{L N}}{r_{B N}}<1$ and $\frac{r_{L P}}{r_{B P}}<1$. Next, according to the system (25) starting from a time $t_{e}$ both populations prey and predator tend to horizontal asymptotes determined by the positive solutions of the system (24)-(25), i.e. both populations prey and predator come into an stationary or equilibrium state kept in time. Notice that if the radiation dose is too high then both populations can become extinct.

Next, we shall assume that after enough time as a result of the constant radiation background mutation accumulation is notable in DNA molecule so as to the linear birth rates of prey $r_{B N}$ and predator $r_{B P}$ are affected. This fact could be expressed by means of the equation:

$$
r_{B i}=c_{B i}-\delta_{B i} c_{B i}\left(1-\frac{1}{D\left(t_{B i}\right)^{n}}\right)
$$

, where $\delta_{B i}=\left\{\begin{array}{l}1 \text { for } t_{B i}<t \\ 0 \text { otherwise }\end{array}(i=N, P)\right.$ and $n$ could be a number not necessary integer. 
The numerical solution of (24) under last constraint is presented in Fig 7 A and B. Since predator population depends on the prey only the parameter $r_{B N}$ is analyzed. As a result, if the radiation background is high enough so as to cause mutation accumulation in time, then, after a threshold time $t_{B i}$ it could be expected that the linear birth rates are affected and the population extinction proceeds faster. Likewise to the single population model, the simultaneously increase of $K_{M}$ and decrease of $k$ delay the time to species extinction or the equilibrium states. These situations can be visualized throughout numerical solutions of the system (24). The graph of these simulations for specific parameter values is presented in Fig $7 \mathrm{~A}$ and $\mathrm{B}$.
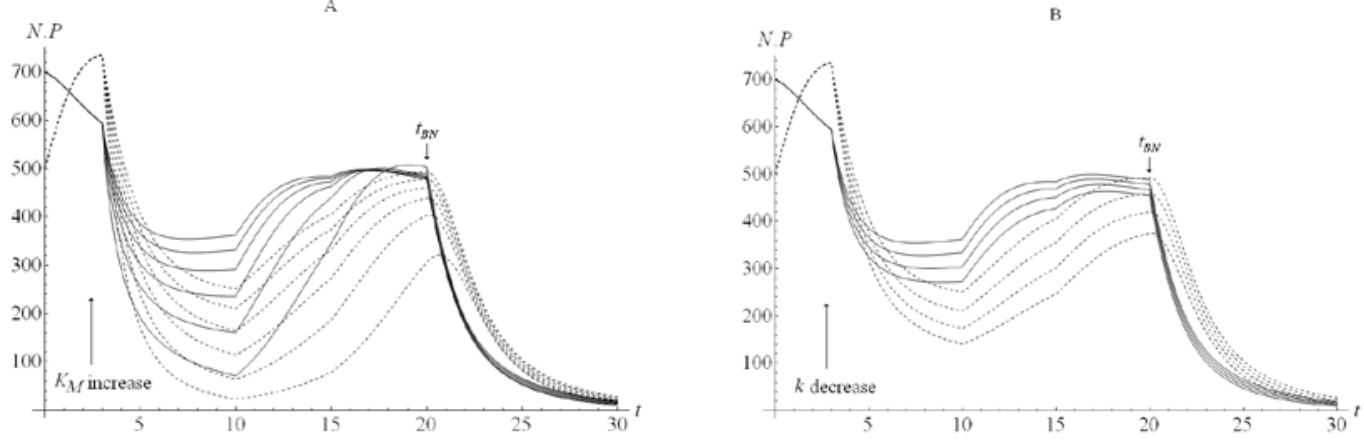

Figure 7. Population densities $N(t)$ and $P(t)$ versus time $t(D(t) / c)$ according the numerical solutions of the differential equation system (23). The dashed curves correspond to predator population density $P(t)$. Here, $c=1$ (radiation unit/time unit), $N(0)=700, P(0)=500, K_{E n v}=1000, K=500, r_{B N_{0}}=0.95$ (in equation (27)), $r_{B P}=0.8$ and $t_{B N}=20$ is the time at the linear birth rates of the prey is affected by mutation accumulation according to equation (27). The starting $K_{M_{N j}}$ and $k_{N j}$ values are taken from Table 1, while $K_{M_{P 1}}=4, K_{M_{P 2}}=7$ and $K_{M_{P 3}}=8$ and $k_{P 1}=0.7, k_{P 2}=0.5, k_{P 3}=0.2$. A: variation of $K_{M_{i j}}$ values with $\Delta K_{M}=-0.7$ and $k_{i j}$ constant. B: variation of $k_{i j}$ values with $\Delta k=0.2$ and $K_{M_{i j}}$ constant. 


\subsubsection{Recovery after a radiation pulse}

The recovery after a radiation pulse can be described by means of the model

$$
\begin{gathered}
\frac{d N}{d t}=N\left[r_{B N}\left(1-\frac{N}{K_{E n v}}\right)-r_{N P} \frac{P}{N+K}-r_{L N}(t)\right] \\
\frac{d P}{d t}=P\left[r_{B P}\left(1-r_{P N} \frac{P}{N}\right)-r_{L N}(t)\right] \\
r_{L i}(t)=r_{L i_{0}}+\delta_{i j} \frac{f_{i j}(D(t))}{K_{M_{i j}}+f_{i j}(D(t))}
\end{gathered}
$$

where, $\delta_{i j}=\left\{\begin{array}{ll}1 & \text { for } D_{i}\left(t_{s j}\right) \leq D(t) \leq D_{i}\left(t_{e j}\right) \\ 0 & \text { otherwise }\end{array}\right.$ determine the pulse duration $t_{e i}-t_{s i}(i=N, P)$ and $j=1,2,3$. As it is shown in Fig 8 both predator and prey populations, undergo a sensible depletion after the radiation pulse. After this disturbance the population dynamics follow the normal behaviour predicted by the predator-prey model described in [33]. The population depletion depends on the overall radiation dose (pulse duration) and the ratio $\frac{r_{L N}}{r_{B N}}\left(K_{M}\right.$ and $\left.k\right)$. At constant dose, the rates $\frac{r_{L N}}{r_{B N}}$ and $\frac{r_{L P}}{r_{B P}}$ are only function of $K_{M}$ and $k$, i.e. these rates are functions of the repair enzymatic systems and the cell resistance/susceptibility capacity. The recovery time of populations after radiation pulse depends on the overall population radiation resistant capacity, which is reflected in our model by $K_{M}$ and $k$. In particular, Figure 8 A suggests that a small capacity of repair system mechanisms have a profound impact in population depletions. The recovery times at different values of $K_{M}$ and $k$ are shown in Fig 9 A and B. The recovery time of predator population undergo the delay effect of the recovery time of prey population and, consequently, the recovery time of predator population is superior to those of prey population. 
Now, if the interval of time $t_{e}-t_{s}$ is too large, the population behavior is analogous to those described in the above subsection. In particular, if $\frac{r_{L N}}{r_{B N}} \geq 1$ both population prey and predator become extinct.
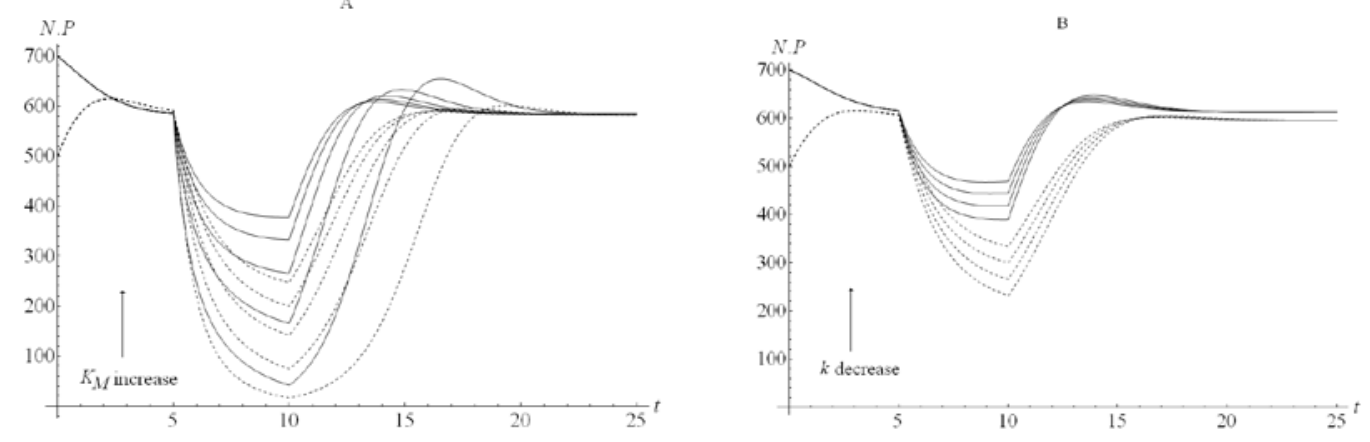

Figure 8. Population density $N(t)$ and $P(t)$ versus time $t$ according the numerical solution of differential equation system (28). The parameter values are $c=1$ (radiation unit/time unit), $N(0)=700, P(0)=500, K_{E n v}=1000, K=1000, r_{B N}=0.95, r_{B P}=0.95$, $r_{N P}=0.8$ and $r_{P N}=0.9$. In order to simplify only one enzymatic repair mechanism at constant dose is involved. The $r_{L N}$ and $r_{L P}$ values are given by equation (29) with parameters: $r_{L N_{0}}=r_{L P 0}=0.1, k_{N}=0.690348, K_{M_{N}}=3.74467, k_{P}=0.7$ and $K_{M_{P}}=4$. A: variation of $K_{M_{i 1}}$ values with $\Delta K_{M}=-1$ and $k_{i 1}$ constant. B: variation of $k_{i 1}$ values with $\Delta k=0.2$ and $K_{M_{i 1}}$ constant. The dashed curves correspond to predator population density $P(t)$.
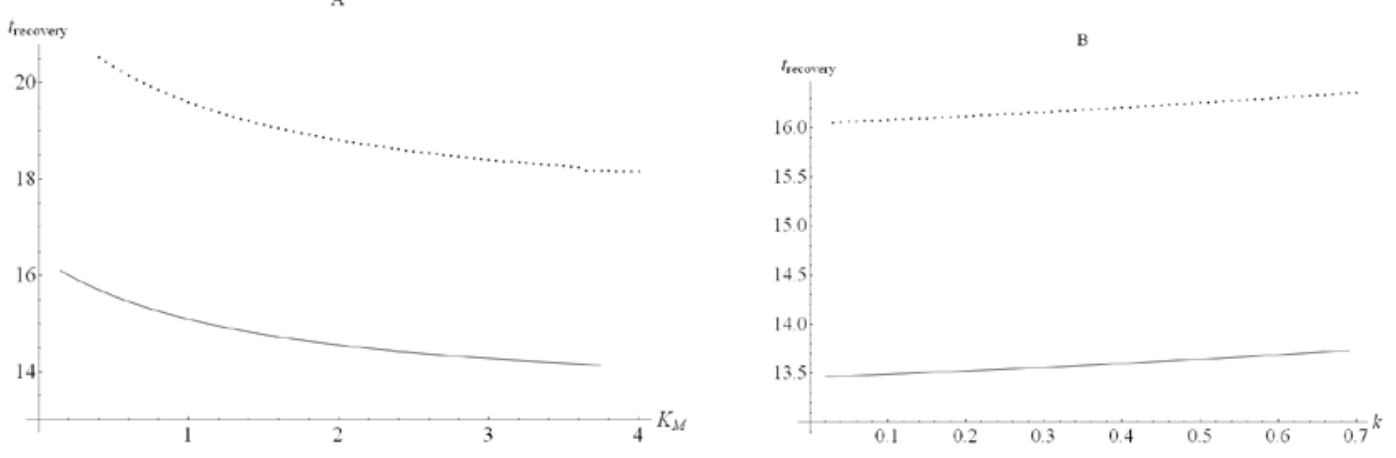
Figure 9. Recovery time after radiation pulse. The parameter values are the same of Fig. 8. A: variation of $K_{M_{i 1}}$ values with $\Delta K_{M}=0.05$ and $k_{i 1}$ constant. B: variation of $k_{i 1}$ values with $\Delta k=0.01$ and $K_{M_{i 1}}$ constant. The dashed curves correspond to predator population density $P(t)$.

\subsubsection{Increasing radiation background}

The increasing radiation background can be described by means of the model,

$$
\begin{aligned}
& \frac{d N(t)}{d t}=N(t)\left[r_{B N}\left(1-\frac{N(t)}{K_{E n v}}\right)-r_{N P} \frac{P}{N+K}-r_{L N}(t)\right] \\
& \frac{d P(t)}{d t}=P(t)\left[r_{B P}\left(1-r_{P N} \frac{P(t)}{N(t)}\right)-r_{L N}(t)\right]
\end{aligned}
$$

where the $r_{L i}$ values are given as in (29). Likewise to the model for a single species it can be supposed three levels in the molecular response against to the increasing background radiation $(j=1,2,3)$ :

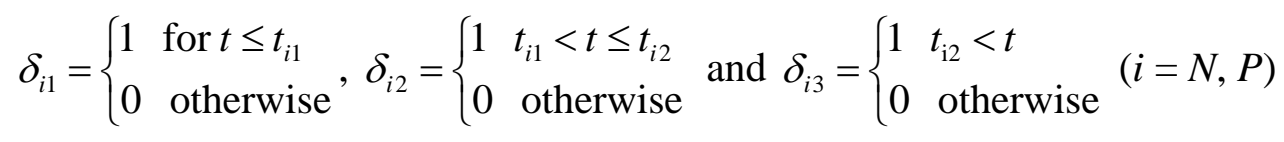

The steady state conditions $\frac{d N(t)}{d t}=0$ and $\frac{d P(t)}{d t}=0$ leads to the nonlinear and nonhomogenous system

$$
\begin{aligned}
& \frac{N(t)}{K_{N}}+\frac{r_{N P}}{r_{B N}} \frac{P(t)}{N(t)+K}=1-\frac{r_{L N}(t)}{r_{B N}} \\
& r_{P N} \frac{P(t)}{N(t)}=1-\frac{r_{L P}(t)}{r_{B P}}
\end{aligned}
$$

Since always $N \geq 0$ and $P \geq 0$, the rate $\frac{r_{L N}}{r_{B N}}>1$ mean the whole population extinction and the solutions of the system (31) with biological interest are given for $\frac{r_{L N}}{r_{B N}}<1$ and 
$\frac{r_{L P}}{r_{B P}}<1$. As a result, with an increasing radiation background, starting from a time $t_{e}$ the right term of (28) become zero or tends asymptotically to zero, independently of the value taken by $\frac{r_{L P}}{r_{B P}}$, i.e. both populations prey and predator become extinct. Likewise to the single population model, the simultaneously increase of $K_{M}$ and decrease of $k$ delay the time to species extinction or the equilibrium states (see Fig. $10 \mathrm{~A}$ and B).

Next, we shall assume that the linear birth rates of prey $r_{B N}$ and predator $r_{B P}$ are nonlinear functions of radiation at high dose. In particular, in the system (30) it can be set

$$
r_{B i}=r_{B i_{0}}\left(1-\delta_{B i} \delta_{i j} \frac{f_{i j}(D(t))}{K_{M_{i j}}+f_{i j}(D(t))}\right)
$$

, where $\delta_{B i}=\left\{\begin{array}{ll}1 & \text { for } t_{B i}<t \\ 0 & \text { otherwise }\end{array}(i=N, P)\right.$ and $t_{B i}$ is the time at which the linear birth rate is affected by the radiation dose. Since predator population depends on the prey only the parameter $r_{B N}$ is analyzed. The numerical solution of (30) under last constraint is presented in Fig $10 \mathrm{C}$ and D. As we can see, if the linear birth rates are affected at high radiation background then both population prey and predator will be extinguished very faster. Again the enzymatic mechanisms have the main effects on the surviving capacity of populations (see Fig $10 \mathrm{~A}$ and C). 

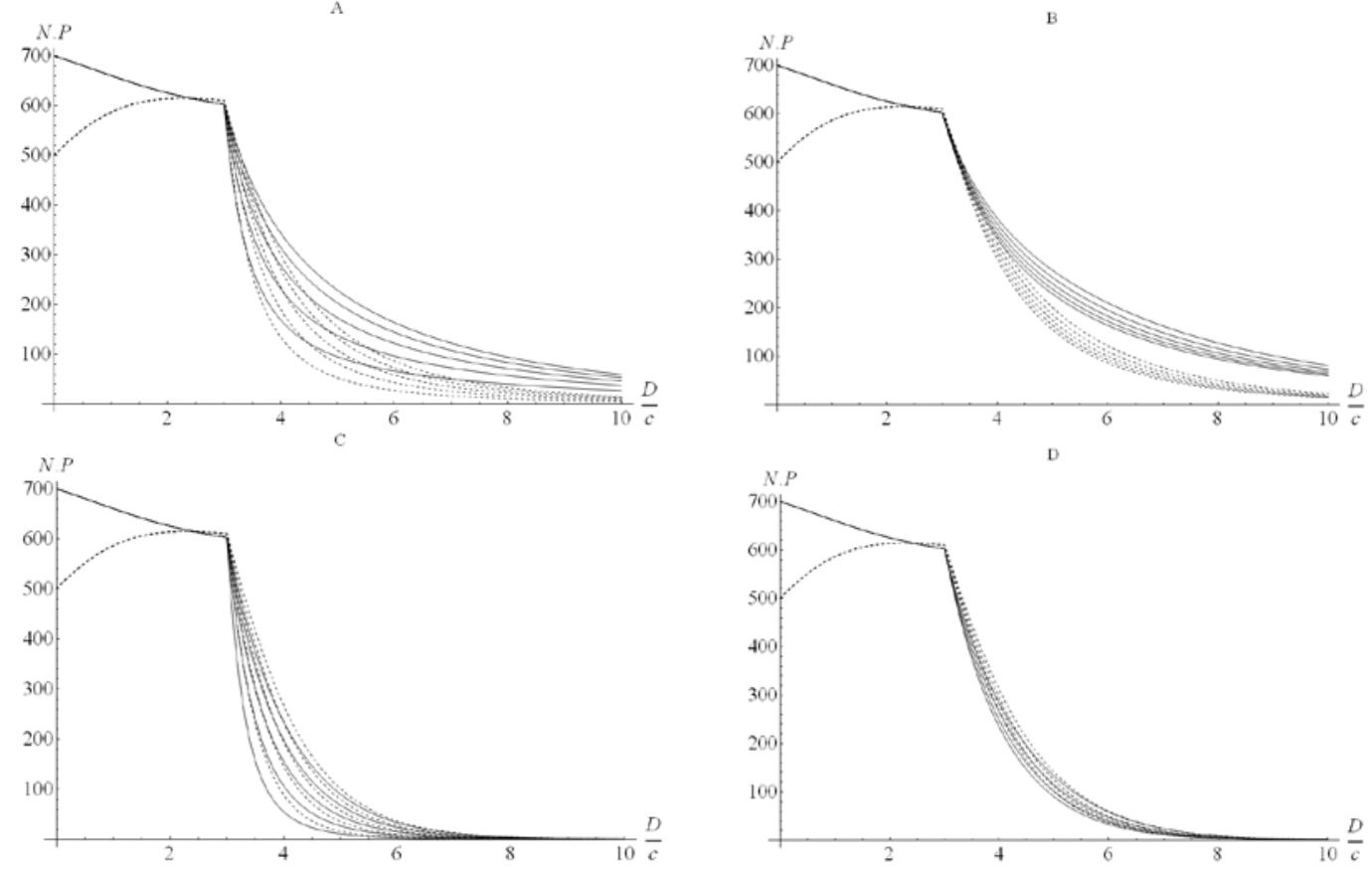

Figure 10. Population density $N(t)$ and $P(t)$ versus time $t(D(t) / c)$ according the numerical solution of differential equation system (30). All parameters except those for $r_{B i}$ and $r_{L i}$ are the same of Fig 8 . The values of $r_{L N}$ and $r_{L P}$ are given by equation (29) with the parameters $r_{L N_{0}}=r_{L P_{0}}=0.1, K_{M_{i N}}$ and $k_{N i}$ for the prey taken from Table (1), while for the predator $K_{M_{1 P}}=4, K_{M_{2 P}}=7, K_{M_{3 P}}=8, k_{1 P}=0.7, k_{2 P}=0.5$ and $k_{3 P}=0.3$. The values of $r_{B N}$ are given by equation (33) with $r_{B N_{0}}=0.95$. The breakpoints are $t_{N 1}=$ $3, t_{N 2}=10$ and $t_{N 3}=15$. The dashed curves correspond to preator population density $P(t)$.

\section{Discussion}

The experimental confrontation of equation (10) combined with equations (6-8) suggests its acceptance. In the parameters $K_{M}$ and $k$ of the resultant equations are reflected two radiation-induced resistant factors: the enzymatic machinery of the repair system and the non-specific cellular response against radiation expressed in the susceptibility to the direct damage of radiation. On the cell, the radiation-induced variation of the $K_{M}$ corresponds to the variation in the enzymatic composition of the 
repair systems after irradiation. Actually, this is an expected result: repair genes can be classified into pathways that use different mechanisms to reverse or bypass damage to DNA. The enzymes associated with these systems correspond to several repair pathways $[8,9,16,19]$.

As proved by Nothel, a gradual increase or small jumps of the radiation dose leads to an adaptation of living organisms to high radiation backgrounds [23]. Our reanalysis of Nothel's experimental results (subsection 2.2.4) suggests the induction of new enzymes from different repair pathways ( $K_{M}$ increase) and de novo expression or reinforcing of non-repair molecular cellular response against radiation ( $k$ decrease). Perhaps this observation could help to explain why mutation rates tend to keep constant in those populations with high radiation background $[3,4,5,6]$. All cells have many pathways to repair damage in DNA, which pathway is used will depend upon the type of damage and the situation $[16,18]$.

The insertion of equation (10) into the population dynamics models provides new insights on the survival chances of populations under radiation disturbance. The analyses of these models in subsections 3.2.1, 3.22 and 3.2.3 suggest that any radiation disturbances from astrophysical events in which high levels of radiation reach the ground could have a profound impact in populations of living organisms.

In equations (21), (24) and (30) the effects of the repair system is present in the linear birth and lethality rates of species. Obviously, high radiation levels reaching living beings saturate the repair system capacity and increase the misrepair frequency of the induced damage. As a result, the accumulation of mutations increases the sterility frequency in female and in male subpopulations and the non-viable embryos. Thus, the overall effect decreases the birth rate and increase the lethality rate observed in 
populations. Under these circumstances, the analyses of equations (21), (24) and (30) suggest that populations could become extinct.

On the contrary, if the repair system could keep the lineal birth rate of the species higher than the lineal lethally rate then the populations can survive reaching new stationary states. Such a situation might have been the case for Cambrian and Late Ordovician mass extinction, which, according to some authors might have been caused by gamma-ray bursts $[10,11]$. In these cases, the high level of radiation in the biosphere would have played the double role of sterilizing those species for which the lethally rate exceeds the birth rate, and allowing the survival of those in which repair system could keep $r_{B}>r_{L}$. The whole effect enhances the speciation due to mutations and empty ecological niches.

In this work our main purpose has been to connect the molecular response of the cell to radiation with aspects of the macroscopic description of an ecosystem, such as the evolution of its population. That is why we have chosen a simple population dynamics model, to gain a first insight into our proposed theoretical framework. We have reserved for (immediate) future work the potential application of the full model to real situations, for instance, the marine extinction occurring in the boundary Pleistocene/Pliocene around two million years ago. This extinction is thought to have been initiated in phytoplankton and then cascaded trophically to mollusks, especially bivalves. Some authors have claimed that a nearby supernova might have been the trigger [Benitez]. Another future direction we are considering is the enrichment of the mathematical structure of the model, with the potential inclusion of trophic levels, the use of generalized functions to obtain analytical solutions, and so on. 


\section{Conclusions}

As can be seen from above examples involving mice, Trogoderma granarium, Carica papaya, Clavibacter michiganensis, mouse spermatozoa and Drosophila melanogaster, the proposed kinetic model reproduces satisfactorily the surviving chances when living organisms are exposed to radiations, UV, X-rays and gamma-rays. It was also shown how this simple model can be incorporated on ecological models to study the response of any biological system to radiation.

The population dynamic analyses suggest that whenever the linear birth rate $r_{B}$ of the species exceeds the linear lethally rate $r_{L}$, radiation can enhance the molecular evolution process. In this case populations of living organism can survive reaching news stationary states. We suggest that such a behavior might be related to the so-called Cambrian explosion [1a], although this has to be studied and understood properly by performing detailed studies.

\section{Acknowledgements}

We thank MES (Cuba), CAPES (Brazil) and FAPESP (Brazil) for the financial support and scholarships.

\section{References}

[1]. Morgan, W. Non-targeted and Delayed Effects of Exposure to Ionizing Radiation: I. Radiation-Induced Genomic Instability and Bystander Effects In Vitro. Radiat. Res. 159, 567-580 (2003).

[2]. Drake, J. W. A constant rate of spontaneous mutation in DNA-based microbes. Proc. Natl. Acad. Sci. USA 88, 7160-7164 (1991). 
[3]. Wei, L., Zha, Y., Tao, Z., He, W., Chen, D., Yuan, Y. and Zhao, R., High Background Radiation Research in Yangjiang, China, AE Press, Beijing, 1996.

[4]. H. Morishima, T. Koga, K. Tatsumi, S. Nakai, T. Sugahara, Y. Yuan, L. Wie, Dose Measurement, Its Distribution and Individual External Dose Assessments of Inhabitants in the High Background Radiation Areas in China J. Radiat. Res. (Tokyo) 41, 9 (2000).

[5]. V.C. Baranwal, S.P. Sharma, D. Sengupta, M.K. Sandilya, B.K. Bhaumik, R. Guin and S.K. Saha .A new high background radiation area in the Geothermal region of Eastern Ghats Mobile Belt (EGMB) of Orissa, India. Radiation Measurements, Volume 41, Issue 5, May 2006, Pages 602-610.

[6]. Joselene de Oliveira, Barbara Paci Mazzilli, Maria Helena de Oliveira Sampa and Edmilson Bambalas. Natural radionuclides in drinking water supplies of São Paulo State, Brazil and consequent population doses.Journal of Environmental Radioactivity, Volume 53, Issue 1, 2001, Pages 99-109.

[7]. Earl, A. M., Mohundro, M. M., Mian, I. S. \& Battista, J. R., “The IrrE Protein of Deinococcus radiodurans R1 Is a Novel Regulator of recA Expression”, J Bacteriol., 184, (22): 6216-6224, (2002).

[8]. Wood, R.D., Mitchell, M., Sgouros, J., Lindahl, T. Human DNA Repair Genes. Science, 291, 1284-1289, (2001).

[9]. Kimura, S, Tahira, Y., Ishibashi, T., Mori Y., Mori1T., Hashimoto, J., Sakaguchi, K. DNA repair in higher plants; photoreactivation is the major DNA repair pathway in non-proliferating cells while excision repair (nucleotide excision repair and base excision repair) is active in proliferating cells. Nucleic Acids Research, 32, 2760-2767 (2004). 
[10]. Paul J. Crutzen and Christoph Bruhl. Mass extinctions and supernova explosions. Proc. Natl. Acad. Sci. USA, 93, (1996) 1582-1584

[11]. Leitch, E. M. \& Vasisht, G, “Mass extinctions and the sun’s encounters with spiral arms”, New Astronomy 3 (1998) 51-56

[12]. Dar, A., Laor, A., Shaviv, N. J., "Life Extinctions by Cosmic Ray Jets”, Physical Review Letters, 80, 26 (1998)

[13]. D. Galante and J.E. Horvath. "Biological effects of gamma-ray bursts: distances for severe damage on the biota” International Journal of Astrobiology 6 (1) : 19-26 (2007).

[14]. Nisbet, E. G. \& Sleep, N. H., The habitat and nature of early life, Nature, 409, February 2001, 1083

[15]. Drake, J. W., Charlesworth, B., Charlesworth, D., and Crow, J. F. (1998). Rates of spontaneous mutation. Genetics 148, 1667-1686.

[16]. Grogan, D. W., Carver, G. T., and Drake, J. W. Genetic fidelity under harsh conditions:analysis of spontaneous mutation in the thermoacidophilic archaeon Sulfolobus acidocaldarius. Proc. Natl. Acad. Sci. USA 98, 79287933 (2001).

[17]. Charles F. Baer, Michael M. Miyamoto and Dee R. Denver. Mutation rate variation in multicellular eukaryotes: causes and consequences. Nature Reviews Genetics 8, 619-631 (2007)

[18]. Jan H. J. Hoeijmakers .Genome maintenance mechanisms for preventing cancer. Nature 411, 366-374 (2001)

[19]. W. L. Russell and E. M. Kelly. "Mutation frequencies in male mice and the estimation of genetic hazards of radiation in men”. Proc. Natl. Acad. Sci. USA. Vol. 79, pp. 542-544, January 1982. 
[20]. Nair, K.K. and Rahalk, G.W. 1963. "Radiation and Radioisotopes Applied to Insect of Agricultural Importance”. Proceedings of Symposium. Athens. IAEA Vienna. pp 465-477.

[21]. Janette L. Jacobs and George W. Sundin.. "Effect Of Solar Uv-B Radiation On A Phyllosphere Bacterial Community”. Applied and Environmental Microbiology, 67, 5488-5496 (2001)

[22]. Leonard A. Relation between the x-ray dose and the rate of dominant lethals induced by irradiation of mouse spermatozoa. Mutat Res. 3, 73-8 (1966)

[23]. Nothel, H. Evolution Adaptation of Drosophila melanogaster populations to high mutation pressure: Evolutionary adjustment of mutation rates. Proc. Natl. Acad. Sci. USA, ,84, ,1045-1049, (1987)

[24]. Verhulst, P. F. Notice sur la loi que la population suit dans son accroissement. Corr.Math et Phys. Publ. Par A. Quetelet, T.X., 113-21 (1838).

[25]. Kauffman, S. and Johnsen, J.. Coevolution to the edge of chaos: coupled fitness landscapes, poised states and coevolutionary avalanches. J. theor. Biol. 149, 467-505 (1991).

[26]. Plotnick, R. and McKinney, M. Ecosystem organization and extinction dynamics. Palaios 8, 202-212 (1993).

[27]. Raup, D.M. Extinction: bad genes or bad luck? Oxford U. Press. Oxford, (1993).

[28]. Raup, D.M. Extinction Models, In: Evolu- tionary Paleoecology. (D. Jablonski, D. H. Erwin and J. Lipps, eds.), pp. 419-433. Chicago: Univer- sity of Chicago Press, (1996). 
[29]. Solé, R. V., Bascompte, J. and Manrubia, S. C. Extinctions: bad genes or weak chaos? Proc. Roy. Soc. London B. 263, 1407-1413, (1996)

[30]. Solé, R. V., Manrubia, S. C., Kauffman, S. A., Ben- ton, M. and Bak, P. Criticality and Scaling in Evolutionary Ecology, Trends Ecol. Evol. 14, 156160 (1999)

[31]. Newman, M. E. J. Self-organized criticality, evolution, and the fossil extinction record,, Proc. R. Soc. London B263, 1605-1610 (1996)

[32]. Newman, M. E. J. A model of mass extinc- tion. J. Theor. Biol. 189, 235-252 (1997)

[33]. Murray, J. D. Mathematical Biology I. An introduction. $3^{\text {rd }}$ ed. (2002) [34].

[Benitez] Evidence for Nearby Supernova Explosions Authors: Narciso Benitez, Jesus Maiz-Apellaniz, Matilde Canelles Journal-ref: Phys.Rev.Lett. 88 (2002) 081101

[10a] Irfaq, M. and Nawab, K. “A Study to determine the proper Dose of Gamma Radiation for Inducing Beneficial Genetic Variability in Bread Wheat (Triticum aestivum L.)”. Asian Journal of Plant Sciences 2 (13): 999-1003, 2003

[11] Melott, A.; Int.J.Astrobiol. 3 (2004) 55

[\$] S. Thorsett , ApJ 1995

[2] Drake, J. W., Charlesworth, B., Charlesworth, D., and Crow, J. F. (1998). Rates of spontaneous mutation. Genetics 148, 1667-1686.

[3] Grogan, D. W., Carver, G. T., and Drake, J. W. (2001). Genetic fidelity under harsh conditions:analysis of spontaneous mutation in the thermoacidophilic archaeon Sulfolobus acidocaldarius. Proc. Natl. Acad. Sci. USA 98, 7928-7933. 
2398. Wood, R. D., Mitchell, M., Sgouros, J., and Lindahl, T. (2001). Human DNA repair genes. Science 291, 1284-1289.

Waldren CA, Jones C, Puck TT: Measurements of mutagenesis in mammalian cells. Proc Natl Acad Sci USA 76:1358-1362, 1979.

Waldren CA, Correll L, Sognier MA, Puck TT:

Measurement of low levels of X-ray mutagenesis in relation to human disease. Proc Natl Acad Sci USA, 83:4839-4843, 1986.

Wu L-J, Randers-Pehrson G, Xu A, Waldren CA, Geard CR, Yu Z-L, and Hei TK: Targeted cytoplasmic irradiation with alpha particles induces mutations in mammalian cells. Proc Natl Acad Sci 96:4959-4964, 1999.

Sawant et al. Radiation Res. 156, 177-180, 2001

[4] Verhulst, P. F. 1838. Notice sur la loi que la population suit dans son accroissement. Corr.Math et Phys. Publ. Par A. Quetelet, T.X., 113-21. 